\title{
Vegetationsgeschichtliche und archäobotanische Untersuchungen zur Landwirtschaft und Umwelt im Bereich der prähistorischen Siedlungen bei Rullstorf, Ldkr. Lüneburg
}

\author{
Dissertation \\ zur Erlangung des Doktorgrades \\ der Mathematisch-Naturwissenschaftlichen Fakultäten \\ der Georg-August-Universität zu Göttingen
}

\author{
vorgelegt von \\ Wiebke Kirleis \\ aus \\ Einbeck
}


D 7

Referent: Prof. Dr. Eberhard Grüger Korreferent: Prof. Dr. Karl-Ernst Behre

Tag der mündlichen Prüfung: 18.06.2002

In gedruckter Fassung erscheint diese Dissertationsschrift in:

Probleme der Küstenforschung im südlichen Nordseegebiet 28, 2004. 
1 Einleitung ................................................................... 4

2 Landschaft im Raum Lüneburg .................................... 6

2.1 Geologie und Bodenkunde ............................ 6

$2.2 \quad$ Klima ..................................................... 8

$2.3 \quad$ Vegetation................................................... 9

3 Pollenanalysen auf der Niederterrasse der Elbe nördlich von Lüneburg und auf der Hohen Geest im Bevenser Becken................................................... 10

3.1 Geländeprospektion ...................................... 10

3.2 Pollenanalytische Untersuchungsmethoden..... 10

3.2.1 Geländearbeit............................................... 10

3.2.2 Probenaufbereitung im Labor ....................... 10

3.2.3 Bestimmung der organischen Reste................. 11

3.2.4 Glührestbestimmungen .................................. 11

3.2.5 Darstellung der Ergebnisse ............................ 12

3.2.6 Radiokarbon-Datierungen............................ 12

3.3 Ergebnisse der Pollenanalysen......................... 12

3.3.1 Zeitstellung der Pollendiagramme .................. 12

3.3.2 Vegetationsgeschichtlicher Nachweis menschlicher Aktivität................................... 13

3.3.3 Elbaer Moor.................................................. 15

3.3.3.1 Stratigraphie und lokale Entwicklung............. 15

3.3.3.2 Radiokarbon-Datierungen.............................. 16

3.3.3.3 Pollendiagramm Elbaer Moor......................... 17

3.3.4 Rullstorfer Osterteich.................................... 21

3.3.4.1 Stratigraphie und lokale Entwicklung............. 21

3.3.4.2 Pollendiagramm Rullstorfer Osterteich ........... 24

3.3.5 Almstorfer Moor......................................... 25

3.3.5.1 Stratigraphie und lokale Entwicklung............. 25

3.3.5.2 Radiokarbon-Datierungen............................. 27

3.3.5.3 Pollendiagramm Almstorfer Moor.................. 27

3.4 Rekonstruktion der Vegetationsund Siedlungsgeschichte............................. 32

3.4.1 Vorneolithische Vegetationsentwicklung ........ 32

3.4.1.1 Präboreal und Boreal ..................................... 32

3.4.1.2 Atlantikum ............................................. 32

3.4.2 Subboreal mit Neolithikum und Bronzezeit .... 33

3.4.2.1 Rückgang der Ulmus-Werte .......................... 33

3.4.2.2 Neolithikum ............................................. 33

3.4.2.3 Bronzezeit........................................................ 34

3.4.3 Älteres Subatlantikum mit Vorrömischer Eisenzeit, Römischer Kaiserzeit, Völkerwanderungszeit und Frühem Mittelalter .......... 34

3.4.3.1 Vorrömische Eisenzeit.................................... 34

3.4.3.2 Römische Kaiserzeit ................................... 35

3.4.3.3 Völkerwanderungszeit und Frühes Mittelalter................................... 36

3.4.4 Jüngeres Subatlantikum mit Hohem und Spätem Mittelalter und Früher Neuzeit............ 37

3.4.4.1 Fagus im jüngeren Subatlantikum................... 37
3.4.4.2 Hohes und Spätes Mittelalter ......................... 37

3.4.4.3 Heide-Entwicklung, intensiver Roggenanbau und Lüneburger Saline .......................... 39

3.4.4.4 Rullstorfer Osterteich und Lüneburger Landwehr.............................. 40

3.4.4.5 Frühe Neuzeit................................................... 42

4 Früchte und Samen aus den Ausgrabungen bei Rullstorf.............................................................. 44

4.1 Archäologische Befunde.................................. 44

4.2 Material und Methoden der archäobotanischen Untersuchungen ........................... 44

4.2.1 Material.......................................................... 44

4.2.2 Bisherige archäobotanische Untersuchungen ............................................ 45

4.2.3 Methoden ...................................................... 45

4.2.4 Darstellung der Ergebnisse ............................. 46

4.2.5 Radiokarbon-Datierungen............................... 46

4.3 Pflanzenreste von der jüngeren Bronzezeit bis zum Frühen Mittelalter.............................. 46

4.3.1 Getreidearten.................................................. 49

4.3.1.1 Panicum miliaceum - Rispenhirse, Echte Hirse. 49

4.3.1.2 Hordeum vulgare - Spelzgerste...................... 50

4.3.1.3 Hordeum vulgare var. nudum - Nacktgerste ... 51

4.3.1.4 Triticum dicoccon - Emmer............................. 52

4.3.1.5 Triticum monococcum - Einkorn ...................... 53

4.3.1.6 Triticum aestivum s. 1. - Saatweizen................ 53

4.3.1.7 Avena sp. - Hafer.............................................. 54

4.3.1.8 Secale cereale - Roggen ................................... 55

4.3.2 Mengegetreide .............................................. 56

4.3.3 Sammelpflanzen............................................... 56

4.3.4 Polygonum lapathifolium - Ampfer-

knöterich als mögliche Nahrungspflanze? ....... 57

4.3.5 Unkräuter aus den Kulturpflanzenproben ........ 58

4.3.5.1 Sommer- oder Wintergetreide? ....................... 59

4.3.5.2 Bodennahe oder bodenferne Ernteweise? ........ 59

4.3.5.3 Bodengüte der Ackerflächen bei Rullstorf....... 61

4.3.6 Funde von Mutterkorn (Claviceps purpurea)

4.4 Zu Landwirtschaft und Ernährung in Rullstorf seit der jüngeren Bronzezeit ......... 62

4.4.1 Nahrungspflanzen der Rullstorfer Siedler........ 62

4.4.2 Zum jüngerbronzezeitlichen

Kulturpflanzenspektrum ............................... 64

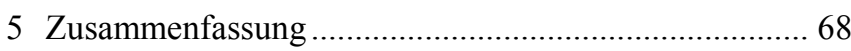

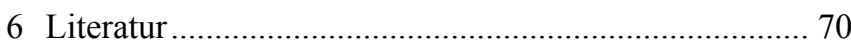

7 Anhang: Tab. 27-30 ................................................... 78 


\section{Einleitung}

Seit 1979 werden vom Niedersächsischen Landesamt für Denkmalpflege in Hannover archäologische Ausgrabungen auf dem Kronsberg bei Rullstorf im Ldkr. Lüneburg durchgeführt (GARBERS 1990; GEBERS 1985a-d; 1986a-b; 1995; GeBERS u. LÜTH 1984; 1996; HORNIG 1993; LAUXTERMANN 2001a-b; STARK 1996). Das Areal bei Rullstorf war von der jüngeren Steinzeit bis ins Frühe Mittelalter besiedelt. Es bietet daher die äußerst seltene Gelegenheit, Kontinuitäten, Neuerungen und Brüche im Ablauf des Siedlungsgeschehens während eines solch langen Zeitraums zu verfolgen.

Die Bearbeitung der botanischen Funde aus den prähistorischen Siedlungen bei Rullstorf setzt die Arbeiten von KROLL (1980) und BEHRE (1990) fort. Vordringlicher Gegenstand des archäobotanischen Teils der vorliegenden Untersuchungen sind die subfossilen Pflanzenreste aus dem jüngerbronzezeitlichen Siedlungshorizont. Bislang liegen zur Bronzezeit aus Niedersachsen - im Gegensatz etwa zur Urnenfelderkultur in Süddeutschland und angrenzenden Gebieten - nur wenige archäobotanische Analysen vor (BEHRE 1996). Die zahlreichen verkohlten Pflanzenreste aus Rullstorf geben Einblick in die Lebensbedingungen der jungbronzezeitlichen Siedler in der norddeutschen Altmoränenlandschaft.

Neben den archäobotanischen Analysen setzt sich diese Untersuchung zum Ziel, erstmals die Umweltveränderungen im Raum Rullstorf vom Neolithikum bis in die Neuzeit mittels vegetationsgeschichtlicher Untersuchungen zu rekonstruieren. Aus der moorarmen Region des nordöstlichen Niedersachsens liegen sehr wenige moderne pollenanalytische Arbeiten vor. In der Übersicht bei OVERBECK (1975, 404 f.) sind lediglich zwei Profilstellen im nordöstlichen Niedersachsen kartiert. Dabei handelt es sich um die richtungsweisenden Arbeiten von OvERBECK u. SCHNEIDER (1938) über das südlich von Lüneburg gelegene Melbecker Moor und die pollenanalytischen Untersuchungen von LESEMANN (1969) über das Hannoversche Wendland. Pollenanalytische Untersuchungen aus dem weiteren Umkreis sind vorwiegend älteren Datums und genügen meist nicht den heutigen Standards (AVERDIECK 1957; 1958; 1976; AVERDIECK u. MÜNNICH 1957; BORNGÄSSER 1941; OvERBECK 1952; SElle 1936; 1939). Die Arbeiten von SCHWAAR (1985) im Ldkr. Rotenburg (Wümme) stellen wie die von BECKER (1995) über die zentrale Lüneburger Heide die Paläoökologie der Moore und die Moorgenese in den Vordergrund. Pollendiagramme weiterer Kleinstmoore aus dem oberen Wümmetal spiegeln besonders stark die lokale Vegetation wider (SCHWAAR 1983).

Die geringe Zahl pollenanalytischer Untersuchungen in Nordostniedersachsen erklärt sich aus der naturräumlichen Ausstattung der subkontinentalen Altmoränenlandschaft: Moore und Seen, deren Torfe und Sedimente Voraussetzung für vegetationsgeschichtliche Arbeiten sind, kommen hier nur selten vor. Zudem sind ihre Ablagerungen teilweise nicht für vegetationsgeschichtliche Untersuchungen geeignet, da die Pollenerhaltung $\mathrm{zu}$ schlecht, die Pollenkonzentration zu niedrig oder das Alter des Untersuchungsmaterials $\mathrm{zu}$ gering ist. Erst nach umfangreicher Geländeprospektion konnte daher an drei Lokalitäten Material für die vegetationsgeschichtlichen Untersuchungen gewonnen werden. Dabei handelt es sich um das Elbaer Moor und den Rullstorfer Osterteich, beide im Ldkr. Lüneburg gelegen, und das Almstorfer Moor im nördlichen Ldkr. Uelzen.

Um der Frage der anthropogenen Landschaftsveränderungen nachzugehen, werden die pollenanalytischen mit den archäobotanischen Untersuchungen verknüpft. Wichtige Anregungen dazu gab die Darstellung der Geschichte der Kulturlandschaft und des Ackerbaus im Elb-Weser-Dreieck von BEHRE u. KUČAN (1994). Während vegetationsgeschichtliche Untersuchungen Veränderungen der Vegetation zumeist großräumig erfassen, ermöglichen Analysen der Pflanzenreste aus prähistorischen Siedlungen, Aussagen zur Landwirtschaft eines kleinen Raumes $\mathrm{zu}$ treffen. Erst durch das Zusammenführen beider Arbeitsweisen kann die Vegetation des unmittelbaren und des peripheren Wirtschaftsraumes einer prähistorischen Siedlung beschrieben werden.

Die vorliegende Arbeit entstand als Dissertation am Niedersächsischen Institut für historische Küstenforschung (NIhK) in Wilhelmshaven und geht auf die Anregung des ehemaligen Institutsleiters, Prof. Dr. Karl-Ernst Behre, zurück. Ihm möchte ich für wertvollen Rat und erhellende Kritik meinen besonderen Dank aussprechen. Sein unermüdlicher Einsatz und seine umfassende Betreuung waren mir stets eine große Hilfe. Prof. Dr. Eberhard Grüger (Georg-August-Universität Göttingen) begleitete die Arbeit mit großem Interesse, gab wichtige Anregungen und war jederzeit zur Unterstützung bereit. Auch ihm gebührt mein herzlicher Dank.

Zahlreiche weitere Personen unterstützten mich während bestimmter Arbeitsphasen. Dr. Wilhelm Gebers (Niedersächsisches Landesamt für Denkmalpflege, Hannover) stellte die zu bearbeitenden Makrorestproben aus der archäologischen Ausgrabung auf dem Kronsberg bei Rullstorf zur Verfügung. Er half auch bei Geländearbeiten. Wertvolle Hinweise zur Geländeprospektion für die pollenanalytischen Untersuchungen gaben Dr. Klaus-Dieter Meyer und Dr. Gerfried Caspers (Niedersächsisches Landesamt für Bodenforschung, Hannover). Die Durchführung der Geländearbeiten ermöglichte die Obere Naturschutzbehörde der Bezirksregierung Lüneburg, die eine Ausnahmegenehmigung zum Betreten und Beproben dreier Naturschutzgebiete erteilte. Dr. Eberhard von Rantzau (Hamburg) und Herr Röhrs (Rullstorf) gestatteten zudem Probenentnahmen auf ihrem Grund.

Wichtige Hinweise zur Bestimmung subfossiler Pflanzenreste gaben Prof. Dr. Karl-Ernst Behre, Dipl.-Biol. 
Dušanka Kučan und Dr. Felix Bittmann (alle NIhK, Wilhelmshaven), Dr. Helmut Kroll (Christian-AlbrechtsUniversität Kiel) und mein akademischer Lehrer Prof. Dr. Hans-Jürgen Beug (Göttingen). In die MakrorestFotografie führte mich Dušanka Kučan ein. Mehrere Radiokarbon-Datierungen wurden am Leibniz-Labor für Altersbestimmung und Isotopenforschung der ChristianAlbrechts-Universität Kiel durchgeführt, wo Dr. Helmut Erlenkeuser sich für anregende Diskussionen freundlichst zur Verfügung stellte.

Die Mitarbeiterinnen und Mitarbeiter des Niedersächsischen Instituts für historische Küstenforschung unterstützten mich in vielfältiger Weise und sorgten für eine angenehme Arbeitsatmosphäre. Speziell halfen Manfred Spohr, Rolf Kiepe und Dr. Patrice de Rijk bei der Bearbeitung von Karten und Fotografien. Während der letzten Phase der Niederschrift waren besonders Dušanka Kučan und Ina Begemann (Göttingen) wichtige Unterstützerinnen.
Das Promotionsprojekt wurde zunächst aus Forschungsmitteln des Niedersächsischen Ministeriums für Wissenschaft und Kultur finanziert. In einem zweiten Abschnitt der Promotion erlaubte mir ein Stipendium der niedersächsischen Landesgraduiertenförderung durch die Universität Göttingen, mich ohne finanzielle Sorgen weiterhin intensiv dem Forschungsprojekt zu widmen. Ich möchte daher dem Land Niedersachsen und allen an der Landesgraduiertenförderung Beteiligten meinen herzlichen Dank für die empfangene Unterstützung und Ermutigung aussprechen.

Durch die Höhen und Tiefen der Anfertigung meiner Dissertation begleitete mich Dr. Kurt Franz (Halle). Er gab zudem wichtige Anregungen aus der Warte des Geisteswissenschaftlers.

Allen Kolleginnen und Kollegen sowie Freundinnen und Freunden, die zum Gelingen dieser Arbeit beigetragen haben, möchte ich an dieser Stelle meinen herzlichen Dank aussprechen. 


\section{Landschaft im Raum Lüneburg}

Ausgangspunkt für die vorliegenden Untersuchungen waren Pflanzenreste aus den prähistorischen Siedlungen auf dem Kronsberg bei Rullstorf nordöstlich von Lüneburg im nordöstlichen Niedersachsen (Abb. 1-2). In der näheren und der weiteren Umgebung dieser Stätte wurden Pollenanalysen durchgeführt. Zwei der bearbeiteten Pollenprofile stammen aus Mooren, die sich nördlich und nordwestlich von Rullstorf im Bereich der Niederterrasse der Elbe befinden (Ldkr. Lüneburg). Ein drittes Pollenprofil wurde aus einem etwa $20 \mathrm{~km}$ südlich von Rullstorf liegenden Moor bei Bad Bevensen auf der Hohen Geest entnommen (Ldkr. Uelzen).

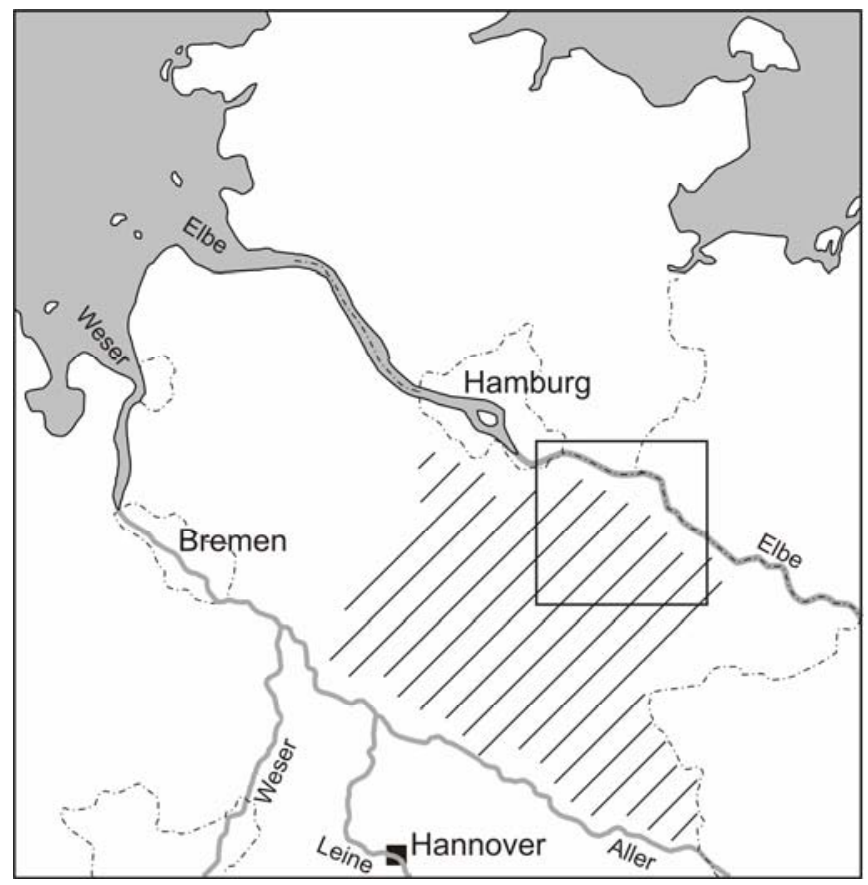

Abb. 1. Übersichtskarte Norddeutschland.

Der Rahmen markiert den Untersuchungsraum.

Die Schraffur zeigt die Ausdehnung der Lüneburger Heide.

\subsection{Geologie und Bodenkunde}

Die Umgebung von Lüneburg ist eine eiszeitlich geformte Landschaft. Ältere, präquartäre Ablagerungen treten nur an wenigen Stellen an die Oberfläche. Wo Salzstöcke mit ihren wasserlöslichen Gesteinen aufstiegen, in Grundwasserkontakt gerieten und abgelaugt wurden, ist die Oberflächengestalt indirekt durch den präquartären Untergrund beeinflußt. Bekanntes Beispiel für die Entstehung von Subrosionssenken und Erdfällen ist der aufsteigende Salzstock, der den Kalkberg im Stadtgebiet von Lüneburg herausgehoben hat (ROESSLER 1987, 19 f.).

Die Gletscher der letzten Kaltzeit, der Weichsel-Kaltzeit, erreichten die Gebiete südlich der Elbe nicht mehr. Das von Nordosten nach Mitteleuropa vorrückende Eis schüttete die weichselzeitlichen Endmoränen schon im heutigen Schleswig-Holstein auf (GRIPP 1924, 208 f.).

Das Relief der südwestlich gelegenen Landschaft ist von der vorangehenden Saale-Kaltzeit, genauer dem Drentheund Warthe-Stadium, geprägt. Im Lüneburger Raum sind Schmelzwassersande abgelagert, die im Jüngeren DrentheStadium vom Inlandeis überfahren wurden. Die Jüngeren Drenthe-Gletscher hinterließen eine Grundmoräne von 5$10 \mathrm{~m}$ Mächtigkeit, die jedoch bis heute stark erodiert wurde. Östlich von Lüneburg hat die Jüngere Drenthe-Moräne an der Oberfläche eine größere Verbreitung als die warthezeitliche Moräne. Die Erwärmung zwischen dem Drenthe- und Warthe-Stadium führte in Norddeutschland zu einem Rückzug des Eises. Eine Ablagerung warmzeitlicher Sedimente oder eine Bodenbildung konnten in Niedersachsen zwischen den beiden Eisvorstößen bisher jedoch nicht nachgewiesen werden.

Die Barendorfer-Endmoräne, ein fast $15 \mathrm{~km}$ langer Höhenzug südöstlich von Lüneburg, liegt inmitten des Warthe-Verbreitungsgebietes. Dieser Höhenzug entstand an einem stagnierenden Eisrand und wurde vom Warthe-Eis überfahren (HöFLE 1991, 166). Am Ende der Saale-Kaltzeit war das Relief noch wesentlich stärker ausgeprägt als heute. Die Erosion der Endmoränenwälle und die Verfüllung der gerade entstandenen Täler hatten erst begonnen. Aus der sich anschließenden Eem-Warmzeit stammen Torfe und (Kalk-) Muddeablagerungen (MEYER 1994, 7 f.).

Während der auf das Eem folgenden Weichsel-Kaltzeit standen die Altmoränenflächen, die nie vom Weichseleis überfahren wurden - etwa das Gebiet des Uelzener Beckens - wesentlich unter dem Einfluß periglazialer Formung, Abtragung und Umlagerung (HAGEDORN 1965, $116 \mathrm{f}$.). Insbesondere ist hier die weichselzeitliche Ausbreitung von Sandlöß im Bevenser Becken zu erwähnen (Abb. 2).

Die Landschaft im Raum Lüneburg ist sowohl von der älteren Saale-Kaltzeit, in der das Inlandeis die Elbe überschritt, als auch von der folgenden, jüngeren WeichselKaltzeit geprägt, in der das Gebiet im periglazialen Raum weit vor dem eigentlichen Eisschild lag.

Das weichselzeitliche Urstromtal der Elbe schnitt sich in die saalezeitlichen Sedimente ein. Die Niederterrasse und auch die Talaue wurden gebildet. In der Talsand-Niederung entstanden schließich Auelehm-Decken (BENZLER u. MEYER 1989, 16 f.). Die im Elbe-Urstromtal abgelagerten glazifluviatilen Sande wurden im Holozän zu Dünen aufgeweht, die durch vorherrschende Westwinde ostwärts wanderten (BENZLER 1965). Heute fällt die Altmoränenlandschaft des nordöstlichen Teils von Niedersachsen steil zur Niederterrasse der Elbe ab; die Geländestufe weist teilweise einen Höhenunterschied von mehr als $20 \mathrm{~m}$ auf. 


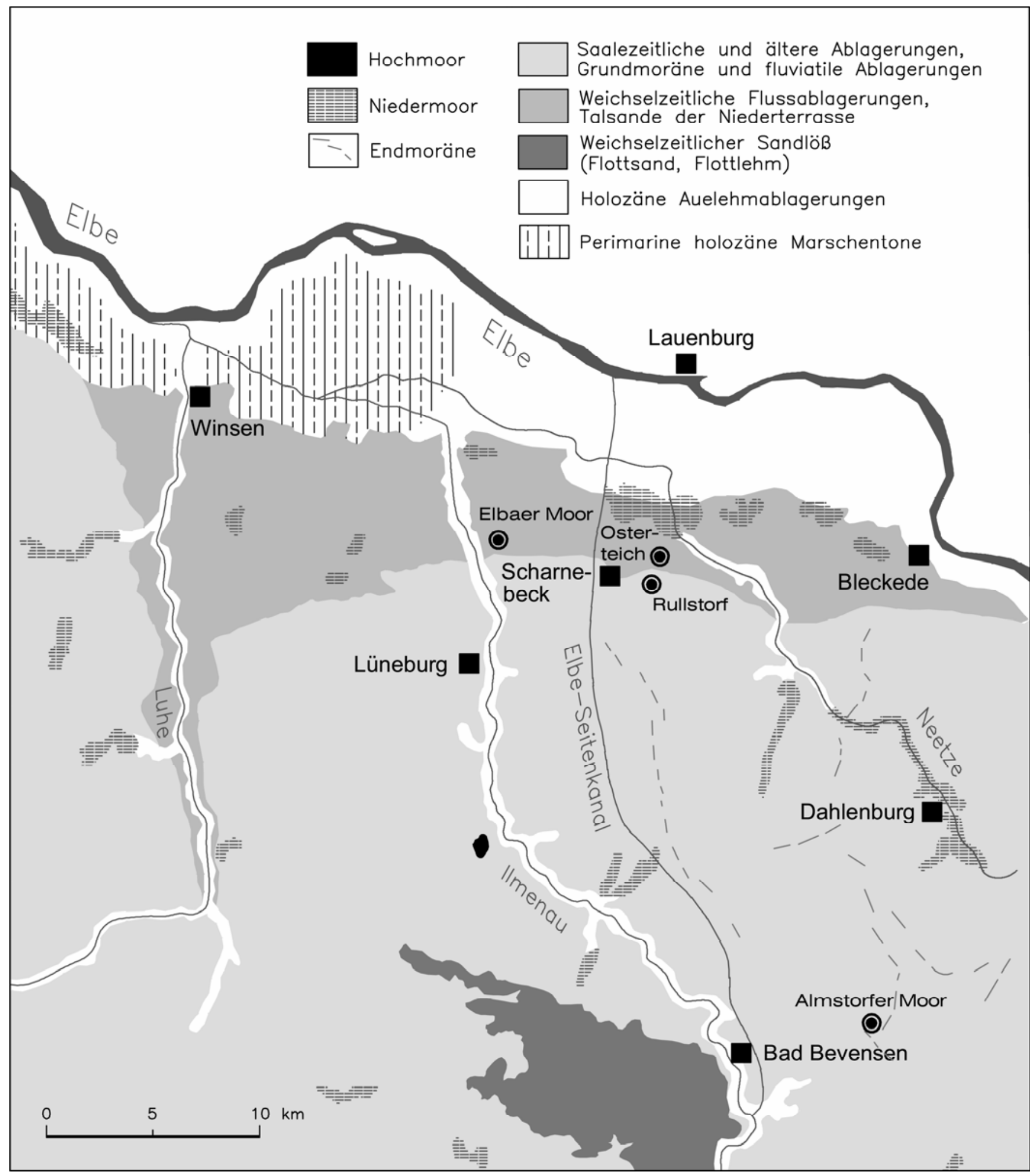

Abb. 2. Naturräumliche Gliederung des Untersuchungsgebietes nach der Geologischen Karte 1:200.000, Blatt CC 3126 Hamburg-Ost (Bearbeitung: W. Kirleis, M. Spohr). 
Die Unterläufe von Ilmenau und Neetze, heute beide eigenständige Zuflüsse der Elbe, interpretiert BENZLER (1965) als Reste von Altarmen der Elbe. Noch im Altholozän setzten Verlandung und Vermoorung in diesen ehemaligen Schmelzwasserrinnen ein. Bei Überschwemmung der Niederterrasse wurde das vom Wasser mitgeführte Material, entsprechend der Transportenergie nach Korngröße sortiert, sedimentiert. Das schwere, grobe Material sank in Ufernähe ab und bildete den Uferwall. Zur Geest hin lagerte sich das leichte, feinkörnige Material ab. Seine Spuren finden sich als Tonbänder in den Torflagen des Sietlandes (BENZLER 1965, $113 \mathrm{f}$.). Heute befindet sich im Bereich der Niederterrasse zwischen dem Elbe-Seitenkanal bei Scharnebeck und der Elbe in Höhe der Ortschaft Bleckede ein Gürtel von größeren Niedermoorflächen, die jedoch landwirtschaftlich genutzt werden und daher weitgehend entwässert sind (Abb. 2). Die Erlenbruchwald- und Seggentorfe erreichen hier Mächtigkeiten von meist weniger als $1 \mathrm{~m}$ (SCHNEEKLOTH u. TÜXEN 1979, 20 f.).

An die Elbaue mit ihren frischen bis feuchten, lehmigsandigen bis schluffig-tonigen Böden schließen sich die fruchtbaren Marschböden an. Zwischen Winsen und Bleckede, ebenfalls noch in der Niederung und insbesondere dort, wo die Luhe ins Elbtal eintritt, kommen frische bis mäßig trockene, sandige und lehmige Böden mit mittlerer bis guter Wasserdurchlässigkeit vor.

Südlich schließt das Gebiet der grundwasserfernen, ebenen bis welligen Geest an, wo sehr trocken sandige Böden vorherrschen. Sie sind gut durchlüftet, meist nährstoffarm und, sofern die Vegetationsdecke fehlt, leicht verwehbar. Westlich der Ilmenau auf der Höhe von Bad Bevensen ist fruchtbarer Sandlöß oder Flottsand, ein Mischsediment aus Löß und Flugsand, anzutreffen. Im Uelzener Becken sind darüber hinaus schwach gebleichte, fruchtbare Geschiebelehmböden kartiert, deren Sandanteil nach Westen zunimmt (MEIBEYER 1970, 33).

\subsection{Klima}

Die Lüneburger Heide wird durch den Haupthöhenzug mit dem Wilseder Berg in eine ozeanisch beeinflußte Westund eine stärker kontinental beeinflußte Ostseite gegliedert (SCHRADER 1958, 79). Als mittlere Temperatur des kältesten Monats (Januar) werden für Lüneburg $-2,6^{\circ} \mathrm{C}$, als mittlere Jahrestemperatur $+8,4^{\circ} \mathrm{C}$ angegeben. Absolut frostfrei sind die Monate Juli und August. Spätfröste können abhängig von der Bodenbeschaffenheit vereinzelt noch im Juni auftreten. Auch in den Monaten September bis November ist Frost möglich (Abb. 3).

Die östliche Lüneburger Heide befindet sich im Regenschatten des Haupthöhenzuges der Heide. Reliefbedingt ist die durchschnittliche Niederschlagssumme pro Jahr mit $611 \mathrm{~mm}$ nicht sehr hoch. Das Klimadiagramm für Lüneburg veranschaulicht die Schwankungen der monatlichen Niederschlagsmittel im Jahresverlauf. Der niederschlagsreichste Monat ist der Juli mit 70-80 mm, Februar und März sind mit Werten um $40 \mathrm{~mm}$ am niederschlagsärmsten. Dennoch hat beispielsweise die atlantische Art Myrica gale (Gagelstrauch) entlang des Verlaufs der Ilmenau noch sporadische Vorkommen, sie erreicht in diesem subkontinentalen Gebiet jedoch ihre Arealgrenze (BENKERT et al. 1998, Karte 1224; HAEUPLER u. SCHÖNFELDER 1988, 122; LOSERT 1969, 33 f.).

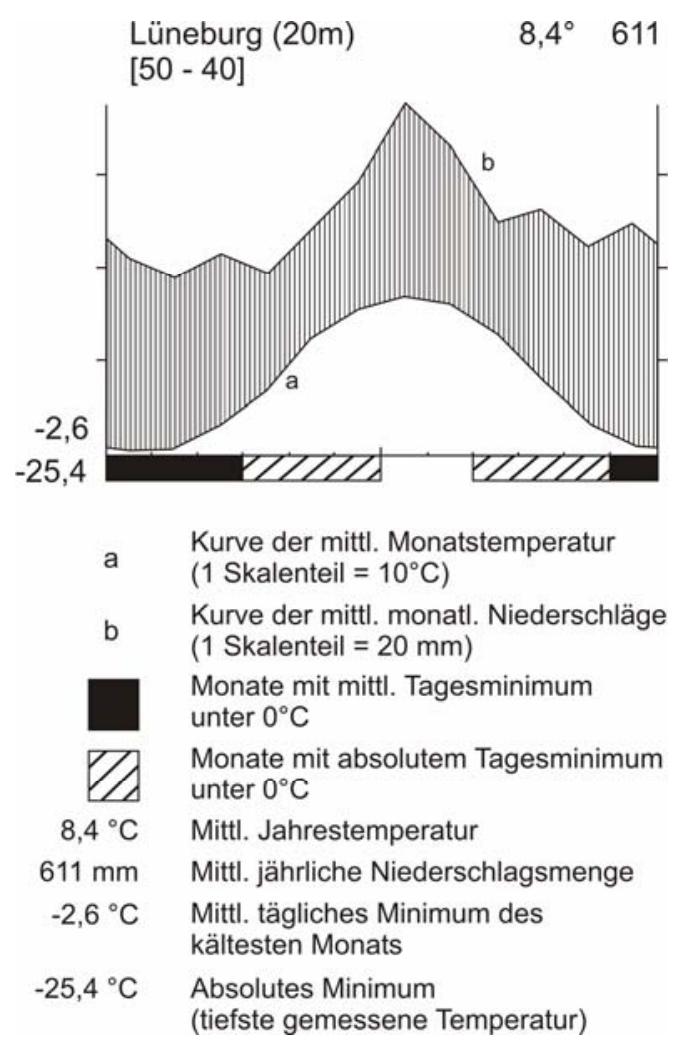

Abb. 3. Klimadiagramm der Station Lüneburg $(+20 \mathrm{~m}$ $\mathrm{NN})$. Beobachtungszeitraum von 50 Jahren (Temperatur) bzw. von 40 Jahren (jährliche Niederschlagssumme) (nach Walther $u$. Lieth 1967, leicht verändert).

Die Verteilung der Windrichtungen in der ersten Jahreshälfte interessiert in der Palynologie besonders, um auf mögliche Herkunftsgebiete des Polleneintrags schließen $\mathrm{zu}$ können. Im Januar überwiegen westliche und südwestliche Winde im Raum Lüneburg. Ab April liegen aufgrund der Umstellung von der winterlichen zur sommerlichen Luftdrucklage ausgeglichene Windverhältnisse vor, das heißt, daß grundsätzlich alle Windrichtungen vorkommen, jedoch wurden Winde aus West bis Südwest sowie Nordost am häufigsten aufgezeichnet. Im Juli hat sich die sommerliche Luftdrucklage eingestellt. Das mäßig starke Luftdruckgefälle ist nun nach Nordosten gerichtet, vorherrschende Windrichtungen verlaufen von Nordwest über West zu Südwest (HOFFMEISTER u. SCHNELLE 1945, Karten 27-29). 


\subsection{Vegetation}

Von der real vorkommenden Vegetation eines Gebietes muß die potentiell natürliche Vegetation unterschieden werden. Darunter wird diejenige Vegetation verstanden, die sich in einem gegebenen Gebiet nach Aussetzen jeglichen menschlichen Einflusses nach dem Ablauf der den Standortund Klimabedingungen entsprechenden Vegetations- und Sukzessionsstadien bis zur Klimaxgesellschaft entwickeln würde. Dabei werden die Standortfaktoren als statisch, sich den ändernden Bedingungen also nicht anpassend, gesetzt.

Im Raum Lüneburg zählen zur potentiell natürlichen Vegetation subatlantische Eichen-Buchenwälder, Eichenmischwälder und Birken-Eichenwälder. Bestandteil dieser Eichenmischwälder ist die Kiefer. Auf den armen Sandböden sind trockene oder feuchte Birken-Eichenwälder $\mathrm{zu}$ erwarten. Die Niederungen bieten Standorte für Erlenbrüche, Erlen-Eschenwälder, feuchte StieleichenHainbuchenwälder sowie arme Niedermoore (KLINK 1995, $160 \mathrm{f}$.).

Jüngere bodenkundliche und pflanzensoziologische Untersuchungen an anthropogen geprägten, jedoch naturnahen Wäldern in der Lüneburger Heide haben gezeigt, daß das buchenfähige Areal auf der Hohen Geest größer ist als bislang angenommen (LEUSCHNER 1994, 306). Ein Nährstoffmangel, der die Buchenausbreitung ausschließen würde, muß nicht generell auf den als ,arm“ eingestuften Sandböden bestehen, sondern kommt am ehesten an anthropogen degenerierten Standorten mit geringmächtiger organischer, erosionsgefährdeter Auflage vor. Bodenchemische Untersuchungen belegen, daß der Hainsimsen-Buchenwald und der Birken-Eichenwald im niedersächsischen Tiefland heute weitgehend unter den gleichen edaphischen Bedingungen vorkommen. Die Nutzungsgeschichte trug wesentlich zur Entwicklung der unterschiedlichen Waldtypen bei (HEINKEN 1995, $161 \mathrm{u}$. $245 \mathrm{f}$.). Da die Rotbuche aber eine sehr große Konkurrenzkraft besitzt, können sich demnach langfristig auch aus den naturnahen Birken-Eichenwäldern auf trockenen Sanden am Ende einer Sukzessionsreihe Buchenwälder vom Typ des Hainsimsen-Buchenwaldes einstellen, sofern sich eine ausreichend mächtige organische Bodenauflage bilden konnte.

Nadelwälder gehören nach heutigem Kenntnisstand nicht zur potentiell natürlichen Vegetation des Gebietes (HEINKEN 1995, 238 f.). Reliktvorkommen der Kiefer soll es vereinzelt auf Mooren geben (FIRBAS 1949, 140 f.; SCHWAAR 1988, $38 \mathrm{f}$.), jedoch ist die heutzutage weite Verbreitung der Kiefer im Lüneburger Raum hauptsächlich auf Aufforstungsmaßnahmen der letzten Jahrhunderte zurückzuführen. Eine Zusammenstellung bei HEIDER (1995, 108) zeigt, daß eine nacheiszeitliche Fichtenausbreitung in Nordwestdeutschland, wie sie von einigen älteren Autoren postuliert wurde, fragwürdig ist.

Die Standorte der Weichholzaue im Elbtal, die Extrembedingungen wie Treibeis, Überflutung und
Wurzelausspülung ausgesetzt sind, wurden größtenteils einer Grünlandnutzung zugeführt. Auf den etwas höher gelegenen Standorten der Elbniederung würden sich potentiell natürliche Hartholzauen entwickeln. Der größte Teil der Standorte von Hartholzauen ist heute jedoch eingedeicht und wird ackerbaulich genutzt (KELM u. STURM 1988, 66).

Im Jahr 1986 nahm der tatsächliche Waldbestand mit etwa 378.000 ha ein Viertel der Gesamtfläche des Regierungsbezirks Lüneburg ein. Wichtigste Baumarten am gesamten Bestand waren in diesen Wäldern Kiefer mit einem Anteil von $63 \%$ und Fichte mit $18 \%$. Als Nadelhölzer kamen daneben auch Douglasie und Lärche vor. Unter den Laubgehölzen war 1986 keine Gattung mit mehr als $5 \%$ am Baumartenspektrum vertreten. Eiche, Buche, Erle, Birke, Pappel und Weide waren die häufigeren Gattungen. Esche, Ahorn und Ulme waren ohne größere Bedeutung. Eine Erhöhung des Laubholzanteils bei gleichzeitigem Rückgang der Kiefer wurde aber zumindest in den Landesforsten durch Nachpflanzung von Buchen unter Kiefern- und Lärchenbeständen angestrebt (KELM u. STURM 1988, 55 f.)

Wird der Blick auf die Ldkr. Lüneburg und Uelzen gerichtet, so zeigt sich ein ähnliches Bild wie im gesamten Regierungsbezirk Lüneburg. Hier waren $198634 \%$ der Fläche bewaldet. Der Vergleich der Kurhannoverschen Landesaufnahme des ausgehenden 18. Jh. mit Kartierungen aus dem Jahr 1986 ergab, daß der Flächenanteil der Bruchund Auenwälder in der Elb- und der Neetzeniederung innerhalb von nur 200 Jahren von $18 \%$ auf $7 \%$ zurückging (KeLM u. STURM 1988, 52 f.). 


\section{Pollenanalysen auf der Niederterrasse der Elbe nördlich von Lüneburg und auf der Hohen Geest im Bevenser Becken}

\subsection{Geländeprospektion}

Der Raum Lüneburg gehört zu den moorarmen Regionen in Niedersachsen. Er befindet sich östlich der Verbreitungsgrenze der großflächigen Hochmoore. Im Bereich des Kartenblattes Hamburg-Ost (Topographische Übersichtskarte 1:200.000, Blatt CC 3126), stehen 120 Niedermooren nur 8 kleine Hochmoore gegenüber (SCHNEEKLOTH u. TÜXEN 1979, 7).

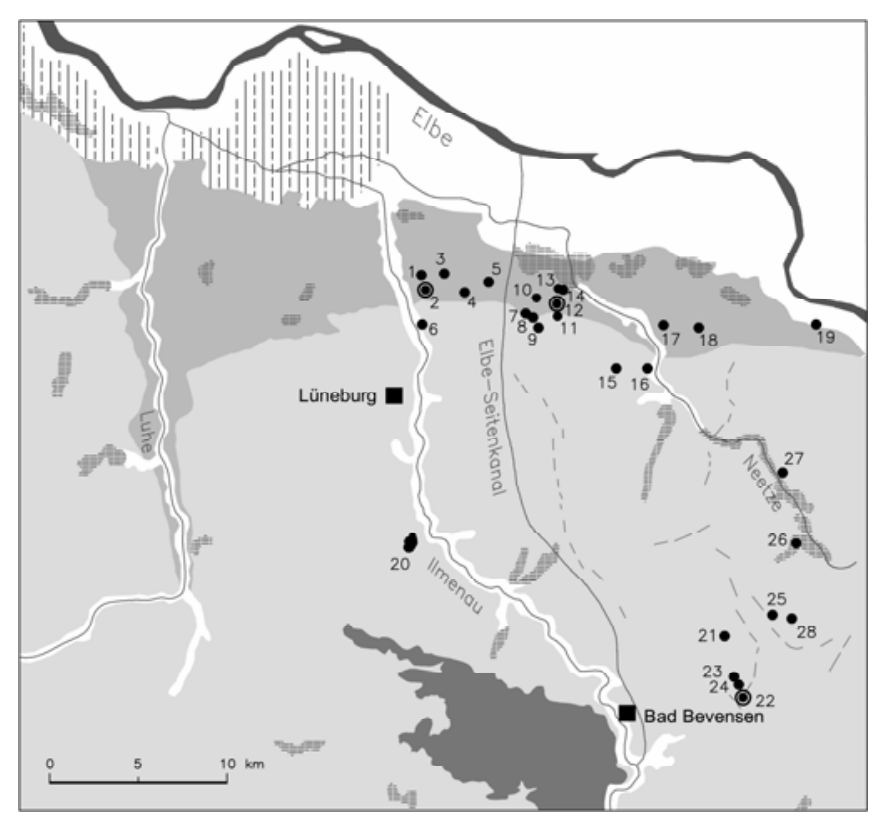

Abb. 4. Lage der Entnahmepunkte. - Erläuterungen s. Tab. 27 - Legende s. Abb. 2

(Bearbeitung: W. Kirleis, M. Spohr).

Um in der Umgebung von Rullstorf, Ldkr. Lüneburg, für Pollenanalysen geeignete Torfe und Ablagerungen aufzufinden, wurde zunächst die Auflistung der Niedersächsischen Naturschutzgebiete (PoHL 1998, 141) durchgesehen. Des weiteren wurden die Moorkartierungen von SchneEKloth u. TÜXEN (1979) herangezogen. Sofern Torfmächtigkeiten von unter $1 \mathrm{~m}$ angeben sind, wurden die Moore nicht in die Voruntersuchungen einbezogen. Die für siedlungsgeschichtliche Untersuchungen so interessanten Kleinstmoore sind in den Moorkartierungen nicht erfaßt, da nur Moore mit einem Durchmesser von mehr als $200 \mathrm{~m}$ berücksichtigt wurden. Aus diesem Grund wurden zusätzlich sowohl topographische, geologische, bodenkundliche und historische Karten als auch Luftbilder ausgewertet.

Bei Geländebegehungen wurden an 14 von 28 ausgewählten Stellen (Abb. 4; s. auch Tab. 27 im Anhang) Torfe bzw. Mudden angetroffen, die gute Erhaltungsbedingungen für Pollen versprachen. Mit Handbohrgeräten (Niederländischer Guts-Stechbohrer,
Dachnowski-Sonde, Russischer Kammerbohrer) wurden hier Kerne gezogen. Nach dem Säubern der Kernoberflächen wurde vor Ort die Stratigraphie aufgenommen. Anschließend wurden die Kerne in der Regel alle $10 \mathrm{~cm}$ beprobt.

Nach ersten Voruntersuchungen wurden schließlich das Elbaer Moor (2), der Rullstorfer Osterteich (12) und das Almstorfer Moor (22) für weitergehende Arbeiten ausgewählt.

\subsection{Pollenanalytische Untersuchungsmethoden}

\subsubsection{Geländearbeit}

Die Profile aus dem Elbaer Moor und aus dem Rullstorfer Osterteich wurden mit Zinkkästen (jeweils $50 \times 10 \times 5 \mathrm{~cm}$ ) aus einer $\mathrm{zu}$ diesem Zweck gegrabenen Profilwand gestochen. Da bei den Erdarbeiten im Elbaer Moor Wasser in die Entnahmegrube sickerte, konnte nur der obere Meter in Zinkkästen entnommen werden. Die Fortsetzung des Zinkkastenprofils wurde mit kleinen Probengläschen entnommen. Direkt neben den Zinkkastensäulen wurden zusätzlich Monolithe mit den Ausmaßen $15 \times 15 \times 25 \mathrm{~cm}$ aus der Profilwand geschnitten.

Um die Störung im Naturschutzgebiet Almstorfer Moor durch die Materialentnahme so gering wie möglich zu halten, wurde das Pollenprofil hier komplett mit dem Russischen Kammerbohrer (LANG 1994, 39) und dem Niederländischen Guts-Stechbohrer (10 cm Durchmesser) an zwei unmittelbar benachbarten Bohrstellen überlappend erbohrt.

Das in Plastikfolie luftdicht verpackte Untersuchungsmaterial wurde bis zur Bearbeitung in einem kühlen dunklen Kellerraum und zum Teil in einer Kühlzelle aufbewahrt.

\subsubsection{Probenaufbereitung im Labor}

Die Kerne des Profils aus dem Elbaer Moor wurden in $2 \mathrm{~cm}$-Abständen, die des Profils aus dem Rullstorfer Osterteich in Abständen von 4-12 cm und die des Profils aus dem Almstorfer Moor in Abständen von 2 und $4 \mathrm{~cm}$ beprobt. Als Probenstecher wurde eine Tiegelzange mit einem angeschweißten Aufsatz benutzt, der ein definiertes Volumen von $1 \mathrm{ml}$ faßt. Der im Guts-Stechbohrer transportierte untere Kernabschnitt des Profils aus dem Almstorfer Moor wurde im Labor in Scheiben von $1 \mathrm{~cm}$ Dicke zerlegt, die mit abgesägten $10 \mathrm{ml}$-Einwegspritzen als Probenstecher beprobt wurden.

Zur Ermittlung der Pollenkonzentrationen und Torfwachstumsraten wurden zunächst Lycopodium-Sporen- 
Tabletten mit $10 \%$ iger Salzsäure aufgelöst und $1 \mathrm{ml}$ Probenmaterial hinzugefügt (STOCKMARR 1971, 615 f.). Die Proben wurden anschließend mit heißer $\mathrm{KOH}$ behandelt, Makroreste wurden abgesiebt und die Pollenproben acetolysiert. Sandige Proben wurden zusätzlich für mindestens 48 h mit 40 \%iger Flußsäure behandelt. Um die Pollendichte $\mathrm{zu}$ erhöhen, wurden die Proben des pollenarmen Profils aus dem Rullstorfer Osterteich (Kap. 3.3.4) durch ein Sieb der Maschenweite $200 \mu \mathrm{m}$ gegeben. Anschließend wurden die Proben maximal $90 \mathrm{sec}$ im Ultraschallbad gereinigt, die dabei benutzte Gaze hatte eine Netzmaschenweite von $5 \mu \mathrm{m}$.

\subsubsection{Bestimmung der organischen Reste}

Die Bestimmung der Pollenkörner, Sporen, Algen und weiterer Mikroreste erfolgte an einem Zeiss-StandardMikroskop bei 500facher Vergrößerung im Durchlichtverfahren. Pollenkörner mit einer schwach strukturierten Oberfläche wurden bei 1250facher Vergrößerung unter Verwendung der Phasenkontrasteinrichtung untersucht.

Jede Probe wurde auf 500-1500 Baumpollenkörner ausgezählt, beim Profil aus dem Rullstorfer Osterteich fielen die BP-Summen einzelner Proben wegen schlechter Pollenerhaltung und geringer Pollenführung niedriger aus. Hier wurde nach dem Zählen einer Probe ein zusätzliches Präparat auf nicht erfaßte Pollen-Typen durchgemustert, so daß pro Probe wenigstens zwei Präparate berücksichtigt wurden.

Die Nomenklatur folgt im allgemeinen MOORE et al. (1991). Centaurea cyanus kann ohne die Bezeichnung „Typ“ auskommen, da Centaurea montana nicht im Gebiet heimisch ist (OBERDORFER 1990, 972). Gleiches gilt für Lythrum salicaria, denn L. hyssopifolia fehlt bzw. ist sehr selten im nordwestdeutschen Flachland (OBERDORFER 1990, 680). Im Rumex acetosa-Typ sind Pollenkörner (PK) von Rumex acetosa und von Rumex acetosella, unter der Bezeichnung Plantago major/media PK beider Arten nach MoORE et al. (1991) zusammengefaßt. Die Benennung der Pollentetraden des Vaccinium-Typs sowie der PK des Anemone-Typs, des Ranunculus acris-Typs, von Ranunculus p. p. und von Myriophyllum alterniflorum richtet sich nach FÆGRI et al. (1989). PK von Potamogeton Sekt. Eupotamogeton wurden nach BEUG (1961) bestimmt.

Zur sicheren Ansprache der Getreide-Typen (BEUG 1961, 30 f.) wurden nach Möglichkeit der größte Durchmesser der Pollenkörner, der Porusdurchmesser sowie Anulusbreite und -höhe im Phasenkontrast bestimmt. Die Unterscheidung von Hydrocotyle und Bupleurum (PUNT u. Clarke 1984, 189 f. u. 208), des Humulus-Typs vom Cannabis-Typ (DöRfler 1989, 40 f.; 1990, 219 f.) und von Jasione und Campanula-Typ (FÆGRI 1993, 56) erfolgte aufgrund der Morphologie und letztlich der Größe der Pollenkörner.
Des weiteren wurden u. a. die Arbeiten von EIDE (1981), ERdTMAN u. SORSA (1971), PUNT (1976) sowie PUNT et al. $(1980 ; 1981 ; 1984 ; 1988 ; 1991)$ als Bestimmungsliteratur benutzt. Zudem konnten die von D. Kučan angelegte Fotokartei subfossiler Mikroreste und die umfangreiche Vergleichssammlung rezenter Pollenkörner und Sporen des Niedersächsischen Instituts für historische Küstenforschung in Wilhelmshaven herangezogen und wertvoller Rat von Prof. Dr. K.-E. Behre, Dipl.-Biol. D. Kučan, Dr. F. Bittmann (alle NIhK, Wilhelmshaven) und Prof. Dr. H.-J. Beug (Universität Göttingen) eingeholt werden.

Die Grünalgen der Gattung Pediastrum sowie Tetraëdron minimum und Scenedesmus wurden nach JANKOVSKÁ u. KOMÁREK (2000) SOWie PARRA BARRIENTOS (1979) bestimmt. Außerdem wurden die Artikel von VAN GeEl $(1978 ; 1979)$, van GEel et al. $(1981 ; 1983)$ und PALS et al. (1980) zur Ansprache weiterer Mikroreste herangezogen. Die Holzkohleflitter im mikroskopischen Präparat, deren Durchmesser über $5 \mu \mathrm{m}$ lag, wurden mit einem Handzähler (H 20 Link) gezählt.

Die bei der Aufbereitung der Proben für Pollenanalysen und Radiokarbon-Datierungen anfallenden Makroreste wurden an einer Stereolupe Stemi SV 6 der Firma Zeiss bei 8-50facher Vergrößerung und an einem Zeiss-StandardMikroskop bei 500facher Vergrößerung untersucht. Als wichtige Hilfsmittel standen hierfür die institutseigene Vergleichssammlung rezenter Samen und Früchte sowie die Sammlung von Dr. F. BITTMANN (NIhK, Wilhelmshaven) zur Verfügung. An Bestimmungsliteratur wurden u. a. die Arbeiten von AALTO (1970), BERGGREN (1969; 1981), Grosse-BrAUCKMANN (1972; 1974), GROSSEBRAUCKMANN u. STREITZ (1992), NiLSSON u. HJELMQUIST (1967) sowie RABIEN (1953) genutzt.

\subsubsection{Glührestbestimmungen}

Für die Glührestbestimmungen wurden aus den Profilen Elbaer Moor und Rullstorfer Osterteich $5 \mathrm{ml}$ Ausgangssubstrat mit $10 \mathrm{ml}$-Einwegspritzen direkt neben den Pollenproben entnommen. Vom Profil Almstorfer Moor wurden jeweils nur $2 \mathrm{ml}$ Ausgangssubstrat verascht, sofern das Material nicht schon für Radiokarbon-Datierungen verbraucht war. Das Naßgewicht der Proben wurde auf einer Analysenwaage festgestellt und die Proben anschließend für $18 \mathrm{~h}$ bei $110^{\circ} \mathrm{C}$ im Trockenschrank getrocknet. Daraufhin wurden die Proben im Exsikkator 20 min abgekühlt, und schließlich wurde ihr Trockengewicht ermittelt. Im Muffelofen wurden diese Proben über $3 \mathrm{~h}$ bei $550{ }^{\circ} \mathrm{C}$ verascht, dann $55 \mathrm{~min}$ im Exsikkator abgekühlt und gewogen. Der Glührestrückstand ist im Pollendiagramm in Prozent vom Trockengewicht dargestellt (DöRFLER $1989,10)$. 


\subsubsection{Darstellung der Ergebnisse}

Die Ergebnisse der Pollenanalysen werden in Form von Pollendiagrammen (PD) präsentiert, die mit den Programmen Tilia 2.0 b4 und Tilia Graph 2.0 b5 erstellt und in TG-View nachbearbeitet wurden. Die Pollendiagramme sind Prozentwertdiagramme auf der Basis der BaumpollenSumme. Sie sind in Pollenzonen nach FIRBAS (1949) gegliedert. Im PD Elbaer Moor konnte der FirbasAbschnitt VI und im PD Almstorfer Moor der FirbasAbschnitt IX anhand biostratigraphischer Kriterien, die nur für das jeweilige Diagramm gültig sind, weiter unterteilt werden. Als Berechnungsgrundlage wurde, sofern nicht anders gekennzeichnet, die Summe des Baumpollens gebildet, definiert als Pollensumme sämtlicher Gehölze mit Ausnahme von Corylus. Unbedingt zu beachten sind die aus zeichnerischen Gründen eingeführten unterschiedlichen Maßstäbe der Ordinaten.

Die folgenden Sammelbezeichnungen finden in den Pollendiagrammen Verwendung:

- Kulturpflanzen: Secale cereale, Hordeum-Typ, TriticumTyp, Avena-Typ, Cerealia indeterminata, Fagopyrum esculentum, Vicia faba, Cannabis sativa.

- Sekundäre Siedlungszeiger (SZ): Centaurea cyanus, Spergula arvensis, Scleranthus annuus, Polygonum aviculare-Typ, Polygonum Sekt. persicaria, Melampyrum, Convolvulus arvensis, Artemisia, Chenopodiaceae, Urtica dioica, Rumex acetosa-Typ, Plantago lanceolata, P. major/media.

Die Werte von Calluna und Poaceae p.p., die in Siedlungszeiten ebenfalls als sekundäre Siedlungszeiger zu werten sind, gehen nicht in diese Summenkurve von sekundären Siedlungszeigern ein.

Unter „Polypodiaceae p. p.“ sind monolete Farnsporen ohne Perispor, unter „Indeterminata“ nicht bestimmbare PK und unter „Varia“ unbekannte PK zusammengefaßt.

Zusätzlich zu den Werten des Pollens, der Sporen und der Algen wurden Werte der Holzkohleflitter in Prozent des BP und Glührest-Werte in Prozent des Trockengewichts in die Diagramme aufgenommen. Eine Tiefenskala, eine Stratigraphiesäule und Altersangaben sind den Diagrammen vorangestellt. Weitere Pilz- und Algenreste sind in PräsenzDiagrammen dargestellt.

Die Pollenkonzentrationen wurden mit dem für jede Probe berechneten Pollenkonzentrationsfaktor berechnet:

$$
\mathrm{F}=\mathrm{n}_{\text {zug. Lycos }} / \mathrm{n}_{\text {gef. Lycos }} \times \text { Volumen }
$$

Die Zahl der zugesetzten Lycopodium-Sporen ( $\mathrm{n}_{\text {zug. Lycos }}$ ) wird zur Zahl der wiedergefundenen Lycopodium-Sporen $\left(\mathrm{n}_{\text {gef. Lycos }}\right)$ ins Verhältnis gesetzt, welches mit dem Volumen multipliziert wird.
Aus zeichnerischen Gründen sind einige seltene PollenTypen nicht in die Diagramme aufgenommen worden. Sie sind in Tab. 28-29 im Anhang dargestellt.

\subsubsection{Radiokarbon-Datierungen}

Radiokarbon-Datierungen wurden am Leibniz-Labor für Altersbestimmung und Isotopenforschung der ChristianAlbrechts-Universität Kiel durchgeführt. Die Kalibrierung der Radiokarbon-Daten erfolgte mit dem Kalibrierungsprogramm Calib 4.3 (STUIVER u. REIMER 1993; STUIVER et al. 1998). Aus der Literatur bezogene Angaben wurden ebenfalls neu kalibriert, sofern Radiokarbonjahre BP angegeben waren. Im Text sind die Daten stets in Radiokarbonjahren BP mit einfacher Standardabweichung und in kalibrierten Kalenderjahren v. bzw. n. Chr. wiedergegeben.

Die Kalibrationen sind vereinfacht dargestellt. Von mehreren Wahrscheinlichkeitsmaxima wurde der mittlere Wert genommen, dahinter wurde in Klammern die Zeitspanne gesetzt, innerhalb derer die Wahrscheinlichkeitsmaxima liegen. So wird die ausführliche Schreibweise des Kalibrationsergebnisses für die Radiokarbon-Datierung auf $4430 \pm 55 \mathrm{BP}$, kal. 3308 (3084, 3064, 3033) 2924 v. Chr. auf die Angabe 3064 (3308-2924) v. Chr. verkürzt.

\subsection{Ergebnisse der Pollenanalysen}

\subsubsection{Zeitstellung der Pollendiagramme}

Zunächst gilt es, die hier im folgenden vorzustellenden Pollendiagramme aus dem nordöstlichen Niedersachsen anhand von gut datierten Standarddiagrammen aus demselben Naturraum zeitlich einzustufen.

Aus dem Altmoränengebiet Nordostniedersachsens liegen zwar verschiedene Pollendiagramme mit einzelnen Radiokarbon-Datierungen vor (BECKER 1995; KUBITZKI 1961; KUBITZKI u. MÜNNICH 1960, 140 f.; LESEMANN 1969). Jedoch gibt es kein hoch aufgelöstes Standarddiagramm mit einem Gerüst zahlreicher, dem pollenanalytischen Befund entsprechender RadiokarbonDatierungen. Daher wird auf Pollendiagramme aus der benachbarten Altmoränenlandschaft des nordwestlichen Niedersachsens zurückgegriffen.

Als Standard-Datierungen sind in der Zeittafel (Tab. 1) die Angaben aus Flögeln im Elb-Weser-Dreieck zugrunde gelegt (BEHRE u. KUČAN 1994, 93 f.). Die Datierungen der Grenzen der Pollenzonen lassen sich zwanglos auf das Altmoränengebiet im nordöstlichen Niedersachsen übertragen.

Das PD Belauer See in Schleswig-Holstein, dessen Profil aus jahresgeschichteten Sedimenten besteht (WIETHOLD 1998), scheidet als Standarddiagramm für die 
Altmoränenlandschaft des nordöstlichen Niedersachsens aus, da es aus einem Jungmoränengebiet stammt. Zudem ist bei den Datierungen Vorsicht geboten, da sich die gesamte Chronologie auf die Radiokarbon-Datierung des Ulmenfalls vom $10 \mathrm{~km}$ entfernt liegenden Dosenmoor stützt. Der Ulmenfall kann jedoch bis zu 200 Jahre von dem Datum aus dem Dosenmoor abweichen.

Die Einteilung der archäologischen Perioden für Nordniedersachsen richtet sich nach Angaben in dem von HÄßLER (1991) herausgegebenen Sammelband „Ur- und Frühgeschichte in Niedersachsen“ (s. HÄßLER 1991a, 196; 1991b, 285 f.; HeEge u. MAIER 1991, 110; MetZleR u. WILBERTZ 1991, 155; SCHWARZ 1991, 238).

\subsubsection{Vegetationsgeschichtlicher Nachweis menschlicher Aktivität}

In einem Pollendiagramm läßt sich menschliche Aktivität erst $a b$ der Zeit sicher nachweisen, in der der Mensch begann, die Landschaft nach seinen Bedürfnissen umzuformen. Das ist im allgemeinen seit Beginn der Seßhaftigkeit des Menschen im Neolithikum der Fall.

Generell gilt, daß der für die Anlage einer Siedlung vorgesehene Platz gerodet und Holz für den Hausbau, als Brennmaterial und für andere Zwecke herbeigeschafft werden muß. Auch um Ackerland zu gewinnen, muß der Wald gerodet werden. Zudem führte die Waldweide, die seit dem Neolithikum betrieben wurde, zu einer erheblichen Auflichtung der Wälder. Im Pollendiagramm verändert sich daher das Verhältnis von Baumpollen (BP) zu Nichtbaumpollen (NBP) zugunsten des NBP. Auf ungenutzten gerodeten Flächen und am Übergang von genutztem Land zu Wald findet eine natürliche Sukzession statt. Dort können sich zunächst lichtliebende Arten wie die Birke und die Hasel ausbreiten.

Wird Ackerbau und Viehzucht betrieben, setzen die Kulturpflanzen, Ackerunkräuter und weitere spezifische Ruderalpflanzen (primäre und sekundäre Siedlungszeiger) Pollen frei, der sich mittels Pollenanalyse nachweisen läßt. Abhängig von der Art und Weise, wie Ackerbau betrieben wurde, können auch Weide- und Brachenzeiger den Ackerbau im Pollendiagramm widerspiegeln. So steht der Brachenzeiger Plantago lanceolata gerade dann im Acker, wenn die Bestandsdichte auf den Feldern gering ist oder wenn die Flächen mit dem Hakenpflug bearbeitet werden, der die unterirdischen Organe der ausdauernden Pflanze nicht zerstört. Pollen von Plantago lanceolata und P. major, Rumex acetosa, Ranunculaceae, Caryophyllaceae, Apiaceae, Chenopodiaceae, Poaceae und Cyperaceae weist auf Viehhaltung hin (BEHRE 1981, 233 f.).

Die auch im Winter betriebene Waldweide verhinderte die natürliche Verjüngung der Wälder und führte zu einer starken Auflichtung, die sich in Pollendiagrammen durch hohe Gräser-Werte abzeichnet (BEHRE 2000, 107 f.). Auch Schwankungen einzelner BP-Kurven stehen in
Zusammenhang mit der Viehhaltung. Seit dem Neolithikum wurden für die Laubfutterwirtschaft bevorzugt die Ulme und die Esche geschneitelt (ElLENBERG 1996, 45 f. u. dort zitierte Autoren). Im Pollendiagramm zeichnet sich daher ein Rückgang der Ulmen-Kurve ab; die Eschen-Kurve kann nach KALIS $(1988,130)$ dagegen höhere Werte erreichen, da sie abhängig von der Schneitelfrequenz stärker zur Blüte kommen und mehr Pollen produzieren kann.

Seit der Vorrömischen Eisenzeit wurden in Landschaften mit armen Böden Soden der durchwurzelten Humusauflage - besonders von Heide- und Waldböden - zur Düngung der Felder eingesetzt. Auf diese Weise verarmten die Böden am Entnahmeort der auch als Plaggen bezeichneten Soden. Letztlich wurde dadurch die Verheidung dieser Flächen vorangetrieben. Seit im Mittelalter Roggen auch als Wintergetreide kultiviert wurde und die Böden durch den Dauerfeldbau stark beansprucht wurden, kam die systematisch betriebene Plaggenwirtschaft zum Einsatz: Bevor die Plaggen auf das Ackerland ausgebracht wurden, dienten sie als Stalleinstreu und wurden mit Dung vermengt, oder sie wurden kompostiert. Nachdem die Plaggen auf diese Weise angereichert waren, wurden sie zur Bodenverbesserung auf die Felder gebracht. Dadurch entstanden im Siedlungsumfeld die mittelalterlichen Plaggenesche als Auftragsböden. Die Plaggenentnahmeorte (Plaggenmatt) lagen meist im weiteren Umkreis der Siedlungen (BEHRE 1976a; 1980; ELLENBERG 1996, 50 f.).

Die Wälder wurden zunehmend als Rohstofflieferanten genutzt, wobei sich spezifische Waldformen entwickelten. So führte die Nutzholzgewinnung zur Förderung von ausschlagsfähigen Gehölzen wie Hainbuche, Linde, Ahorn, Eiche, Esche und Hasel und begünstigte die Entstehung von Niederwäldern (POTT 1985, 6). Das massive Ausweiten der Viehweide in den Wäldern führte zur Entstehung von Hudewäldern, in denen Eichen als Überhälter stehengelassen wurden, um dem Vieh Schatten und Futter zu spenden (ELLENBERG 1996, 38 f.). Außerdem verhinderte das im Wald weidende Vieh die natürliche Sukzession, weil es das Unterholz, zu dem auch die Keimlinge und der Jungwuchs der Holzgewächse gehören, abfraß. Auch Übergangsformen zwischen Nieder- und Hudewäldern kamen vor. In der Neuzeit wurden zur Bauholzgewinnung Hochwälder in Form von Forsten angelegt (ELLENBERG 1996, 53 f.). Heideflächen wurden seit dem 18. Jh. mit Kiefern aufgeforstet (KREMSER 1990, 355). 
Tab. 1. Zeittafel mit den waldgeschichtlichen Abschnitten, der Gliederung der Pollendiagramme und den archäologischen Perioden.

Die graue Rasterung zeigt an, welche Zeitabschnitte die einzelnen Bohrkerne umfassen. Gestrichelte Linien trennen lokale Pollenzonen ab.

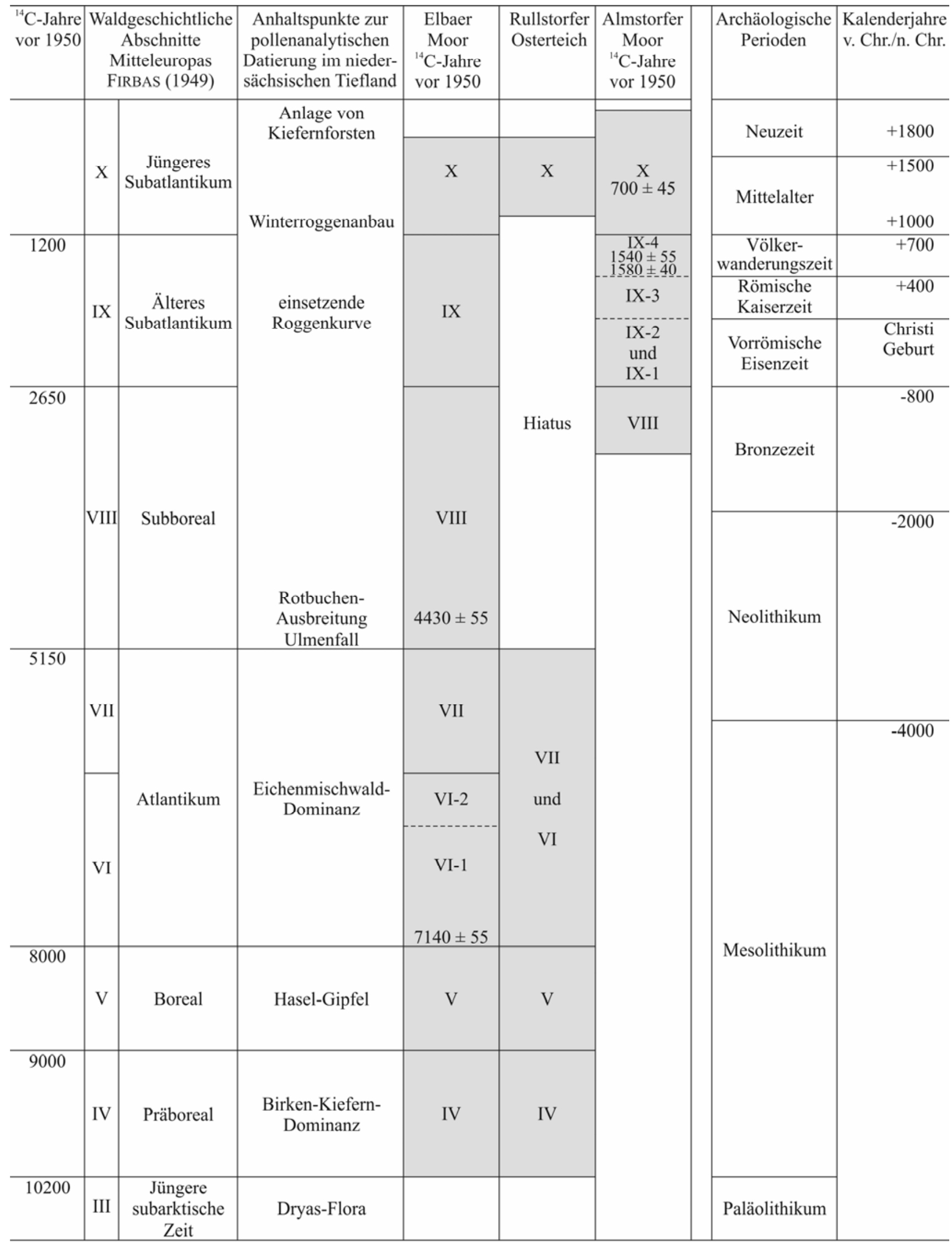




\subsubsection{Elbaer Moor}

Das Elbaer Moor (TK 25, Blatt 2628 Artlenburg, r 3595 200, h 5908 555) liegt nördlich von Lüneburg im Bereich der Niederterrasse der Elbe auf $+8 \mathrm{~m} \mathrm{NN}$ (Abb. 2). Es bedeckt eine Fläche von ca. 2,25 ha und ist deshalb als kleines Moor zu klassifizieren. Der Polleneintrag einer solch kleinen Lagerstätte stammt überwiegend von der Vegetation des Moores selbst und von der Vegetation aus seiner unmittelbaren Umgebung. Der regionale Polleneintrag aus einem Umkreis von $5-10 \mathrm{~km}$ stellt den zweiten wichtigen Anteil an den Pollenspektren aus dem Elbaer Moor dar. Die maximalen Mächtigkeiten der organischen Ablagerungen erreichen etwa $120 \mathrm{~cm}$.

Das Elbaer Moor liegt ca. $8 \mathrm{~km}$ Luftlinie in nordwestlicher Richtung vom archäologischen Ausgrabungsgelände bei Rullstorf entfernt. Der Polleneintrag in das Moor stammt daher aus einem peripheren Wirtschaftsraum der Rullstorfer Siedler.

Das Elbaer Moor ist von Gruben und Stegen des bäuerlichen Torfstiches zergliedert. Dieser wurde noch im 20. Jh. betrieben (frdl. Mitteilung Dr. E. von Rantzau). Im östlichen Bereich des Moores steht Grundwasser in den Torfentnahmegruben an. Sie werden künstlich offen gehalten. Hier befindet sich auch ein schmaler Röhrichtsaum mit Phragmites, Carex rostrata und Hydrocotyle. Im westlichen Teil des Moores sind Sphagnum-Rasen in den Torfentnahmegruben ausgebildet. Auf den Bulten wachsen klassische Hochmoorpflanzen wie Drosera, Andromeda, Oxycoccus und Erica. Der Jungwuchs von Betula pubescens zeigt einen Zugang zum Mineralbodenwasser an. Die heutige Vegetation des Elbaer Moores ist ein Mosaik aus Resten einer Hochmoorvegetation, Bereichen, in denen sich Niedermoorarten ausbreiten, und einem armen Röhricht. Auf den an das Moor grenzenden trockenen bis sehr trockenen, nährstoffarmen, verwehbaren Sandböden (Bodenkundliche Standortkarte 1:200.000, Blatt CC 3126 Hamburg-Ost, 1979) stocken Kiefernforste.

Die Kurhannoversche Landesaufnahme von 1776 (Blatt Scharnebeck) zeigt, daß sich damals auf den Talsanden insbesondere nördlich des Elbaer Moores Heideflächen ausdehnten; südlich des vor dem Geestrand gelegenen Moores, auf der Hohen Geest, sind Ackerflächen kartiert (Abb. 15).

\subsubsection{Stratigraphie und lokale Entwicklung}

Das Profil Elbaer Moor hat eine Länge von $113 \mathrm{~cm}$ (Abb. 5-7). Über Fein- und Mittelsand ist eine Feindetritusmudde abgelagert. Oberhalb der Mudde wurden im Profil verschiedene Torfe angetroffen.

Die Senke des Elbaer Moores entstand vermutlich als spätglaziale Ausblasungswanne. Die ältesten Ablagerungen aus Voruntersuchungen an der Entnahmestelle des Profils
Elbaer Moor (nicht in den Abb. 5-7 enthalten) lassen auf eine spätglaziale Zeitstellung schließen, denn neben BetulaWerten von $57 \%$ sowie Pinus-Werten von $41 \%$ treten auch hohe NBP-Werte auf. Die Anteile der Poaceae p. p. sind mit $22 \%$ und die des Anemone-Typs mit $21 \%$ sehr hoch (Bezugssumme 200 BP). Außerdem erreicht Artemisia Werte von $4 \%$. Dieses liefert Hinweise auf eine spätglaziale Vegetation.

Tab. 2. Makroreste des Profils Elbaer Moor. Die PZ VI nach Firbas (1949) ist lokal untergliedert.

\begin{tabular}{|c|c|c|c|}
\hline $\begin{array}{c}\text { PZ } \\
{[\text { Firbas] }}\end{array}$ & Stratigraphie & $\begin{array}{l}\text { Tiefe } \\
{[\mathrm{cm}]}\end{array}$ & Makrorest \\
\hline \multirow[t]{2}{*}{$\mathrm{X}$} & Moostorf & 7 & $\begin{array}{l}\text { Drepanocladus sp. und } \\
\text { Sphagnum sp. } \\
\text { (Blättchen u. Ästchen) }\end{array}$ \\
\hline & \multirow{2}{*}{$\begin{array}{c}\text { stark } \\
\text { verdichteter } \\
\text { Sphagnum-Torf }\end{array}$} & 19 & Carex sp. (1 Nüßchen) \\
\hline VIII & & 31 & $\begin{array}{l}\text { Siebzellendeckel } \\
\text { (Holz) }\end{array}$ \\
\hline VII & \multirow{3}{*}{ Sphagnum-Torf } & 53 & $\begin{array}{l}\text { Ranunculus flammula } \\
\text { (1 Nüßchen) }\end{array}$ \\
\hline VI-2 & & 73 & $\begin{array}{l}\text { Carex (1 Schlauchrest), } \\
\text { verkohlt }\end{array}$ \\
\hline VI-1 & & 83 & Luzula sp. (5 Samen) \\
\hline
\end{tabular}

Im Präboreal entstand ein von einem Verlandungssumpf mit Sparganium, Filipendula, Menyanthes, Cyperaceae und Equisetum umgebener See in der Senke. Utricularia ist als einzige Wasserpflanze nachgewiesen. Auf dem Seeboden wurde eine Feindetritusmudde abgelagert. Um die Senke stockte ein lichter Birken-Kiefernwald. Der hohe Anteil minerogenen Materials (hohe Glührestwerte) zeigt, daß die Böden der Umgebung erodiert wurden.

Im Verlauf des Boreals setzt die Sphagnum-Kurve im PD ein. Sie zeigt den Beginn des Hochmoorwachstums und den Beginn der Verlandung des kleinen Tümpels an. Im Bohrkern löst in dieser Tiefe ein stark zersetzter SphagnumTorf die liegende Feindetritusmudde ab. Die nachgewiesenen Algentaxa Zygnema-Typ, Mougeotia, Spirogyra, Cosmarium und Closterium idiosporum (Abb. 5) stammen aus Bereichen mit stehendem Wasser wie den Schlenken (VAN GEEL et al. 1981). Ob Calluna zu dieser Zeit das Moor besiedelte, ist fraglich, da hier keine Makroreste angetroffen wurden. Wahrscheinlicher ist, daß sie gemeinsam mit Jasione auf dem Sandboden eines Übergangsstreifens zwischen dem Verlandungssumpf und dem umgebenden Wald bzw. im lichten Wald stand. Das Spektrum der Sumpfpflanzen im Boreal ist durch Succisa und Lythrum erweitert.

Im Atlantikum beginnt die Massenausbreitung der Erle. Sie besiedelte vermutlich auch den Rand des Elbaer Moores. 
Tab. 3. Ergebnisse der Radiokarbon-Datierungen am Profil Elbaer Moor mit einfacher Standardabweichung. $\mathrm{Zu}$ alt ausgefallene Daten sind kursiv gesetzt.

\begin{tabular}{|c|c|c|c|c|}
\hline $\begin{array}{l}\text { Tiefe } \\
{[\mathrm{cm}]}\end{array}$ & $\begin{array}{c}\text { vegetationsgeschichtliches } \\
\text { Ereignis }\end{array}$ & $\begin{array}{l}{ }^{14} \mathrm{C}-\mathrm{Alter} \\
{[\mathrm{BP}]}\end{array}$ & $\begin{array}{c}\text { ermitteltes }{ }^{14} \mathrm{C} \text {-Alter } \\
\text { [kal. BP] }\end{array}$ & $\begin{array}{c}\text { ermitteltes }{ }^{14} \mathrm{C} \text {-Alter } \\
\text { [kal. v. / n. Chr.] }\end{array}$ \\
\hline $14-16$ & Buchweizen tritt auf & $2110 \pm 30$ & $2079(2145$ - 2009) & 130 ( $196-$ 60) v. Chr. \\
\hline $19-21$ & Siedlungszeiger $>10 \%$ & $1490 \pm 25$ & $1352(1408-1333)$ & 598 ( $542-617)$ n. Chr. \\
\hline $23-25$ & Roggen-Kurve setzt ein & $2190 \pm 25$ & $2176(2303-2133)$ & 227 ( $354-184)$ v. Chr. \\
\hline $29-31$ & Rotbuchen-Werte $>1 \%$ & $3170 \pm 35$ & 3381 (3442 - 3359) & $1432(1493-1410) v$. Chr. \\
\hline $39-41$ & erste PK der Rotbuche & $4430 \pm 55$ & $5013(5258-4874)$ & 3064 (3308 - 2924) v. Chr. \\
\hline $80-82$ & Haselgipfel & $7140 \pm 55$ & $7956(8006-7874)$ & 6007 (6056 - 5924) v. Chr. \\
\hline
\end{tabular}

Die Böden am Geestrand waren nun durch dichte Eichenmischwälder befestigt, der minerogene Eintrag wurde dadurch verringert. Die Sphagnen (in PZ VII Werte um $95 \%$ ) dehnten sich vermutlich auf Kosten der Cyperaceae aus. Die neu zum Sumpfpflanzenspektrum hinzutretenden PK von Hydrocotyle und von Lysimachia sowie der Fund eines Nüßchens von Ranunculus flammula $(53 \mathrm{~cm}$ Tiefe; Tab. 2) deuten auf nasse Verhältnisse hin.

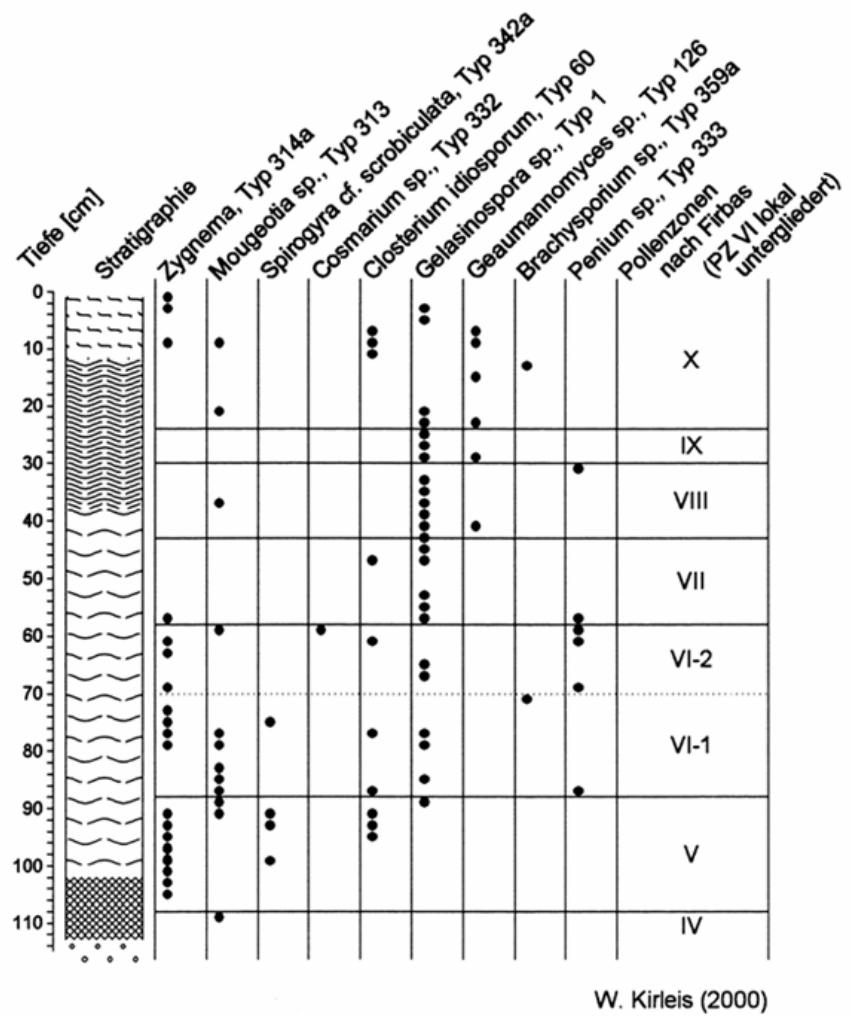

Abb. 5. Präsenzdiagramm der Algen- und Pilzreste im Profil Elbaer Moor, Ldkr. Lüneburg.

Im Subboreal und am Beginn des Subatlantikums sind im Bohrkern nur noch einzelne Algenreste aus mesotrophen Gewässern oder Schlenken vertreten, das Sumpfpflanzenspektrum ist verkleinert, und gleichzeitig gehen die Sphagnum-Werte zurück. Gelasinospora und Geaumannomyces, die in stark zersetztem Torf und
Seggentorf auftreten (VAN GeEL 1978, 48 f.; 1980, 406), sind nun regelmäßig nachgewiesen (Abb. 5). Besonders zu Beginn der PZX treten zudem gehäuft Radizellen im Sphagnum-Torf auf. Im Bereich der Entnahmestelle des Profils wuchsen daher vermutlich Cyperaceae.

Im Abschnitt zwischen 38 und $12 \mathrm{~cm}$ Tiefe ist der stark zersetzte Torf verdichtet. Mit dem Wechsel der Torfdichte steht der erhöhte Glührest-Eintrag in $37 \mathrm{~cm}$ Tiefe in Zusammenhang. Die Pollenkonzentration ist, wie dies für stark komprimiertes Material zu erwarten ist, teilweise sehr hoch (Abb. 6).

In der Tiefe von 12-1 cm wurde ein schwach zersetzter Moostorf aus Torf- und Braunmoosen (Sphagnum sp. und Drepanocladus sp.) gebildet. Eine zunehmende Vernässung zeigen die häufiger nachgewiesenen Sumpfpflanzen-PK von Succisa, Lysimachia und Hydrocotyle sowie die Algenreste vom Zygnema-Typ und von Closterium idiosporum an.

\subsubsection{Radiokarbon-Datierungen}

An sechs pollenstratigraphisch markanten Punkten (Corylus-Gipfel, Auftreten der ersten Fagus-PK, Überschreiten der 1\%-Marke durch die Fagus-Kurve, Einsetzen der Secale-Kurve, Anstieg der SiedlungszeigerSummenkurve auf Werte über $10 \%$, Auftreten von Fagopyrum) wurden Proben für konventionelle Radiokarbon-Datierungen entnommen. Um Verunreinigungen (hier: erkennbare, filzige Würzelchen) zu entfernen, wurde der Torf zunächst gewässert und durch ein Küchensieb gegeben. Das Wasser wurde von dem nunmehr muddeartig aussehenden Rückstand abzentrifugiert. Die feuchten Proben wogen nach dieser Behandlung zwischen 245 und $575 \mathrm{~g}$.

Die beiden ältesten Datierungen bestätigen den pollenanalytischen Befund, hingegen liefern die vier Datierungen aus dem stark verdichteten Torf zu alte Werte (Tab. 3). 


\subsubsection{Pollendiagramm Elbaer Moor}

Die Pollenerhaltung im Profil aus dem Elbaer Moor ist gut, die Pollenkonzentrationen schwanken zwischen 206.217 PK/ml und 1.509.000 PK/ml (Abb. 6).

Präboreal (PZ IV nach Firbas; 113-108 cm)

Das PD Elbaer Moor setzt im ausgehenden Präboreal ein (Abb. 7). Pinus und Betula waren die wichtigsten Baumarten der grundwasserfernen Talsandböden am Geestrand zur Niederterrasse der Elbe. Ihre Bestände reichten bis an die Senke des kleinen Gewässers heran, das vermutlich von Salix-Gebüschen gesäumt war. In lichten Bereichen der Birken-Kiefernwälder fanden heliophile Kräuter ihre natürlichen Standorte. Darunter waren auch solche, die als ,sekundäre Siedlungszeiger“ bezeichnet sind.

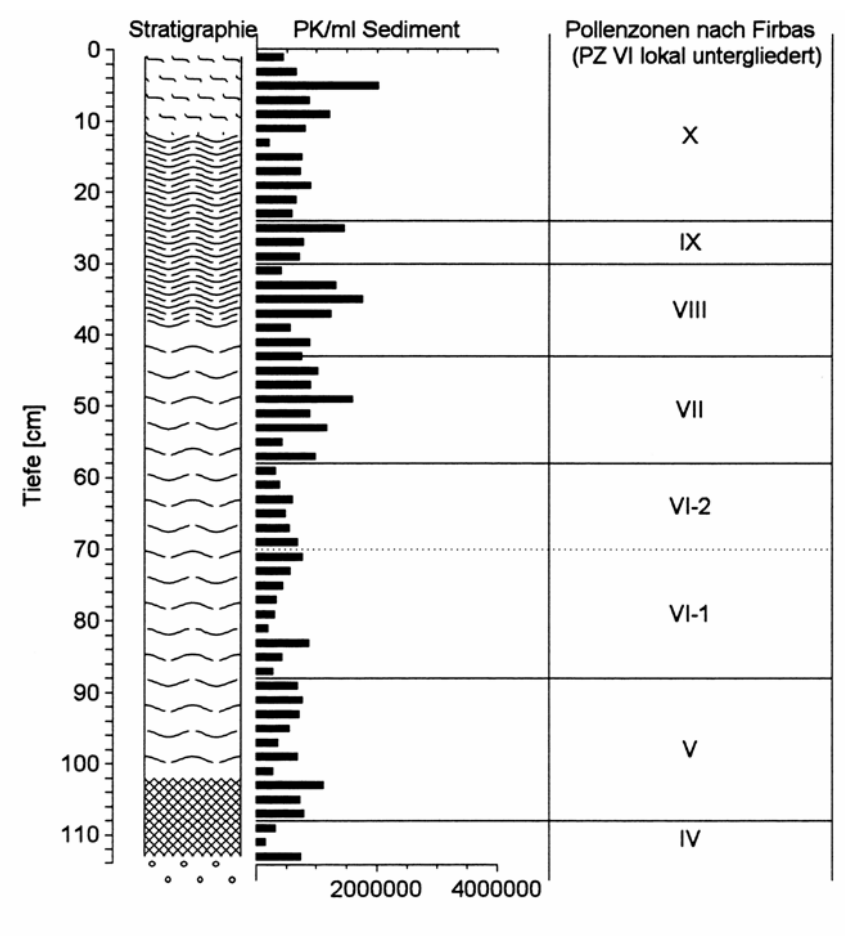

Abb. 6. Pollenkonzentrationen im Profil Elbaer Moor, Ldkr. Lüneburg.

Boreal (PZ V nach Firbas; 108 -88 cm)

Grenze IV/V (108 cm): Beginn des Corylus-Anstiegs

Nach FIRBAS (1949, 49 f.) beginnt das Boreal mit dem Anstieg der Corylus-Werte; im Elbaer Moor steigen diese Werte sehr langsam an.

Die lichtdurchlässigen Wälder waren von Pinus dominiert (Werte $>80 \%$ ), die Bedeutung von Betula ging zurück (Werte $<20 \%$ ). Corylus konnte sich im Unterwuchs dieser Wälder ausbreiten und war ein wichtiger Bestandteil der Waldsäume. Der boreale Corylus-Gipfel erreicht im PD
Werte von nur $24 \%$ und bestätigt, daß die mittlere Elbe in dieser Zeit ein haselarmes Gebiet war (FIRBAS 1949, 150).

Die Eichenmischwaldarten Ulmus, Quercus und Tilia wanderten im Boreal in die Region ein und durchsetzten die Kiefernwälder auf den Talsanden und auf der Hohen Geest am Geestrand zur Niederterrasse der Elbe.

Atlantikum (PZ VI und VII nach Firbas; $88-43 \mathrm{~cm}$ ) Grenze PZ V/VI-1 $(88 \mathrm{~cm})$ : starker Anstieg der Alnus-Werte

Im PD Elbaer Moor beginnt das Atlantikum mit einem starken Anstieg der Alnus-Werte. Dieses ist in ganz Nordwestdeutschland kennzeichnend für den Beginn des Atlantikums (FIRBAS 1949, 49 f.).

OVERBECK (1975, 466) beschreibt das ca. 3000 Radiokarbonjahre dauernde Atlantikum für Nordwestdeutschland als eine Phase mit stabilem Waldbild. Er sieht daher von einer weiteren Untergliederung ab. Im PD Elbaer Moor zeichnet sich ab, daß sich die Eichenmischwaldarten in der Umgebung des Moores ausbreiteten und Pinus zurückdrängten. Die Eichenmischwälder bestanden überwiegend aus Quercus, doch hatte auch Pinus noch erhebliche Anteile in diesen Wäldern. Ulmus, Tilia und Fraxinus waren weniger häufig vertreten. Acer kam nur sporadisch vor, ebenso Viscum und Hedera als Zeiger eines sommerwarmen und wintermilden Klimas (IVERSEN 1944, 468 f.). Die insektenblütigen Taxa Linde und Ahorn haben eine geringe Pollenstreuung (ANDERSEN 1973, 110) und sind daher im Pollendiagramm unterrepräsentiert. Der reale Anteil der Linde am Waldbestand hat daher vermutlich mindestens dem von Ulmus entsprochen. Im Profil aus dem Elbaer Moor variiert die Zusammensetzung der Eichenmischwälder leicht, weshalb die PZ VI in zwei biostratigraphische Einheiten PZ VI-1, 88-70 cm, und PZ VI-2, 70-58 cm, aufgeteilt wurde.

Die PZ VI-1 zeichnet sich durch Ulmus-Werte unter $5 \%$ und hohe Corylus-Werte aus. Die Hasel erfährt somit ihre stärkste holozäne Ausbreitung zu Beginn des Atlantikums, radiokarbon-datiert auf $7140 \pm 55 \mathrm{BP}, \mathrm{kal} .6007$ (60565924) v. Chr. Corylus stockte im Unterwuchs der Eichenmischwälder. Zudem sind die Werte der HolzkohleFlitter in diesem Abschnitt sehr hoch. Dieses zeigt, daß häufiger natürliche Waldbrände auftraten.

Grenze PZ VI-1/VI-2 (70 cm): Anstieg der Ulmus-Werte auf über $5 \%$

$\mathrm{Zu}$ Beginn der PZ VI-2 steigen die Ulmus-Werte auf über $5 \%$, die Corylus-Kurve ist abgefallen. Ulmus konnte sich in dieser Phase in den Wäldern in der Nähe des Elbaer Moores stärker ausbreiten. Das einzelne PK des TriticumTyps in PZ VI-2 stammt wahrscheinlich nicht von einer Kulturpflanze. Es ist auf ein Wildgras zurückzuführen, dessen PK aufgrund ihrer ähnlichen Größe und 
Oberflächenstruktur im Triticum-Pollen-Typ erfaßt werden (BEUG 1961, 40).

Grenze PZ VI-2/VII (58 cm): Anstieg der Fraxinus-Werte auf über $3 \%$

Als Grenzziehungskriterium zwischen PZ VI und VII wird die zunehmende Fraxinus-Kurve herangezogen (FIRBAS 1949, 49 f.). Häufiger sind nun auch PK vom Tilia platyphyllos-Typ nachgewiesen. Zudem wurden in diesem Abschnitt einzelne aus dem Harz und dem Thüringer Wald ferntransportierte PK von Picea eingetragen, deren Ausbreitung in den Eichenmischwäldern des Harzes im jüngsten Abschnitt des Atlantikums begann (BEUG et al. 1999, 46).

Subboreal (PZ VIII nach Firbas; 43-30 cm) Grenze PZ VII/VIII (43 cm): kurz vor dem Einsetzen des allmählichen Ulmenrückgangs

Der im Elb-Weser-Dreieck mit der Grenze Atlantikum/Subboreal korrelierte Ulmenfall (ca. 5000 BP, Zusammenstellung bei DÖRFLER 1989, 26) zeichnet sich im PD Elbaer Moor als allmählicher Rückgang der UlmenWerte ab. Die ohnehin sehr niedrigen und schon im Atlantikum schwankenden Ulmen-Werte fallen erst in einer Tiefe von $39 \mathrm{~cm}$, radiokarbon-datiert auf $4430 \pm 55 \mathrm{BP}$, kal. 3064 (3308-2924) v. Chr., um $2 \%$ ab. Aufgrund dieser Radiokarbon-Datierung muß die Grenze Atlantikum/Subboreal kurz vor dem Einsetzen des allmählichen Ulmenrückgangs bei $43 \mathrm{~cm}$ gezogen werden. Die Hasel-Werte eigenen sich hier nicht als Grenzziehungskriterium, da die Hasel durch den Menschen gefördert wird und ihre Pollenkurve aus diesem Grund nicht überregional konnektiert werden kann. Die Fagus-Kurve, deren Anstieg über $1 \%$ des BP für den Harz und das Harzvorland gern zur Beschreibung der Grenze Atlantikum/Subboreal genutzt wird (BEUG 1992, 320; BEUG et al. 1999, 47), greift im Elbaer Moor nicht. Diese Art wanderte hier erst im Verlauf des Subboreals ein.

$\mathrm{Zu}$ Beginn des Subboreals blieben die atlantischen Eichenmischwälder am Geestrand zur Elbniederung in ihrer Zusammensetzung im wesentlichen bestehen. Die steigenden Holzkohle-Anteile am Übergang zum Subboreal können möglicherweise als erste Anzeichen menschlicher Aktivität gewertet werden. Gleichzeitig sind die GlührestWerte leicht erhöht, und auch die Werte von Corylus sowie Poaceae sind gestiegen. Beides macht eine geringfügige Öffnung des bis dahin dichten Urwaldes wahrscheinlich. Kulturpflanzen sind jedoch nicht nachgewiesen worden. Von sekundären Siedlungszeigern treten einzelne PK der Chenopodiaceae, des Rumex acetosa-Typs und von Plantago lanceolata auf.

Im weiteren Verlauf des Subboreals wurden die ersten PK von Fagus in das kleine Moor eingetragen. Zeitgleich sinken die Ulmus-Werte von 5 auf $3 \%$, radiokarbon-datiert auf $4430 \pm 55$ BP, kal. 3064 (3308-2924) v. Chr. Früheste Nachweise des Getreideanbaus finden sich erst nach Beginn der Fagus-Einwanderung. Gleichzeitig treten auch erste PK von Carpinus auf, und die Holzkohle- und Glührest-Werte sind erhöht. Eventuell stehen die Gipfel der HolzkohleKurve in 35 und $37 \mathrm{~cm}$ Tiefe nun mit Brandrodung in Zusammenhang. Die Betula-Werte sind in dieser Tiefe ebenfalls erhöht. Betula kann als Pionierpflanze Brandflächen und andere gerodete Flächen rasch besiedeln (IVERSEN 1941，25). Einzelne PK des Triticum- und Hordeum-Typs belegen zwar den Ackerbau, es kam jedoch nicht zu einer nennenswerten Auflichtung der Wälder um das Elbaer Moor. Die Werte der Kulturpflanzen- und Siedlungszeiger-Summenkurven im Subboreal sind sehr niedrig. Vermutlich war der Geestrand zur Elbniederung hin nur spärlich besiedelt. Siedlungsphasen können hier leider nicht ausgewiesen werden, da die zeitliche Auflösung dieses Profils im Subboreal (PZ VIII, ca. 5150-2650 BP) mit knapp $200 \mathrm{Jahren} / \mathrm{cm}$ sehr gering ist.

\section{Älteres Subatlantikum (PZ IX nach Firbas; 30-24 cm) Grenze PZ VIII/IX (30 cm): Anstieg von Fagus}

In diesem Abschnitt begann ähnlich wie im Elb-WeserDreieck (PD Swienskuhle, PD Immenmoor u. a., BEHRE u. KUČAN 1994) die Ausbreitung von Fagus in den Eichenmischwäldern. Das Moorwachstum war im Älteren Subatlantikum, der PZ IX, langsam. Der Torf ist stark verdichtet, die $6 \mathrm{~cm}$ mächtige Torfschicht der PZ IX bildete sich innerhalb von 1500 Jahren (ca. 800 v. - 700 n. Chr.). Werden ein gleichmäßiges Torfwachstum und eine gleichmäßige Verdichtung vorausgesetzt, so bedeutet dies eine zeitliche Auflösung von $250 \mathrm{Jahren} / \mathrm{cm}$. Die Abschnitte der ausgehenden jüngeren Bronzezeit, der Vorrömischen Eisenzeit, der Römischen Kaiserzeit und der Völkerwanderungszeit drängen sich im Pollenprofil auf nur wenigen Zentimetern Torf. Eine Untergliederung in archäologische Zeiträume ist daher kaum möglich.

Für dieses Pollendiagramm ist festzuhalten, daß Waldflächen um etwa 2650 BP, also zu Beginn der PZ IX, gerodet wurden (erhöhte Werte der sekundären Siedlungszeiger, besonders der Poaceae und von Calluna). Nach wie vor prägten Eichenmischwälder die Landschaft. Quercus dominierte diese Bestände. Zum Artenspektrum der Mischwälder gehörten des weiteren Fagus, Carpinus und Pinus. Die Werte von Corylus, Fraxinus, Ulmus und Tilia gehen in diesem Abschnitt zurück. Ulmus wurde vermutlich geschneitelt und das Laub zur Laubheufütterung verwendet. Tilia wurde zudem als Bastlieferantin geschätzt (IVERSEN 1941, 80; ELLENBERG 1996, 45 f.).

In den feuchten Niederungsbereichen war Alnus verbreitet. Der leicht verwehbare Pollen des starken Pollenproduzenten Alnus wurde jedoch durch die zunehmende Öffnung des Geländes um das Elbaer Moor verstärkt ins Moor eingetragen und ist daher im Pollendiagramm überrepräsentiert. 


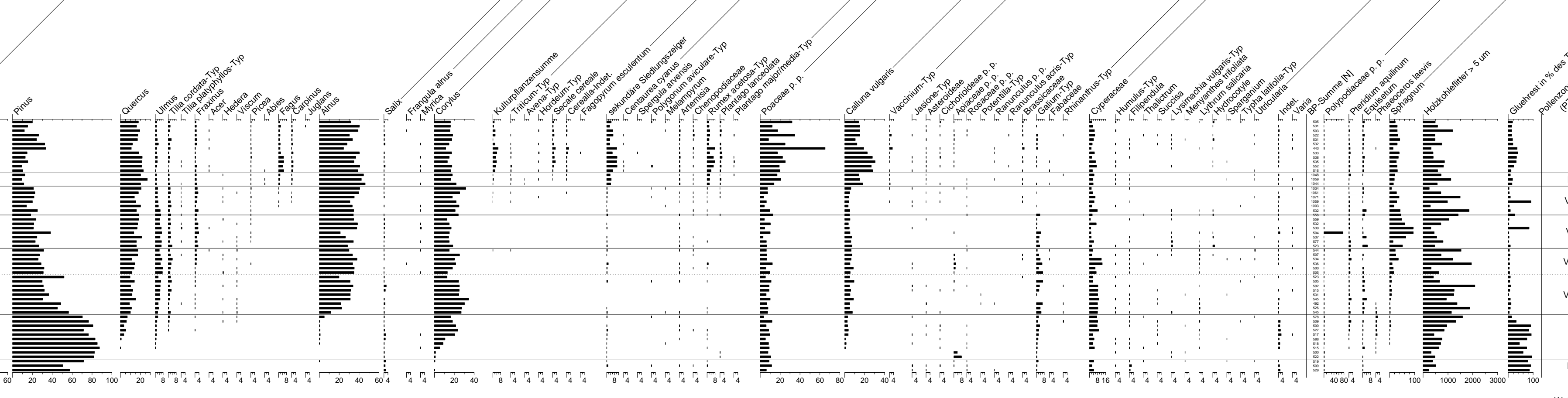

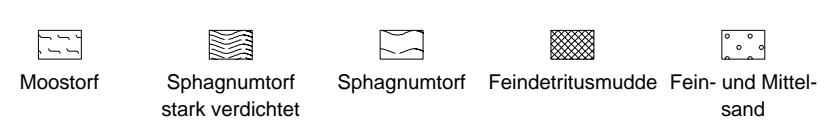


Die pollenanalytischen Hinweise auf menschliche Aktivität um das Elbaer Moor im Älteren Subatlantikum beschränken sich auf Nachweise einzelner PK der GetreideTypen und gegenüber dem Subboreal erhöhte Werte verschiedener sekundärer Siedlungszeiger. Darunter sind die erhöhten Calluna-Werte hervorzuheben, die auf eine Ausdehnung der Heideflächen in der unmittelbaren Umgebung des Moores schließen lassen. Vermutlich ist das die Folge von Rodungen und einer anschließenden, längeranhaltenden Beweidung, die die natürliche Wiederbewaldung der Heideflächen verhinderte (vgl. BEHRE 1998a, 95).

Im weiteren Verlauf der PZ IX wird das Getreidespektrum durch Secale cereale erweitert. Der Roggen wird seit der Römischen Kaiserzeit gezielt als Feldfrucht angebaut (BEHRE 1992, 146; 2001, 76). Wichtigster sekundärer Siedlungszeiger ist der Rumex acetosa-Typ. Vermutlich handelt es sich hier vorwiegend um PK von Rumex acetosella, der als Pionierpflanze offene Sandflächen besiedelt aber auch im Wintergetreide steht (BEHRE 1976a, 206). Da die Ackerflächen in größerer Entfernung zum Elbaer Moor, wahrscheinlich auf der Hohen Geest, lagen (niedrige Kulturpflanzen-Werte), stammt der Eintrag des Rumex-Pollens nicht von dort, sondern von vegetationsarmen Flächen in der unmittelbaren Umgebung des Moores. Von dort wurde auch minerogenes Material eingeweht (leicht erhöhter Glührest-Anteil). Unter den sekundären Siedlungszeigern sind die Werte des Acker-, Brachen- und Weidezeigers Plantago lanceolata nur wenig angestiegen.

Im jüngsten Spektrum der PZ IX sind die angestiegenen Pteridium-Anteile vielleicht als Hinweis auf Waldweide zu werten. Des weiteren verweist das Vorkommen der Trittpflanze Plantago major auf Viehzucht (Pollentyp Plantago major/media, das Auftreten von P. media ist im norddeutschen Tiefland eher unwahrscheinlich; OBERDORFER 1990, 872).

Die erhöhten Werte bei Poaceae, weiteren Siedlungszeigern und Kulturpflanzen zeigen, daß die Landschaft in der Umgebung des Elbaer Moores in diesem Abschnitt stärker aufgelichtet war als zuvor.

Jüngeres Subatlantikum (PZ X nach Firbas; 24-1 cm) Grenze PZ IX/X (24 cm): Anstieg der SiedlungszeigerWerte

Die untere Grenze der PZX ist durch steigende Siedlungszeiger-Werte gekennzeichnet (vgl. Raum Flögeln, u. a. PD Swienskuhle, BEHRE u. KUČAN 1994). Im Pollendiagramm aus dem Elbaer Moor sind die QuercusWerte stabil, auffällig sind jedoch die erhöhten Fagus-Werte sowie der Anstieg verschiedener NBP-Kurven.

Zu Beginn der PZ X, im Frühen und Hohen Mittelalter, wurde die Landschaft stark umgeformt. Sie wurde nun teilweise von landwirtschaftlichen Nutzflächen dominiert.
Neben den offenen Flächen blieben vereinzelt Eichenmischwälder bestehen, die im Mittelalter als Allmenden gemeinschaftlich bewirtschaftet wurden. Durch Biomasseentzug entwickelten sie sich meist zur Ausprägung armer Eichen-Birkenwälder. Buchenwälder waren hingegen überwiegend in landesherrlichem Besitz und unterlagen dadurch anderen Nutzungsstrategien. Beispielsweise trug die herrschaftliche Jagd zur Erhaltung der Buchenwälder bei (HEINKEN 1995, 143).

Werden die Kurvenverläufe der sekundären Siedlungszeiger und der Kulturpflanzen verfolgt, kann der Abschnitt 24-8 cm Tiefe als mittelalterliche Siedlungsphase mit Initialstadium, dem Erreichen der maximalen Siedlungszeiger-Werte und schließlich deren Rückgang beschrieben werden. Die gleichzeitig steigenden Werte von Kulturpflanzen und sekundären Siedlungszeigern, besonders des Rumex acetosa-Typs und von Calluna, sowie der allmähliche Anstieg des minerogenen Eintrags in dieser Siedlungsphase sind Zeichen einer zunehmenden wirtschaftlichen Nutzung des Geländes. Die Verheidung weiter Flächen um das Moor wurde vermutlich nicht nur durch die Beweidung der Heiden, sondern auch durch die Plaggenwirtschaft vorangetrieben. Schon das Auftreten einzelner Pollenkörner der insektenblütigen Kornblume zeigt, daß der Roggen nun als Wintergetreide angebaut wurde. In Ostfriesland erscheint Centaurea cyanus im Roggen während des 10. Jh. n. Chr. (BEHRE 1993, 451 f.). In Mittel- und Ostdeutschland ist sie dagegen schon im Frühen Mittelalter in archäobotanischen Unkrautproben enthalten (WILlERDING 1986, 87). Die Bindung von Centaurea cyanus an Secale ist im Elbaer Moor nicht so auffällig wie beispielsweise im Diagramm aus der Swienskuhle im ElbWeser-Dreieck, wo Secale und Centaurea cyanus gleichzeitig Extremwerte erreichen; die Swienskuhle befand sich jedoch inmitten einer mittelalterlichen Ackerflur (BEHRE u. KUČAN 1994, 94). Im Gegensatz dazu lagen die Ackerflächen, von denen die Getreide-Pollenkörner sowie die Pollenkörner der insektenblütigen und daher nur wenig Pollen verteilenden Kornblume im Pollendiagramm aus dem Elbaer Moor stammen, vermutlich in einiger Entfernung südlich des Elbaer Moores, auf der Hohen Geest. Schon 80$300 \mathrm{~m}$ Entfernung der Pollenprofilentnahmestelle $\mathrm{zu}$ einer mit Ackerflächen umgebenen Siedlung können ausreichen, daß die Werte der Getreide einschließlich des anemogamen Roggens bei höchstens 1 \% liegen (BEHRE u. KUČAN 1986, 99). Die Plaggenentnahmestellen befanden sich vermutlich auf den Talsanden in unmittelbarer Umgebung des Elbaer Moores.

Fagopyrum tritt im Verlauf der Siedlungsphase zum Kulturpflanzenspektrum hinzu. Der Buchweizen wurde nach schriftlichen Quellen in Deutschland im 14. Jh. kultiviert (LOSERT 1953, 139). Aus Flögeln im Ldkr. Cuxhaven liegen jedoch sehr frühe, ins 12. Jh. datierende FagopyrumNachweise vor. Auch außerhalb Niedersachsens reichen Fagopyrum-Funde bis ins Hohe Mittelalter zurück (BEHRE u. KUČAN 1994, 128 u. 160). Der Fund aus dem Elbaer Moor stammt vermutlich ebenfalls aus dem Hohen Mittelalter. 
Der Rückgang der Siedlungszeiger- und der GlührestWerte korreliert mit der Wüstungsperiode des 14./15. Jh. Der Waldanteil nimmt langsam wieder zu (Quercus), obwohl die Fagus-Werte nun zurückgehen. Zunächst erreichen die Poaceae noch sehr hohe Werte. Die starke Auflichtung der Landschaft bedingt, daß Pinus als starker Pollenproduzent nun überrepräsentiert ist.

Auf die Wüstungsperiode folgt eine neuerliche Ausweitung von landwirtschaftlicher Nutzfläche. Auch die Heiden dehnten sich wieder etwas aus. Nach wie vor befanden sich die Ackerflächen aber in weiter Entfernung des Elbaer Moores. Andernfalls würde besonders der windblütige Roggen weitaus höhere Werte im Pollendiagramm erreichen. Die stark schwankenden Poaceae-Werte sind hier im wesentlichen auf lokale Verhältnisse im Moor zurückzuführen. Die Anlage der Kiefernforste im 18./19. Jh. ist im Pollendiagramm aus dem Elbaer Moor nicht erfaßt. Die hohen Pinus-Werte in 7$11 \mathrm{~cm}$ Tiefe sind ein Effekt der starken Auflichtung bzw. der lokalen, jetzt feuchteren Verhältnisse, die dazu führten, daß Pinus-PK zusammengeschwemmt wurden.

\subsubsection{Rullstorfer Osterteich}

Das Weideland mit den Flurbezeichnungen Rullstorfer Osterteich und Osterbruch (TK 25, Blatt 2729 Scharnebeck, r 4402 450, h 5907 600) befindet sich im Bereich der Niederterrasse der Elbe auf 7-8 m NN. Das Gebiet um die Entnahmestelle des Pollenprofils wird im folgenden als Rullstorfer Osterteich bezeichnet. Nach Süden steigt das Gelände zur Hohen Geest auf über $20 \mathrm{~m} \mathrm{NN}$ an. Nach Norden erheben sich sanfte Kuppen bis zu $10 \mathrm{~m} \mathrm{NN}$ aus dem Gelände im Bereich südlich des Neetze-Kanals. Südöstlich liegt auf einem Geestsporn in einer Entfernung von etwa $1 \mathrm{~km}$ Luftlinie die Grabungsstelle bei Rullstorf (Abb. 2).

Der Rullstorfer Osterteich ist in historischen Karten aus dem 16. Jh. noch als Teich abgebildet (Abb. 14). Er wurde früher u. a. von einer Quelle am Geesthang gespeist, deren Wasser heute in einem Entwässerungsgraben abgeführt wird. Da die Kapazität des Entwässerungsgrabens oft nicht ausreicht, ist die Weide sehr feucht.

Die flache Senke am Rullstorfer Osterteich läßt erwarten, daß im Pollenprofil der regionale Polleneintrag gegenüber dem lokalen, mooreigenen dominiert. Das Pollenprofil wurde im Bereich der größten Mächtigkeit der organischen Ablagerungen (ca. $1 \mathrm{~m}$ ) im Randbereich der flachen Senke erbohrt. Die Bedingungen für eine Rekonstruktion der Siedlungsgeschichte, die auch die Aktivitäten der Rullstorfer Siedler widerspiegelt, schienen zu Beginn der Untersuchungen sehr günstig zu sein.

\subsubsection{Stratigraphie und lokale Entwicklung}

Das Profil Rullstorfer Osterteich hat eine Länge von $100 \mathrm{~cm}$ (Abb. 8-9). Über Fein- und Mittelsand (100-97 cm) wurde im Präboreal eine Mudde abgelagert $(97-76 \mathrm{~cm})$, die im unteren Abschnitt ockergelb bis bräunlich gefärbt ist und teilweise schwarze, reduzierte Bereiche enthält. CharaceenOogonien, Daphniden-Eier, Kolonien von Pediastrum boryanum, $P$. integrum sowie Tetraëdron minimum und Pollen von Myriophyllum spicatum zeigen, daß im Präboreal ein offenes meso- bis eutrophes Gewässer bestand.

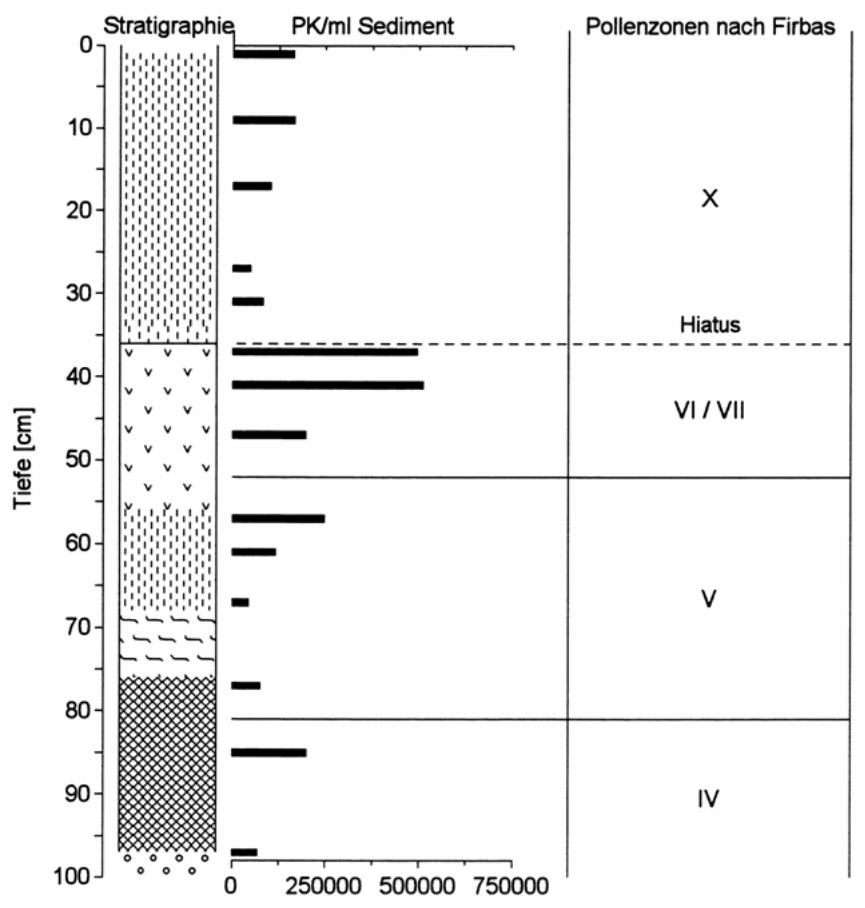

W. Kirleis (2000)

Abb. 8. Pollenkonzentrationen im Profil Rullstorfer Osterteich, Ldkr. Lüneburg.

Um den See waren vermutlich Moorwiesen bzw. anmoorige, häufig überschwemmte Wiesen mit Thalictrum verbreitet. Im ausgehenden Präboreal war das Gewässer von einem Verlandungsgürtel mit Typha latifolia, Filipendula und Equisetum gesäumt, der von einer Niedermoorzone mit Carex und Betula umgeben war. Auf der Hohen Geest dehnten sich lichte Birken-Kiefernwälder aus (hohe Anteile beider Taxa im Pollendiagramm).

Im Boreal schritt die Verlandung des Sees voran. Die Farbe der Mudde ändert sich über graubraun $\mathrm{zu}$ dunkelbraun. An Makroresten wurden Holzreste, Braunmoose, eine Knospenschuppe von Betula sp. sowie eine Carex-Frucht gefunden. Oberhalb der Mudde ist ein Braunmoostorf $(76-68 \mathrm{~cm})$ ausgebildet, der von einem Seggentorf (68-56 cm) abgelöst wird. Beide enthalten neben Braunmoos- auch Betula- sowie Carex-Reste. 
Tab. 4. Makroreste des Profils aus dem Rullstorfer Osterteich.

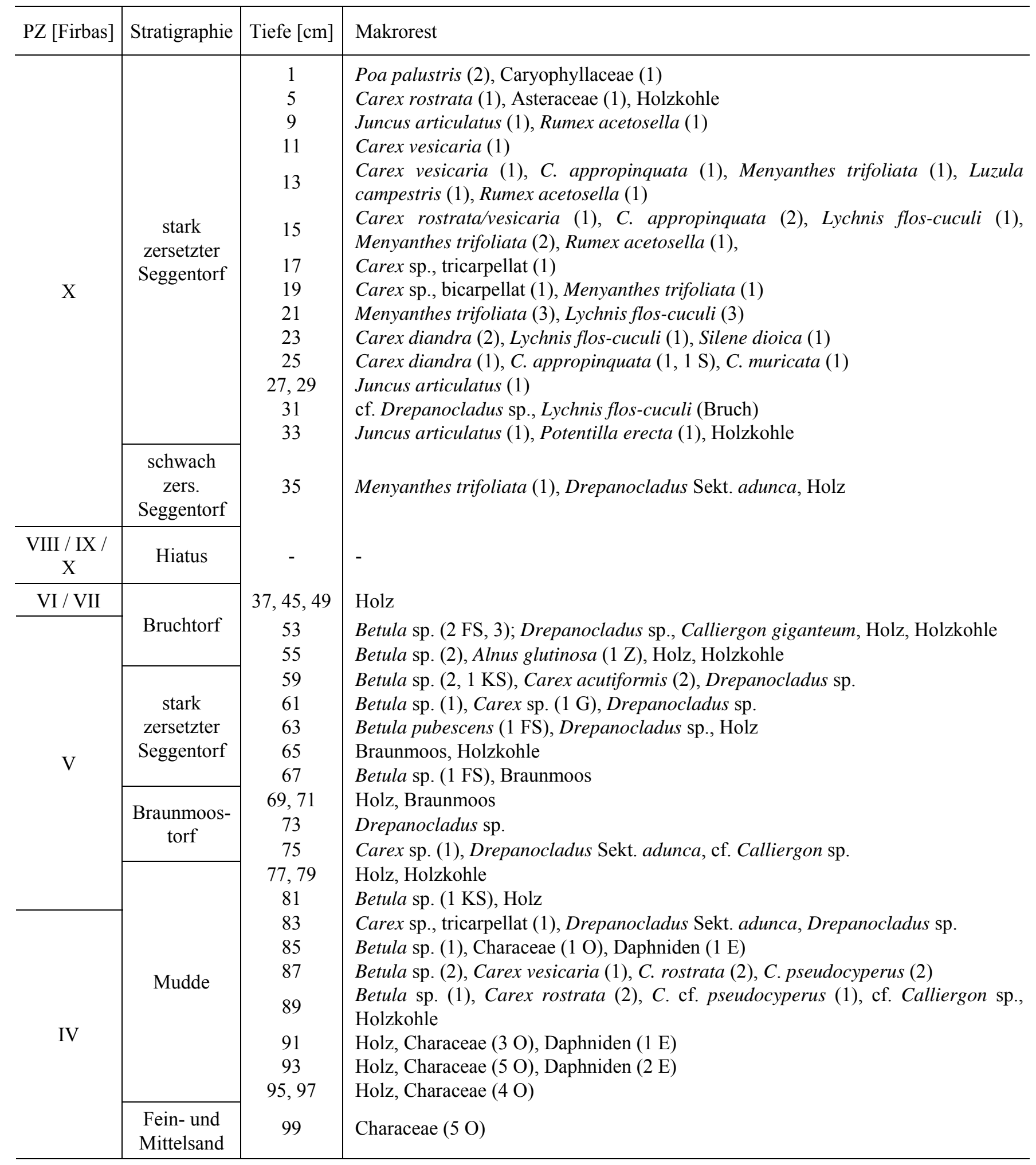

E Ei - FS Fruchtschuppe - G Griffelrest - KS Knospenschuppe - O Oogonium - S Schlauchrest Z Zapfenbruchstück - Alles übrige: Früchte bzw. Samen sowie Moosblättchen und -stämmchen. 


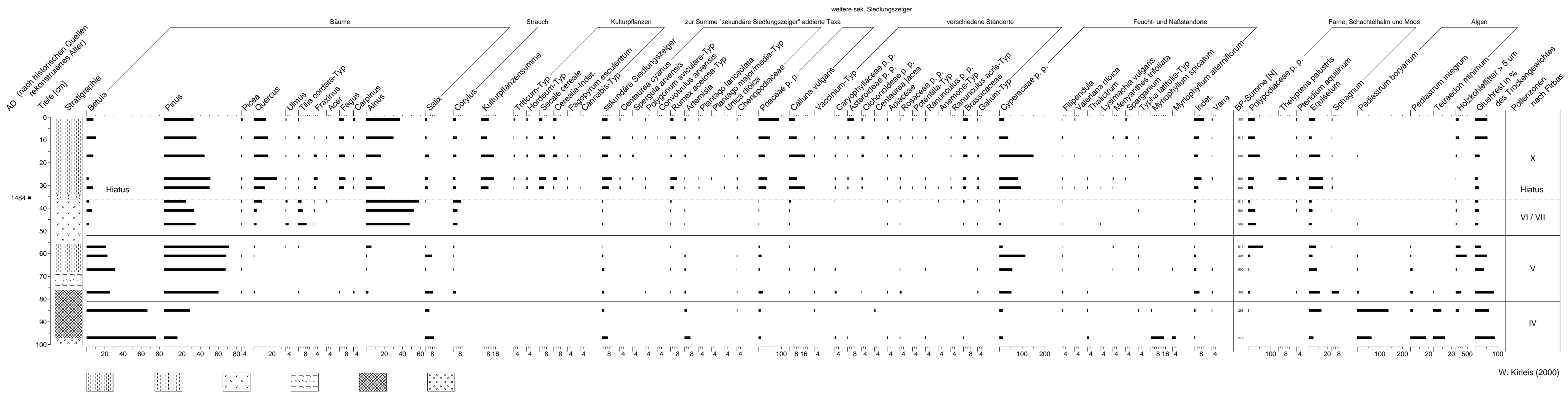

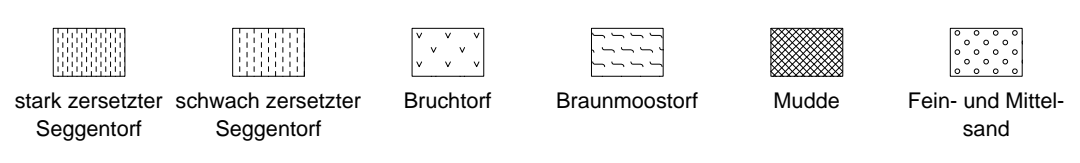


Im Atlantikum wird die Verlandungsserie vorerst durch die Entstehung eines Bruchwaldes abgeschlossen. Der Bruchwaldtorf (56-36 cm) enthält Makroreste von Betula sp. und Alnus sp. Alle bisher beschriebenen Abschnitte einschließlich des sandigen Untergrundes sind von Holzwurzeln mit bis zu 4 cm Durchmesser durchzogen.

Über dem Bruchtorf folgt ein Hiatus - es fehlen die Ablagerungen aus dem Subboreal und dem Älteren Subatlantikum. Gegen den atlantischen Bruchwaldtorf scharf abgesetzt ist hier ein Band schwach zersetzten Seggentorfes mit Samen von Menyanthes trifoliata gewachsen $(36-34 \mathrm{~cm})$. Dieses Band wird von einem stark zersetzten Seggentorf $(34-1 \mathrm{~cm})$ abgelöst, der besonders in den oberen $13 \mathrm{~cm}$ stark von minerogenem Material durchsetzt ist (hohe Glührest-Werte im PD). Die nachgewiesenen Makroreste von Carex appropinquata, $C$. rostrata, C. vesicaria, Juncus articulatus, Menyanthes trifoliata, Poa palustris und von Lychnis flos-cuculi stammen aus einem sehr feuchten Seggenried (Tab. 4).

\subsubsection{Pollendiagramm Rullstorfer Osterteich}

Nach ersten Untersuchungen stellte sich heraus, daß im Pollenprofil aus dem Rullstorfer Osterteich Ablagerungen aus den siedlungsgeschichtlich interessanten PZ VIII, PZ IX und dem älteren Teil der PZX (Neolithikum bis beginnendes Mittelalter) fehlen.

Das Profil ist außerdem teilweise durch Bioturbation gestört. Die Pollenkonzentrationen sind insgesamt gering (Abb. 8), daher fallen die BP-Summen teilweise sehr niedrig aus (<300 BP). Das Profil wurde aus diesem Grund in großen Abständen beprobt, um zumindest einen Überblick zum Ablauf der Vegetationsgeschichte an dieser Lokalität gewinnen zu können.

\section{Präboreal (PZ IV nach Firbas; 100-81 cm)}

Die Sedimentation im Rullstorfer Osterteich setzte im Präboreal (PZ IV) ein (Abb. 9). Wie in der Umgebung des Elbaer Moores sind in dieser Zeit auch hier die Mineralbodenstandorte von lichten Birken-Kiefernwäldern geprägt. Salix steht in unmittelbarer Nähe des Gewässers. Die Anteile der Steppenpflanze Artemisia sind relativ hoch (6\%). Der Eintrag von minerogenem Material in das Gewässer ist erheblich (Glührest-Anteil >80\%), die Sandböden waren demnach noch sehr mobil.

Boreal (PZ V nach Firbas; 81-52 cm)

Grenze PZ IV/V (81 cm): Pinus-Werte übersteigen BetulaWerte

Im Boreal übernahm Pinus die Vorherrschaft in den lichten Kiefern-Birkenwäldern. Durch ihre leicht brennbare Streu sind Kiefernbestände stark brandgefährdet. Die große Zahl der nachgewiesenen Holzkohleflitter bestätigt, daß im
Boreal wiederholt Waldbrände auftraten. Die hohen Glührestanteile zeigen, daß minerogenes Material eingeschwemmt werden konnte.

Die älteste Probe des Boreals $(77 \mathrm{~cm})$ ist durch Bioturbation gestört. Mindestens die Eichenmischwald-, die Fagus- sowie die Carpinus-PK dieses Spektrums sind umgelagert worden. Die PK von Picea sind vermutlich ebenfalls sekundär in die borealen Ablagerungen verschleppt worden.

Im weiteren Verlauf des Boreals treten die ersten PK von Alnus, Quercus, Ulmus und Tilia auf. Gegen Ende dieses Abschnitts begann schließlich die Ausbreitung der Erlenbrüche und der Eichenmischwälder. Die CorylusKurve steigt in diesem Abschnitt nur langsam an. Ein borealer Corylus-Gipfel ist nicht erfaßt.

Atlantikum (PZ VI und VII nach Firbas; $52-36 \mathrm{~cm}$ ) Grenze PZ V/VI-VII (52 cm): Alnus-Werte $>48 \%$

Am Rullstorfer Osterteich begann im Atlantikum (PZ VI) die Massenausbreitung von Alnus. Die Erle besiedelte die an das weitgehend verlandete Gewässer angrenzenden Bereiche. Ihr Kronendach verringerte den regionalen Polleneintrag in den Osterteich. Zudem drückt ihre hohe Pollenproduktion die Werte der anderen Taxa im PD. Dennoch zeichnet sich im PD der Pollen der auf den Mineralböden stockenden Eichenmischwälder ab. Diese setzten sich aus Quercus, Pinus, Ulmus, Tilia, Fraxinus, Acer, Betula und Corylus zusammen. Der starke Pollenproduzent Pinus hat im PD Rullstorfer Osterteich überhöhte Werte. Am Geestrand südlich des Rullstorfer Osterteiches gab es vermutlich lindenfähige Standorte, denn Tilia erreicht im Pollendiagramm anfangs höhere Werte als Quercus.

Auf die atlantischen Ablagerungen folgt in einer Tiefe von $36 \mathrm{~cm}$ ein Hiatus. Wie noch diskutiert werden wird, stammt das jüngere Material entsprechend der nachgewiesenen Siedlungszeiger-PK aus dem Mittelalter (Kap. 3.4.4.4).

Jüngeres Subatlantikum (PZ X nach Firbas; 36-1 cm)

Im Jüngeren Subatlantikum (PZ X) stockten auf den Mineralböden der Hohen Geest südlich des Rullstorfer Osterteiches weiterhin Eichenmischwälder. Die lindenfähigen Standorte wurden nunmehr von Fagus eingenommen. Auch Carpinus zählte jetzt zum Artenspektrum der Eichenmischwälder. Tilia und Ulmus hatten an Bedeutung verloren. Die Waldfläche war bis ins Späte Mittelalter durch den Menschen stark verringert worden. Pollennachweise des Triticum- und Hordeum-Typs sowie von Secale cereale zeigen, daß Ackerflächen auf der Hohen Geest lagen. Auf ihnen wurde auch Wintergetreide angebaut, wie es die Nachweise der Wintergetreideunkräuter 
Centaurea cyanus und Spergula arvensis nahe legen. Zudem wurden Buchweizen und vermutlich auch Hanf kultiviert.

Der Eintrag von Calluna-Pollentetraden bleibt unter $20 \%$. Die Heideflächen lagen demnach in einiger Entfernung vom Rullstorfer Osterteich auf der Hohen Geest. In der Niederung erstreckten sich feuchte Wiesen mit Asteraceae, Ranunculaceae, Caryophyllaceae, Rosaceae und Brassicaceae, die vermutlich zur Viehweide genutzt wurden. Erlenbruchwälder unterbrachen diese Weidelandschaft.

Ein sekundärer Kieferngipfel, der die neuzeitliche Forstgeschichte reflektiert, ist im Pollendiagramm aus dem Rullstorfer Osterteich nicht erfaßt.

\subsubsection{Almstorfer Moor}

Das Naturschutzgebiet Almstorfer Moor (TK 25, Blatt 2830 Dahlenburg, r 4412500 , h 5886000$)$ liegt auf $72,5 \mathrm{~m} \mathrm{NN}$ im Bereich von warthezeitlichen Endmoränenwällen, die die Grundmoränenlandschaft des Bevenser Beckens im Ldkr. Uelzen umgeben (Abb. 2). Im Bevenser Becken sind von Sanden überdeckte Geschiebelehmböden mit geringer Bodengunst verbreitet. Nahe des Almstorfer Moores verläuft jedoch ein Streifen mäßig gebleichter Braunerden von Nordwest nach Südost. Diese Lehmböden haben einen günstigen Basenhaushalt und geben gute Pflanzenstandorte ab (MEIBEYER 1980, $16 \mathrm{f}$.). Zudem ist westlich von Bad Bevensen weichselzeitlicher, fruchtbarer Sandlöß kartiert.

Die Gesamtfläche des Almstorfer Moores ist etwa 13 ha groß, knapp die Hälfte davon ist dauerhaft vernäßt. Der Polleneintrag dieses Moores mit einem Durchmesser von mehreren hundert Metern stammt sowohl von der Moorvegetation selbst als auch der weiteren Umgebung (5$10 \mathrm{~km})$. Heute stockt ein dichter Erlen-Bruchwald im Naturschutzgebiet.

\subsubsection{Stratigraphie und lokale Entwicklung}

Das Profil Almstorfer Moor hat eine Länge von $165 \mathrm{~cm}$ (Abb. 10-12). Über Fein- und Mittelsand ist eine Feindetritusmudde abgelagert. Oberhalb der Mudde wurden im Profil verschiedene Torfe angetroffen.

Vermutlich im ausgehenden Subboreal entstand in der Senke des heutigen Almstorfer Moores ein meso- bis eutrophes Gewässer mit Potamogeton natans, Characeae, verschiedenen Pediastren sowie Scenedesmus (Tab. 5. Abb. 12).

Reste des Zygnema-Typs, des Typs 178, von Closterium idiosporum und von Mougeotia (Abb. 10) unterstreichen den mesotrophen Charakter des Sees. Er war von einem Röhricht umgeben, welches vermutlich mit einem Großseggenried verzahnt war. In diesem Verlandungsbereich kamen Typha, Sagittaria sagittifolia,
Sparganium, Lycopus europaeus, Eleocharis palustris, Menyanthes trifoliata und der heute seltene Rumex maritimus vor. Salix, Frangula alnus und Myrica gale wuchsen in Ufernähe.

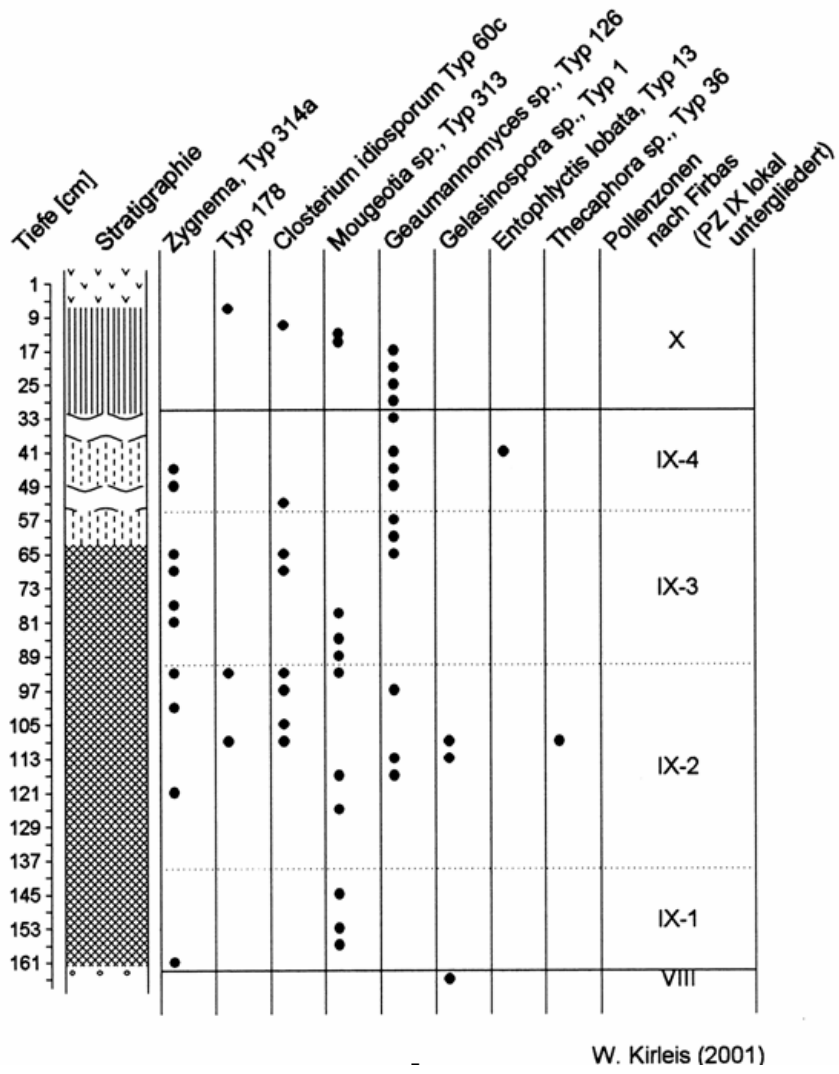

Abb. 10. Präsenzdiagramm der Algen- und Pilzreste im Profil Almstorfer Moor, Ldkr. Uelzen.

Bis der See im Bereich der Bohrstelle im fortgeschrittenen Subatlantikum (PZ IX-3) verlandete, wurden eine Feindetritusmudde abgelagert und zudem sehr viel minerogenes Material eingetragen (166-66 cm).

Auch der heute in die Rote Liste der gefährdeten Farnund Blütenpflanzen aufgenommene Pillenfarn (Pilularia globulifera) hatte im älteren Subatlantikum seinen Standort im Ufersaum des Gewässers. Sein Vorkommen als Vertreter der Familie der Schlammfarne ist an die FeindetritusmuddeAblagerungen gebunden. Er verschwindet mit Einsetzen des Torfwachstums. Sowohl westlich als auch östlich in etwa $15 \mathrm{~km}$ Entfernung von Uelzen wurde der Pillenfarn in den Jahren 1982-1992 kartiert. Im Raum Lüneburg wurde er seit 1982 nicht mehr nachgewiesen (GARVE 1994, 634).

Im weiteren Verlauf des Subatlantikums (PZ IX-3/4) schritt die Verlandung voran. Regelmäßig konnten nun die an Cyperaceae gebundenen Geaumannomyces-artigen Hyphopodien (PALs et al. 1980, 407) nachgewiesen werden. Sphagnum-Rasen begannen sich auszubreiten, und die typische Hochmoorpflanze Drosera rotundifolia bzw. D. anglica wuchs vor Ort (Pollentetrade auf $53 \mathrm{~cm}$ Tiefe im PD). Wie die erhöhten Sphagnum- und Cyperaceae-Werte zu Beginn der PZ X erkennen lassen, entwickelte sich ein 
Tab. 5. Makroreste des Profils aus dem Almstorfer Moor. Die PZ IX nach FIRBAS (1949) ist lokal untergliedert.

\begin{tabular}{|c|c|c|c|}
\hline PZ [Firbas] & Stratigraphie & Tiefe $[\mathrm{cm}]$ & Makrorest \\
\hline \multirow{3}{*}{$\mathrm{X}$} & \multirow{3}{*}{$\begin{array}{l}\text { Erlenbruch- } \\
\quad \text { torf }\end{array}$} & 1,3 & Alnus (diverse Früchte, Knospenschuppen, Blatt- u. Zapfenreste) \\
\hline & & 5 & Lycopus europaeus (2), Alnus (1, 3 Z), Betula (1 FS), Alisma/Sagittaria (1), Holz \\
\hline & & 9 & Alnus (4 Z), Holz \\
\hline \multirow{6}{*}{ IX-4 } & \multirow{9}{*}{$\begin{array}{l}\text { schwach } \\
\text { zersetzter } \\
\text { Torf mit } \\
\text { Sphagnum- } \\
\text { Bändern }\end{array}$} & 37 & Sphagnum palustre, Juncus sp. (1) \\
\hline & & $38-39$ & Carex lasiocarpa (5) \\
\hline & & 41 & Sphagnum palustre, Betula sp. (1) \\
\hline & & 45 & Holz, Braunmoos \\
\hline & & 49 & Comarum palustre (1), Menyanthes trifoliata (2), Braunmoos \\
\hline & & 53 & Sphagnum Sekt. cymbifolia \\
\hline \multirow{9}{*}{ IX-3 } & & 57 & Sphagnum palustre, Menyanthes trifoliata (Bruch), Braunmoos \\
\hline & & 61 & Sagittaria sagittifolia (1), Juncus sp. (1), Braunmoos \\
\hline & & 65 & $\begin{array}{l}\text { Potamogeton sp. (1), Betula sp. (1, 1 KS), Menyanthes trifoliata (Bruch), Juncus } \\
\text { bufonius (1), Ranunculus sceleratus (1), Holz, Braunmoos, Sphagnum Sekt. } \\
\text { acutifolia, Sphagnum Sekt. cymbifolia }\end{array}$ \\
\hline & \multirow{24}{*}{$\begin{array}{l}\text { Feindetritus- } \\
\text { mudde }\end{array}$} & 69 & $\begin{array}{l}\text { Alisma/Sagittaria (1), Potamogeton sp. (1), Rumex maritimus (1), Sphagnum Sekt. } \\
\text { acutifolia, Sphagnum Sekt. cymbifolia }\end{array}$ \\
\hline & & 73 & Characeae (1 O), Sphagnum Sekt. cymbifolia, Braunmoos \\
\hline & & 77 & Sagittaria sagittifolia (1), Lycopus europaeus (1), Juncus sp. (1), Braunmoos \\
\hline & & 79 & $\begin{array}{l}\text { Potamogeton natans (2), Sagittaria sagittifolia (1), Sagittaria/Alisma (1), } \\
\text { Sparganium emersum (1) }\end{array}$ \\
\hline & & 81 & Potamogeton natans (2), Sagittaria/Alisma (1), Betula sp. (1 FS), Poaceae (1 SpG) \\
\hline & & 85 & $\begin{array}{l}\text { Potamogeton natans (2), Sagittaria sagittifolia (1), Sphagnum sp. } \\
\text { Potamogeton natans (3), Potamogeton sp. (1), Sagittaria sagittifolia (2), } \\
\text { Sagittaria/Alisma (3), Betula sp. (1), Quercus (1 KS), Sparganium emersum (1), } \\
\text { Sphagnum Sekt. cymbifolia, Rumex maritimus (1), Menyanthes trifoliata (1), } \\
\text { Eleocharis palustris (1) }\end{array}$ \\
\hline \multirow{11}{*}{ IX-2 } & & 93 & Poaceae (1), Sphagnum Sekt. cymbifolia \\
\hline & & 97 & Rumex sp. (1), Juncus sp. (1) \\
\hline & & 101 & Potamogeton natans (1) \\
\hline & & 105 & Rumex maritimus $(2 \mathrm{P}, 1)$ \\
\hline & & 109 & $\begin{array}{l}\text { Potamogeton natans (1), Potamogeton sp. (3), Betula sp. (1), Scleranthus annuus } \\
\text { (1 K), Rumex sp. (1) }\end{array}$ \\
\hline & & 113 & Rumex maritimus (1, 1 P), Sagittaria sagittifolia (1) \\
\hline & & 117 & Rumex maritimus (4, 4 P), Sphagnum sp., Braunmoos \\
\hline & & 121 & Menyanthes trifoliata (1), Betula sp. (1), Juncus sp. (1), Sphagnum sp., Braunmoos \\
\hline & & 129 & $\begin{array}{l}\text { Sagittaria sagittifolia (1), Rumex sp. (1), Carex rostrata (1), Caryophyllaceae (1), } \\
\text { Stellaria media (1), Sphagnum sp., Holzkohle }\end{array}$ \\
\hline & & 133 & $\begin{array}{l}\text { Potamogeton natans (2), Potamogeton sp. (1), Characeae (1 O), Betula sp. (3, } \\
2 \text { FS), Ranunculus sceleratus (1) }\end{array}$ \\
\hline & & 137 & $\begin{array}{l}\text { Rumex maritimus (1 P), Rumex sp. (1), Potamogeton natans (1), Sphagnum sp., } \\
\text { Holzkohle }\end{array}$ \\
\hline \multirow{6}{*}{ IX-1 } & & 141 & $\begin{array}{l}\text { Potamogeton natans (1), Potamogeton sp. (1), Betula sp. (2, } 1 \text { FS), Juncus bufonius } \\
\text { (1), Characeae (2 O), Holz }\end{array}$ \\
\hline & & 145 & Potamogeton sp. (1), Betula sp. (2), Holzkohle \\
\hline & & 149 & Betula sp. (1, 1 FS), Lycopus europaeus (1), Holzkohle \\
\hline & & 153 & $\begin{array}{l}\text { Betula sp. (2), Rumex acetosella (1), Potamogeton natans (1), Braunmoos, } \\
\text { Holzkohle }\end{array}$ \\
\hline & & 157 & Betula sp. (2), Potamogeton natans (1), Sphagnum sp., Braunmoos \\
\hline & & 161 & $\begin{array}{l}\text { Betula sp. (1), Potamogeton natans (1), Polygonum aviculare (1), Sphagnum sp., } \\
\text { Braunmoos, Holzkohle }\end{array}$ \\
\hline VIII & & 165 & $\begin{array}{l}\text { Betula sp. (1), Rumex sp. (1 P), Potamogeton natans (4), Polygonum lapathifolium } \\
\text { (1), Juncus bulbosus (1), Braunmoos }\end{array}$ \\
\hline
\end{tabular}


Zwischenmoor, in dem auch Carex lasiocarpa auftrat (Tab. 5).

In jüngster Zeit bildete sich ein lockerer Erlenbruchtorf (10-1 cm), der Früchte, Knospenschuppen, Zapfen- und Blattreste von Alnus enthält. Die Verlandung des Gewässers schloß mit der Entwicklung dieses Erlenbruchwaldes ab.

\subsubsection{Radiokarbon-Datierungen}

Ziel der Radiokarbon-Datierungen am Profil Almstorfer Moor war es, vor allem eine sich im PD abzeichnende Siedlungslücke einzugrenzen.

Das Material für drei Radiokarbon-Datierungen aus dem Profil Almstorfer Moor wurde aus demselben Bohrkern entnommen, aus dem auch die Pollenproben stammen (Kap. 3.2.1). Die daher sehr kleinen Torfproben wurden in speziell für Kleinstproben konstruierten Zählrohren konventionell datiert. Diese Meßweise hat keine Auswirkungen auf die Genauigkeit der Datierungen, ihre Ergebnisse sind mit denen konventionell datierter StandardProben vergleichbar (Tab. 6).

\subsubsection{Pollendiagramm Almstorfer Moor}

Das Profil Almstorfer Moor weist eine sehr gute Pollenerhaltung auf. Die Pollenkonzentrationen sind, abgesehen von dem Bereich in 66-35 cm Tiefe, sehr hoch (Abb. 11).

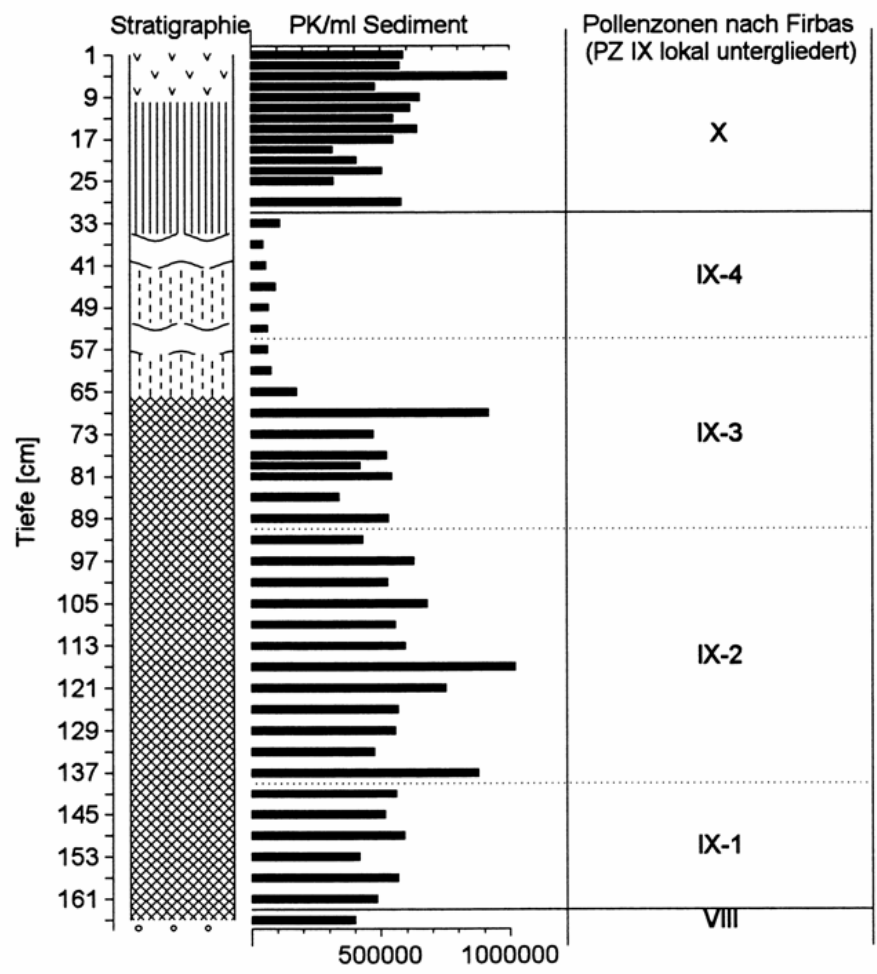

Abb. 11. Pollenkonzentrationen im Profil Almstorfer Moor, Ldkr. Uelzen.
Subboreal (PZ VIII nach Firbas; 165-163 cm)

Im ausgehenden Subboreal stockten auf den Altmoränenböden in der Umgebung des Almstorfer Moores Eichenmischwälder, in denen Pinus und Tilia weit verbreitet waren. Ulmus, Fraxinus und Acer kamen ebenfalls vor. Hingegen waren Fagus und Carpinus im nordöstlichen Niedersachsen noch selten. An lichten Standorten waren Betula und besonders Corylus vertreten, in feuchten Senken war Alnus verbreitet. Kulturpflanzen-Nachweise (Triticumund Hordeum-Typ) sind selten. Siedlungszeiger, besonders der Acker-, Brachen- und Weidezeiger Plantago lanceolata, sind stärker vertreten. Calluna ist in geringem Umfang nachgewiesen.

Demnach war die Landschaft im ausgehenden Subboreal stark bewaldet. Landwirtschaftliche Nutzflächen nahmen nur wenig Raum ein.

Älteres Subatlantikum (PZ IX nach Firbas; $163-31 \mathrm{~cm}$ )

Das Ältere Subatlantikum (PZ IX nach Firbas) beginnt im Profil aus dem Almstorfer Moor mit dem Anstieg der Fagus-Kurve über $2 \%$.

Der Firbas-Abschnitt PZ IX (163-31 cm) konnte in vier biostratigraphische Einheiten untergliedert werden (PZ IX-1 bis IX-4), die jedoch nur für das Almstorfer Moor gültig sind. Die Zusammensetzung der Eichenmischwälder war nach den Befunden aus den beiden Abschnitten PZ IX-1 und PZ IX-2 (Vorrömische Eisenzeit, Tab. 1) stabil. Nach Quercus waren Tilia und Fagus die wichtigsten Baumarten. Pinus, Betula, Corylus, Fraxinus und Ulmus erweiterten das Eichenmischwaldspektrum. Nur vereinzelt trat Acer auf. Beide Untereinheiten unterscheiden sich dadurch, daß die Poaceae-Werte in PZ IX-2 erhöht sind und eine Auflichtung des Geländes aufzeigen.

PZ IX-1 (163-139 cm)

Grenze PZ VIII/IX-1 (163 cm): Fagus-Werte $>2 \%$

Die PZ IX-1 mit der älteren Vorrömischen Eisenzeit (Tab. 1) beschreibt eine Eichen-Birken-Hasel-Zeit. Das Schattholz Fagus breitete sich im Eichenmischwald aus und konnte vereinzelt Tilia von ihren Standorten mit hoher Bodengunst verdrängen. Tilia hatte jedoch weiterhin größeren Anteil an den Wäldern als Fagus. PK von Hedera zeigen, daß ein wintermildes Klima herrschte. Siedlungszeiger sind regelmäßig nachgewiesen, und die Kulturpflanzen-Kurve setzt nur kurzfristig aus. Demnach war die Umgebung des Almstorfer Moores in der älteren Vorrömischen Eisenzeit kontinuierlich besiedelt. Auffällig ist, daß PK des Hordeum-Typs nur im ältesten Spektrum dieser PZ auftreten. Die Kurve des Triticum-Typs schließt sich parallel zum Aussetzen der Kurve des Hordeum-Typs. Eventuell verschob sich der Getreideanbau zu Gunsten der Weizen-Kultur. 
Tab. 6. Ergebnisse der Radiokarbon-Datierungen am Profil aus dem Almstorfer Moor mit einfacher Standardabweichung.

\begin{tabular}{clrrr}
\hline $\begin{array}{c}\text { Tiefe } \\
{[\mathrm{cm}]}\end{array}$ & $\begin{array}{c}\text { vegetationsgeschichtliches } \\
\text { Ereignis }\end{array}$ & $\begin{array}{c}{ }^{14} \mathrm{C} \text {-Alter } \\
{[\mathrm{BP}]}\end{array}$ & $\begin{array}{c}\text { ermittelte }{ }^{14} \mathrm{C}-\mathrm{Alter} \\
{[\mathrm{kal} . \mathrm{BP}]}\end{array}$ & $\begin{array}{c}\text { ermittelte }{ }^{14} \mathrm{C}-\mathrm{Altter} \\
{[\mathrm{kal} . \mathrm{n} . \mathrm{Chr} .]}\end{array}$ \\
\hline $20-23$ & starker NBP-Anstieg & $700 \pm 45$ & $660(671-573)$ & $1290(1279-1377)$ \\
$38-41$ & Aussetzen der Getreide-Kurve & $1540 \pm 55$ & $1412(1519-1350)$ & $538(431-600)$ \\
$51-54$ & Rückgang der Siedlungszeiger & $1580 \pm 55$ & $1493(1526-1411)$ & $457(424-539)$ \\
\hline
\end{tabular}

PZ IX-2 (139-91 cm)

Grenze PZ IX-1/IX-2 (139 cm): Poaceae-Werte $>40 \%$

Der Abschnitt PZ IX-2 läßt sich als Birken-EichenSüßgräser-Zeit charakterisieren. Seit dieser Zeit wurden die Waldflächen geringfügig verkleinert. Der Anstieg der Poaceae-Kurve und der Siedlungszeiger-Summenkurve zeigt eine Ausweitung des Siedlungsareals an. Vor allem scheint Quercus in der ersten Hälfte dieser Zeit eingeschlagen worden $\mathrm{zu}$ sein. Zudem belegen die geschlossenen Kulturpflanzen- und SiedlungszeigerSummenkurven, daß der Mensch in der Vorrömischen Eisenzeit weiterhin ohne Unterbrechung, jedoch mit unterschiedlicher Intensität, in der Region wirtschaftete. Unter den sekundären Siedlungszeigern sind der Plantago lanceolata- und der Rumex acetosa-Typ am häufigsten. Darüber hinaus kommen PK des Polygonum aviculareTyps, von $P$. Sekt. persicaria, von Artemisia, der Chenopodiaceae und des Plantago major/media-Typs vor. Vereinzelt ist Spergula arvensis nachgewiesen. Dieser tritt im Mittelalter als klassisches Unkraut der Hackfruchtfelder auf, hier ist er jedoch noch als Zeiger von Ruderalflächen oder Waldschlägen zu werten (WILLERDING 1986, 262).

Die Landschaft um das Almstorfer Moor war schon etwas aufgelichtet. In der Vorrömischen Eisenzeit gab es dort jedoch noch keine ausgedehnten Heiden.

\author{
PZ IX-3 $(91-55 \mathrm{~cm})$ \\ Grenze PZ IX-2/IX-3 (91 cm): Carpinus-Werte $>2 \%$
}

Während der PZ IX-3 breiteten sich Fagus und Carpinus in den Eichenmischwäldern der Umgebung des Almstorfer Moores stärker aus. Die Carpinus-Werte steigen zu Beginn dieses Abschnitts auf über $2 \%$. Im Elb-Weser-Dreieck variiert der Zeitpunkt des Anstiegs der Carpinus-Kurve auf über $2 \%$ erheblich. In kleinen Kesselmooren datiert er um 200 n. Chr., in großen Mooren wird die Marke auch früher überschritten (HEIDER 1995, 75 f.). Für das Almstorfer Moor wurde daher das Einsetzen der Secale-Kurve als Datierungshilfe herangezogen, denn der Roggen wird in Nordwestdeutschland erst seit der Römischen Kaiserzeit in Monokultur angebaut (BEHRE 1992, 144 f.). Der CarpinusAnstieg im Almstorfer Moor erfolgte demnach in den ersten Jahrhunderten nach Christi Geburt.

Die erhöhten Siedlungszeiger-Werte der PZ IX-3 können in Zusammenhang mit einem nahe gelegenen frühkaiserzeitlichen Siedlungsareal stehen, welches im 2. Jh. n. Chr. aufgelassen wurde (MILDENBERGER u. KÖHNCKE 1962, 163). Daß die Kurven des Triticum-Typs und von Secale im Bereich 71-61 cm Tiefe aussetzen, die Werte der sekundären Siedlungszeiger in der zweiten Hälfte dieses Abschnitts jedoch durchgängig sehr hoch sind, könnte eine Verlagerung des Siedlungsareals bzw. der Wirtschaftsflächen widerspiegeln.

PZ IX-4 $(55-31 \mathrm{~cm})$

Grenze PZ IX-3/IX-4 (55 cm): Fagus-Werte $>20 \%$

Die PZ IX-4 kann als Eichen-Buchen-Zeit beschrieben werden. Das älteste Pollenspektrum aus der PZ IX-4 wurde mit der Radiokarbon-Methode auf $1580 \pm 40$ BP, kal. 457 (424-539) n. Chr., datiert. Fagus erreicht hier die höchsten Werte im PD, da die Buche sich stark in den Eichenmischwäldern rund um das Almstorfer Moor ausbreitete. Betula, Pinus, Quercus und auch Corylus wurden von ihr zurückgedrängt. Die niedrigen Nichtbaumpollen-Werte (Kulturpflanzen, Siedlungszeiger) belegen, daß sich die Wälder wieder stärker ausdehnen konnten. Der ältere Teil dieses Abschnitts zeigt noch Hinweise auf Siedlungsaktivität. Jedoch haben Artemisia, Plantago lanceolata und der Rumex acetosa-Typ niedrigere Werte als im vorherigen Abschnitt. Die ChenopodiaceaeKurve setzt aus. Allerdings ist daraufhin mit einem kurzfristigen Anstieg der Kurven von Plantago lanceolata und des Rumex acetosa-Typs noch einmal eine leichte Auflichtung der Wälder erfaßt.

Der wichtigste Befund in diesem Abschnitt ist aber die fast vollständige Wiederbewaldung in der zweiten Hälfte der durch die PZ IX-4 repräsentierten Zeit. Betula erreicht hier erhöhte Werte, da aufgegebene Wirtschaftsflächen zunächst von Pionierwäldern vereinnahmt wurden. Die älteren, dichten Wälder setzten sich überwiegend aus Quercus sowie Fagus und Carpinus zusammen. Die NichtbaumpollenWerte (Kulturpflanzen, Siedlungszeiger) sind auf ein Minimum abgesunken. In dem auf $1540 \pm 55$ BP, kal. etwa 538 (431-600) n. Chr., datierten Pollenspektrum (41 cm Tiefe) setzt die Summenkurve der Kulturpflanzen sogar aus. Das Pollendiagramm spiegelt in diesem Abschnitt die Aufgabe von Wirtschaftsflächen und die Abnahme der Siedlungsdichte im Einzugsgebiet des Almstorfer Moores wider. Die Radiokarbon-Datierung legt nahe, daß es sich hier um den spätvölkerwanderungszeitlichen Siedlungsrückgang handelt. Aus historischen Quellen ist bekannt, daß die beiderseits der Niederelbe siedelnden Langobarden bereits im Verlauf des 4 . Jh. ins heutige 


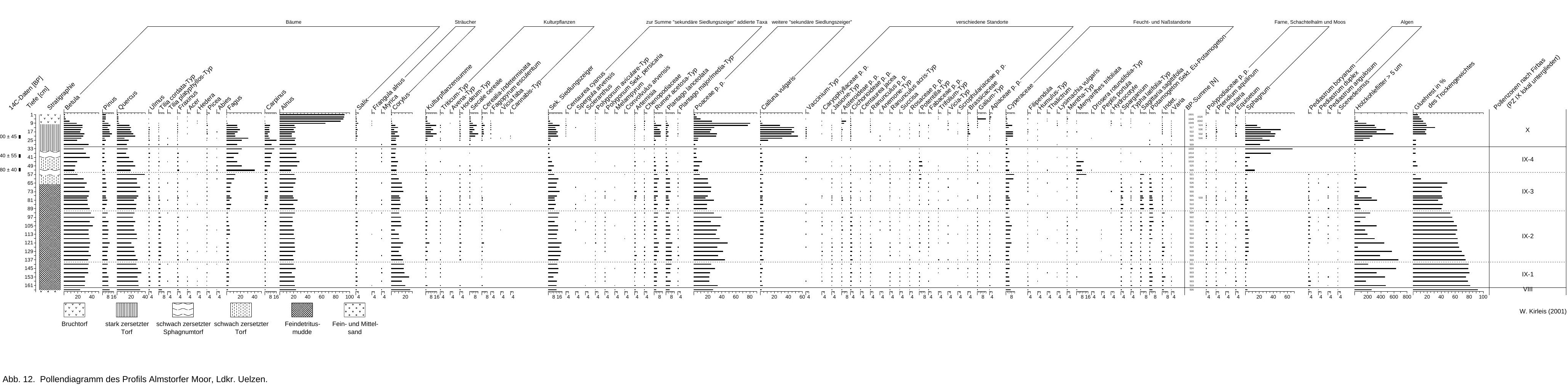




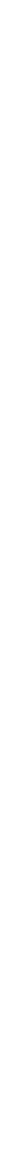


Niederösterreich abzuwandern begannen (Häßler 1991, 288 f.).

Die Entvölkerung des Bevenser Beckens wirkte lange Zeit fort. Zwar deuten einzelne Kulturpflanzen- und Siedlungszeiger-Nachweise der Folgezeit auf eine im Gebiet ansässige Restbevölkerung hin. Eine intensive Wiederbesiedlung setzte aber dem pollenanalytischen Befund zufolge erst im Späten Mittelalter ein (RadiokarbonDatierung auf $700 \pm 45$ BP, kal. 1290 [1279-1377] n. Chr.).

Jüngeres Subatlantikum (PZ X nach Firbas; 31-1 cm) Grenze PZ IX-4/X (31 cm): Secale-Kurve geschlossen

Der Beginn der PZ X fällt ins Frühe Mittelalter (Tab. 1), die Grenzziehung orientiert sich u. a. an den vorliegenden Radiokarbon-Datierungen. In der Umgebung des Almstorfer Moores stockten nach wie vor dichte, mosaikartig strukturierte Eichenmischwälder, in denen auf reichhaltigen, trockenen bis mäßig feuchten Böden Rotbuchen-Bestände vorkamen und an feuchten Stellen Eichen-HainbuchenBestände wuchsen.

Zunächst sind die Hinweise auf die Besiedlung der Region noch sehr schwach. Erst mit Beginn des spätmittelalterlichen Siedlungsausbaus wurden die Wälder schlagartig aufgelichtet und die Siedlungsdichte und Wirtschaftsweise intensiviert. Deutlich erhöht sind nun die Werte von Poaceae, Calluna, weiteren sekundären Siedlungszeigern und von Secale. Die RadiokarbonDatierung gibt ein Alter von $700 \pm 45$ BP, kal. 1290 (12791377) n. Chr., an. Besonders vom Einschlag betroffen waren Fagus und Carpinus, deren Kurven stark zurückgehen. Eventuell steht die Entnahme von Fagus mit dem großen Holzbedarf der Lüneburger Saline in Zusammenhang.

Quercus wurde in den Wäldern zunächst geschont. Die erhöhten Eichen-Werte im PD sind möglicherweise auf die Freistellung einzelner Bäume im Hudewald zurückzuführen. Der stärkere Lichtgenuß bewirkt eine Steigerung der Pollenproduktion.

Neben der holz- und weidewirtschaftlich bedingten Auflichtung der Wälder fand eine starke Ausweitung der landwirtschaftlichen Nutzflächen auf Kosten der Wälder statt. Häufigstes Getreide war nun Secale. Nachgewiesen wurde auch der Hordeum-, der Triticum- und der Avena-Typ sowie Fagopyrum, Vicia faba und der Cannabis-Typ. Unter den sekundären Siedlungszeigern tritt erstmals Centaurea cyanus auf, die als Wintergetreideunkraut in den Roggenfeldern vorkam. Auch die Werte vom Acker-, Grünland- und Brachenzeiger Plantago lanceolata sind erhöht. Der gleichzeitige starke Anstieg der Kurven von Calluna, des Rumex acetosa-Typs sowie des Glührestes sind sichere Hinweise für die Ausweitung der Heideflächen und eine sich anschließende Entnahme von Plaggen auf diesen entwaldeten Flächen nahe des Moores. Die Rumex-Werte zeigen überwiegend das Vorkommen von Rumex acetosella an, der als Pionier offene Sandflächen besiedelt. In der Nähe des Almstorfer Moores wurde offensichtlich die Plaggenwirtschaft betrieben.

Für die Gemeinde Lüder beim Schweimker Moor, nahe des untersuchten Almstorfer Moores südlich von Uelzen, ist überliefert, daß die Plaggenentnahme zu einer großflächigen Degradation der Böden führte (SELlE 1936, 387). In der südöstlichen Lüneburger Heide wurde eine intensive Plaggenwirtschaft mindestens seit dem 16. Jh. betrieben (DELFS 2000).

In den jüngsten Pollenspektren der $\mathrm{PZ} X$ wird das Baumpollen-Spektrum von hohen Werten der lokal vorkommenden Erle überprägt. Aus diesem Grund wurden für diesen Abschnitt die Proben höher ausgezählt und ein eigenes Pollendiagramm (Abb. 13) berechnet, das auf einer Baumpollen-Summe basiert, welche die prozentualen Anteile der Erle nicht enthält. Mit dieser Berechnungsgrundlage tritt der regionale Polleneintrag stärker hervor.

Die recht hohen Betula-Werte gehen vermutlich auf Anflugwälder zurück, die sich auf ehemaligen Heideflächen ansiedeln konnten, denn die Calluna-Werte sind abgesunken. Jedoch wurde die Birke darüber hinaus weiterhin durch eine von der Waldweide bedingte Auflichtung gefördert, obwohl ihr Jungwuchs teilweise verbissen wurde.

Der jüngste Teil der PZX kann als Kiefern-Zeit beschrieben werden. Der Eintrag von Pinus-Pollen stammt zum Teil von Kiefern, die sich in den Birken-Anflugwäldern auf den ehemaligen Heideflächen angesiedelt haben. Die große Menge des Kiefern-Pollens geht jedoch auf neuzeitlich angelegte Kiefernforste auf den ehemaligen Heideflächen zurück.

Der regelmäßige Eintrag von Picea-Pollen muß bis in die beginnende PZX als Fernflug gewertet werden. OvERBECK (1975, 398) konnektiert die im späten Atlantikum geschlossene Picea-Kurve in PD aus der südöstlichen Lüneburger Heide mit ihrer ersten Massenausbreitung im Harz. In den jüngsten Spektren des PD aus dem Almstorfer Moor ist der Picea-Anteil leicht erhöht, weil Picea nun angepflanzt wurde. Hingegen sind die Anteile von Fagus und Carpinus im PD nur noch gering. Neben den Kiefernforsten kamen etwas häufiger noch arme Birken-Eichenwälder vor.

Der Anbau von Getreide ist vor allem durch Nachweise der PK von Secale, des Hordeum-Typs, aber auch des Triticum- und Avena-Typs weiterhin belegt. Auch Buchweizen wurde kultiviert. Die Werte der Poaceae und weiterer sekundärer Siedlungszeiger gehen vor allem in den drei jüngsten Spektren deutlich zurück. Da es unwahrscheinlich ist, daß speziell siedlungszeigender Pollen durch das dichte Krondach des lokalen Erlenbruchs abgeschirmt wurde, liegt es nahe anzunehmen, daß nun landwirtschaftliche Nutzflächen in der Umgebung des Moores aufgegeben und zunehmend Kiefernforste angelegt wurden. 
3.4 Zur Rekonstruktion der Vegetationsund Siedlungsgeschichte

\subsubsection{Vorneolithische Vegetationsentwicklung}

\subsubsection{Präboreal und Boreal}

Die Ablagerungen aus dem Elbaer Moor und aus dem Rullstorfer Osterteich im Bereich der Niederterrasse der Elbe reichen bis ins Präboreal (Abschnitt IV nach Firbas) zurück. Besonders im Diagramm Rullstorfer Osterteich zeichnet sich die präboreale Dominanz der Baumbirke gegenüber der Kiefer ab. Erhöhte Anteile von Artemisia zeigen, daß die Birken-Kiefernwälder stark lichtdurchlässig waren. Die zeitliche Auflösung des Diagramms Rullstorfer Osterteich läßt keine Rückschlüsse darüber zu, ob und wie sich die präboreale Klimaschwankung, die BEHRE (1966, $75 \mathrm{f}$.) für Westrhauderfehn (Ostfriesland) nachweisen konnte, auf die Vegetation im Untersuchungsgebiet ausgewirkt hat. Die Ablagerungen aus dem Elbaer Moor können dieses nicht zeigen, da sie jünger sind. Hier war die Kiefer stärker präsent, weshalb diese Ablagerungen bereits ins Boreal überleiten.

Das Boreal (Abschnitt V nach Firbas) ist ebenfalls in den beiden Diagrammen aus der Niederterrasse der Elbe nördlich von Lüneburg erfaßt. Die zunehmende Erwärmung förderte an beiden Profilentnahmestellen die mit Torfwachstum verbundene Verlandung der Seen.

In den Wäldern breitete sich zunächst die Kiefer auf Kosten der Birke und Artemisia aus. Im jüngeren Boreal drangen, wie es der bekannten Vegetationsentwicklung für Nordwestdeutschland entspricht, die Eichenmischwaldarten in die Kiefern-Birkenwälder ein. Die Massenausbreitung der Hasel ist häufig durch einen borealen Gipfel mit Werten weit über $100 \%$ des Baumpollens belegt (FIRBAS 1949, $149 \mathrm{f}$.). Jedoch sind die Werte in den vorliegenden Untersuchungen erheblich niedriger. Im Profil aus dem Rullstorfer Osterteich ist, vermutlich wegen der ungünstigen Auflösung, gar kein borealer Hasel-Gipfel erfaßt. Im Profil aus dem Elbaer Moor wird ein Hasel-Gipfel mit $24 \%$ im jüngeren Boreal erreicht. Die Hasel, deren Pollenproduktion sehr hoch ist und etwa der der Birke oder der Kiefer entspricht (LANG 1994, 49), kam im Raum Lüneburg im Boreal vermutlich nur im Unterwuchs der Wälder sowie an den Waldsäumen vor und hatte, wenn überhaupt, nur sehr geringen Anteil am Kronendach der kiefernreichen Mischwälder.

Der wichtigste die Massenausbreitung der Hasel behindernde Faktor ist die Bodengüte. Die Hasel bevorzugt frische und nährstoffreiche Böden (OBERDORFER 1990, 312), wie sie in Altmoränenlandschaften kaum vorkommen. Eine Übersicht für Nordwestdeutschland bei OVERBECK (1975, 539) zeigt, daß Hasel-Maxima von weit über $100 \%$ des Baumpollens in Pollendiagrammen auftreten, die aus der Jungmoränenlandschaft Schleswig-Holsteins mit ihren kalkhaltigen, frischen Böden und aus dem Gebiet der fruchtbaren Lößböden um den Harz stammen. In der
Altmoränenlandschaft mit ihren armen Sandböden variieren die Hasel-Gipfel hingegen stark, liegen jedoch weit unter $100 \%$ des Baumpollens: Beispielsweise werden in der Siedlungskammer Flögeln im Ldkr. Cuxhaven keine 30\% erreicht (BEHRE u. KUČAN 1994, 145), im Melbecker Moor südlich von Lüneburg steigen die Werte auf bis zu $50 \%$ an (OvERBECK u. SCHNEIDER 1938, Profil I) und im Hannoverschen Wendland liegen die Gipfel bei 35 und $60 \%$, nachdem hier die Werte der vor Ort wachsenden Erle und Birke aus der BP-Grundsumme herausgenommen wurden (LeSEMANN 1969, 496 f., Profile Heuweg I u. II).

\subsubsection{Atlantikum}

Auch das Atlantikum ist in den beiden Profilen Elbaer Moor und Rullstorfer Osterteich erfaßt. Möglicherweise fehlt jedoch beim Rullstorfer Osterteich die jüngere atlantische PZ VII, weil hier eine Schichtlücke auftritt (Kap. 3.4.4.4).

Der Beginn des Atlantikums ist in Nordwestdeutschland durch einen starken Anstieg der Erlen-Kurve gekennzeichnet. In der Folgezeit ist die Erle das wichtigste Gehölz auf den Feuchtböden der Niederungsbereiche. An der Entnahmestelle des Profils Rullstorfer Osterteich entwickelte sich in dieser Zeit tatsächlich ein Erlenwald, der einen Bruchtorf entstehen ließ.

Die thermophilen Eichenmischwaldarten breiteten sich auf der Hohen Geest aus. In diesen Wäldern spielte die Linde eine bedeutende Rolle, die auf den reicheren Böden stockte. Lindenblüten werden von Insekten bestäubt und erzeugen klebrige Pollenkörner. Die Pollenemission der Linde ist daher gering. In einem Mischwald sind die LindenAnteile unterrepräsentiert (ANDERSEN 1973, 110; KALIS 1988, 132). Die atlantischen Eichenmischwälder setzten sich nicht aus gleichmäßig vertretenen Eichen, Kiefern, Linden, Ulmen, Eschen und Ahornen zusammen. Vielmehr existierte ein Mosaik unterschiedlicher, von verschiedenen Baumarten dominierter Bestände. Die mosaikartige Struktur der atlantischen Eichenmischwälder konnte durch pollenanalytische Untersuchungen auf der Geestinsel Flögeln im Ldkr. Cuxhaven anhand der PD eng beieinanderliegender Profile rekonstruiert werden. Dort wurde für das Immenmoor ein Lindenbestand nachgewiesen, den die umliegenden Pollendiagramme nicht widerspiegeln (BEHRE u. KUČAN 1994, 146). Ein Beispiel für einen lindendominierten Wald ist der Wald „Draved“ in Süd-Dänemark, wo bis ins ausgehende Subboreal ein primärer Lindenwald stockte, dessen Waldzusammensetzung durch die Laubheufutterwirtschaft nur unwesentlich verändert wurde. Bis ins Subatlantikum war dieser Wald lindenreich, bis die Linde dort im 17. Jh. selektiv geschlagen wurde (AABY 1983, 95 f.).

Die insektenblütigen Gattungen Hedera und Viscum, die als gute Klimaindikatoren gelten, sind in den atlantischen Ablagerungen aus dem Elbaer Moor regelmäßig, wenn auch mit geringen Werten, vertreten. Während der Efeu zum 
Gedeihen wintermilde Klimate benötigt, belegt die Mistel die gegenüber heute höheren Sommertemperaturen. Die hohe Konkurrenzkraft der Linde ist ebenfalls auf das günstige Klima des Atlantikums zurückzuführen.

$\mathrm{Zu}$ Beginn des Atlantikums erfuhr die Hasel ihre stärkste Ausbreitung in der Umgebung des Elbaer Moores. Dieser zweite und höchste Hasel-Gipfel im Pollendiagramm aus dem Elbaer Moor datiert auf $7140 \pm 55$ BP, kal. 6007 (60565924) v. Chr. Während die boreale Massenausbreitung der Hasel in Nordwestdeutschland weitgehend synchron verlief, lassen sich jüngere Hasel-Gipfel in den Pollendiagrammen kaum überregional konnektieren (OVERBECK 1975, 400). Der oft vielzackige und sprunghafte Kurvenverlauf ist von lokalen Faktoren wie einer kleinräumigen Auflichtung der Wälder abhängig. Jedoch zeigt ein Vergleich des Befundes aus dem Elbaer Moor mit dem Pollendiagramm aus dem Pietzmoor in der südwestlichen Lüneburger Heide (BECKER 1995) und dem aus dem südlich von Lüneburg gelegenen Melbecker Moor (OvERBECK u. SCHNEIDER 1938), daß sich auch dort Hasel-Gipfel für das frühe Atlantikum abzeichnen. Hingegen gehen die Hasel-Werte in den Pollendiagrammen aus dem Hannoverschen Wendland (LESEMANN 1969, Profile Heuweg I u. II) und aus der Prignitz von jenseits der Elbe (KIRLEIS 1998, Profil Boberow) gegenüber den Werten aus der Zeit der borealen Massenausbreitung zurück. Gleiches gilt für die Diagramme aus dem Osten Hamburgs (AVERDIECK 1958, 171). Nur in der Umgebung Lüneburgs und Teilen der Lüneburger Heide breitete sich die Hasel zu Beginn des Atlantikums deutlich in den Eichenmischwäldern aus. Für den weiteren Umkreis trifft der von LANG $(1994,158)$ postulierte Bedeutungsverlust der Hasel während des Atlantikums zu, der im kontinentalen Bereich eine Folge der Konkurrenz mit den anderen Laubgehölzen ist.

Einzelne im frühen und mittleren Atlantikum als Siedlungszeiger klassifizierte heliophile Kräuter zeigen, daß im natürlichen Urwald Lichtungen von Baumwürfen oder von natürlichen Bränden vorhanden waren, die von diesen Arten besiedelt wurden. Pollenanalytische Hinweise auf den Menschen finden sich hier jedoch noch nicht, da der Mesolithiker als Jäger und Sammler natürliche Ressourcen nutzte und die Landschaft nicht nach seinen Bedürfnissen umformte. Eine bewußte Umstrukturierung der Landschaft kann vegetationsgeschichtlich für die Altsiedelgebiete der Lößlandschaften im jüngeren Atlantikum und für das norddeutsche Tiefland erst im Subboreal (Tab. 1) mit dem Übergang zur seßhaften Lebensweise im Neolithikum erfaßt werden.

\subsubsection{Subboreal mit Neolithikum und Bronzezeit}

\subsubsection{Rückgang der Ulmus-Werte}

In Norddeutschland und angrenzenden Gebieten fand der sog. klassische Ulmenfall weitgehend synchron zu Beginn des Subboreals um 5000 BP statt. In Pollendiagrammen mit niedrigen Ulmen-Werten, die meist aus Gegenden mit armen Böden stammen, ist der Ulmenfall nur schwach ausgebildet (DÖRFLER 1989, 26 f.; BEHRE u. KUČAN 1994, 147).

Im Pollendiagramm Elbaer Moor zeichnet sich der Ulmenfall als allmählicher Rückgang der Ulmen-Werte ab. Erst in einer Tiefe von $39 \mathrm{~cm}$ fallen die Werte um $2 \%$. Dieses Ereignis datiert auf $4430 \pm 55$ BP, kal. 3064 (33082924) v. Chr. Werden die Bereiche berücksichtigt, innerhalb derer die Wahrscheinlichkeitsmaxima der Kalibrierung streuen, so gibt es Überschneidungen mit der Datierung des Ulmenrückgangs im nahe gelegenen Melbecker Moor auf $4630 \pm 120$ BP, kal. 3474 (3626-3122) v. Chr. (KUBITZKI u. MÜNNICH 1960, 140 f.). Im Raum Lüneburg fand der Ulmenrückgang daher weitgehend gleichzeitig statt.

In Norddeutschland lösten anthropogene Einflüsse, die Ulmenkrankheit, Veränderungen des Klimas und eine Verschlechterung der Bodenverhältnisse den Ulmenrückgang aus. Eine Konkurrenz zur Rotbuche, wie sie für Süddeutschland postuliert wird (KÜSTER 1988a, 87), kann hier ausgeschlossen werden, da die Rotbuche den Norden Deutschlands erst im Verlauf des Subboreals erreichte. Auch im Elbaer Moor traten die ersten Pollenkörner der Rotbuche nicht vor dem Ulmenfall auf.

Häufig kommt es nach dem ersten starken Ulmenfall wieder zur Erholung der Ulmenbestände. In der Folge können weitere Ulmenrückgänge stattfinden, die zumeist mit dem rodenden und die Bäume schneitelnden Menschen und der Ulmenkrankheit in Zusammenhang stehen (ANDERSEN u. RASMUSSEN 1993, 133 f.). Am Geestrand zur Elbe nördlich Lüneburgs konnte sich die Ulme nach ihrem subborealen Rückgang jedoch nicht wieder ausbreiten.

\subsubsection{Neolithikum}

Während das Neolithikum im südlichen Niedersachsen schon im 6. Jahrtausend v. Chr. entwickelt war, fällt sein Beginn im nördlichen Niedersachsen erst ins 4. Jahrtausend v. Chr. Archäologisch deutlich faßbar ist das Neolithikum hier mit der Ausbreitung der Megalithgräber der jüngeren Trichterbecherkultur (ca. 3300-2700 v. Chr., HEEGE u. MAIER 1991, 118 f.). Im Untersuchungsgebiet streuen die Megalithgräber der Trichterbecherleute vornehmlich im Südwesten und Osten von Lüneburg (SPROCKHOFF 1975, 37 f.). Hausgrundrisse dieser Kultur sind bislang nur wenige bekannt (AsSENDORP 1999, 180 f.). Bei den Ausgrabungen in Rullstorf nordöstlich von Lüneburg wurde ein trichterbecherzeitliches Siedlungsareal angeschnitten (GEBERS 1995, 57 f.).

Im PD Elbaer Moor, welches als einziges der in dieser Arbeit vorgestellten neuen Pollendiagramme das Subboreal abdeckt, sind die Hinweise auf menschliche Aktivität sehr schwach. Die erhöhten Holzkohle-Werte am Übergang zum Subboreal sind eventuell auf Brandrodung zurückzuführen. Die Holzkohlepartikel können jedoch auch durch natürliche Waldbrände freigesetzt worden seien. Durch die Brände 
wurde die Hasel gefördert, da sie sich auf freien Flächen ausbreiten konnte. Auch Betula wird von den Waldbränden begünstigt, da sie als Pionierpflanze gern Brand- und Ruderalflächen besiedelt. Ihre Kurve reagiert im PD mit einem Anstieg auf die hohen Holzkohle-Werte. Die GräserKurve verweist ebenfalls auf eine vermutlich anthropogene Auflichtung der Wälder.

Der erste Eintrag von Kulturpflanzen-Pollen (Triticumund Hordeum-Typ) ins Elbaer Moor kann möglicherweise auf das Wirtschaften der Rullstorfer Trichterbecherleute im 4. Jahrtausend v. Chr. zurückgeführt werden. Makrorestuntersuchungen aus vergleichbaren Siedlungen (z. B. Flögeln-,,Im Örtjen“, BEHRE u. KUČAN 1994, 26 f.) lassen in dieser Zeit zumindest den Anbau der Vierzeilgerste und der Weizenart Emmer erwarten. Die menschlichen Eingriffe ins Waldgefüge werden nur schwach im Profil aus dem Elbaer Moor reflektiert, woraus geschlossen wird, daß Siedlungen und Wirtschaftsflächen in großer Entfernung zum Moor lagen (beispielsweise bei Rullstorf). Eine mit einer starken Auflichtung der Wälder durch die Waldweide verbundene „Landnam“-Phase (IVERSEN 1973, 86 f.) ist im Pollendiagramm aus dem Elbaer Moor nicht zu erkennen. Die leichte Öffnung der Vegetation um das Elbaer Moor, die vermutlich durch die Waldweide und auch durch Brandrodung vorangetrieben wurde, führte $\mathrm{zu}$ einer Einwehung minerogenen Materials. Die Poaceae-Werte sind leicht erhöht, und es sind erste Getreide-Typen nachgewiesen. Die Werte der Birke bleiben hoch. Lindenund Ulmen-Werte gehen allmählich zurück. Laubfutterwirtschaft hielt vermutlich die Anteile der Ulmen in den Wäldern um das Elbaer Moor niedrig. Auch der Anstieg der Eschen-Kurve ist möglicherweise durch das Schneiteln bedingt (s. o.).

In den Niederlanden werden die Trichterbecherleute nach Untersuchungen an Pollenproben aus Grabhügeln in Verbindung mit der Laubfutterwirtschaft gebracht, während der Einzelgrab- und Glockenbecherkultur die pollenanalytisch nachweisbare „Landnam“ zugeschrieben wird (VAN ZEIST 1967, 58 f.). In Nordostniedersachsen wurde die Trichterbecherkultur im Verlauf des 3. Jahrtausends v. Chr. von der Kugelamphoren- und der Einzelgrabkultur abgelöst. Im Profil aus dem Elbaer Moor verhindert jedoch die geringe zeitliche Auflösung im späten Subboreal eine klare Abgrenzung der im Gebiet aufeinander folgenden Kulturen und ihrer unterschiedlichen Wirtschaftsweisen.

\subsubsection{Bronzezeit}

Eine Vielzahl archäologischer Funde aus der Bronzezeit im nordöstlichen Niedersachsen läßt wie auch schon für das Neolithikum eine relativ hohe Siedlungsdichte annehmen (Metzler u. Wilbertz 1991, 156 f.).

Im Pollendiagramm Elbaer Moor ändert sich im Vergleich zu den neolithischen Spektren nur wenig. Die Summenkurve der Kulturpflanzen setzt zwar im jüngsten subborealen Spektrum aus, doch das Niveau der Kurve der sekundären Siedlungszeiger bleibt zunächst unverändert. Die Anwesenheit von Plantago lanceolata, der als Unkraut in Feldern mit lockerer Bestandesdichte steht und zudem auf Brachen vorkommt, zeigt, daß Ackerbau kontinuierlich betrieben wurde. Geringfügig dehnten sich die Heideflächen in der Umgebung des Moores weiter aus. Die Landschaft am Geestrand zur Elbniederung war weiterhin von dichten Eichenmischwäldern bedeckt, in die inselartig Lichtungen mit Siedlungen und Wirtschaftsflächen eingestreut waren.

Bei Rullstorf wurde eine Siedlung aus der jüngeren Bronzezeit ausgegraben (GEBERS 1995, $58 \mathrm{f}$.). Die umfangreichen, verkohlten Funde von Pflanzenresten aus den Erdsilos im Siedlungsareal wurden im Rahmen der vorliegenden Arbeit untersucht (Kap. 4.3). Die vielen Getreidereste lassen auf ausgedehnte Ackerflächen in der Umgebung der Siedlung schließen. Auffällig erhöht sind die siedlungszeigenden Pollenkurven im Profil aus dem etwa $8 \mathrm{~km}$ von Rullstorf entfernt liegenden Elbaer Moor jedoch erst am Übergang zur älteren Vorrömischen Eisenzeit im frühen Subatlantikum.

\subsection{3 Älteres Subatlantikum mit Vorrömischer Eisenzeit, Römischer Kaiserzeit, Völkerwanderungszeit und Frühem Mittelalter}

\subsubsection{Vorrömische Eisenzeit}

Im nordöstlichen Niedersachsen ist die archäologische Fundstellendichte für die Vorrömische Eisenzeit ungefähr ebenso hoch wie in der Bronzezeit (HARCK 1972, 93). Anhand archäologischer Untersuchungen von Gräberfeldern wurde eine kontinuierliche Besiedlung von der mittleren Bronzezeit bis in die ältere Kaiserzeit für dieses Gebiet festgestellt (LAUX 1998, 145 f.). Um die Siedlungsgeschichte darüber hinaus palynologisch nachzuvollziehen, stehen nun die Pollendiagramme aus dem Elbaer Moor nördlich von Lüneburg und aus dem Almstorfer Moor bei Bad Bevensen zur Verfügung.

Obwohl das frühe Subatlantikum im Profil aus dem Elbaer Moor zeitlich schlecht aufgelöst ist, wird zu Beginn der PZ IX eine Ausweitung oder Verlagerung von Siedlungs- und Wirtschaftsflächen reflektiert. Die Kurven der Süßgräser, der Besenheide, weiterer Siedlungszeiger und des minerogenen Eintrags reagieren mit plötzlich stark steigenden Werten. Dieses kann vermutlich nicht auf die Rullstorfer Siedler zurückgeführt werden, da deren Siedlungsareal $\mathrm{zu}$ weit entfernt lag. Jedoch ergab die Untersuchung verkohlter Pflanzenreste aus zwei Darröfen und mehreren Vorratsgruben aus dieser ältereisenzeitliche Siedlung bei Rullstorf, daß viel Ackerbau betrieben wurde. Die wichtigsten Anbaufrüchte waren Spelzgerste, Emmer und Saatweizen. Darüber hinaus wurden Hafer (ein sehr früher Beleg für die Haferkultivierung, vgl. Kap. 4.3.1), Rispenhirse und Lein angebaut (BEHRE 1990, $143 \mathrm{f}$.). Generell liefern archäobotanische Ergebnisse Artbestimmungen, die die Pollenanalyse nicht leisten kann. 
Erst anhand der Verknüpfung der Untersuchungen der Rullstorfer Makroreste mit den Pollenanalysen aus dem Elbaer Moor entsteht das Bild der eisenzeitlichen Agrarlandschaft am Geestrand nördlich von Lüneburg, die überwiegend von Acker- und Waldflächen geprägt ist.

Im Profil aus dem Almstorfer Moor erstreckt sich die Vorrömische Eisenzeit über die PZ IX-1 und IX-2 (Tab. 1). Das Pollendiagramm beschreibt in diesem Abschnitt ein kontinuierlich besiedeltes Gebiet, es treten keine Siedlungslücken auf. Dieses bestätigt den archäologischen Befund einer Siedlungskontinuität in der Vorrömischen Eisenzeit (archäologische Stufen: Frühe Eisenzeit, 800-550 v. Chr.; ältere Jastorf-Stufe, 550-300 v. Chr.; Jastorf c und Ripdorf, 300-120 v. Chr., Seedorf, 120 v. - 5 n. Chr.; LAUX 1998, Abb. 7). Da sich die Schwankungen der siedlungszeigenden Pollenkurven in einem Bereich bewegen, der der Pollenanalyse inhärent ist, werden keine Zuweisungen $\mathrm{zu}$ den eisenzeitlichen Kulturstufen unternommen.

Am Übergang von der Bronzezeit zur Eisenzeit (ca. 800 v. Chr.) gehen die Linden-Anteile (165-155 cm Tiefe) im Pollendiagramm aus dem Almstorfer Moor deutlich zurück. Da die Linde gewöhnlich auf reichen Böden stockt, ist es denkbar, daß sie von der Rotbuche verdrängt wurde. Zudem ist es möglich, daß speziell die Linden zur Gewinnung von Ackerflächen gerodet wurden und zudem ihr Bast genutzt wurde. Pollenkörner des Triticum- und des Hordeum-Typs zeigen, daß Ackerbau betrieben wurde. Im weiteren Verlauf (155-139 cm Tiefe) fällt der Hordeum-Typ aus, jedoch tritt der Triticum-Typ regelmäßig auf. Die Größenmessungen der Pollenkörner dieses Abschnitts (PK-Durchmesser $>50 \mu \mathrm{m}$, Anulus-Breite $>4 \mu \mathrm{m}$ und Anulus-Dicke $>3 \mu \mathrm{m}$ ) zeigen, daß es sich hier vor allem um Kulturweizen-PK handelt. Geschiebelehmböden mit hoher Bodengüte standen für den Anbau dieses anspruchsvollen Getreides nahe dem Almstorfer Moor zur Verfügung (Kap. 3.3.5).

In der ersten Hälfte der PZ IX-2 (139-115 cm Tiefe) wurden die höchsten Werte von Poaceae, der Summenkurve weiterer sekundärer Siedlungszeiger und von Kulturpflanzen (Triticum- und Hordeum-Typ) im älteren Subatlantikum nachgewiesen. Die Wälder wurden demnach verkleinert (Rückgang bei Quercus) und die Wirtschaftsflächen ausgeweitet. Die hohen Poaceae-Werte können auf die Waldweide zurückgeführt werden. Im Anschluß an diese Phase gehen die Siedlungszeiger-Werte wieder zurück (115$99 \mathrm{~cm}$ ). Die Kurven der Kulturpflanzen und der sekundären Siedlungszeiger verlaufen nun auf einem niedrigeren Niveau als zuvor, und der Eichenbestand erholte sich wieder. In einer Tiefe von $99-91 \mathrm{~cm}$ gehen schließlich auch die Kulturpflanzen-Anteile zurück. Dies steht im Gegensatz zu den deutlich erhöhten Werten der Siedlungszeiger. Besonders die Poaceae und der im Zusammenhang mit den niedrigeren Getreide-Werten als Grünlandzeiger zu wertende Spitzwegerich sind stärker vertreten. In dieser Phase wurden die Weideflächen ausgeweitet und die Getreidefelder verkleinert.
Im Laufe der Vorrömischen Eisenzeit verändert sich das Verhältnis von Kulturpflanzen zu sekundären Siedlungszeigern im Profil aus dem Almstorfer Moor immer wieder. Ein gleichzeitiges Aussetzen beider Kurven kommt indessen nicht vor. Für die Umgebung des Almstorfer Moores ist daher von einer Siedlungskontinuität während der Vorrömischen Eisenzeit auszugehen. Obwohl der Wald um das Almstorfer Moor in der Vorrömischen Eisenzeit durch den Menschen schon stark aufgelichtet war, gab es dort noch keine ausgedehnten Heiden. Die geringen Anteile der Besenheide im Pollendiagramm sind auf die relativ günstigen Böden der Umgebung des Almstorfer Moores zurückzuführen. Sie konnten nicht so schnell ausgelaugt werden, wie das beispielsweise nahe dem Elbaer Moor geschah.

\subsubsection{Römische Kaiserzeit}

In Nordostniedersachsen ist die Dichte der Fundstellen aus der Römischen Kaiserzeit geringer als in den Perioden der Bronzezeit und der Vorrömischen Eisenzeit. Im Verlauf der Römischen Kaiserzeit nimmt sie noch weiter ab (HARCK 1972, 93). Durch die Untersuchungen der Gräberfelder Nordostniedersachsens wurde sogar eine Besiedlungslücke für den Zeitraum 150-300 n. Chr. nachgewiesen (LAUX 1998, Abb. 7).

Wiederholt wurden kaiserzeitliche Eisenverhüttungsplätze aufgedeckt. Überreste eines Rennfeuerofens, von Eisenschlacken und von Raseneisenerz aus Scharmbeck bei Winsen datieren ins 2. Jh. n. Chr. (WEGEWITZ 1957, 13 f.). Auch auf dem Kronsberg bei Rullstorf zeichneten sich Spuren einer kaiserzeitlichen bis völkerwanderungszeitlichen Siedlung mit Plätzen der Eisenverhüttung ab (GARBERS 1990, 50; GEBERS 1985c, 191 f.). Das Brennholz für den Betrieb der Rennfeueröfen wurde vermutlich aus den Wäldern der Umgebung der Siedlung bezogen. Untersuchungen eines Eisenverhüttungsplatzes in Joldelund (Nordfriesland) zeigen, daß die Wälder durch die Eisenverhüttung nicht längerfristig beeinträchtigt wurden. So ergibt eine Modellrechnung, daß der jährliche Holzbedarf beim Betrieb von fünf Rennfeueröfen geringer ist als der Holzbedarf zur Errichtung eines eisenzeitlichen Gehöftes (DÖRFLER u. WIETHOLD 2000, 232 f.).

Im Pollendiagramm aus dem Elbaer Moor ist die Römische Kaiserzeit am Einsetzen der Roggen-Kurve zu erkennen. Aus dem Diagramm ist keine starke Holzentnahme aus den Wäldern des Umlandes abzulesen. Jedoch verbietet die ungünstige Auflösung, in diesem Abschnitt weitergehende Interpretationen bezüglich Eisenverhüttung und Holzverbrauch in Rullstorf vorzunehmen.

In der Umgebung des Almstorfer Moores dehnten sich die Eichenmischwälder zur Zeit von und vor allem nach Christi Geburt stark aus. Die Standorte der Linden wurden nun von Rotbuchen eingenommen. Das Getreide-Spektrum 
ist durch den Roggen und den Hafer erweitert. Möglicherweise korreliert der Abschnitt 89-69 cm Tiefe mit einem 9 ha großen frühkaiserzeitlichen Siedlungsareal, welches sich in einer Entfernung von knapp $1000 \mathrm{~m}$ Luftlinie nordöstlich des Almstorfer Moores auf dem Wiernitzberg befand (KÖHNCKE 1965, $191 \mathrm{f}$.$) . Die$ Kulturpflanzen (Triticum-, Hordeum-, Avena-Typ und Secale) sowie die sekundären Siedlungszeiger erreichen in dieser Siedlungsphase relativ hohe Werte. Gleichzeitig breiteten sich Fagus und Carpinus aus, die als Schattholzarten in den vom Menschen aufgelichteten Wäldern einen Konkurrenzvorsprung hatten. Anschließend gehen die Kulturpflanzen-Werte zurück. Jedoch bleiben die sekundären Siedlungszeiger auf dem vorherigen Niveau. Fagus konnte sich im Verlauf dieses Abschnitts vermutlich auf aufgegebenen Ackerflächen weiter ausdehnen. Der Rückgang der Kulturpflanzen-Werte bei gleichzeitig hohen Werten der sekundären Siedlungszeiger spricht für eine starke Auflichtung, die auf Siedlungsverlagerungen in der Umgebung des Moores zurückgeht. Tatsächlich wurde die Siedlung auf dem Wiernitzberg im 2. Jh. n. Chr. aufgelassen (MildenBERGER u. KÖHNCKE 1962, 163) und möglicherweise an einem nahegelegenen Standort neu errichtet.

In der Römischen Kaiserzeit ist eine Siedlungskontinuität für die Umgebung des Almstorfer Moores anhand des pollenanalytischen Befundes gegeben. Die von LAUX (1998, Abb. 7) angeführte Siedlungslücke im 2./3. Jh. n. Chr. kann für die Umgebung des Almstorfer Moores palynologisch nicht nachgewiesen werden. Jedoch zeichnet sich im PD Elmer Hochmoor aus dem Bremervördener Raum eine ins 2. Jh. n. Chr. datierende Siedlungslücke ab (HEIDER 1995, 97). Demnach scheint die Siedlungsgeschichte in verschiedenen Kleinräumen Nordostniedersachsens unterschiedlich abgelaufen zu sein.

\subsubsection{Völkerwanderungszeit und Frühes Mittelalter}

Die Völkerwanderungszeit datiert ins 4.-6. Jh. n. Chr. Norddeutschland war nur indirekt vom Zusammenbruch des antiken Römischen Reiches betroffen. Dennoch wurde die Bevölkerung von der allgemeinen völkerwanderungszeitlichen Unruhe ergriffen. Die Sachsen aus dem Elb-Weser-Raum beteiligten sich an der Migration nach Britannien, die ihren Höhepunkt in der zweiten Hälfte des 5. Jh. n. Chr. fand. Die beiderseits der Niederelbe siedelnden Langobarden begannen im 4. Jh. n. Chr. ins heutige Niederösterreich abzuwandern. Eine Restbevölkerung verblieb in Nordwestdeutschland, jedoch fehlen besonders für das 6./7. Jh. n. Chr. deutliche Besiedlungshinweise (HÄßLER 1991b, 285 f.). Vielerorts bricht die Belegung der Gräberfelder Nordostniedersachsens im 6. Jh. n. Chr. ab (LAUX 1998, Abb. 7).

In Rullstorf hingegen bestand die kaiserzeitliche Siedlung im 5. Jh. n. Chr. fort, und ein sächsisches Gräberfeld des 6./7. Jh. leitet ins Frühe Mittelalter über (GARBERS 1990， 49; GEBERS 1995, 57 f.). $\quad$ Im
Pollendiagramm aus dem nahe gelegenen Elbaer Moor sind Siedlungszeiger und Kulturpflanzen für das Ältere Subatlantikum in allen drei untersuchten Proben dieses Abschnitts nachgewiesen. Eine Siedlungskontinuität kann in der Umgebung des Moores von der Vorrömischen Eisenzeit bis ins Frühe Mittelalter aber nur vermutet werden. Die starke Torfverdichtung bewirkte hier, daß dieses Pollenprofil zeitlich nicht hoch aufgelöst werden konnte. Daher ist es nicht möglich, anhand dieses Pollendiagramms genauere Informationen zur Siedlungskontinuität zu liefern.

Im Profil Almstorfer Moor zeichnet sich hingegen ein völkerwanderungszeitlicher Siedlungsrückgang ab. Im Verlauf der PZ IX-4 gehen die siedlungszeigenden Pollenkurven zurück. Schließlich setzt die KulturpflanzenKurve sogar aus. Gleichzeitig erreicht die Rotbuche ihren höchsten Wert, der daraufhin zwar etwas absinkt, jedoch für diese Region immer noch sehr hoch ist. Dieser Abschnitt korreliert mit der Abwanderung großer Bevölkerungsteile aus der Region. Zwar gibt es in dieser Phase schwache Hinweise auf eine Restbevölkerung (einzelne PK der Kulturpflanzen, geringe Werte der sekundären Siedlungszeiger), jedoch nimmt nun die Bewaldungsdichte stark zu (Abnahme der Werte von Poaceae und weiteren Taxa). Zwei Radiokarbon-Messungen datieren diesen Abschnitt ins 5./6. Jh. n. Chr. (Tab. 6).

Aus historischen Quellen ist bekannt, daß die beiderseits der Niederelbe siedelnden Langobarden bereits im Verlauf des 4. Jh. ins heutige Niederösterreich abzuwandern begannen und dort seit 489 siedelten (HÄßLER 1991b, 288 f.). Die Belegung der während der jüngeren Kaiserzeit angelegten Urnenfriedhöfe der Region bricht im späten 5 . bzw. zu Beginn des 6. Jh. n. Chr. ab. Daraus wurde eine Besiedlungslücke für diesen Zeitraum abgeleitet (LAUX 1998, 150 f.). Die pollenanalytischen Untersuchungen aus dem Almstorfer Moor bestätigen, daß die Bevölkerungsdichte in diesem Abschnitt stark ausdünnte. Demnach kann ausgeschlossen werden, daß die Fundleere auf einer archäologischen Forschungslücke beruht.

Auch in dem weiter im Westen und im Siedlungsgebiet der Chauken entnommenen Pollenprofil aus dem Mehemoor datiert ein Siedlungsrückgang in die späte Völkerwanderungszeit (HEIDER 1995, 97). Weitere Pollendiagramme aus dem Elb-Weser-Dreieck beschreiben ebenfalls die Abnahme der Siedlungsdichte und eine zunehmende Bewaldung für die späte Völkerwanderungszeit. Dort geht sie auf die Abwanderung der Sachsen nach Britannien zurück (BEHRE 1976b, 114 f.; BEHRE u. KUČAN 1986, 99; 1994, 157).

Die Datierung des Bevölkerungsrückgangs am Profil aus dem im Siedlungsgebiet der Langobarden gelegenen Almstorfer Moor paßt zu den spätvölkerwanderungszeitlichen Migrationsbewegungen, wie sie auch im Elb-Weser-Dreieck stattfanden. Eine intensive Wiederbesiedlung setzte in der Umgebung des Almstorfer Moores dem pollenanalytischen Befund zufolge erst im Späten Mittelalter ein. 
3.4.4 Jüngeres Subatlantikum mit Hohem und Spätem Mittelalter und Früher Neuzeit

\subsubsection{Fagus im jüngeren Subatlantikum}

Im Pollendiagramm aus dem Elbaer Moor sind die Fagus-Werte generell sehr niedrig. Ihre Höchstwerte erreicht die Rotbuche mit Werten von $5 \%$ erst im Hohen Mittelalter. Der Pollen stammt von Rotbuchen-Beständen, die auf eng begrenzten Flächen mit hoher Bodengüte im mosaikartig aufgebauten Eichenmischwald auf der Hohen Geest verbreitet waren.

Zwei Profile vom Geestrand zur Elbniederung im Osten Hamburgs bilden ebenfalls nur niedrige Rotbuchen-Werte ab. Dort liegen die Höchstwerte der Rotbuche im Hohen Mittelalter bei $8 \%$ (Profil Börnsen) und bei maximal $15 \%$ (Profil Sternwarte Bergedorf, AVERDIECK 1958). Diese im Vergleich zu anderen Diagrammen niedrigen RotbuchenWerte erklären sich daraus, daß an den Entnahmestellen dieser Pollenprofile ein beträchtlicher Anteil des Polleneintrags aus der Elbniederung eingeweht wurde, wo die Rotbuchen-Ausbreitung wegen des hohen Grundwasserstandes ausgeschlossen ist. Dafür sprechen auch die hohen Erlen-Anteile in den Pollendiagrammen, die auf Polleneintrag aus den Niederungsbereichen zurückzuführen sind. Der Polleneintrag von der Hohen Geest ist in diesen Pollendiagrammen unterrepräsentiert.

Im Profil Almstorfer Moor erreicht die Rotbuche ihre höchsten Werte am Übergang der Römischen Kaiserzeit zur Völkerwanderungszeit (Beginn der PZ IX-4). Einen zweiten Schub erfuhr die Rotbuchen-Ausbreitung in der Umgebung des Almstorfer Moores im Hohen Mittelalter. Jedoch wurde dieser Prozeß durch Rodungen im 13. Jh. n. Chr. abrupt beendet (Kap. 3.4.4.2).

Im norddeutschen Tiefland erreicht die Buchen-Kurve verschiedentlich erst dann ihre Höchstwerte in Pollendiagrammen, wenn die Entwaldung am weitesten vorangeschritten ist. Dieses Ereignis datiert zumeist ins Hohe Mittelalter nach 1000 n. Chr. (z. B. Profil Elbaer Moor, s. o.; Profil Flögelner Holz I, BEHRE u. KUČAN 1994; Profil AP 8 Herrenhof u. Profil AP 6 Rehhornsmoor, DöRFLER 1989). Hier fand eine anthropogene Förderung statt, weil sich die Rotbuche in aufgelichteten Wäldern besser durchsetzen kann als in bereits bestehenden dichten Wäldern, wo die buchengeeigneten Standorte besetzt sind. Die Rotbuche mag auch direkt bevorzugt worden sein, da sie neben der Eiche als Mastbaum für die Schweinehaltung diente (OvERBECK 1975, 497 f.).

Im Vergleich zur Umgebung des Elbaer Moores waren die Rotbuchen-Bestände in den Eichenmischwäldern um das Almstorfer Moor stärker verbreitet (Werte bis $40 \%$ bei Quercus-Werten von 20-40\%). Ein Nährstoffmangel auf den armen Sandböden auf der Hohen Geest beim Elbaer Moor wird einer der Gründe gewesen sein, weshalb ihre Werte dort weit hinter denen der Eiche zurückblieben. Jedoch wurde die Rotbuchen-Ausbreitung mindestens genauso stark von der Konkurrenz im Waldgefüge, dem Wasserhaushalt und dem Menschen bestimmt.

\subsubsection{Hohes und Spätes Mittelalter}

Nach der deutlichen Bevölkerungsausdünnung in der Völkerwanderungszeit wurde mit dem Anwachsen der Bevölkerungszahlen seit dem 7./8. Jh. die Siedlungsdichte in Niedersachsen erhöht (WULF 1991, 328). Der planmäßig durchgeführte innere Landesausbau, der den Franken neue Einflußgebiete verschaffte, setzte im Lüneburger Land erst im 13. Jh. ein (MichAEL 1997, 158). Durch das fränkische Besitzrecht begründet, hatte der König das Verfügungsrecht über alles herrenlose Wald- und Ödland. Die Verleihung oder Schenkung dieser Bezirke einschließlich jeglicher Nutzungsrechte an Grundherren, Bistümer, Klöster und Kirchen, die neue Siedler für diese Flächen anwarben, führte $\mathrm{zu}$ einer steigenden Besiedlungsdichte und einer Ausweitung der Kulturflächen (WULF 1991, 329).

Ins 14./15. Jh. datiert eine Wüstungsperiode, die u. a. durch einen epidemisch bedingten Bevölkerungsrückgang (Pest, Hungertyphus), Fehden im Raum Lüneburg (Erbfolgekrieg, Satekrieg, Prälatenkrieg) und durch Siedlungskonzentration bedingt war (MATTHAEI 1956, 7 f.; OSTEN 1961, 61 f.).

Der Landesausbau des 13. Jh. ist im Pollendiagramm aus dem nördlich von Lüneburg gelegenen Elbaer Moor in der ersten Hälfte der PZ X reflektiert. Zur Ausweitung des Kulturlandes in diesem Gebiet trug die Gründung des Zisterzienserklosters in Scharnebeck bei Rullstorf im 13. Jh. bei (KREMSER 1990, 90; MiCHAEL 1997, 158). Anhand der pollenanalytischen Ergebnisse ist der Anbau von Winterroggen belegt, denn neben hohen Secale-Werten wurde auch das Wintergetreideunkraut Centaurea cyanus nachgewiesen. Der damit verbundene Dauerfeldbau beanspruchte die Böden sehr stark. Um die armen Sandböden mit Nährstoffen anzureichern, wurde die Plaggenwirtschaft eingeführt. Sie bedingte die drastische Ausweitung der Heiden um das Elbaer Moor (s. u.).

Auf diese intensive Siedlungsphase folgte im 14./15. Jh. eine Wüstungsperiode. Im Pollendiagramm Elbaer Moor zeichnet sich ein sehr deutlicher Rückgang bei Calluna und weiteren Siedlungszeigern ab. Tatsächlich kam es im Kreis Lüneburg im 15. Jh. n. Chr. im Vergleich zu vorigen Jahrhunderten zur Aufgabe von $60 \%$ der Höfe. Die Bevölkerungszahlen gingen stark zurück (OSTEN 1961, 57 f.).

Im PD Almstorfer Moor bezieht sich die Interpretation der jüngsten Pollenspektren auf die mit der BP-Summe ohne Alnus berechneten Prozentwerte, um die Überrepräsentanz der nun im Moor wachsenden Erle auszugleichen. Der nach Ausschluß der Erlen-Anteile höhere BP-Faktor (z. B. statt 1/1500 inkl. Alnus jetzt 1/350 exkl. Alnus) führt zu höheren 
Tab. 7. Prozentwerte ausgewählter Pollenkurven des Hohen und Späten Mittelalters und der Frühen Neuzeit im Profil aus dem Almstorfer Moor.

Angegeben sind Prozentwerte der BP-Summe (Grundsumme BP) jeweils in der linken Spalte sowie die Prozentwerte der BP-Summe (Grundsumme BP ohne Erle) jeweils in der rechten Spalte. Die Werte, auf die sich der Text bezieht, sind fett gedruckt.

\begin{tabular}{|c|c|c|c|c|c|c|c|c|c|c|c|c|c|c|c|c|c|c|c|c|c|c|}
\hline \multirow{2}{*}{ 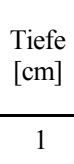 } & \multirow[t]{2}{*}{$\begin{array}{c}\mathrm{PZ} \\
\text { [Firbas] }\end{array}$} & \multirow[t]{2}{*}{ Zeitstufe } & \multicolumn{2}{|c|}{$\begin{array}{l}\text { Kulturpflanzen- } \\
\text { Summe }\end{array}$} & \multicolumn{2}{|c|}{ Triticum-Тyp } & \multicolumn{2}{|c|}{ Hordeum-Тур } & \multicolumn{2}{|c|}{ Secale } & \multicolumn{2}{|c|}{$\begin{array}{c}\text { Sekundäre } \\
\text { Siedlungszeiger (ohne } \\
\text { Calluna u. Poaceae p. p.) }\end{array}$} & \multicolumn{2}{|c|}{ Calluna } & \multicolumn{2}{|c|}{ Poaceae p.p. } & \multicolumn{2}{|c|}{ Fagus } & \multicolumn{2}{|c|}{ Quercus } & \multicolumn{2}{|c|}{ Pteridium } \\
\hline & & & 0,4 & 5,3 & 0,1 & 0,9 & 1,0 & 0,9 & 0,1 & 0,9 & 0,7 & 8,9 & 0,1 & 0,9 & 1,8 & 23,9 & 0,3 & 4,4 & 1,1 & 14,2 & - & - \\
\hline 3 & \multirow{12}{*}{ X } & Neuzeit & 1,9 & 22,7 & - & - & 1,0 & 1,6 & 0,6 & 7,0 & 0,9 & 10,9 & 0,2 & 2,3 & 3,9 & 46,1 & 0,3 & 3,1 & 1,6 & 19,5 & - & - \\
\hline 5 & & & 1,4 & 14,4 & - & - & - & - & 0,7 & 6,9 & 0,7 & 7,5 & - & - & 9,2 & 97,3 & - & - & 1,7 & 18,5 & - & - \\
\hline 7 & & \multirow{10}{*}{ Mittelalter } & 2,2 & 17,0 & - & - & 0,1 & 0,5 & 1,7 & 13,0 & 2,6 & 20,0 & 0,3 & 2,0 & 25,8 & 199,0 & 0,2 & 1,5 & 1,4 & 10,5 & 0,1 & 0,5 \\
\hline 9 & & & 6,3 & 18,2 & - & - & 0,3 & 0,7 & 4,0 & 11,5 & 6,1 & 17,6 & 2,5 & 7,1 & 80,6 & 231,5 & 1,2 & 3,5 & 2,7 & 7,8 & 0,1 & 0,4 \\
\hline 11 & & & 14,7 & 18,5 & 0,2 & 0,2 & 0,6 & 0,7 & 9,7 & 12,3 & 15,8 & 20,0 & 27,9 & 35,1 & 76,9 & 96,9 & 5,1 & 19,0 & 17,0 & 21,4 & 0,6 & 0,7 \\
\hline 13 & & & 7,9 & 10,3 & 0,6 & 0,8 & 0,4 & 0,5 & 5,0 & 6,5 & 9,7 & 12,5 & 47,8 & 61,8 & 29,2 & 37,6 & 15,5 & 20,0 & 19,5 & 25,3 & 0,8 & 1,0 \\
\hline 15 & & & 10,4 & 12,9 & - & - & 0,9 & 1,2 & 6,6 & 8,2 & 11,1 & 13,9 & 44,5 & 55,5 & 24,7 & 30,8 & 18,9 & 23,5 & 18,3 & 22,8 & 1,3 & 1,7 \\
\hline 17 & & & 7,1 & 9,0 & 0,8 & 1,0 & 0,2 & 0,2 & 3,6 & 4,6 & 13,2 & 16,8 & 47,7 & 60,7 & 22,8 & 29,2 & 15,5 & 20,0 & 20,1 & 25,6 & 1,7 & 2,2 \\
\hline 19 & & & 15,5 & 18,7 & - & - & 0,6 & 0,7 & 12,0 & 14,4 & 11,8 & 14,1 & 43,8 & 52,6 & 32,9 & 39,5 & 11,8 & 14,1 & 22,5 & 27,0 & 0,4 & 0,5 \\
\hline 21 & & & 10,4 & 12,5 & - & - & 0,8 & 0,9 & 7,7 & 9,3 & 13,8 & 16,6 & 53,4 & 64,2 & 31,9 & 38,3 & 12,3 & 14,7 & 25,5 & 30,6 & 0,9 & 1,1 \\
\hline 23 & & & 2,3 & 3,0 & 0,2 & 0,3 & 0,2 & 0,3 & 0,8 & 1,0 & 2,7 & 3,5 & 31,0 & 40,1 & 6,2 & 8,0 & 30,8 & 39,9 & 10,1 & 13,0 & 1,0 & 1,3 \\
\hline 25 & & & 2,4 & 3,0 & 0,6 & 0,8 & 0,4 & 0,5 & 0,6 & 0,8 & 3,6 & 4,5 & 10,7 & 13,6 & 5,7 & 7,3 & 21,4 & 27,1 & 16,0 & 20,4 & 0,2 & 0,3 \\
\hline
\end{tabular}


NBP-Werten. Die starke Ausweitung von Weideland und Ackerflächen und das Zurückdrängen der Wälder in der Region wird dadurch betont. In Tab. 7 ist zu erkennen, daß in dem Abschnitt, in dem die Erle als Bestandteil der regionalen Wälder gewertet wird und ihre Anteile daher in die BP-Grundsumme einfließen, die Kurvenverläufe dieselben Tendenzen aufweisen wie die, die unter Ausschluß der Erle aus der BP-Summe berechnet wurden. Die Werte sind nur etwas niedriger. Hingegen weichen die Kurvenverläufe im jüngsten Abschnitt deutlich voneinander $\mathrm{ab}$, da hier der Pollen des lokalen Erlenbestandes den Gesamtpolleneintrag überdeckt. Für die siedlungsgeschichtliche Interpretation müssen in diesem jüngsten Abschnitt unbedingt die unter Ausschluß der Erle berechneten Werte zugrunde gelegt werden.

Von einem Spektrum auf das nächste $(23$ auf $21 \mathrm{~cm}$ Tiefe) vervielfachen sich die Werte des NBP. Die landwirtschaftlichen Nutzflächen wurden stark ausgeweitet. Jedoch schwankt die Intensität der agrarischen Wirtschaftsweise in der Folgezeit. Anhand der RadiokarbonDatierung (20-23 cm Tiefe) auf $700 \pm 45$ BP, kal. 1290 (1279-1377) n. Chr. kann diese Siedlungsphase mit dem planmäßigen Landesausbau im 13. Jh. korreliert werden (MiCHAEL 1997, 158). Besonders intensiv wurde Roggen angebaut. Dieses führte auch hier eine starke Heideausweitung herbei (s. u.). Der Anstieg der EichenWerte und die gleichzeitig leicht erhöhten Werte vom Adlerfarn zeigen, daß Waldweide betrieben wurde. Hudewälder, in denen Eichen als Mastbäume freigestellt wurden, nahmen große Flächen ein. Der Unterwuchs dieser Wälder wurde vom Vieh verbissen, weshalb eine Regeneration nicht stattfand. Der giftige Adlerfarn wurde vom Vieh gemieden. Da er sich sehr effektiv vegetativ vermehrt, konnte er sich vermutlich massenhaft in den lichten Hudewäldern ausbreiten. Auch heute gilt der Adlerfarn als Störungszeiger in den Wäldern (PоTT 1988, 33).

Eine Wüstungsphase ist in diesem Pollendiagramm kaum zu erkennen, wenn im oberen Abschnitt der Erlenpollen aus der BP-Grundsumme ausgenommen wird. Nach historischen Quellen war das Ausmaß des Bevölkerungsrückgangs und der Siedlungskonzentration im Ldkr. Uelzen weitaus geringer als im Ldkr. Lüneburg. So wurden lediglich $25 \%$ der Höfe des Jahres 1300 in der Folgezeit aufgegeben (OSTEN 1965, 185 f.). Das Pollendiagramm bestätigt, daß die Siedlungsdichte in der Umgebung des Almstorfer Moores zu Beginn der Frühen Neuzeit vorübergehend nur leicht abnahm.

An dieser Stelle soll auf die im Vergleich zu anderen Diagrammen (z. B. PD Swienskuhle, BEHRE u. KUČAN 1994) relativ niedrigen mittelalterlichen Roggen-Werte sowohl im Pollendiagramm aus dem Elbaer Moor (höchstens $3 \%$ ) als auch in dem aus dem Almstorfer Moor (höchstens $12 \%$ ) hingewiesen werden. Die Entfernung der Pollenprofile zu Siedlungen und Ackerflächen spielt für die Repräsentanz des Getreide-Pollens in den Diagrammen eine sehr wichtige Rolle. Secale-Pollen, der gemeinhin als weit verwehbar eingestuft wird, schlägt sich erstaunlicherweise zum größten Teil schon im Acker nieder. Schon bei einer Distanz eines Secale-Feldes zur Entnahmestelle eines Pollenprofils in einem offenen Hochmoor von nur $1,5 \mathrm{~km}$ zeichnet sich der Roggenanbau lediglich mit Werten von $2 \%$ im Pollendiagramm ab (BEHRE u. KUČAN 1986, 109 f.). Daraus erschließt sich für die hier untersuchten Pollenprofile, daß die Ackerflächen vermutlich nie direkt an eines der Moore angrenzten.

\subsubsection{Heide-Entwicklung, intensiver Roggenanbau und Lüneburger Saline}

Sollen pollenanalytische Daten für die Rekonstruktion der Geschichte der Heiden interpretiert werden, muß zunächst ausgeschlossen werden, daß der Calluna-Pollen das Produkt der mooreigenen Vegetation ist. Eine Heidebildung in der Moorumgebung kann dann postuliert werden, wenn sich im Pollendiagramm ein gleichzeitiger Kurvenanstieg bei Calluna und bei weiteren Siedlungszeigern abzeichnet und die Glührestwerte sowie die Zahl der Holzkohleflitter erhöht sind (HüPPE 1993, 58).

Für die Umgebung des Elbaer Moores können nach den pollenanalytischen Indizien zwei Etappen der Heideausbreitung ausgewiesen werden: Der starke Anstieg der Besenheide-Werte zu Beginn des Subatlantikums geht vermutlich auf Rodungen und eine starke Beweidung am Übergang der Bronzezeit zur Vorrömischen Eisenzeit zurück. Dies trieb die Degradation der Böden voran und begünstigte die Ausbildung von Calluna-Heiden. Der zweite Schub der Heideausbreitung um das Elbaer Moor steht mit der mittelalterlichen Intensivierung des Roggenanbaus in Zusammenhang (erhöhte Secale-Werte in PZX). Wie Pollenkörner von Centaurea cyanus im Profil aus dem Elbaer Moor belegen (21-5 cm Tiefe), wurde der Roggen als Wintergetreide angebaut. Die Wechselfeldwirtschaft wurde vermutlich aufgegeben. Brachezeiten, in denen sich die Böden wieder erholen konnten, wurden dadurch auf die Monate zwischen der Ernte und der Aussaat des Wintergetreides verkürzt. Dieser „ewige“ Roggenbau führte $\mathrm{zu}$ einer fortschreitenden Verarmung der ohnehin schon armen Sandböden. Ein besonders großer Nährstoffentzug ergab sich dadurch, daß der langhalmige Roggen bodennah geerntet wurde und neben dem Korn auch das Stroh genutzt wurde. Damit wurde eine Düngung der Ackerflächen notwendig.

Mineralischer Kunstdünger steht erst seit dem 19. Jh. zur Verfügung. In prähistorischer und historischer Zeit wurde kalkreicher Mergel als Dünger eingesetzt, sofern er zur Verfügung stand. Wichtiger aber war eine spezielle Form des Ackerbaus, die Plaggenwirtschaft: Als Plaggen oder Erdsoden wurde der fruchtbare Oberboden im Wald und in der Heide abgetragen. Die Plaggen wurden mit Stallmist vermischt oder kompostiert und schließlich als Dünger auf die Felder gebracht (BEHRE 1976a; 2000). Plaggenentnahmestellen, an denen sich Heideflächen ausweiteten, lagen vermutlich um das Elbaer Moor. An 
diesen Plaggenentnahmestellen faßte der Wind in den frisch aufgerissenen Boden und nahm Sand und Staub auf, der schließlich ins Elbaer Moor eingeweht wurde (erhöhte Glührestwerte im PD Elbaer Moor). PYRITZ (1972, 81 f.) beschreibt für West-Niedersachsen, wie solcher Sand als Flugsand und Dünen auf Kulturland und Siedlungen abgelagert wurde. Die Regeneration der offenen Heideflächen dauerte bei zunehmender Nutzung bis zu 20 Jahre (BEHRE 1976a, 216; HÜPPE 1993, 66). Dies zeigt, daß immer neue Flächen abgeplaggt werden mußten, um den hohen Bedarf an Dünger decken zu können. Daher führte diese Wirtschaftsweise zu einer starken Ausbreitung der Heiden.

Die Indizien im PD Almstorfer Moor sprechen ebenfalls für die Plaggenwirtschaft als Ursache der Heideausbreitung. Hier ist die Heide-Entwicklung an den intensiven Landesausbau im 13. Jh. gekoppelt. Vermutlich wurde das Kulturland im Zuge des Landesausbaus von den günstigen Geschiebelehmböden auf die armen Sandböden ausgeweitet, so daß auch in der Umgebung des Almstorfer Moores mit Plaggen gedüngt werden mußte. Hier werden die neuen Siedler die Plaggenwirtschaft eingeführt haben (vgl. BEHRE 1980, 33). Nach historischen Quellen wurde eine intensive Plaggenwirtschaft in der südöstlichen Lüneburger Heide mindestens seit dem 16. Jh. betrieben (DELFS 2000).

Weiteren Einfluß auf die Heideausbreitung kann die Rodung der Rotbuche und der Hainbuche gehabt haben, obwohl diese nicht zwangsläufig zur Ausweitung der Heiden führen muß. Zu Beginn der PZ X gehen die Fagusund die Carpinus-Werte im Pollendiagramm Almstorfer Moor zurück. Eventuell stehen die selektiven Rodungen hier mit dem großen Holzbedarf der urkundlich erstmals 956 n. Chr. erwähnten Lüneburger Saline in Zusammenhang. Besonders die Rotbuche war eine für die Salzherstellung bevorzugte Art, mit der angeblich ein leichtes und gleichförmiges Salz erzielt werden konnte (LAMSCHUS 1993, 323 f.).

Bis zu Beginn des 14. Jh. wurde der Holzbedarf der Saline noch aus der Umgebung Lüneburgs gedeckt, erst im 15. Jh. waren die Holzvorräte endgültig erschöpft. Daher wurde das Brennholz im 16. und 17. Jh. in Mecklenburg geschlagen (LAMSCHUS 1993, 322 f.). Bereits im 14. Jh. gelang es den Lüneburger Bürgern, sich die Wälder des Uelzener Beckens für Rodungen zu erschließen. Die nach historischen Quellen noch im 14. Jh. in der Mulde an der oberen Ilmenau bzw. im Uelzener Becken stockenden größeren Laubwaldbestände konnten jedoch erst gerodet und das Holz über die Ilmenau nach Lüneburg geflößt werden, nachdem die Lüneburger die Schiffbarkeit der Ilmenau sichergestellt hatten. Schon gegen Ende des 15. Jh. mußten die Holzungen dort mangels Jungwuchs wieder eingestellt werden (MAKOWSKI 1983, 12 f.). Das Pollendiagramm aus dem Almstorfer Moor bestätigt, daß nach 1300 besonders die Buchen in den Wäldern des Bevenser Teils des Uelzener Beckens eingeschlagen wurden. So stehen die Ergebnisse der Pollenanalysen mit den historischen Quellen in Einklang.
$\mathrm{Da}$ die mittelalterliche Ausbreitung von CallunaHeiden im Raum Lüneburg vornehmlich durch die Plaggenwirtschaft ausgelöst wurde, kann besonders aus dem PD Elbaer Moor abgelesen werden. Beweidung und Rodungen verstärkten die Degradation der Böden und begünstigten die Ausweitung der Heideflächen. Zudem konnte mittels vegetationsgeschichtlicher Untersuchungen gezeigt werden, daß seit dem Neolithikum unter menschlichem Einfluß lokale Heiden aus Waldlandschaften heraus entstanden und bei Aufgabe der ringsum liegenden Siedlungen wieder verschwanden (BEHRE u. KUČAN 1994, 97; BEHRE 2000, 107 f.). Auch in der zentralen Lüneburger Heide stellte BECKER (1995, 85 f.) mehrere Zyklen von Heideausweitung, Wiederbewaldung und erneuter Verheidung im Profil aus dem Moor bei Undeloh fest. Die meisten Heiden sind als anthropozoogene Ersatzgesellschaften zu klassifizieren, die sich nach Aufgabe der Bewirtschaftung wieder bewalden. Natürliche Heidestandorte gibt es hingegen nur sehr wenige. Als stabile natürliche Vegetation kommen Heiden beispielsweise als schmaler Gürtel auf sandhaltigen Böden im Übergangsbereich von Moorrändern zum Wald oder auf Bulten und an Randgehängen der Moore vor (HÜPPE 1993, $53 \mathrm{f}$.).

\subsubsection{Rullstorfer Osterteich und Lüneburger Landwehr}

Stratigraphie und pollenanalytische Ergebnisse zeigen, daß es im Pollendiagramm Rullstorfer Osterteich eine Schichtlücke gibt. In einer Tiefe von $36 \mathrm{~cm}$ erfolgt ein scharfer Sedimentwechsel von einem Erlenbruchtorf $\mathrm{zu}$ einem $2 \mathrm{~cm}$ mächtigen, schwach zersetzten Seggentorf, der von einem jüngeren, stark zersetzten Seggentorf abgelöst wird. Die im Pollendiagramm nachgezeichnete, für Nordwestdeutschland typische Waldentwicklung bricht hier spätestens am Übergang Atlantikum/Subboreal (5150 BP) ab. Danach setzen unvermittelt die Kulturpflanzen-Kurven ein. Offensichtlich fehlen in diesem Pollenprofil die Sedimente aus dem Subboreal und dem älteren Teil des Subatlantikums. In der Tiefe von $36 \mathrm{~cm}$ liegt hier also ein Hiatus vor. Im folgenden soll der Beginn der Bildung der jüngeren Torfe eingegrenzt werden.

Unter den Getreiden ist Roggen relativ häufig. Das Auftreten der typischen Wintergetreideunkräuter Kornblume und Spörgel zeigt, daß Roggen offenbar schon als Wintergetreide kultiviert wurde. Nach BEHRE (1992, 150; 1976a, 206 f.) ist mit dem Anbau von Winterroggen seit dem Hohen Mittelalter zu rechnen.

Buchweizen wurde beim kontinuierlichen Roggenanbau gern als Zwischenfrucht verwendet. Aus dem ausgehenden 14. Jh. stammt die älteste schriftliche Quelle, die den Buchweizenanbau in Nordostniedersachsen erwähnt (LOSERT 1953, 139). Archäobotanische Nachweise aus dem Rheinland datieren ins Späte Mittelalter, und in den Niederlanden sind Buchweizenfrüchte im Fundspektrum seit dem 13. Jh. vertreten (KÖRBER-GROHNE 1994, $343 \mathrm{f}$. und dort zitierte Autoren). Im Elb-Weser-Dreieck wurde der 


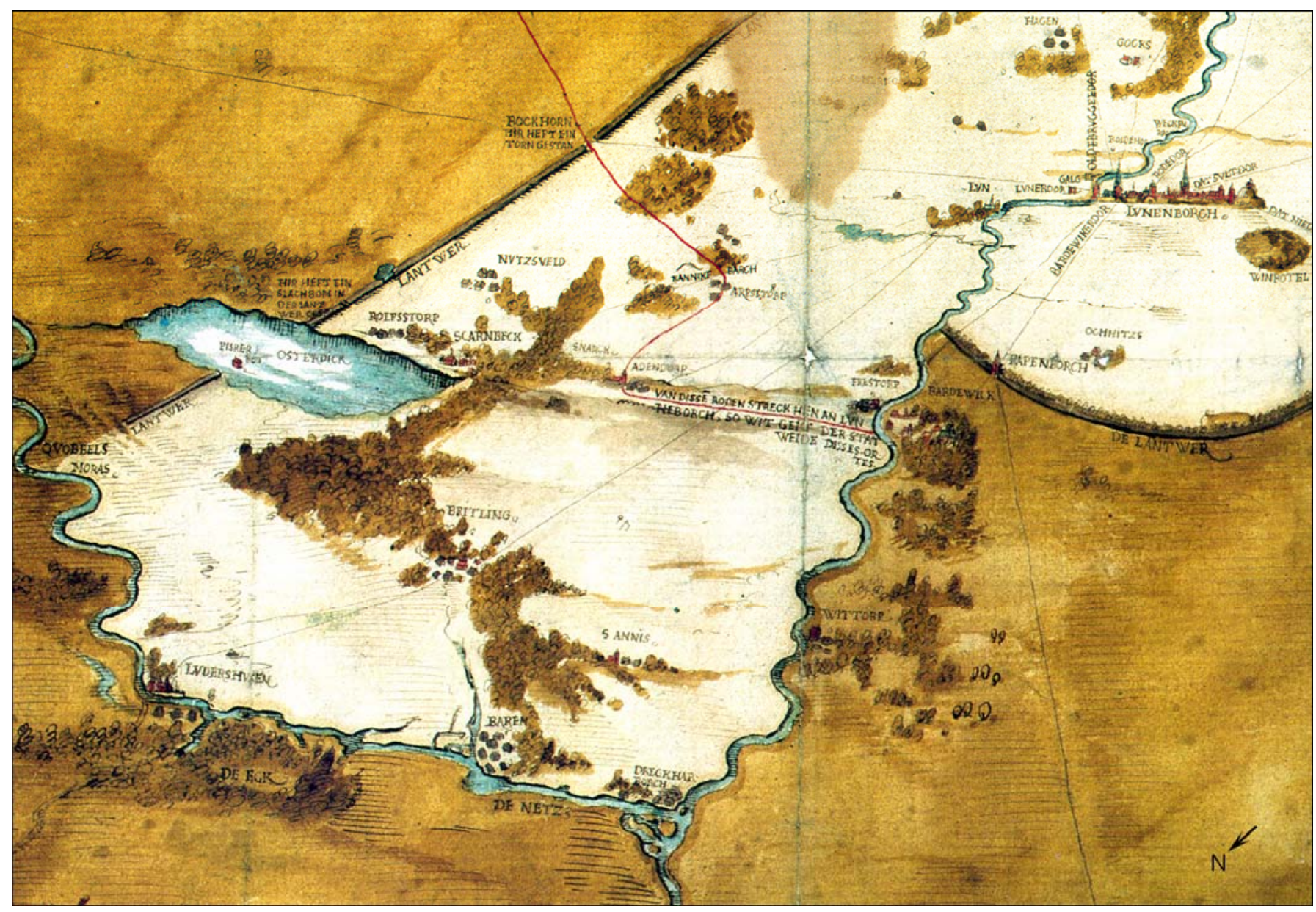

Abb. 14. Ausschnitt aus dem „Abriß der Landwehren um Lüneburg“ von Daniel Freese (1576).

Das Moor Rullstorfer Osterteich ist hier noch als Gewässer abgebildet (o. M.).

Buchweizen schon für das 12. Jh. nachgewiesen (BEHRE u. KUČAN 1994, 160). Da der Buchweizen im PD Rullstorfer Osterteich in drei aufeinanderfolgenden Spektren auftritt, fällt der Beginn des Seggentorfwachstums also dem pollenanalytischen Befund zufolge in das Späte Mittelalter. Die Datierung wird zudem dadurch bestätigt, daß die Zahl der nachgewiesenen NBP-Taxa (Abb. 9. Tab. 29) von den atlantischen Ablagerungen mit 28 Taxa auf nunmehr 49 Taxa in dem jüngeren Seggentorf steigt. Dieses Ereignis ist in Übereinstimmung mit WILLERDING $(1986,319)$ ins Mittelalter zu datieren, da das Unkrautspektrum in Mitteleuropa im Mittelalter wegen Umstrukturierungen in der Landwirtschaft stark erweitert ist. Im PD Rullstorfer Osterteich betrifft die Erweiterung des NBP-Spektrums besonders die Kulturpflanzen und die sekundären Siedlungszeiger. Der Hiatus beginnt demnach also spätestens zu Beginn des Subboreals und endet im Späten Mittelalter, also im Verlauf der PZ X nach Firbas.

Auf historischem Weg kann das Ende der Schichtlücke genauer eingegrenzt werden. Eine mögliche Erklärung und einen Hinweis zur Datierung liefert eine historische Karte aus dem Jahr 1576 (LEERHOFF 1985, 123). Der Maler und Kartograph Daniel Freese (1540-1611) erhielt im Zuge von Rechtsstreitigkeiten zwischen den Landesherren und der Stadt Lüneburg den Auftrag, einen „Abriß der Landwehren um Lüneburg“ (Abb. 14) zu erstellen. Dort, wo der Rullstorfer Osterteich und das Osterbruch zu erwarten wären, ist auf dieser - nicht eingenordeten, sondern nach Südosten ausgerichteten - Karte ein Teich mit der Bezeichnung „Osterdick“ abgebildet. Es soll nun die Vorstellung begründet werden, daß die Bohrungen für die pollenanalytischen Untersuchungen im Randbereich dieses von Freese kartierten Fischteiches „Osterdick“ durchgeführt wurden und daß die im Bohrkern auftretende Schichtlücke durch die Anlage des Teiches zu erklären ist.

Zunächst soll die Übereinstimmung der Örtlichkeiten geklärt werden: Gewiß kann die historische Karte heutigen Genauigkeitsansprüchen nicht genügen, zeigt sich doch im Vergleich mit aktuellen Karten beispielsweise, daß die Neetze einen etwas anderen Verlauf als im 20. Jh. hat. Das kann, muß aber keineswegs der damaligen Realität entsprechen. Die Erfahrung von ENGEL $(1978,26)$ zeigt, daß unwegsames Gelände wie eine feuchte Niederung häufig nur in Umrissen aufgenommen und Bachläufe oft recht willkürlich eingezeichnet wurden. Da aber der Ort Rullstorf in der Karte als „Rolfsdorp“ verzeichnet ist und die Flurstücke Osterteich und Osterbruch dem Ort nördlich vorgelagert sind, muß der nördlich vor „Rolfsdorp“ liegende „Osterdick“ den beiden Flurstücken entsprechen. 
Die Entstehung der Schichtlücke und ihre Datierung sollen im folgenden diskutiert werden. Der Fischteich „Osterdick“ ist der historischen Karte zufolge Bestandteil der Lüneburger Landwehr. Bei Landwehren handelt es sich meist um Wallanlagen mit Graben, die mit einer dichten Hecke bepflanzt sind. Die Lüneburger Landwehr, deren östlicher Abschnitt in den Jahren 1479-1484 angelegt wurde, wies in schwer passierbarem Gelände wie etwa in Sümpfen und an Bach- und Flußläufen Lücken auf. Der Fischteich „Osterdick“ wurde offenbar an einer solchen Stelle aufgestaut. Nach einer alten Akte über die „Streitigmachung der Stadt Landwehren jenseits der Ilmenau“ ist der nun als „Osterdeich“ bezeichnete Fischteich „nach Verfertigung der Landwehr erst gemachet und gestauet worden “ (MIDDELHAVE 1950, 17 f.). Daß nun sowohl das Machen als auch das Aufstauen des Teiches in dieser Akte erwähnt sind, dürfte dahingehend zu interpretieren sein, daß vor dem Aufstauen im Bereich des Teiches Erdarbeiten vorgenommen wurden. Für den Ausbau der Wallanlagen der Landwehr bestand Bedarf an Bodenaushub. Das Erdreich wurde nicht über weite Strecken transportiert, sondern vor Ort, also wahrscheinlich im Bereich des Osterteiches und des Osterbruchs, entnommen. Da der Osterteich ausweislich der oben zitierten Akte nach der Fertigstellung der Landwehr im Jahr 1484 angelegt wurde, kann dieser Interpretation zufolge das Jahr 1484 als terminus post quem für die Entstehung des Teiches „Osterdick“ wie auch für das Einsetzen des schmalen Bandes schwach zersetzten Seggentorfes und des jüngeren, stark zersetzten Seggentorfes im Pollenprofil gelten. Für die hier vorgebrachte Hypothese mag auch der Umstand sprechen, daß die erwähnten historischen Anhaltspunkte geeignet sind, die pollenanalytische Datierung für das Endes des Hiatus ins Späte Mittelalter zu bestätigen.

Auch das Kartenblatt 21 „Daß Amt Lühne undt Scharnebeck" des vor 1599 erstellten Ämteratlas des Fürstentums Lüneburg von MELLINGER (2001) belegt, daß bei Rullstorf im 16. Jh. ein größerer Teich existierte.

Aus dem Kartenblatt Scharnebeck der Kurhannoverschen Landesaufnahme (ENGEL 1978, 17 f.) kann die weitere Entwicklung des Osterteiches abgelesen werden. Nördlich von Rullstorf, d. h. im Gebiet des mittelalterlichen Osterteiches, ist ein Bruchwald kartiert und mit der Flurbezeichnung „Oster-Bruch“ versehen (Abb. 15).

Demzufolge muß der Osterteich innerhalb vor knapp 300 Jahren soweit verlandet gewesen sein, daß sich ein Bruchwald entwickeln konnte. Stratigraphisch sind oberhalb des Hiatus keine Seeablagerungen nachgewiesen, sondern nur ein schmales Band schwach zersetzten Seggentorfes mit Menyanthes und Drepanocladus, welches aus dem Randbereich des Teiches stammt. Auf den jüngeren Seggentorf folgt dann zwar kein Bruchwaldtorf, wie es nach der Kartierung des Bruchwaldes auf dem Kartenblatt Scharnebeck $\mathrm{zu}$ erwarten wäre. Dennoch weist das PD Rullstorfer Osterteich durchaus darauf hin, daß ein
Erlenbruch bestand, steigen doch die Erlen-Anteile zum jüngsten Spektrum hin an.

\subsubsection{Frühe Neuzeit}

Im 15./16. Jh. ist die Umstellung der Forstverfassung landschaftsgeschichtlich bedeutend. Während im Mittelalter durch Könige, Herrschaften und Genossenschaften Rodungsbeschränkungen auferlegt wurden, regelten in der Neuzeit die landesherrlichen Forstverfassungen die Bewirtschaftung der Wälder. Dadurch wurde die wilde Plenterwirtschaft, d. h. die Entnahme von Einzelstämmen und Gruppen von Stämmen ohne Rücksicht auf den Erhalt des Waldbestandes, von der geregelten Schlagwirtschaft abgelöst (MANTEL 1990, 328 f.).

Der 30jährige Krieg (1618-1648) hatte nur geringe Auswirkung auf den Waldflächenanteil. Er bewirkte einen Bevölkerungsrückgang, weshalb in seiner Folge der Bedarf an Feldern und Feldprodukten abnahm. Zerstörungen der Waldbestände im unmittelbaren Kriegsgebiet wurden teilweise durch diesen Bevölkerungsrückgang aufgefangen, wodurch dort eine Erholung einiger Waldbestände gesichert war (MANTEL 1990, 65 f.).

Im PD Elbaer Moor zeichnet sich ab, daß die Siedlungsdichte im Vergleich mit der vorangegangenen Wüstungsperiode in der Frühen Neuzeit (7-1 cm Tiefe) wieder leicht anstieg (erhöhte Siedlungszeiger-Werte). Auch die Heiden breiteten sich erneut aus (erhöhte CallunaWerte).

Die erhöhte Holzkohleflitter-Konzentration in $5 \mathrm{~cm}$ Tiefe ist eventuell auf die Auswirkungen des 30jährigen Krieges zurückzuführen, von dem die Umgebung Lüneburgs unmittelbar betroffen war. Es finden sich jedoch keine weiteren Hinweise auf den 30jährigen Krieg im Pollendiagramm. REINSTORF (1929, 111) hatte zwar eine starke Schädigung der Wälder postuliert, diese Aussage ist jedoch umstritten. So betont KREMSER (1990, 65), daß der Krieg nur geringe Auswirkungen auf den Waldbestand hatte, wie es sich auch im Pollendiagramm aus dem Elbaer Moor abzeichnet.

Die Kurhannoversche Landesaufnahme (Abb. 15) zeigt, daß die Waldverwüstung ihr größtes Ausmaß schließlich im 18. Jh. erreichte. Seit Mitte des 18. Jh. fanden im Lüneburger Raum Aufforstungen von Heideflächen in großem Maßstab statt. Die Aussaat von Buche und Eiche wurde angestrebt, jedoch wurde der größte Teil der Flächen mit Kiefern aufgeforstet (KREMSER 1990, 355). Aufforstungsmaßnahmen des 18. Jh. und jüngerer Zeit sind im PD Elbaer Moor aber nicht erfaßt.

Der frühneuzeitliche Abschnitt im PD Almstorfer Moor (5-1 cm Tiefe) setzt verglichen mit dem vorangehenden Abschnitt mit niedrigen Siedlungszeiger-Werten ein (Tab. 7). Danach werden höhere Werte erreicht, und im jüngsten Spektrum sinken die Kurven wieder ab. 


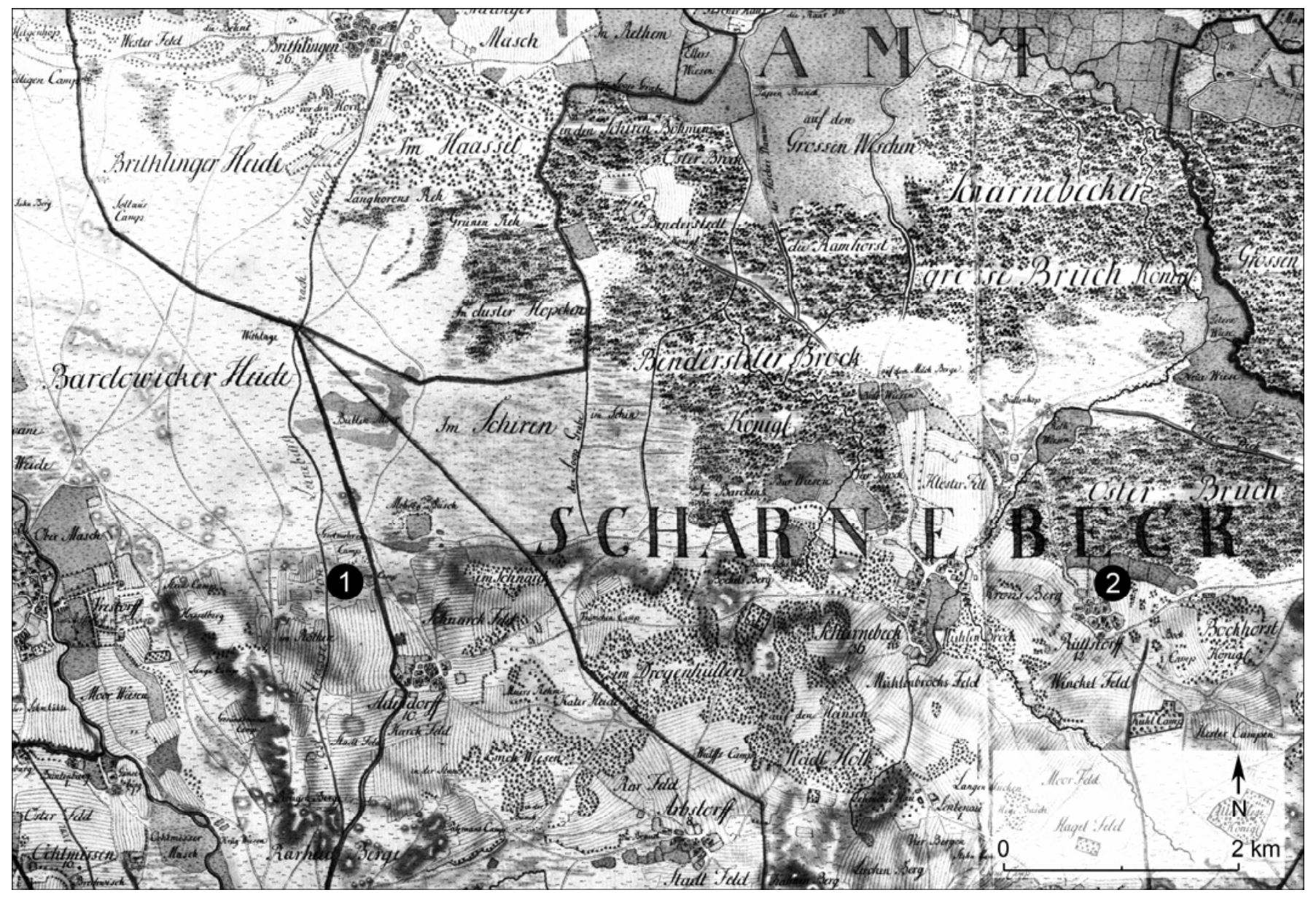

Abb. 15. Ausschnitt aus Blatt 68 Scharnebeck der Kurhannoverschen Landesaufnahme (1776). 1 Elbaer Moor - 2 Rullstorfer Osterteich.

Möglicherweise sind die zu Beginn niedrigen Siedlungszeiger-Werte noch ein Nachwirken der schwach ausgeprägten spätmittelalterlichen Wüstungsperiode im Ldkr. Uelzen. Für die Umgebung des Almstorfer Moores zeichnet sich eine Wiederbewaldung der Heiden mit der Kiefer ab (niedrige Calluna-Werte, steigende Pinus-Werte, sinkende Poaceae-Werte). Etwas häufiger kamen arme Birken-Eichenwälder vor. Buchen standen nur noch sehr wenige in den Wäldern. Weiterhin ist der Anbau von Getreide (vor allem Secale und Hordeum-Typ) belegt. Die Zeit der Anlage von Nadelholzforsten (18./19. Jh.) ist möglicherweise noch im jüngsten Spektrum dieses Pollendiagramms abgebildet (erhöhte Werte bei Pinus und Picea). Hier sind die Siedlungszeiger-Werte rückläufig.
Im Zuge der Flurbereinigung wurden im 19. Jh. die Heiden verkoppelt. Sie wurden zum Teil aufgeforstet, jedoch auch in Äcker und Weiden überführt, deren arme Böden nun mit Kunstdünger angereichert werden konnten. Hinter der Aufforstung der Heiden standen wiederum die wirtschaftlichen Interessen des Menschen, der einen großen Bedarf an schnellwüchsigem Holz hatte. Zudem spielte die Festlegung der Böden durch die Anlage der Forste eine wichtige Rolle, da regelrechte Sandstürme $\mathrm{zu}$ einem Problem der Bauern und Siedler geworden waren (PYRITZ 1972, 80 f.). 


\section{Früchte und Samen aus den Ausgrabungen bei Rullstorf}

\subsection{Archäologische Befunde}

Das Ausgrabungsgelände Kronsberg bei Rullstorf liegt wenige Kilometer nordöstlich von Lüneburg. Der Kronsberg selbst befindet sich zwischen Scharnebeck und Rullstorf auf der Hohen Geest unmittelbar am Rand zur nördlich anschließenden Niederterrasse des Elbe-Urstromtales (TK 25, Blatt 2729 Scharnebeck, r 4401 400, h 5907 600). Der Kronsberg ist eine eiszeitliche Bildung aus Sanden, Kies und Lehm. Ursprünglich war sie $800 \mathrm{~m}$ lang und $200 \mathrm{~m}$ breit, der höchste Punkt der Kuppe lag bei 27 m NN. Im Westen und Südwesten des Kronsberges ist der Sauerbach in die Geest eingeschnitten.

In den siebziger Jahren wurde der Kronsberg teilweise zum Bodenabbau freigegeben. 1979 wurden beim Sandabbau die ersten archäologischen Befunde aufgedeckt, woraufhin von der Bezirksarchäologie Lüneburg eine Notgrabung durchgeführt wurde. Aufgrund der umfangreichen, vielversprechenden Befunde und Funde wird die Grabungstätigkeit seit 1980 vom Niedersächsischen Landesamt für Denkmalpflege, Hannover, unter der Leitung von W. Gebers systematisch fortgesetzt (GARBERS 1990; GEBERS 1985a-d; 1986a-b; 1995; GEBERS u. LÜTH 1984; 1996; HORNIG 1993; LAUXTERMANN 2001a-b; STARK 1996).

Das Areal Kronsberg hat aufgrund seiner Lage am unmittelbaren Südrand des Elbe-Urstromtals und aufgrund seiner Begrenzung im Westen und Süden durch den Sauerbach einen nahezu inselförmigen Charakter. Der aus topographischen Gründen günstig erscheinende Siedlungsplatz wurde im Laufe der Zeit wiederholt aufgesucht. Früheste Nachweise der Siedeltätigkeit reichen bis zur neolithischen Trichterbecherkultur zurück. Das Areal dieser Siedlung liegt im Randbereich des zum Bodenabbau freigegebenen Geländes und wurde bei den bisherigen Grabungskampagnen nur angeschnitten. Im Westen des Kronsberges konnte ein Urnengräberfeld der jüngeren Bronzezeit mit 130 Grabanlagen vollständig aufgedeckt werden. Es gehört zu einem bronzezeitlichen Siedlungshorizont, der sich vor allem durch die Anlage von kreisrunden Erdspeichern auszeichnet. Aus der älteren Vorrömischen Eisenzeit ist ein anhand der Keramik ins 6.2. Jh. v. Chr. datierter Wirtschaftsbereich mit Vorratsgruben und Darröfen belegt. Zu einem ähnlichen Wirtschaftsbereich aus dem 1. Jh. v. Chr. gehört ein dreischiffiges Hallenhaus. Ein Urnengräberfeld aus der Vorrömischen Eisenzeit repräsentiert vermutlich die Bevölkerung nur eines der eisenzeitlichen Gehöfte. Deutlich zeichneten sich die Pfostenlöcher der kaiser- bis völkerwanderungszeitlichen Langhäuser sowie Herdstellen der Eisenverhüttung in der Grabungsfläche ab. In der Römischen Kaiserzeit wurden die Vorratsgruben der Vorrömischen Eisenzeit von kleineren oberirdischen Speicherbauten abgelöst, subfossile Pflanzenreste aus diesen Speichern sind jedoch nicht erhalten. Jüngster archäologischer Befund in Rullstorf ist ein spätsächsisches Gräberfeld aus dem 6./7. Jh. Der Befund erweckt den Eindruck eines von Adelsgräbern dominierten, durch Mitbestattung der Jagdmeute (darunter 6 geschirrte Hunde und ein geschirrter Lockhirsch) geprägten Friedhofs (GEBERS 1995, 59).

\subsection{Material und Methoden \\ der archäobotanischen Untersuchungen}

Von den großen Mengen pflanzlichen Materials wie Holz, Nahrungsmittel und Stroh, die in einer Siedlung anfallen, erhalten sich nur sehr wenige Reste über mehrere Jahrtausende. In gut durchlüfteten Sandböden mit niedrigem Grundwasserstand, wie sie in der Altmoränenlandschaft bei Rullstorf vorkommen, wird unverkohltes organisches Material rasch abgebaut. In der Regel bleibt höchstens eine dunkle Verfärbung im Boden zurück, die keine Gattungsoder gar Artbestimmung eines organischen Restes zuläßt. Hingegen sind verkohlte Pflanzenreste unter den oben angeführten Bedingungen erhaltungsfähig und bestimmbar.

\subsubsection{Material}

Die Pflanzenreste aus Rullstorf verkohlten bei Bränden in den prähistorischen Siedlungen und in Scheiterhaufen eines Gräberfeldes (GEBERS 1986, 85 f.). Teilweise lagerten sie weit genug vom eigentlichen Brandherd entfernt und konnten deshalb, anstatt vollständig $\mathrm{zu}$ veraschen, verkohlen. Außerdem wurden Pflanzenreste unter Sauerstoffabschluß verkohlt. Das nachweisbare Pflanzenspektrum ist begrenzt und vermittelt einen selektiven Einblick in das Spektrum der in prähistorischer Zeit verwendeten Arten. Einerseits haben die Pflanzenreste unterschiedliche Chancen, zur Verkohlung zu gelangen (WILlERDING 1991, 43 f;; Willerding u. HiLleBRECHT 1994, $140 \mathrm{f}$.), andererseits unterliegen die von Menschenhand in die Siedlungen und Gräberfeld eingebrachten Reste einer gewissen Vorauswahl.

Die Rullstorfer subfossilen Reste stammen aus Erdsilos und Darröfen in den Siedlungsarealen und aus Pfostenlöchern der Scheiterhaufen auf dem sächsischen Gräberfeld.

Aus der Fundstelle 5 der Grabung Rullstorf, die Siedlungsbefunde aus der jüngeren Bronzezeit sowie der Vorrömischen Eisenzeit und der Römischen Kaiserzeit umfaßt, wurden 62 Bodenproben mit einem Gesamtgewicht von mehr als $600 \mathrm{~kg}$ zur archäobotanischen Bearbeitung sichergestellt. Darüber hinaus waren 58 Proben bereits auf der Grabung geschlämmt und mit 6 weiteren, ungeschlämmten Proben nach Wilhelmshaven an das Niedersächsische Institut für historische Küstenforschung weitergeleitet worden.

Aus dem Bereich des sächsischen Gräberfeldes (Fundstelle 8) auf dem Kronsberg bei Rullstorf, wurden 
Tab. 8. Ergebnisse der Radiokarbon-Datierungen an verkohltem Getreide aus Rullstorf mit einfacher Standardabweichung.

\begin{tabular}{|c|c|c|c|c|}
\hline Befund & datiertes Material & $\begin{array}{l}{ }^{14} \mathrm{C} \text {-Alter } \\
{[\mathrm{BP}]}\end{array}$ & $\begin{array}{c}\text { ermitteltes }{ }^{14} \mathrm{C} \text {-Alter } \\
{[\text { kal. BP }]}\end{array}$ & $\begin{array}{l}\text { ermitteltes }{ }^{14} \mathrm{C} \text {-Alter } \\
\text { [kal. v. Chr.] }\end{array}$ \\
\hline 6273 & $\begin{array}{l}\text { ca. } 6,0 \mathrm{~g} \text { entspelzte Gersten- } \\
\text { und Emmerkörner }\end{array}$ & $\begin{array}{c}2880 \pm 30 \\
\text { (konventionell) }\end{array}$ & $2979(3075-2950)$ & $1030(1126-1001)$ \\
\hline 9519:2 & ca. $0,5 \mathrm{~g}$ entspelzte Hirsekörner & $\begin{array}{l}2963 \pm 29 \\
(\mathrm{AMS})\end{array}$ & $3125(3208-3076)$ & $1176(1259-1127)$ \\
\hline
\end{tabular}

Proben aus den Pfostenlöchern der Scheiterhaufen für archäobotanische Untersuchungen entnommen. Zunächst wurden 50 Proben untersucht, von denen aber 39 fundleer waren. Die Durchsicht 54 weiterer, auf der Grabung vorgeschlämmter Proben ergab leider nur eine Vielzahl kleinster Holzkohlefragmente, die nicht zur Auswertung herangezogen wurden. Zehn eigenhändig flotierte Proben änderten dieses Bild nur unwesentlich. Einige der Proben enthielten wenige Kultur- und Sammelpflanzenreste. Die erhofften zahlreichen Funde von Nahrungspflanzen blieben aus.

Aus der Fundstelle 9 wurden zahlreiche Urnen der Vorrömischen Eisenzeit sichergestellt. 16 Proben aus den Urnenfüllungen wurden auf botanische Reste durchgesehen. Sie enthielten jedoch nur rezente Samen vom Gänsefuß (Chenopodium sp.) sowie rezente Blütenkelche vom Knäuel (Scleranthus sp).

Aus zwei weiteren Befunden konnte außerdem Keramik und Hüttenlehm mit Pflanzenabdrücken geborgen und zusammen mit einem schon am Niedersächsischen Landesamt für Denkmalpflege, Hannover, präparierten Silikonkautschukabguß zur weiteren Bearbeitung nach Wilhelmshaven geschickt werden. Die Pflanzenabdrücke stammen zum einen von Pflanzenresten, die dem Hüttenlehm zur Magerung beigefügt wurden. Zum anderen wurde Keramik während ihrer Herstellung möglicherweise zum Trocknen auf Pflanzenresten abgestellt, die im feuchten Ton haften blieben und letztlich ihre Abdrücke als Hohlformen im gebrannten Gefäß hinterließen.

Diese Abdrücke in Hüttenlehm und Keramik wurden mit Tapetenkleister gefestigt und mit Abdruckmasse aus dem zahnärztlichen Bedarf ausgefüllt. Auf diese Weise entstanden genaue, oberflächengetreue Abgußmodelle.

Das Hauptaugenmerk der vorliegenden archäobotanischen Untersuchungen ist wegen des großen Fundumfangs auf die Auswertung der jüngerbronzezeitlichen verkohlten Makroreste gerichtet, zumal gerade diese Periode in Niedersachsen archäobotanisch kaum bekannt ist (BEHRE 1996).

\subsubsection{Bisherige archäobotanische Untersuchungen}

Ein erster Vorratsfund aus dem Bereich der Siedlung der Vorrömischen Eisenzeit wurde von H. Kroll, Kiel, bearbeitet und 1980 publiziert. Weitere Proben aus zwei Darröfen und aus Vorratsgruben der eisenzeitlichen Siedlungen wurden von K.-E. Behre, Wilhelmshaven, untersucht und 1990 veröffentlicht. Die Ergebnisse beider Untersuchungen fließen in die hier vorgelegte Auswertung der archäobotanischen Reste aus Rullstorf ein.

\subsubsection{Methoden}

Die Proben wurden von W. Gebers und dem Grabungsteam des Niedersächsischen Landesamtes für Denkmalpflege in Hannover aus geschlossenen Fundkomplexen entnommen. Sie stammen aus Befunden, in denen sich dunkle Verfärbungen abzeichneten, verkohlte Makroreste schon mit bloßem Auge zu erkennen waren oder die Ansprache als Vorratsgrube begründet schien (JACOMET u. KREUZ 1999, 77 f.). Im Bereich eines Befundes wurden Proben aus verschiedenen Tiefen entnommen, so daß aus einer Grube mehrere Proben bearbeitet werden konnten.

Als geeignete Aufbereitungsmethode für die lockeren, sandigen Proben wurde die behutsame Technik der Flotation angewandt (KNÖRZER 1970, 15; JACOMET u. KREUZ 1999, 114 f.). Da es sich um durchgetrocknete Proben handelte, wurde zunächst das Probengewicht festgestellt; es mißt 1$3 \mathrm{~kg}$. Daraufhin wurden die Proben in flachen Schalen mit Wasser eingeweicht und die aufschwimmenden verkohlten Pflanzenreste vorsichtig über einem zweiteiligen Siebsatz mit Sieben der Maschenweite 0,25 und 0,71 mm abgegossen. Stichprobenartig wurde der sedimentierte Teil einer jeden Probe auf Makroreste durchgesehen. Die subfossilen Pflanzenreste wurden durch die Flotationstechnik vollständig erfaßt, in den Probenrückständen waren keine Makroreste zurückgeblieben. Schließlich lagen zwei getrennte feuchte Makrorest-Fraktionen vor, die auf Zellstoff getrocknet wurden. Die Trennung erleichterte das Auslesen der Pflanzenreste, zur Auswertung wurden die zwei Fraktionen wieder zusammengefaßt.

Die Makroreste wurden an einem Zeiss-StereoMikroskop Stemi SV 6 im Auflicht bei 8-50facher Vergrößerung ausgelesen, bestimmt, gezählt und vermessen.

Die morphologische Bestimmung der subfossilen Pflanzenreste erfolgte mit Hilfe der institutseigenen Sammlung rezenter und subfossiler Samen und Früchte und der von D. Kučan angelegten Fotokartei subfossiler Reste. 
Zusätzlich konnte auf das Rullstorfer Material der bereits abgeschlossenen Untersuchungen von BEHRE (1990) und KROLL (1980) zurückgegriffen werden. Zur Bestimmung wurden $u$. a. die folgenden Titel herangezogen: BEHRE (1976b), HillMAN (1984), JACOMET (1987), JACOMET et al. (1989), KÖRBER-GROHNE (1967), KNÖRZER (1970; 1971) und LANGE (1979).

Wertvolle Unterstützung erhielt ich bei den Bestimmungen von Dipl.-Biol. D. Kučan und Prof. Dr. K.E. Behre (beide NIhK, Wilhelmshaven) sowie von Dr. H. Kroll (Universität Kiel).

Die Funde wurden mit einem Aristophot der Firma Leitz mit einer Balgenkamera Leica M 1 fotografisch dokumentiert. Sämtliche verkohlten Reste sind am NIhK archiviert.

\subsubsection{Darstellung der Ergebnisse}

Berücksichtigt wurden in der Auswertung ausschließlich Proben, die Kulturpflanzenreste enthielten. Bei den Pflanzenresten handelt es sich meist um Früchte und Samen. Wurden andere Pflanzenteile nachgewiesen, ist dies in den Fundtabellen vermerkt.

Die absoluten Häufigkeiten und die Stetigkeit der Pflanzenreste sind einander in den Fundtabellen jeweils in Zahlen- und in Prozentwerten gegenüber gestellt. Der Begriff der „Stetigkeit“ ist der Pflanzensoziologie entlehnt. Die Stetigkeit einer Art ist eine Angabe zu ihrer relativen Häufigkeit. Sie beschreibt den prozentualen Anteil der Proben, in denen eine Art auftritt. Darüber hinaus kann der Repräsentanzwert einer Pflanzenart ermittelt werden. Beispielsweise erreicht die jungbronzezeitliche Rispenhirse aus Rullstorf nach den absoluten Häufigkeiten $31 \%$ der Kulturpflanzenmenge. Nach ihrer Stetigkeit ist sie in $53 \%$ der Proben vertreten. Bei Nachweisen einzelner Diasporen ist deren Vorkommen an sich entscheidend für die Bedeutung der entsprechenden Art. Einzelfunde werden durch die Berechnung der Stetigkeit leicht überbewertet.

$\mathrm{Zu}$ den Getreidekaryopsen sind die Mittelwerte und die Spannen der Länge (L), Breite (B) und Höhe (H) angegeben. Ergebnisse der Messungen von BEHRE $(1990,145)$ und von KROLL (1980, 382) an Rullstorfer Körnern der Vorrömischen Eisenzeit wurden, von den Werten für Avena sativa (Saathafer) abgesehen, in die Tabellen mit den Maßangaben aufgenommen. Die Angaben zur Nomenklatur der Kulturpflanzenarten im beschreibenden Teil (Kap. 4.3.1) folgen MANSFELD (1986).

\subsubsection{Radiokarbon-Datierungen}

Zwei der Makrorestproben wurden am Leibniz-Labor für Altersbestimmung und Isotopenforschung der Universität Kiel datiert. Die Kalibrierung der Radiokarbon-Daten in Kalenderjahre erfolgte mit dem Programm Calib 4.3
(StUiver u. ReIMer 1993; Stuiver et al. 1998). Die Daten sind in Radiokarbonjahren mit einfacher Standardabweichung angegeben. Die Kalibrationen sind vereinfacht dargestellt (s. auch Kap. 3.2.6).

Die Resultate der Radiokarbon-Datierungen von verkohltem Getreide (Tab. 8) bestätigen die archäologische Datierung in die jüngere Bronzezeit.

\subsection{Pflanzenreste aus dem Zeitraum von der jüngeren Bronzezeit bis zum Frühen Mittelalter}

Den größten Teil der untersuchten Funde bilden Kulturpflanzenreste aus der jüngeren Bronzezeit mit 20.895 Nachweisen (Tab. 9). Ihnen stehen 944 Unkrautreste gegenüber. Alle diese Funde stammen aus 38 Befunden, die anhand der Keramik und der Radiokarbon-Datierungen als jungbronzezeitlich eingestuft und als Vorratsgruben interpretiert wurden. Die meisten der Vorratsgruben sind in der Aufsicht kreisrunde Gruben mit einem Durchmesser von ungefähr $1 \mathrm{~m}$. Sie haben einen flachen Boden und senkrechte Seitenwände. Sohle und Seitenwände sind durch dunkle Verfärbungen vom Grubeninhalt abgesetzt. Die Vorratsgruben befinden sich nur in einem Bereich der Grabungsfläche, in dem lockerer, feiner Sand ansteht, während in Bereichen mit tonigen und lehmigen Böden keine Gruben angelegt wurden (GEBERS 1985a, 146 f.). Als mögliche Auskleidung und als Überbau der Erdsilos mag eine Flechtwerkkonstruktion gedient haben, wie sie bei GEBERS (1985a, 149) abgebildet ist. Unter dem botanischen Material wurden jedoch keine Holzkohlen von Weidenruten o. ä. nachgewiesen, die von einer mutmaßlichen Flechtwerkauskleidung der Gruben hätten stammen können.

Von hirsereichen Vorratsgruben lassen sich in der jüngeren Bronzezeit in Rullstorf emmer- und gerstenreiche Vorratsgruben unterscheiden. Außerdem treten neben stark verunkrauteten auffällig reine Getreidevorräte auf (Tab. 30).

Aus einem Darrofen sowie acht Vorratsgruben aus der Siedlung der Vorrömischen Eisenzeit stammen 1300 Kulturpflanzen- sowie 430 Unkrautreste. Ergänzt um das bereits von BEHRE (1990) bearbeitete Material, ergibt sich auch für die Vorrömische Eisenzeit (6.-2. Jh. v. Chr.) ein repräsentatives Bild der genutzten Kulturpflanzenarten (Tab. 10).

Weitere Pflanzenfunde aus dem 1. Jh. v. Chr., die von BEHRE (1990) und von KROLL (1980, 378 f.) untersucht wurden, ergänzen die Kenntnis des Rullstorfer Kulturpflanzeninventars (Tab. 11). Die von BEHRE (1990) untersuchten Haferkörner, die in Tab. 11 als Avena sp. angeführt sind, können wie die von KROLL (1980) bearbeiteten dem Saathafer zugeordnet werden, da das Material aus dem gleichen Vorrat stammt. Letztere waren jedoch schon auf der Grabung geschlämmt und dabei entspelzt worden, weshalb die Artbestimmung nicht möglich war (Kap. 4.3.1). Bei dem großen Rullstorfer Saathafervorrat handelt es sich um den ältesten sicheren 
Tab. 9. Kultur- und Sammelpflanzenspektrum der jüngeren Bronzezeit in Rullstorf nach verkohltem Material aus 38 Vorratsgruben.

\begin{tabular}{|c|c|c|c|c|c|}
\hline & \multicolumn{2}{|c|}{ absolute Häufigkeit } & \multicolumn{2}{|c|}{ Stetigkeit } & \\
\hline & {$[\mathrm{n}]$} & {$[\%]$} & {$[\mathrm{n}]$} & {$[\%]$} & \\
\hline Triticum monococcum, esp. & 22 & 0,11 & 2 & 5,26 & entspelztes Einkorn \\
\hline Triticum dicoccon, esp. & 7254 & 34,72 & 7 & 18,42 & entspelzter Emmer \\
\hline Triticum dicoccon, Spelzengabelhälften & 51 & 0,24 & 5 & 13,16 & Emmer, Spelzengabelhälften \\
\hline Triticum aestivum s. 1. & 94 & 0,45 & 5 & 13,16 & Saat- u. Zwergweizen \\
\hline Triticum sp. & 1 & 0,01 & 1 & 2,63 & Weizen allg. \\
\hline Hordeum vulgare, esp. & 6300 & 30,15 & 12 & 31,58 & Spelzgerste \\
\hline Hordeum vulgare, esp., KRS & 424 & 2,03 & 3 & 7,89 & Spelzgerste, KRS \\
\hline Hordeum vulgare var. nudum & 165 & 0,79 & 3 & 7,89 & Nacktgerste \\
\hline Hordeum vulgare var. nudum, KRS & 8 & 0,04 & 3 & 7,89 & Nacktgerste, KRS \\
\hline Panicum miliaceum & 6536 & 31,28 & 20 & 52,63 & Rispenhirse \\
\hline Avena sp. & 7 & 0,03 & 2 & 5,26 & Hafer allg. \\
\hline Secale cereale & 2 & 0,01 & 1 & 2,63 & Roggen \\
\hline Getreide indet. & 31 & 0,15 & 7 & 18,42 & Getreide allg. \\
\hline Summe & 20895 & 100,00 & 38 & - & \\
\hline Getreidebruch $[\mathrm{g}]$ & 100,68 & - & 12 & 31,58 & \\
\hline Quercus sp., Kotyledonen-Bruchstücke & 42 & - & 2 & 5,26 & Eiche, Keimblattbruchstücke \\
\hline Malus, Kerne & 6 & - & 2 & 5,26 & Apfel, Kerne \\
\hline Corylus, Perikarp-Bruchstücke & 11 & - & 6 & 15,78 & Hasel, Nußschalen-Bruchstücke \\
\hline
\end{tabular}

Tab. 10. Kultur- und Sammelpflanzenspektrum des 6.-2. Jh. v. Chr. in Rullstorf nach verkohltem Material aus 10 Befunden. In den Spalten unter dem $\Sigma$-Zeichen sind die neu erhobenen Daten und die Daten von BEHRE (1990) zusammengefaßt.

\begin{tabular}{|c|c|c|c|c|c|c|c|c|c|}
\hline & \multicolumn{6}{|c|}{ absolute Häufigkeit } & \multicolumn{3}{|c|}{ Stetigkeit } \\
\hline & \multicolumn{3}{|c|}{$[\mathrm{n}]$} & \multicolumn{3}{|c|}{$[\%]$} & \multirow{2}{*}{$\begin{array}{l}{[\mathrm{n}]} \\
\Sigma\end{array}$} & \multicolumn{2}{|l|}{$[\%]$} \\
\hline & $\begin{array}{l}\text { eigene } \\
\text { Daten }\end{array}$ & $\begin{array}{l}\text { BEHRE } \\
\text { (1990) }\end{array}$ & $\Sigma$ & $\begin{array}{l}\text { eigene } \\
\text { Daten }\end{array}$ & $\begin{array}{l}\text { BEHRE } \\
(1990)\end{array}$ & $\Sigma$ & & $\Sigma$ & \\
\hline Triticum monococcum, esp. & 2 & 5 & 7 & 0,15 & 0,03 & 0,04 & 2 & 20 & entspelztes Einkorn \\
\hline Triticum dicoccon, esp. & 4 & 552 & 556 & 0,31 & 3,54 & 3,29 & 2 & 20 & entspelzter Emmer \\
\hline Trit. dicoccon, Spelzengabelhälften & 1 & - & 1 & 0,08 & - & 0,01 & 1 & 10 & \\
\hline Triticum aestivum s. 1. & 53 & 239 & 292 & 4,10 & 1,53 & 1,73 & 2 & 20 & Saat- u. Zwergweizen \\
\hline Hordeum vulgare, esp. & 1024 & 10075 & 11099 & 78,77 & 64,53 & 65,62 & 5 & 50 & entspelzte Spelzgerste \\
\hline Hordeum vulgare, esp., KRS & 54 & - & 54 & 4,15 & - & 0,32 & 1 & 10 & Spelzgerste, KRS \\
\hline Hordeum vulgare var. nudum & 52 & 3176 & 3228 & 3,99 & 20,34 & 19,08 & 3 & 30 & Nacktgerste \\
\hline Hordeum vulgare var. nudum, KRS & 4 & - & 4 & 0,31 & - & 0,02 & 1 & 10 & Nacktgerste, KRS \\
\hline Panicum miliaceum & 15 & 789 & 804 & 1,15 & 5,05 & 4,75 & 4 & 40 & Rispenhirse \\
\hline Avena sp., Spelzenreste & 2 & - & 2 & 0,15 & - & 0,01 & 1 & 10 & Hafer allg. \\
\hline Avena sp., esp. & 18 & 521 & 539 & 1,39 & 3,34 & 3,19 & 2 & 20 & entspelzter Hafer \\
\hline Vicia faba & 1 & - & 1 & 0,08 & - & 0,01 & 1 & 10 & Ackerbohne \\
\hline Linum usitatissimum & 2 & 256 & 258 & 0,15 & 1,64 & 1,53 & 2 & 20 & Lein \\
\hline Getreide indet. & 68 & - & 68 & 5,22 & - & 0,40 & 2 & 20 & Getreide allg. \\
\hline Summe & 1300 & 15613 & 16913 & 100,00 & 100,00 & 100,00 & 10 & - & \\
\hline Getreidebruch [g] & 10,65 & 57,35 & 68,00 & - & - & - & - & - & \\
\hline Prunus spinosa, Steinkerne & 1 & 1 & 2 & - & - & - & 2 & 20 & Schlehen-Steinkerne \\
\hline Fragaria vesca, Nüßchen & - & 2 & 2 & - & - & - & 2 & 20 & Walderdbeere \\
\hline Corylus, Perikarp-Bruchstücke & 10 & - & 10 & - & - & - & 3 & 30 & Hasel \\
\hline
\end{tabular}


Tab. 11. Kulturpflanzenspektrum des 1. Jh. v. Chr. in Rullstorf nach verkohltem Material aus 3 Vorratsgruben. In den Spalten unter dem $\Sigma$-Zeichen sind die Daten von BEHRE (1990) und KROLL (1980) zusammengefaßt.

\begin{tabular}{|c|c|c|c|c|c|c|c|c|c|}
\hline \multicolumn{7}{|c|}{ absolute Häufigkeit } & \multicolumn{3}{|c|}{ Stetigkeit } \\
\hline & & {$[\mathrm{n}]$} & & & {$[\%]$} & & {$[\mathrm{n}]$} & {$[\%]$} & \\
\hline & $\begin{array}{l}\text { BEHRE } \\
(1990)\end{array}$ & $\begin{array}{c}\text { KROLL } \\
(1980)\end{array}$ & $\Sigma$ & $\begin{array}{l}\text { BEHRE } \\
(1990)\end{array}$ & $\begin{array}{l}\text { KROLL } \\
(1980)\end{array}$ & $\Sigma$ & $\Sigma$ & $\Sigma$ & \\
\hline Triticum monococcum, esp. & 8 & - & 8 & 0,12 & - & 0,04 & 1 & 33,33 & entspelztes Einkorn \\
\hline Triticum dicoccon, esp. & 304 & 74 & 378 & 4,55 & 0,61 & 2,00 & 2 & 66,66 & entspelzter Emmer \\
\hline Triticum aestivum s. 1. & 3 & - & 3 & 0,04 & - & 0,02 & 1 & 33,33 & Saat- u. Zwergweizen \\
\hline Hordeum vulgare, esp. & 63 & 1 & 64 & 0,94 & 0,01 & 0,34 & 2 & 66,66 & entspelzte Spelzgerste \\
\hline Hordeum vulgare var. nudum & 137 & 19 & 156 & 2,05 & 0,16 & 0,83 & 2 & 66,66 & Nacktgerste \\
\hline Avena sativa & 110 & 12124 & 12234 & 1,65 & 99,21 & 64,74 & 2 & 66,66 & Saathafer \\
\hline Avena sp. & 6024 & - & 6024 & 90,23 & - & 31,87 & 2 & 66,66 & Hafer allg. \\
\hline Panicum miliaceum & - & 3 & 3 & - & 0,02 & 0,02 & 1 & 33,33 & Rispenhirse \\
\hline Linum usitatissimum & 2 & - & 2 & 0,03 & - & 0,01 & 1 & 33,33 & Lein \\
\hline Pisum sativum & 25 & - & 25 & 0,37 & - & 0,13 & 1 & 33,33 & Erbse \\
\hline Summe & 6676 & 12221 & 18897 & 100,00 & 100,00 & 100,00 & 3 & - & \\
\hline
\end{tabular}

Tab. 12. Kulturpflanzenspektrum der Römischen Kaiserzeit in Rullstorf nach verkohltem Material aus 4 Befunden.

\begin{tabular}{|c|c|c|c|c|c|}
\hline & \multicolumn{2}{|c|}{ absolute Häufigkeit } & \multicolumn{2}{|c|}{ Stetigkeit } & \\
\hline & {$[\mathrm{n}]$} & {$[\%]$} & {$[\mathrm{n}]$} & {$[\%]$} & \\
\hline Triticum monococcum, esp. & 1 & 4,30 & 1 & 25 & entspelztes Einkorn \\
\hline Triticum dicoccon, esp. & 4 & 17,40 & 2 & 50 & entspelzter Emmer \\
\hline Triticum dicoccon, Spelzengabelhälften & 2 & 0,24 & 1 & 25 & Emmer, Spelzengabelhälften \\
\hline Triticum sp. & 3 & 13,00 & 2 & 50 & Weizen allg. \\
\hline Hordeum vulgare, esp. & 4 & 17,40 & 2 & 50 & Spelzgerste \\
\hline Secale cereale & 6 & 26,10 & 3 & 75 & Roggen \\
\hline Getreide indet. & 3 & 13,00 & 1 & 25 & Getreide allg. \\
\hline Summe & 23 & 100,00 & 4 & - & \\
\hline Getreidebruch [g] & 0,39 & - & - & - & \\
\hline
\end{tabular}

Tab. 13. Kultur- und Sammelpflanzen aus dem sächsischen Gräberfeld des 6./7. Jh. in Rullstorf.

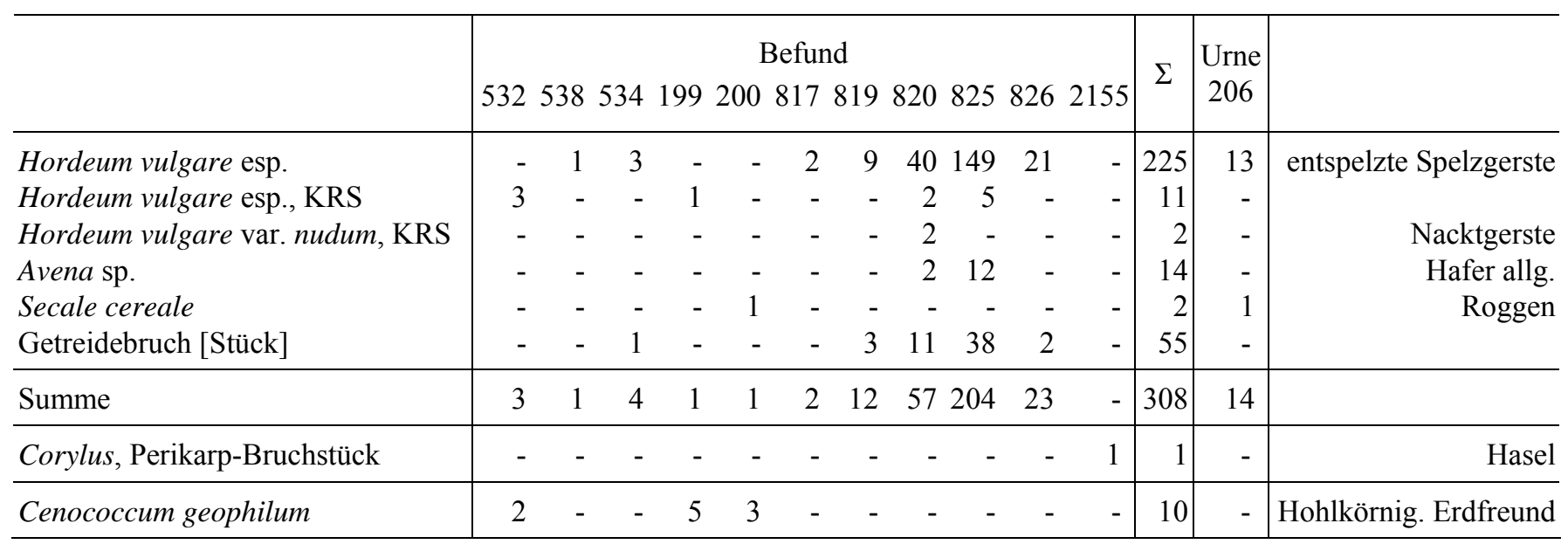


Nachweis vom Anbau des Saathafers in Monokultur für Norddeutschland. Für die Vorrömische Eisenzeit wurde in Rullstorf des weiteren Pisum sativum nachgewiesen.

Aus vier Befunden stammen 23 Kulturpflanzenreste der Römischen Kaiserzeit (Tab. 12), Unkräuter kamen nicht vor. Der Aussagewert dieser wenigen Funde ist beschränkt. Sie zeigen, daß Triticum dicoccon und Hordeum vulgare weiterhin genutzt wurden. Secale cereale kann hier wahrscheinlich schon als Kulturpflanze gewertet werden. Untersuchungen an Makroresten aus Flögeln-Eekhöltjen und Loxstedt, beide Ldkr. Cuxhaven, sowie archäobotanische Untersuchungen an Material aus Groß Meckelsen, Ldkr. Rotenburg, und aus Kosel, Schleswig-Holstein, zeigen, daß die Nachweise der sekundären Kulturpflanze Roggen im Verlauf der Römischen Kaiserzeit und der Völkerwanderungszeit stark zunehmen. Diese Funde belegen, daß ein Reinanbau des Roggens seit der Römischen Kaiserzeit in Norddeutschland stattfand (BEHRE 1992, 146 f.; Behre u. KUČAN 1994, 38; MÜller-Wille et al. 1988,63 f.).

Aus dem Frühen Mittelalter liegen ebenfalls nur sehr wenige archäobotanische Funde vor (Tab. 13). Von den 308 verkohlten Resten, die allesamt von Kulturpflanzen stammen, kommen über 200 Stück aus nur einer Pfostengrube eines Scheiterhaufens auf dem sächsischen Gräberfeld. Zudem wurden in einer Bodenscherbe einer Urne Abdrücke mehrerer Spelzgerstenkörner sowie eines Roggenkorns festgestellt. Der Nachweis des frühmittelalterlichen Roggenanbaus wird durch den Abdruck des Kornes in der Keramik bestätigt.

\subsubsection{Getreidearten}

\subsubsection{Panicum miliaceum - Rispenhirse, Echte Hirse}

Nomenklatur: Panicum miliaceum L., Sp. P. (1753) 58

Funde: $\quad 7340$ subfossile, verkohlte Karyopsen aus 23 Fundstellen, z. T. bespelzt bzw. mit Spelzresten

Datierung: jüngere Bronzezeit, Vorrömische Eisenzeit

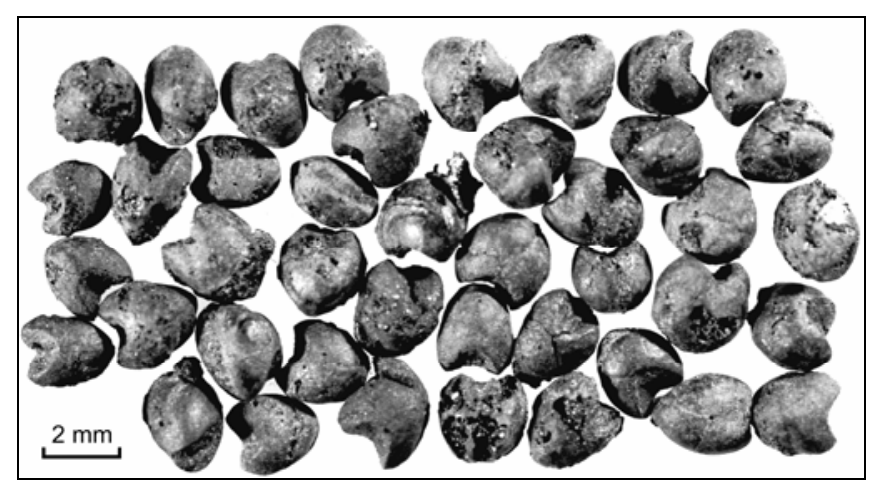

Abb. 16. Verkohlte Karyopsen von Panicum miliaceum (Rispenhirse), jungbronzezeitlich, Befund 8105 .
Die kugeligen Körner von Panicum miliaceum zeichnen sich durch eine breite, flach gewölbte Keimlingsgrube aus, die teilweise bis über die Mitte der Rückenlänge hinausreicht (Abb. 16). Oft haften noch Spelzreste am Korn. Daher lassen sich die Karyopsen der Gattung Panicum mit ihren glatten Spelzen gut von denen der Gattung Setaria (Kolbenhirse) unterscheiden, deren Spelzen mit Papillenreihen besetzt sind. Der Nabel an der Bauchseite der Karyopse ist im Gegensatz zum länglichen Nabel bei Setaria eingesenkt und punktförmig (KNÖRZER 1971, 46 f.). Zur Abgrenzung gegen die Körner der Unkrauthirsen ist die Größe der Karyopsen kein zuverlässiges Kriterium, da nicht alle Körner einer Rispe gleichzeitig reifen. Die verkohlten Rullstorfer Körner sind vielfach von der Hitze deformiert, aufgetrieben und blasig.

Im jungbronzezeitlichen Siedlungsbereich gehört die Rispenhirse mit 6536 Körnern und einem Anteil von $31 \%$ der Kulturpflanzen zu den drei wichtigsten Getreidearten. Anhand der Stetigkeit ist sie mit $53 \%$ die Kulturpflanze mit dem höchsten Repräsentanzwert. Die RadiokarbonDatierung auf $2963 \pm 29$ BP, kal. 1176 (1259-1127) v. Chr., weist diesen Fund als den ältesten Rispenhirsevorrat Niedersachsens aus. Ein einzelnes Rispenhirsekorn konnten BEHRE u. KUČAN $(1994,29)$ aus der trichterbecherzeitlichen Siedlung Flögeln-,,Im Örtjen“ im Ldkr. Cuxhaven nachweisen.

Generell fand der Hirseanbau, der besonders im Mittelalter intensiv betrieben wurde, wohl überwiegend auf der Geest statt. Hirse wächst gern auf leicht erwärmbaren Sand- und Kies- aber auch auf sandigen Lehmböden, wie sie auf der Geest vorkommen. Auch die klimatischen Bedingungen im norddeutschen Tiefland lassen ein Anbau der Rispenhirse zu (BECKER-DILLINGEN 1927, 572 f.).

Die Marschenböden sind jedoch für die Rispenhirsekultur wenig geeignet. Für die Feddersen Wierde, Ldkr. Cuxhaven, wägt KöRBER-Grohne (1967, 145) ab, ob die Hirsekörner dort importiert wurden. Geringe Fundmengen aus Marschengrabungen verschiedener Zeithorizonte, beispielsweise der kaiserzeitlichen Siedlung Bentumersiel an der Unterems (BEHRE 1977, 70) oder der frühmittelalterlichen Wurt Niens in Butjadingen (BEHRE 1991a, 148), gehen auf die Feuchtbodenerhaltung zurück, die eine andere Repräsentanz der Hirsereste bewirkt, da die Hirsekaryopsen in Feuchtbodenablagerungen vergehen. Hingegen überdauern unter diesen Ablagerungsbedingungen die robusten Vor- und Deckspelzen die Jahrhunderte. Daher konnten unmittelbar aus der Nahrungszubereitung stammende entspelzte Hirsevorräte in Marschensiedlungen bislang nicht erfaßt werden. Auch bei der Grabung des NIhK in Rodenkirchen, Ldkr. Wesermarsch, bei der ein jungbronzezeitlicher Hausgrundriß aufgedeckt und subfossile Pflanzenreste systematisch untersucht wurden, zeichnet sich ab, daß die Nachweise der Rispenhirse weit hinter die der Gerste und des Emmers zurücktreten (frdl. Mitteilung von D. Kučan). Hingegen lassen die zahlreichen Hirsefunde aus der Marschensiedlung Jemgumkloster 
Tab. 14. Maße der verkohlten, entspelzten Karyopsen von Panicum miliaceum aus Rullstorf.

\begin{tabular}{lccccc}
\hline & Körner [n] & Befund & Länge [mm] & Breite [mm] & Höhe [mm] \\
\hline jüngere Bronzezeit & 100 & 6273 & $1,9(1,3-2,2)$ & $1,7(1,3-1,9)$ & $1,5(0,9-1,9)$ \\
Vorröm. Eisenzeit, 6.-2. Jh. v. Chr. (BEHRE 1990) & 100 & 2715 & $1,6(1,4-2,0)$ & $1,6(1,1-1,8)$ & - \\
\hline
\end{tabular}

(1. Jh. v. Chr.) einen Anbau in der Marsch möglich erscheinen (BEHRE 1972, 170 u. 177).

Interessant wäre es, Anbauversuche mit Rispenhirse auf den schweren Marschenböden durchzuführen. Sie könnten dazu beitragen, die Frage nach einem Anbau vor Ort oder einem Import aus den Geestgebieten zu klären. Möglicherweise ergäben sich daraus Anhaltspunkte, die auf einen Warenaustausch zwischen Marsch und Geest hinweisen würden. Jedoch wurde bislang weder von archäologischer noch von archäobotanischer Seite ein Austausch von Nahrungsmitteln zwischen bäuerlichen Siedlungen nachgewiesen (BEHRE u. KUČAN 1994, 44).

Während die Rispenhirse eines der drei jungbronzezeitlichen Hauptgetreide in Rullstorf darstellt, geht ihre Bedeutung hier in der Vorrömischen Eisenzeit zurück. Insgesamt sind für das 6.-2. Jh. nur noch 804 Körner nachgewiesen, was einem Anteil von knapp $5 \%$ der Kulturpflanzen entspricht. Neben der Spelzgerste ist sie aufgrund der Stetigkeit mit einem Anteil von $36 \%$ jedoch weiterhin als wichtiges Getreide zu bezeichnen.

Sowohl in der Römischen Kaiserzeit als auch im Frühen Mittelalter konnte die Rispenhirse in Rullstorf nicht nachgewiesen werden, da in diesen Abschnitten nur wenige Fundstellen botanische Makroreste enthielten.

Die Rullstorfer Hirsekörner sind überwiegend entspelzt. Es handelt sich daher um Vorratsfunde, die für den baldigen Verzehr angelegt wurden. Als Saatgutvorräte wären hingegen bespelzte Hirsekörner gelagert worden, da in ungeschütztem, entspelzten Zustand der Embryo zu leicht verletzt würde bzw. aus der Keimlingsgrube herausfiele (JACOMET u. KREUZ 1999, 151). Die hirsereichen Vorräte zeichnen sich durch die Dominanz der Rispenhirse und die Seltenheit anderer Getreide oder Sammelpflanzen aus. Womöglich ist dies ein Hinweis darauf, daß die pflegeintensive Hirse als Hackfrucht schon in der Bronzezeit auf gesonderten Flächen angebaut wurde, wie dies für historische Zeiten beschrieben ist (GOY 1938, 20 f.).

\subsubsection{Hordeum vulgare - Spelzgerste}

Nomenklatur: Hordeum vulgare L. Sp. Pl. (1753) 84

Funde: $\quad 8042$ subfossile, verkohlte entspelzte

Karyopsen sowie 13 Abdrücke von Karyopsen und 1 Abdruck eines Rachisfragmentes mit aufsitzendem Ährchen

Datierung: jüngere Bronzezeit, Vorrömische Eisenzeit, Römische Kaiserzeit, Frühes Mittelalter
Die Kulturformen der Gerste können anhand zweier systematischer Kriterien unterschieden werden. Zum einen entscheidet die Anzahl der fertilen Ährchen pro Spindelglied darüber, ob es sich um eine zwei- oder eine mehrzeilige Gerste handelt. Zum anderen können bespelzte und nackte Formen der Gerste voneinander getrennt werden. Bei den Rullstorfer Gerstennachweisen handelt es sich überwiegend um entspelzte Körner der vierzeiligen Spelzgerste. Daneben ist die vierzeilige Nacktgerste nachgewiesen.

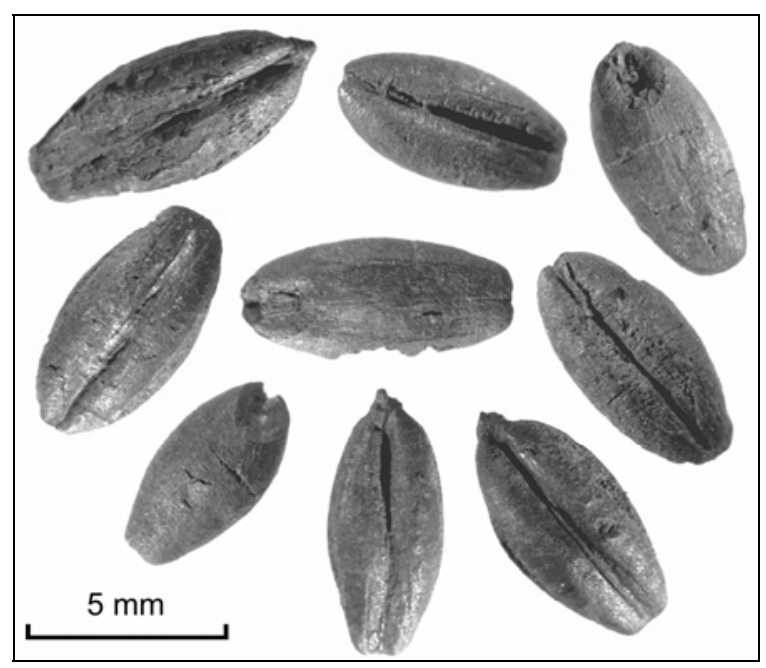

Abb. 17. Verkohlte, entspelzte Karyopsen von Hordeum vulgare (Spelzgerste), jungbronzezeitlich, Befund 6273.

Die Karyopsen von Hordeum vulgare sind in der Mitte am dicksten (Abb. 17). Sie flachen zu beiden Enden hin ab, werden außerdem schmaler und wirken dadurch spindelförmig (SCHIEMANN 1948, 71 f.; KNÖRZER 1970, 26). Auf der Ventralseite verläuft in der meist breiten Mittelfurche die Raphe. Neben geraden Körnern treten auch schiefe, verdrehte Körner der vierzeiligen Gerste auf, die sog. Krummschnäbel. Bei der lockerährigen Vierzeilgerste behindern sich die randlich auf dem Spindelglied sitzenden schlank-ovalen Körner der gegenüberliegenden Ährchentriplets; die Seitenährchen krümmen sich, während das mittlere Ährchen meist gerade wächst (BEHRE 1976b, 7 f.). Bei der dichtährigen Sechszeilgerste ist das Ährchentriplet auf dem Spindelglied hingegen so weit nach außen gespreizt, daß sich die drei Ährchen, deren Körner zudem eher rundlich ausgebildet sind, ohne Verdrehung entwickeln können (JACOMET 1987, 31). 
Tab. 15. Maße der verkohlten, entspelzten Karyopsen von Hordeum vulgare aus Rullstorf.

\begin{tabular}{lccccc}
\hline & Körner [n] & Befund & Länge [mm] & Breite [mm] & Höhe [mm] \\
\hline jüngere Bronzezeit & 300 & 6273 & $5,6(4,2-7,0)$ & $2,8(1,9-3,3)$ & $2,2(2,2-2,7)$ \\
Vorröm. Eisenzeit, 6.-2. Jh. v. Chr. (BEHRE 1990) & 100 & 2148 & $5,0(3,6-6,9)$ & $2,5(1,5-3,5)$ & $2,0(1,3-2,8)$ \\
& 100 & 2715 & $4,7(3,6-6,3)$ & $2,3(1,6-2,5)$ & $1,9(1,1-2,5)$ \\
& 2 & 7150 & $5,2(4,4-5,9)$ & $3,1(3,0-3,1)$ & $2,2(2,0-2,4)$ \\
Römische Kaiserzeit & 50 & $200,820,825$ & $5,6(4,4-6,9)$ & $3,1(2,3-4,0)$ & $2,5(1,8-3,1)$ \\
Frühes Mittelalter & & &
\end{tabular}

Tab. 16. Maße der verkohlten Karyopsen von Hordeum vulgare var. nudum aus Rullstorf.

\begin{tabular}{lccccc}
\hline & Körner [n] & Befund & Länge [mm] & Breite [mm] & Höhe [mm] \\
\hline jüngere Bronzezeit & 30 & 6273 & $4,7(3,0-5,6)$ & $2,6(1,3-3,5)$ & $2,1(1,3-2,5)$ \\
Vorröm. Eisenzeit, 6.-2. Jh. v. Chr. (BeHRE 1990) & 100 & 2148 & $4,1(3,0-5,2)$ & $2,3(1,7-3,1)$ & $1,9(1,3-2,6)$ \\
Vorröm. Eisenzeit, 1. Jh. v. Chr. (BEHRE 1990) & 70 & 10 & $4,4(3,1-5,8)$ & $2,5(1,7-3,5)$ & $2,0(1,3-2,5)$ \\
Vorröm. Eisenzeit, 1. Jh. v. Chr. (KROLL 1980) & 25 & 104 & $4,8(3,9-6,0)$ & $2,7(2,1-3,2)$ & $2,1(1,6-2,6)$ \\
Frühes Mittelalter & 2 & 820 & 5,0 & $2,8(2,6-2,9)$ & $2,2(2,1-2,3)$ \\
\hline
\end{tabular}

Im Rullstorfer Fundspektrum wurden nur auffällig verkrümmte Körner als Krummschnäbel angesprochen, weshalb sie hier unterrepräsentiert sind. Daher entspricht das Verhältnis von Krummschnäbeln zu geraden Körnern in der jüngeren Bronzezeit mit 1:15 keineswegs dem zu erwartenden Verhältnis von 2:1 (Tab. 9). Der Nachweis der Krummschnäbel spricht dennoch für den Anbau der lockerährigen Vierzeilgerste in Rullstorf. Der Abdruck eines Spindelgliedes mitsamt aufsitzendem Ährchen der Spelzgerste in Hüttenlehm (Befund 5082) bestätigt, daß in Rullstorf die vierzeilige Form der Gerste (Hordeum vulgare ssp. tetrastichum) kultiviert wurde. Die Länge des Spindelgliedes ist als Bestimmungskriterium zwar nicht ausreichend, variieren die Längen der Rachisfragmente doch schon innerhalb einer Ähre. Bei Sechszeilgerste gilt jedoch für den mittleren Teil einer Ähre, daß Spindelglieder kürzer als 2,4 mm sind (JACOMET 1987, 31). Das Rullstorfer Exemplar hat eine Länge von 3,0 mm. Es ist deutlich länger als die mittleren Spindelglieder der Sechszeilgerste und muß daher ein Fragment der vierzeiligen Gerste sein. Zudem zeichnet sich die hufeisenförmige Vertiefung der vierzeiligen Gerste an der Deckspelzenbasis des auf dem Spindelglied sitzenden Ährchens ab.

Die Längenmaße der Rullstorfer Spelzgerstenkörner entsprechen denen der spätbronzezeitlichen Spelzgerste aus Hesel (BEHRE 1998, 299). Im Vergleich zu Messungen von Kornabdrücken aus Befunden aus der Elbniederung und aus anderen Fundorten in Niedersachsen bei HopF (1982, 54 f.) sind die Körner der Rullstorfer Spelzgersten zwar etwas kürzer, doch die Verkohlungsexperimente von Hopf (1955, 191 f.) zeigen, daß die Körner beim Verkohlen verkürzt werden. Die Mittelwerte der Breitenangaben stimmen hingegen mit den Kornabdrücken überein.

In Rullstorf war die vierzeilige Spelzgerste neben Rispenhirse und Emmer eins von drei jungbronzezeitlichen
Hauptgetreiden. In der Vorrömischen Eisenzeit war sie mit $66 \%$ die häufigste und mit $55 \%$ die am stetigsten vertretene Kulturpflanze. In der Römischen Kaiserzeit ist sie weiterhin im Kulturpflanzenspektrum vertreten. Unter den Pflanzenresten des sächsischen Gräberfeldes ist sie schließlich mit 225 von 308 verkohlten Körnern die wichtigste Getreideart.

\subsubsection{Hordeum vulgare var. nudum - Nacktgerste}

Nomenklatur: Hordeum vulgare L. Sp. Pl. (1753) 84, s. lat. Funde: 231 subfossile, verkohlte Karyopsen Datierung: jüngere Bronzezeit, Vorrömische Eisenzeit, Frühes Mittelalter

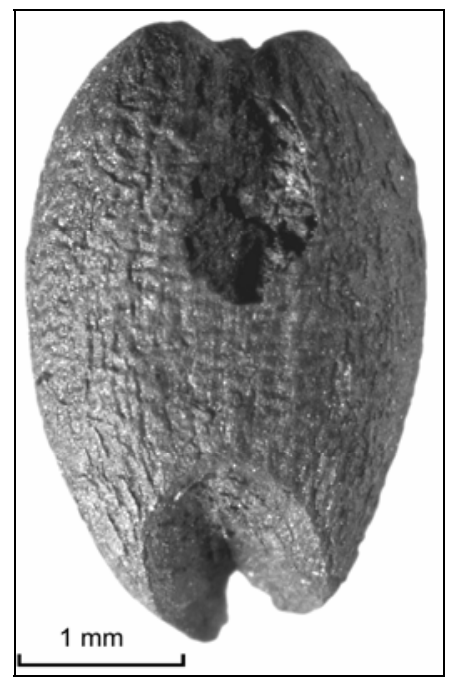

Abb. 18 Verkohlte Karyopse von Hordeum vulgare var. nudum (Nacktgerste), jungbronzezeitlich, Befund 6273. 
Tab. 17. Maße der verkohlten, entspelzten Karyopsen von Triticum dicoccon aus Rullstorf.

\begin{tabular}{lccccc}
\hline & Körner [n] & Befund & Länge [mm] & Breite [mm] & Höhe [mm] \\
\hline jüngere Bronzezeit & 400 & 6273 & $5,2(4,0-6,1)$ & $2,7(1,6-3,3)$ & $2,1(1,5-2,7)$ \\
Vorröm. Eisenzeit, 6.-2. Jh. v. Chr. (BEHRE 1990) & 100 & 2175 & $4,5(3,0-5,7)$ & $2,3(1,5-3,4)$ & $2,0(1,2-3,0)$ \\
Vorröm. Eisenzeit, 1. Jh. v. Chr. (BEHRE 1990) & 100 & 10 & $4,9(3,5-6,2)$ & $2,3(1,6-3,4)$ & $2,0(1,5-2,9)$ \\
Römische Kaiserzeit & 3 & 7150 & $4,8(4,5-5,0)$ & $2,1(2,0-2,3)$ & $2,2(2,0-2,4)$ \\
\hline
\end{tabular}

Die Trennung von Spelz- und Nacktgersten ist nicht in allen Fällen möglich. Das wesentliche hier zur Bestimmung herangezogene Merkmal sind die Querrunzeln auf der Oberfläche der Karyopse (Abb. 18). Nachgeordnet wurde auch die im Querschnitt kugelige Form der Körner berücksichtigt. Einzelne Karyopsen der Nacktgerste sind asymmetrisch, so daß auch hier eine vierzeilige Form belegt ist.

Die Nacktgerste bleibt in der jüngeren Bronzezeit mit Anteilen um $1 \%$ weit hinter den anderen Kulturpflanzen zurück. Vermutlich stand sie als Beimengung anderen Getreides auf dem Acker. Auch in der Vorrömischen Eisenzeit erreicht sie nur niedrige Werte, in der Römischen Kaiserzeit fällt sie ganz aus. In den Proben aus dem sächsischen Gräberfeld wurden zwei Nacktgerstenkörner nachgewiesen.

\subsubsection{Triticum dicoccon - Emmer}

Nomenklatur: Triticum dicoccon Schrank, Baier. Flora 1 (1789) 389

Funde: $\quad 7259$ subfossile, verkohlte Karyopsen sowie 57 Spelzengabeln bzw. Spelzengabelhälften

Datierung: jüngere Bronzezeit, Vorrömische Eisenzeit, Römische Kaiserzeit

Die Körner des Spelzweizens Emmer sind schlank. Die maximale Höhe der leicht gewölbten Rückenlinie befindet sich meist direkt oberhalb des Keimlings. Im Petrischälchen kommt die überwiegende Zahl der Körner im Gegensatz zu denen vom Einkorn auf der Bauchseite zu liegen.

In Rullstorf war der Emmer in der jüngeren Bronzezeit eines der drei Hauptgetreide, er führt die Getreide mit absoluten Häufigkeiten von $35 \%$ an. Nach der Stetigkeit steht er hinter Rispenhirse und Spelzgerste an dritter Stelle im Kulturpflanzenspektrum. In der Vorrömischen Eisenzeit ging die Bedeutung des neben Gerste und Einkorn zu den ältesten Getreiden zählenden Emmers zurück. In der Römischen Kaiserzeit wurden schließlich nur noch ein Korn und zwei Spelzengabelhälften nachgewiesen, im Frühen Mittelalter tritt der Emmer nicht auf.

Für den Emmer gilt wie auch für die Spelzgerste, daß die mittleren Längen der Rullstorfer Körner geringer ausfallen als die Mittelwerte der Längen von bronzezeitlichen Kornabdrücken aus dem Weser-Ems-Gebiet (HopF 1982, 54 f.). Die mittlere Breite der Emmerkörner ist hingegen größer, wie es nach den Verkohlungsexperimenten von HopF $(1955,191)$ für Kornabdrücke auch zu erwarten ist.

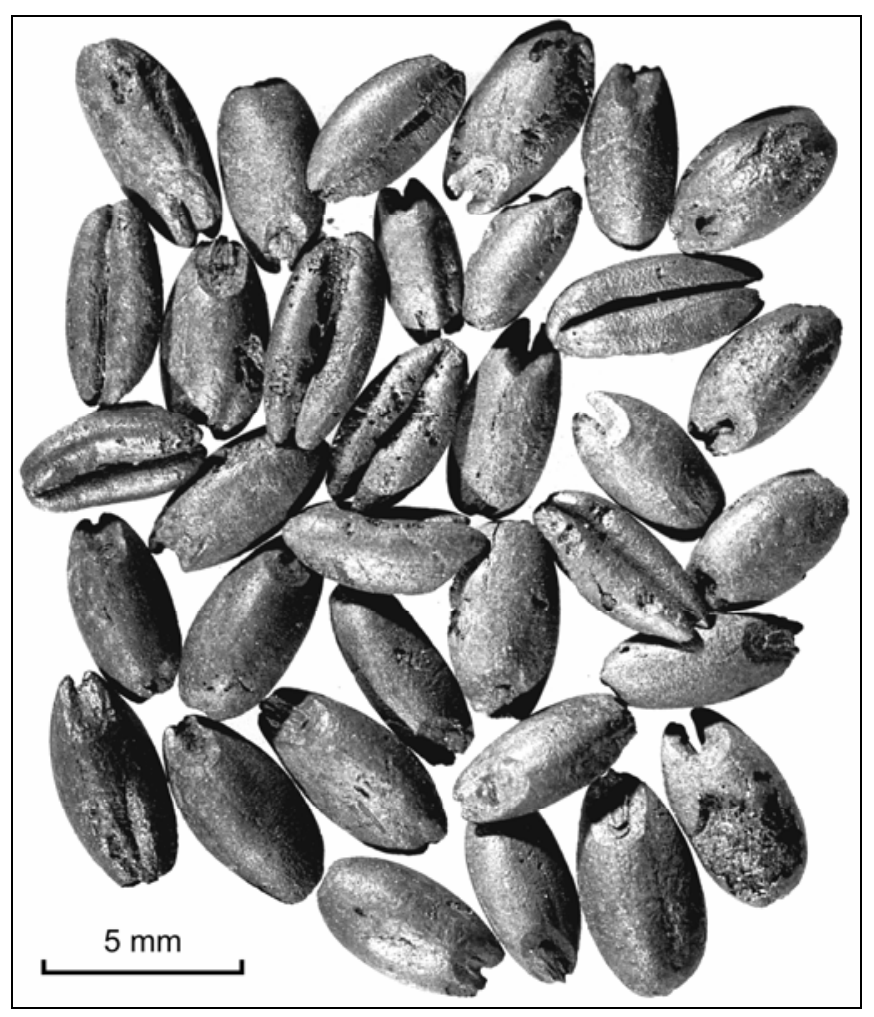

Abb. 19. Verkohlte, entspelzte Karyopsen von Triticum dicoccon (Emmer), jungbronzezeitlich, Befund 6273.

Neben den typisch ausgebildeten Rullstorfer Emmerkörnern kommen auffällig breite und flache Körner vor, die denen vom Dinkel ähneln (Abb. 19). Eine sichere Trennung von Emmer und Dinkel kann jedoch allein anhand der Körner nicht vorgenommen werden. Dazu sind Spelzengabeln und Spindelglieder erforderlich (Abb. 20).

Von 400 vermessenen Karyopsen liegt der Mittelwert des Längen-Höhen-Verhältnisses (L/H-Index) bei 2,4. Dieser Wert fällt gerade noch in den Bereich der für Emmer zu erwartenden Werte mit 1,57-2,5 (JACOMET 1987, 43). Einige der Rullstorfer Karyopsen haben einen deutlich höheren L/H-Index (max. 3,6), der eigentlich für Dinkelkörner charakteristisch ist. Diese recht flachen Karyopsen wurden schließlich zum Emmer gerechnet, da es im gesamten Fundspektrum keine sicheren Hinweise auf 
Tab. 18. Maße der verkohlten, entspelzten Karyopsen von Triticum monococcum aus Rullstorf.

\begin{tabular}{lcccll}
\hline & Körner [n] & Befund & Länge [mm] & Breite [mm] & Höhe [mm] \\
\hline jüngere Bronzezeit & 11 & 6273 & $4,7(4,2-5,5)$ & $1,9(1,3-2,4)$ & $2,1(1,2-2,5)$ \\
Vorröm. Eisenzeit, 1. Jh. v. Chr. (BEHRE 1990) & 8 & 10 & $4,7(4,4-5,1)$ & $2,1(2,0-2,3)$ & $2,3(2,1-2,5)$ \\
Römische Kaiserzeit & 1 & 6431 & 4,8 & 1,5 & 2,2 \\
\hline
\end{tabular}

Tab. 19. Maße der verkohlten Karyopsen von Triticum aestivum s. 1. aus Rullstorf.

\begin{tabular}{lccccc}
\hline & Körner [n] & Befund & Länge [mm] & Breite [mm] & Höhe [mm] \\
\hline jüngere Bronzezeit & 91 & 6273,6300 & $4,9(3,5-5,9)$ & $3,0(2,1-3,6)$ & $2,3(1,8-2,9)$ \\
Vorröm. Eisenzeit, 6.-2. Jh. v. Chr. (BEHRE 1990) & 36 & 2148 & $4,0(3,4-5,0)$ & $2,8(2,0-3,7)$ & $2,3(1,7-3,4)$ \\
& 43 & 2148 & $3,6(2,9-4,5)$ & $2,4(1,7-3,0)$ & $2,0(1,5-2,7)$ \\
& 66 & 2715 & $3,4(2,8-4,2)$ & $2,4(1,6-3,0)$ & $1,9(1,4-2,6)$ \\
\hline
\end{tabular}

Triticum spelta gibt. Es treten weder Spelzengabeln noch Spindelglieder mit eindeutigen Dinkel-Merkmalen auf. Vom Emmer konnten dagegen vereinzelt Spelzengabelhälften nachgewiesen werden.

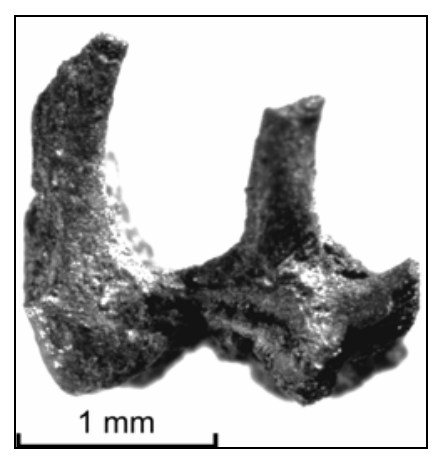

Abb. 20. Verkohlte Spelzengabel von Triticum dicoccon (Emmer), jungbronzezeitlich, Befund 6273.

Möglicherweise war dem Rullstorfer Emmer Dinkel beigemengt. Jedoch läßt das Material keine endgültige Entscheidung zu. Dinkel wurde wegen der Bestimmungsschwierigkeiten der entspelzten Körner bislang nur selten in Norddeutschland für die Bronze- und die Vorrömische Eisenzeit nachgewiesen (HOPF 1982, 10). Der größere Dinkelfund aus dem ältereisenzeitlichen Langenbek bei Hamburg (KUČAN 1986, 90 f.) belegt sein Vorkommen in der Region.

\subsubsection{Triticum monococcum - Einkorn}

Nomenklatur: Triticum monococcum L., Sp. Pl. (1753) 86 Funde: $\quad 25$ subfossile, verkohlte Karyopsen

Datierung: jüngere Bronzezeit, Vorrömische Eisenzeit, Römische Kaiserzeit
Die Karyopse des Einkorns ist hochrückig, die Rückenlinie ist gewölbt. Die Bauchlinie ist konvex ausgebildet. Die Körner sind sehr schmal, im Petrischälchen fallen sie in der Regel auf die Seite, im Gegensatz zu den Emmerkörnern, die meist auf der breiteren Bauchseite zu liegen kommen. Die Bauchfurche ist eng zusammengepreßt und tief (JACOMET 1987, 41).

Einkorn gehört neben Gerste und Emmer zu den ältesten Kulturpflanzen überhaupt.

In allen drei Zeithorizonten, in denen Einkorn aus Rullstorf nachgewiesen ist, war er von geringer Bedeutung. Stets wurden nur wenige Körner angetroffen.

\subsubsection{Triticum aestivum s. 1. - Saatweizen}

Nomenklatur: Triticum aestivum L., Sp. Pl. (1753) 85, em. Fiori et Paoletti, Fl. Ital. 1, 1 (1896) 107, p. p. (excl. T. turgidum, durum, spelta) und Triticum aestivum L. grex. aestivocompactum SCHIEM.

Funde: $\quad 147$ subfossile, verkohlte Karyopsen Datierung: jüngere Bronzezeit, Vorrömische Eisenzeit

In ähren- und kornmorphologischer Hinsicht können die beiden Nacktweizenformen Zwerg- und Saatweizen voneinander unterschieden werden. Im Gegensatz zum Saatweizen ist die Ähre des Zwergweizens kompakt ausgebildet, und seine Körner haben eine rundliche Form. Anhand des Längen-Breiten-Index (L/B-Index) können die Körner vom Saatweizen im engeren Sinne von denen des Zwergweizens abgetrennt werden. JACOMET $(1987,57)$ gibt einen Trennwert von 1,5 an. JÄGER $(1966,169)$ faßt hingegen den L/B-Index für Zwergweizen mit 1,20-1,60 etwas weiter. BEHRE $(1983,22)$ folgt dieser letzteren Angabe und ordnet Körner mit einem L/B-Index über 1,60 als sichere Saatweizen-Körner ein. Nach WERNECK (1955, 
105) können hingegen Körner mit einem L/B-Index von 1,56-1,67 nicht sicher zugeordnet werden.

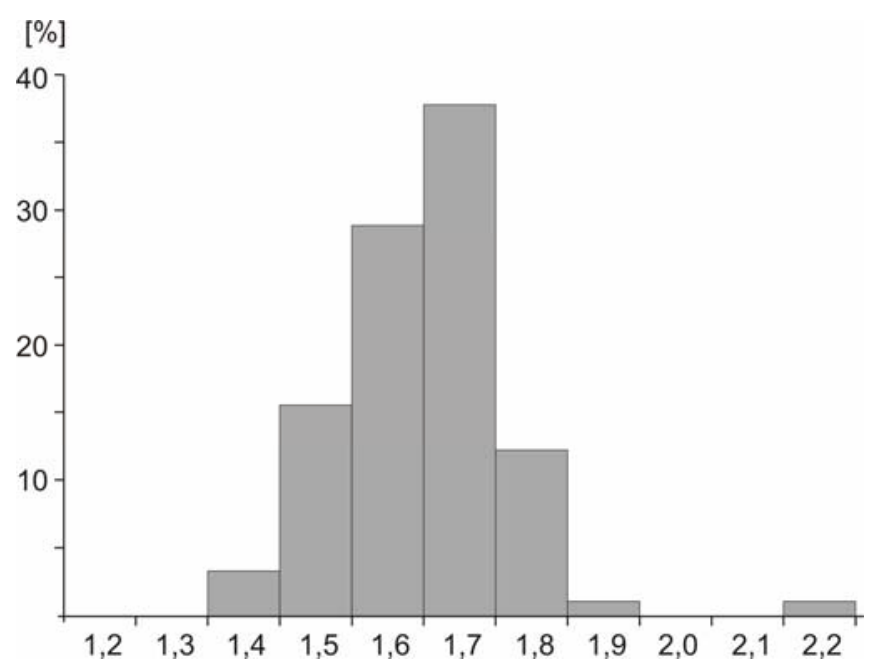

Abb. 21. Verteilungsdiagramm der Längen-Breiten-Indices von 90 Nacktweizenkörnern aus den Befunden 6273, 6300 u. 8389.

Der Zwergweizen ist nicht als eigenständige Art vom Saatweizen abzugrenzen (SCHIEMANN 1948, 53). Häufig kommen Mischpopulationen vor, denn Zwerg- und Saatweizen können sich miteinander kreuzen. Der Zwergweizen wird unter der Bezeichnung Triticum aestivocompactum systematisch zum Saatweizen gruppiert.

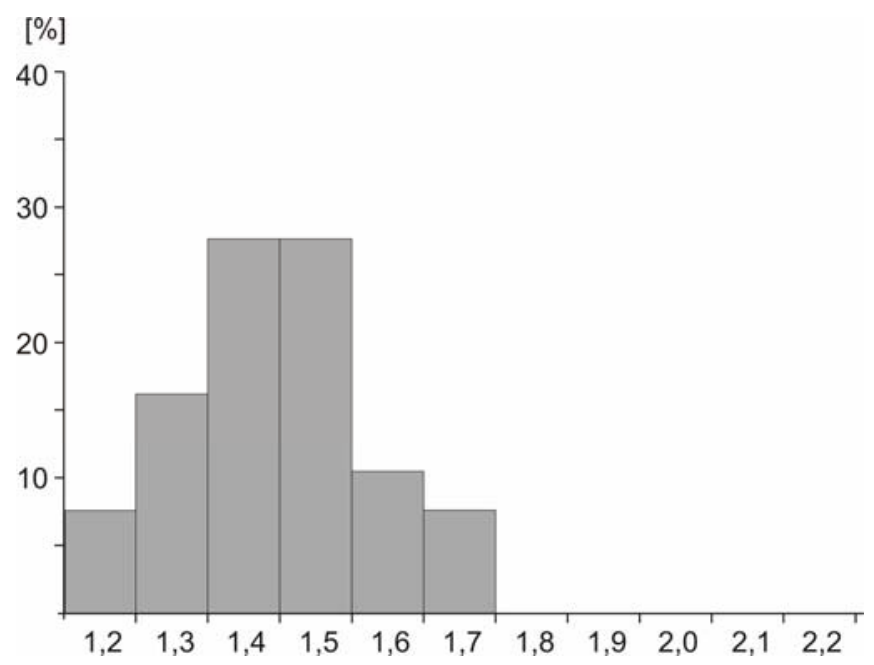

Abb. 22. Verteilungsdiagramm der Längen-Breiten-Indices von 36 Nacktweizenkörnern aus Befund 2148.

Der Saatweizen ist in Rullstorf von nachgeordneter Bedeutung. Seine absolute Häufigkeit liegt unter $2 \%$. Die Nacktweizenkörner erreichen eine Stetigkeit von höchstens $18 \%$. Vom Rullstorfer jungbronzezeitlichen Material konnten über den L/B-Index einzelne Körner als Zwergweizen bestimmt werden. Die meisten der Körner haben jedoch einen L/B-Index in den Größenklassen 1,6
$(1,55-1,65)$ und $1,7(1,65-1,75)$ (Abb. 21). Daher sind die jungbronzezeitlichen Nacktweizenkörner aus Rullstorf überwiegend als Saatweizen im engeren Sinne (Triticum aestivum s. str.) zu bewerten. Die wenigen morphologisch als Zwergweizen abtrennbaren Körner sind nicht einzeln aufgeführt. Tabellarisch sind die Saatweizenkörner als Saatweizen im weiteren Sinne (Triticum aestivum s. 1.) angegeben.

Das Verteilungsdiagramm der L/B-Indices der Nacktweizenkörner aus der Nachuntersuchung des Darrofens der Vorrömischen Eisenzeit (Befund 2148) zeigt einen Schwerpunkt in den Größenklassen 1,3 $(1,25-1,35)$ bis 1,5 (1,45-1,55) (Abb. 22). Der überwiegende Teil dieser vermessenen Körner muß als Zwergweizen angesprochen werden. BEHRE (1990, 153) wies aus den zwei Rullstorfer Darröfen (Befund 2148 u. 2715) beide Saatweizenformen nach. Das Ergebnis der nachuntersuchten Pflanzenreste bekräftigt die Annahme, daß in der Vorrömischen Eisenzeit in Rullstorf die beiden Formengruppen vom Saat- und vom Zwergweizen nebeneinander angebaut wurden.

Weder aus der Römischen Kaiserzeit noch aus dem Frühen Mittelalter waren Saatweizenkörner nachzuweisen.

\subsubsection{Avena sp. - Hafer}

Nomenklatur: Avena sp. L., Sp. Pl. (1753) 79. Pl. ed. 5 (1754) 34

Funde: $\quad 27$ subfossile, verkohlte entspelzte Karyopsen sowie 2 Spelzenreste

Datierung: jüngere Bronzezeit, Vorrömische Eisenzeit, Frühes Mittelalter

Die Karyopsen vom Hafer sind länglich, schlank und an den Enden abgerundet. Ihr Querschnitt ist rund, zur Bauchseite leicht abgeflacht. Die Bauchfurche ist eine sehr schmale, enge Rinne. Die in der vorliegenden Untersuchung in Rullstorf nachgewiesenen Haferkörner waren entspelzt, weshalb sie als Avena sp. kategorisiert sind.

Aus einem der ältereisenzeitlichen Darröfen (Befund 2148) stammen zwei Spelzenreste, die die Unterscheidungsmerkmale zwischen Saathafer und Flughafer jedoch nicht eindeutig erkennen lassen. Die Bruchkante der Spelzen läßt noch Reste des für Flughafer typischen Ringverschlusses zwischen Ährchen und Rispenstiel erahnen (Abb. 23). Bei beiden ist die Oberfläche sehr rauh. Vermutlich stammen diese Reste vom Flughafer (Avena fatua).

Der Saathafer (Avena sativa) ist eine sekundäre Kulturpflanze. Seine Abstammung ist bislang noch nicht endgültig geklärt. Auch die Geschichte seiner Domestikation in Mitteleuropa ist unsicher, da hier sowohl Wildhafer Avena fatua als auch die Kulturhafer Avena sativa und A. strigosa vorkommen. In der Morphologie weichen die Spelzen der verschiedenen Haferarten voneinander $a b$, hingegen sind die nackten Haferkörner 
Tab. 20. Maße der verkohlten, entspelzten Karyopsen von Avena sp. aus Rullstorf.

\begin{tabular}{lccccc}
\hline & Körner [n] & Befund & Länge [mm] & Breite [mm] & Höhe [mm] \\
\hline jüngere Bronzezeit & 6 & 6273 & $5,6(4,7-6,5)$ & $1,9(1,7-2,1)$ & $1,5(1,4-1,7)$ \\
Vorröm. Eisenzeit, 1. Jh. v. Chr. (BEHRE 1990) & 100 & 10 & $5,4(3,3-6,8)$ & $2,0(1,5-2,5)$ & $1,7(1,2-2,2)$ \\
& 100 & 104 & $5,6(3,4-7,1)$ & $2,0(1,3-2,5)$ & $1,7(1,0-2,2)$ \\
Frühes Mittelalter & 12 & 825 & $6,0(5,0-6,9)$ & $2,0(1,7-2,5)$ & $1,8(1,4-2,0)$ \\
\hline
\end{tabular}

morphologisch nicht zu unterscheiden. $\mathrm{Da}$ bei prähistorischen Funden meist nur die nackten Körner vorliegen, ist eine Artzuordnung dann nicht möglich. Daher ist die Geschichte des (Saat-) Hafers an prähistorischem Material schwer zu rekonstruieren (KÖRBER-GROHNE 1994, $57 \mathrm{f}$.$) .$

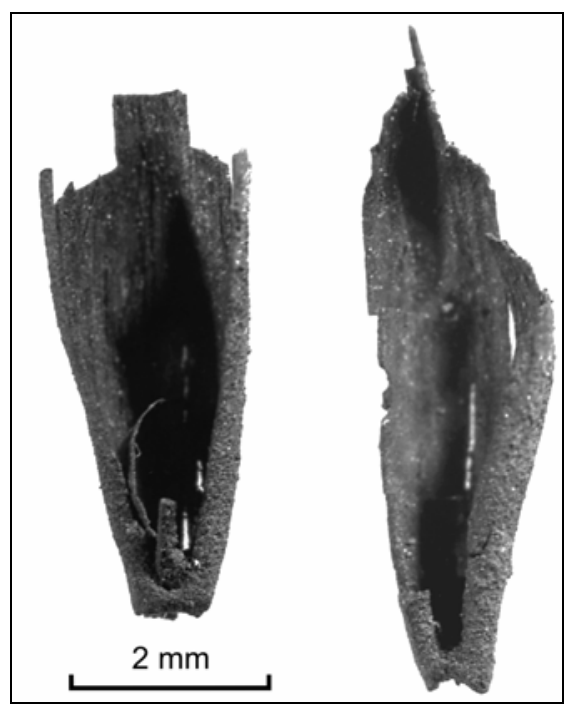

Abb. 23. Verkohlte Spelzenreste von Avena sp. (Hafer), ältereisenzeitlich, Befund 2148.

Die ältesten Funde einzelner Haferkörner datieren in Mitteleuropa in die Steinzeit und die Bronzezeit (KöRBERGROHNE 1994, 59). Ein wichtiger spätbronzezeitlicher Fund aus Langweiler, Ldkr. Jülich (KNÖRZER 1972, 399 f.), zeigt, daß Avena sativa und A. fatua dort nebeneinander als Beimengungen im Hauptgetreide vorkamen.

In der Vorrömischen Eisenzeit breitete sich der Hafer aus. Zunächst wurde er vermutlich noch nicht eigens ausgesät. Durch Anpassung an den Getreideanbau wurde er vom Menschen selektiert. Der früheste Beleg für den Reinanbau des Saathafers stammt schließlich aus Rullstorf und datiert ins 1. Jh. v. Chr. Dieser Fund ist der einzige sichere Nachweis, daß Saathafer schon in der Vorrömischen Eisenzeit getrennt kultiviert wurde und ist deshalb sehr wichtig. Der große Saathafervorrat enthielt eine Form, die noch das Wildpflanzenmerkmal der begrannten Spelze trug (BEHRE 1990, 150; KROLL 1980, 379).
Seit der Römischen Kaiserzeit wurde der Saathafer häufiger angebaut. Große Vorratsfunde stammen besonders von der Nordseeküste und von der Niederelbe. In Süddeutschland war der Hafer in der Römischen Kaiserzeit noch ein spärliches Unkraut im Sommergetreide. Sein Anbau wurde dort erst im Mittelalter üblich (KÖRBERGROHNE 1994, 59).

In der hier vorgelegten Untersuchung wurde Hafer nur in geringem Umfang nachgewiesen. Die mit Werten bis zu $3 \%$ am Kulturpflanzenspektrum beteiligten jungbronzezeitlichen und ältereisenzeitlichen Haferkörner stammen vermutlich vom Flughafer (Avena fatua).

Aus der Römischen Kaiserzeit wurde kein Hafer nachgewiesen. Unter den Funden aus dem sächsischen Gräberfeld in Rullstorf ist jedoch der Hafer mit 14 Körnern das zweithäufigste Getreide nach der Spelzgerste.

\subsubsection{Secale cereale - Roggen}

Nomenklatur: Secale cereale L., Sp. Pl. (1753) 84

Funde: $\quad 8$ subfossile Karyopsen

Datierung: jüngere Bronzezeit, Römische Kaiserzeit, Frühes Mittelalter

Das Roggenkorn hat ein spitzes Vorderende und parallele Seiten. Das Hinterende des Kornes ist hingegen stumpf. Der Embryo nimmt bis zu einem Drittel der Kornlänge ein. Der Querschnitt des Roggenkornes tendiert zu einer Herzform.

Die frühesten Funde einzelner Roggenkörner in Mitteleuropa datieren ins Neolithikum und in die Bronzezeit. Der Roggen ist eine sekundäre Kulturpflanze. Zunächst stand er als Unkraut in den Gersten- und Weizenfeldern. Der Unkrautroggen war an den Getreideanbau angepaßt. Er besaß bereits die wichtigsten morphologischen Merkmale einer Kulturpflanze wie die feste Ährenachse. Mit der Einführung der bodennahen Ernteweise in der Vorrömischen Eisenzeit war der Roggen begünstigt. Wurde er bei der zuvor ausgeführten Ährenernte ausgelesen, gelangte der Roggen jetzt bei der bodennahen Ernte ins geerntete Getreide. Der Reinanbau des Roggens begann in Mitteleuropa in der Römischen Kaiserzeit. Besonders auf armen Sandböden wie sie im norddeutschen Tiefland verbreitet sind, besa $\beta$ er gegenüber den anspruchsvolleren Getreiden einen Konkurrenzvorsprung. Eines der bzw. das Hauptgetreide war der Roggen in der 
Tab. 21. Maße der verkohlten, entspelzten Karyopsen von Secale cereale aus Rullstorf.

\begin{tabular}{lcccll}
\hline & Körner [n] & Befund & Länge [mm] & Breite [mm] & Höhe [mm] \\
\hline jüngere Bronzezeit & 2 & 6273 & $4,9(4,5-5,3)$ & $2,4(2,0-2,8)$ & $2,0(1,9-2,0)$ \\
Römische Kaiserzeit & 1 & 7150 & 5,2 & 2,9 & 2,3 \\
Frühes Mittelalter & 1 & 200 & 7,0 & 2,8 & 2,8 \\
Frühes Mittelalter (Kornabdruck, Lateralansicht) & 1 & 206 & 8,0 & - & 3,0 \\
\hline
\end{tabular}

Römischen Kaiserzeit in den prähistorischen Siedlungen Flögeln-Eekhöltjen und Loxstedt, beide Ldkr. Cuxhaven, sowie in Groß Meckelsen, Ldkr. Rotenburg, und Kosel bei Schleswig (BEHRE 1992, 146 f.; BEHRE u. KUČAN 1994, 36 f.; MÜLLER-WiLle et al. 1988, 63 f.). Der Roggen wurde $\mathrm{zu}$ dieser Zeit noch als Sommergetreide angebaut, vermutlich erreicht er deshalb in Pollendiagrammen nur sehr niedrige Prozentwerte. Zum wichtigsten Getreide wurde der Roggen schließlich zu Beginn des Mittelalters. Erst der mittelalterliche Winterroggenanbau führte zur Freisetzung sehr großer Pollenmengen (BEHRE 1992, 148 f.; KÖRBERGROHNE 1994, 40 f.).

In Rullstorf stand der Roggen in der Bronzezeit noch als Unkraut in den Äckern. In den reichhaltigen Vorratsfunden konnten zwei Karyopsen nachgewiesen werden. Sie kommen aus einem ungereinigten Gersten-Emmer-Vorrat, der auf $2880 \pm 30$ BP, kal. 1030 (1126-1001) v. Chr., datiert ist. Ein zweiter reiner Gersten-Emmer-Vorrat dieser Zeit enthält nur drei Unkrautreste auf 466 Getreidekaryopsen. Auch Roggen ist als unerwünschte Beimengung aus diesem Vorrat vermutlich ausgelesen worden. In der Vorrömischen Eisenzeit fehlt der Roggen in Rullstorf. Erst in der Römischen Kaiserzeit war er mit $26 \%$ das häufigste und mit $75 \%$ sogar das stetigste Getreide, wobei bemerkt werden muß, daß die vier Befunde des 2. Jh. n. Chr. nur einen beschränkten Einblick in diese Zeit gewähren. Aus dem frühmittelalterlichen Gräberfeld stammen nur ein einziges Roggenkorn sowie der Abdruck eines weiteren.

\subsubsection{Mengegetreide}

In zwei Erdspeichern aus der jüngeren Bronzezeit sind Spelzgerste und Emmer zu annähernd gleichen Teilen als Hauptgetreide vertreten (Tab. 30).

Bei den Rullstorfer Mischfunden aus den beiden Spelzgetreiden Emmer und Spelzgerste liegt es nahe anzunehmen, daß diese beiden Arten in der jüngeren Bronzezeit als Mengegetreide angebaut wurden: Stellen verschiedene Getreide gleiche Anforderungen an die Reinigung und lassen sie sich außerdem auch der gleichen Verwendung zuführen, so ist es sehr wahrscheinlich, daß diese Getreide einfachheitshalber auf derselben Fläche angebaut wurden (JACOMET et al. 1989, $160 \mathrm{f}$.). In prähistorischer Zeit wurde Getreide häufiger im Gemenge angebaut. In Archsum auf Sylt wies KrOLL (1975, 128 f.) anhand eines bronzezeitlichen Vorratsfundes den Anbau von Emmer mit Gerste nach. Dabei ist der Emmer wesentlich häufiger als die Spelzgerste. Die Gerste interpretiert er hier als Getreide, welches womöglich die Halme des starklaubigen, zum Lagern neigenden Emmers stützen sollte.

Der Anbau von Mengegetreide ist keineswegs auf Mitteleuropa beschränkt. Jüngst beschrieb MARINOVA (2001, 74) den Mischanbau von Emmer und Einkorn anhand neolithischen Materials aus Karanovo und Kapitan Dimitrievo in Südost-Bulgarien. In Griechenland wird noch heute eine Getreidemischung von Weizen mit Gerste ausgesät. Durch Gemengeanbau dieser beiden Arten kann die Gefahr einer totalen Mißernte abgewendet werden (JONES et al. 1986, 91). KUČAN $(1995,157)$ berichtet aus Bosnien, daß dort im 19. Jh. und in Notzeiten auch im 20. Jh. verschiedene Getreidearten im Gemenge kultiviert wurden. Auch in Deutschland war der Sommer- und Wintermengegetreideanbau im 20. Jh. üblich. Während in Nord- und Mitteldeutschland vorwiegend Gemenge aus Gerste, Hafer und Sommerroggen angebaut wurden, war in Süddeutschland ein Winterroggen-Winterweizen-Gemenge verbreitet (BROUWER 1972, 454 f. u. 474).

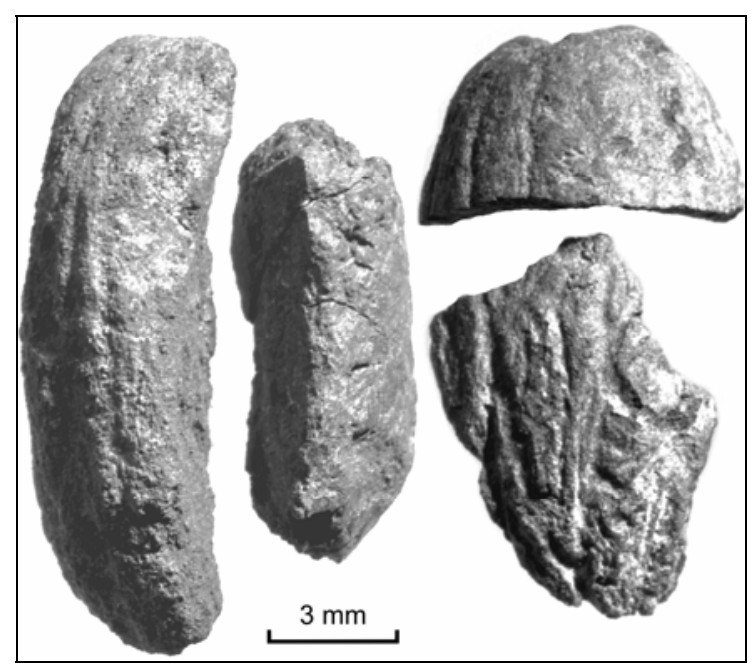

Abb. 24. Verkohlte Bruchstücke von Kotyledonen von Quercus sp. (Bruchstücke von EichelKeimblättern), jungbronzezeitlich, Befund 6273.

\subsubsection{Sammelpflanzen}

Sammelpflanzen wurden in Rullstorf kaum nachgewiesen. Besonders Obst und Beeren gelangen in 
prähistorischen Siedlungen nur selten zur Verkohlung. In größerer Zahl kommen in der jüngeren Bronzezeit 42 Bruchstücke der Kotyledonen von Eicheln vor (Abb. 24). Daneben treten auch einzelne Apfelkerne (Abb. 25) und Haselnußschalen (Abb. 26) auf.

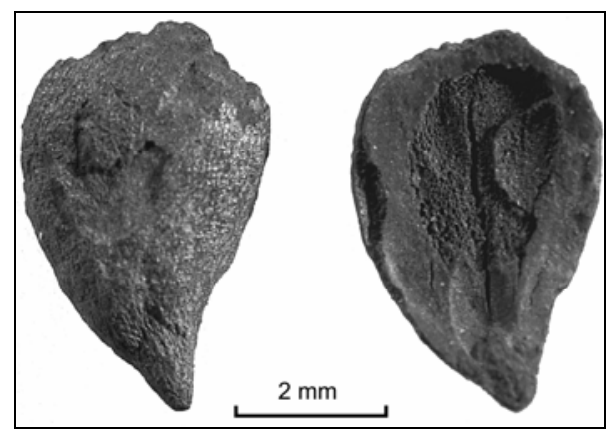

Abb. 25. Verkohlte Kerne von Malus sp. (Apfel), jungbronzezeitlich, Befund 6273.

Eicheln enthalten eine große Menge Bitterstoffe (Tannine). Sie müssen, sofern sie vom Menschen verzehrt und nicht als Viehfutter genutzt werden sollen, entgiftet werden. Andernfalls würden die Tannine eine Eiweißfällung im Magen hervorrufen. Um die Tannine auszuwaschen, werden die Eicheln über mehrere Tage in Wasser eingelegt und gekocht (BAUER et al. 1995, 5). Bruchstücke der Keimblätter von Eicheln wurden des öfteren in prähistorischem Material bestimmt (BEHRE u. KUČAN 1994, $34 \mathrm{u}$. dort zitierte Autoren). Sie sind in Rullstorf die am häufigsten auftretenden Sammelpflanzen in der jüngeren

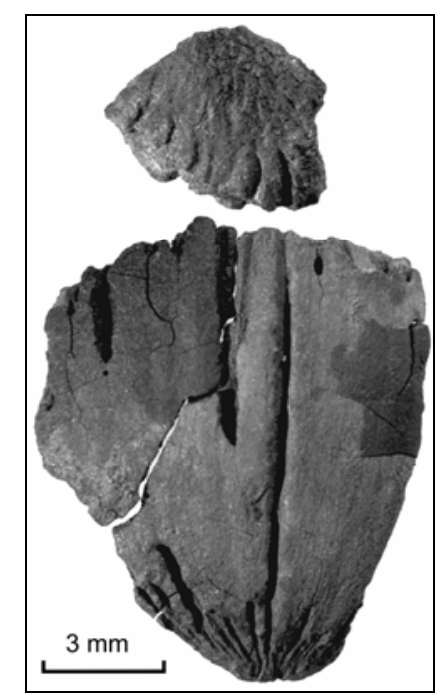

Abb. 26. Verkohlte Bruchstücke des Perikarps von Nüssen von Corylus avellana (Bruchstücke von Haselnußschalen), jungbronzezeitlich, Befund 6273.

Bronzezeit. Aus der bronzezeitlichen Siedlung bei Schmalstede im Ldkr. Rendsburg-Eckernförde konnte HoPF
(1973, 203 f.) mit Trockenäpfeln vergesellschaftete Eicheln nachweisen. Dort wurden die Eicheln nach dem Schälen und Halbieren ebenso gedörrt wie die Äpfel. In Flögeln, Ldkr. Cuxhaven, wurde ein bronzezeitliches Gefäß ausgegraben, welches 39 verkohlte Keimblätter von Eicheln bzw. deren Bruchstücke enthielt (BEHRE u. KUČAN 1994, 34). In Hesel kommen aus der Wende der Bronze- zur Eisenzeit als einzige Funde von Sammelpflanzen zwölf halbe Eicheln vor (BEHRE 1998, 286).

\subsubsection{Polygonum lapathifolium - Ampferknöterich als mögliche Nahrungspflanze?}

Der Vorrat aus Befund 8225 (Tab. 30) fällt durch die hohe Zahl der Früchte vom Ampferknöterich auf. 297 dieser Früchte (Abb. 27) sind mit 150 Karyopsen der Rispenhirse vermengt. Daneben liegen in weit geringerer Zahl auch Reste von Polygonum convolvulus und P. persicaria sowie jeweils ein Samen von Chenopodium album und eine Karyopse Bromus secalinus vor. Es ist unwahrscheinlich,

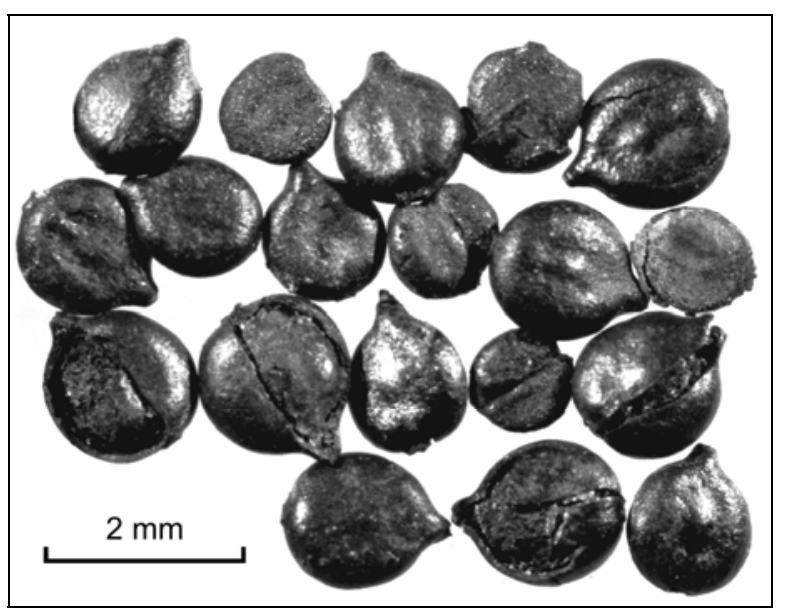

Abb. 27. Verkohlte Früchte von Polygonum lapathifolium (Ampferknöterich), jungbronzezeitlich, Befund 8225.

daß ein Getreidevorrat durch die Früchte nur eines bestimmten Unkrautes derart stark verunreinigt ist. Eventuell war die Beimengung der eiweißhaltigen Früchte des Ampferknöterichs erwünscht, denn inzwischen ist bekannt, daß sie beispielsweise in der Eisenzeit zur normalen Kost gehörten. Zuletzt konnte BEHRE (1999, 77 f.) dieses bei der Untersuchung des Magen- und Darminhaltes einer Moorleiche, des „Jungen von Kayhausen“, belegen. Auch bei botanischen Untersuchungen an den Magen- und Darminhalten der Moorleichen von Tollund, Grauballe und Borremose aus Dänemark (HELBÆK 1951, 316; 1958, 84 f.; BRANDT 1951, 342 f.; BROTHWELL 1986, 92; VAN DER SANDEN 1996, $108 \mathrm{f}$.), der Moorleiche aus dem Lindow Moss („Lindow Man“) in Großbritannien (HoLDEN 1986, 118) und der Moorleiche von Dätgen in Schleswig-Holstein (MARTIN 1967, 77 f.), die allesamt in die Vorrömische Eisenzeit datieren, wurde der Ampferknöterich 
Tab. 22. Unkrautreste der jüngeren Bronzezeit und des 6.-2. Jh. v. Chr. in Rullstorf nach pflanzensoziologischer Gruppierung (absolute Häufigkeiten). In den Spalten unter dem $\Sigma$-Zeichen sind die neu erhobenen Daten und die Daten von BEHRE (1990) zusammengefaßt.

\begin{tabular}{rl|cccccc}
\hline jüngere Bronzezeit & Vorrömische Eisenzeit & & & \\
& & eigene & BEHRE & $\Sigma$ & eigene & $\Sigma$ & \\
Daten & $(1990)$ & & Daten & & \\
& {$[\mathrm{n}]$} & {$[\%]$} & {$[\mathrm{n}]$} & {$[\mathrm{n}]$} & {$[\mathrm{n}]$} & {$[\%]$} & {$[\%]$} \\
\hline
\end{tabular}

Unkräuter des Sommergetreides und der Hackfrüchte

\begin{tabular}{lrr|rrrrrr}
\hline Chenopodium album s. 1. & 127 & 13,82 & 50 & 140 & 190 & 11,66 & 3,06 & Weißer Gänsefuß \\
Chenopodium cf. ficifolium & 1 & 0,11 & 7 & - & 7 & 1,63 & 0,11 & Feigenblättriger Gänsefuß \\
Chenop. cf. polyspermum & - & - & - & 2 & 2 & - & 0,03 & Vielsamiger Gänsefuß \\
Echinochloa crus-galli & 5 & 0,54 & 52 & 753 & 805 & 12,12 & 12,98 & Hühnerhirse \\
Polygonum aviculare & 2 & 0,22 & 3 & 2 & 5 & 0,70 & 0,08 & Vogelknöterich \\
Polygonum lapathifolium & 431 & 46,79 & 201 & 3407 & 3608 & 46,85 & 58,18 & Ampferknöterich \\
Polygonum persicaria & 191 & 20,78 & 42 & 1020 & 1062 & 9,79 & 17,13 & Flohknöterich \\
Setaria viridis & - & - & 15 & 36 & 51 & 3,50 & 0,82 & Grüne Borstenhirse \\
Solanum nigrum & - & - & - & 1 & 1 & - & 0,02 & Schwarzer Nachtschatten \\
Urtica urens & 1 & 0,11 & - & 2 & 2 & - & 0,03 & Kleine Brennessel \\
\hline Summe & 758 & 82,37 & 370 & 5363 & 5733 & 86,25 & 92,44 &
\end{tabular}

Unkräuter des Sommer- und Wintergetreides

\begin{tabular}{|c|c|c|c|c|c|c|c|c|}
\hline Avena fatua & - & - & - & 2 & 2 & - & 0,03 & Flughafer \\
\hline Bromus secalinus & 1 & 0,11 & 4 & - & 4 & 0,93 & 0,06 & Roggentrespe \\
\hline cf. Sinapis arvensis & - & - & - & 268 & 268 & - & 4,32 & Acker-Senf \\
\hline Galeopsis segetum & - & - & - & 1 & 1 & - & 0,02 & Gelber Hohlzahn \\
\hline Galeopsis tetrahit/speciosa & - & - & - & 8 & 8 & - & 0,13 & Gewöhnl./Bunter Hohlzahn \\
\hline Galium cf. spurium & - & - & - & 20 & 20 & - & 0,32 & Saat-Labkraut \\
\hline Polygonum convolvulus & 142 & 15,45 & 6 & 65 & 71 & 1,40 & 1,14 & Windenknöterich \\
\hline Rumex acetosella & 1 & 0,11 & 17 & 23 & 40 & 3,96 & 0,65 & Kleiner Sauerampfer \\
\hline Scleranthus annuus, Kelche & 3 & 0,33 & 1 & - & 1 & 0,23 & 0,02 & Einjähriges Knäuelkraut \\
\hline Spergula arvensis & 4 & 0,44 & 30 & 15 & 45 & 6,99 & 0,73 & Ackerspörgel \\
\hline Urtica dioica & - & - & 1 & - & 1 & 0,23 & 0,02 & Große Brennessel \\
\hline Vicia hirsuta & - & - & - & 3 & 3 & - & 0,05 & Rauhhaarwicke \\
\hline Vicia cf. tetraspermum & 3 & 0,33 & - & - & - & - & - & Viersamige Wicke \\
\hline Viola tricolor & 5 & 0,54 & - & 4 & 4 & - & 0,06 & Acker-Veilchen \\
\hline Summe & 159 & 17,31 & 59 & 409 & 468 & 13,74 & 7,55 & \\
\hline
\end{tabular}

Weitere

\begin{tabular}{|c|c|c|c|c|c|c|c|c|}
\hline Lychnis flos-cuculi & 1 & 0,11 & - & - & - & - & 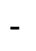 & Kuckucks-Lichtnelke \\
\hline Viscaria cf. vulgaris & 2 & 0,22 & - & - & - & - & - & Gewöhnliche Pechnelke \\
\hline
\end{tabular}

nachgewiesen. Der Rullstorfer Vorrat aus Ampferknöterich und Rispenhirse ist vermutlich ebenfalls als Nahrungsvorrat anzusprechen. Zudem wurde das klassische Hackfruchtunkraut Ampferknöterich wahrscheinlich auf der Ackerfläche gesammelt, auf der die Hirse angebaut wurde. Es ist durchaus nicht ungewöhnlich, daß in Getreidebeständen eine zweite Frucht steht, die keineswegs eine Halmfrucht ist. KÖRBER-GROHNE (1994, 49), zitiert den Hinweis von JÄNICHEN (1970), daß heutzutage auf der Schwäbischen Alb Lens culinaris (Linse) zwischen der Gerste ausgesät wird.

\subsubsection{Unkräuter aus den Kulturpflanzenproben}

22.532 nachgewiesene Kulturpflanzenreste stehen in Rullstorf bei der vorliegenden Untersuchung 1380 Unkrautresten gegenüber (Tab. 30). Letztere stammen aus den Vorratsgruben und Darröfen der Jüngeren Bronzeund Vorrömischen Eisenzeit. Als wichtigste Unkrautarten kommen Ampfer-, Floh- und Windenknöterich sowie Weißer Gänsefuß vor (Tab. 30). Der Ampferknöterich kann jedoch zum Teil als Nahrungspflanze gewertet werden (Kap. 4.3.4). 
Die Unkräuter und die Getreide, die aus einer Vorratsgrube stammen, gehören vermutlich zu einer PaläoBiozönose. Aus diesem Grund gibt der Unkrautbesatz der Getreidevorräte Auskunft über die Anbauweise der Kulturpflanzen. In den Tab. 22-24 wurden die Unkräuter berücksichtigt, die sich bis auf die Gattung bzw. bis zur Art bestimmen ließen.

\subsubsection{Sommer- oder Wintergetreide?}

Die Unkrautarten sind nach dem aktualistischen Prinzip den pflanzensoziologischen Klassen der Sommergetreide und Hackfrüchte (Chenopodietea) sowie der Sommer- und Wintergetreide (Secalietea) zugewiesen (Tab. 22).

Einige Arten wie Polygonum convolvulus, Spergula arvensis und Galeopsis tetrahit sind keineswegs streng an Secalietea-Gesellschaften gebunden, sie kommen auch in den Polygono-Chenopodietalia-Gesellschaften vor. Die Einordnung ist problematisch, da die Natur der Deckfrucht oftmals unerheblich ist und vielmehr Faktoren wie die Nährstoffversorgung, die Art der Bodenbearbeitung und die Keimungstemperatur für das Vorkommen eines Unkrautes maßgeblich sind (ELLENBERG 1996, 878 f.).

Die hohen Prozentwerte der als Sommergetreide- und Hackfruchtunkräuter ausgewiesenen Unkräuter (82 bzw. $92 \%$ ) lassen vermuten, daß in Rullstorf in der jüngeren Bronzezeit und in der Vorrömischen Eisenzeit Sommergetreide angebaut wurde.

Ein Wintergetreideanbau kann dennoch nicht vollständig ausgeschlossen werden. Viele der Chenopodietea-Arten benötigen eine hohe Keimungstemperatur und sind daher durch einen späten Keimungstermin gekennzeichnet. Nur ein dicht geschlossen stehendes Wintergetreide verhindert das Aufkommen dieser spätkeimenden Arten. Jedoch waren die Getreidebestände in prähistorischer Zeit generell lückenhaft, da die Bodenbearbeitung damals mit dem einfachen Hakenpflug vorgenommen wurde. Deshalb konnten sich spätkeimende Unkräuter, die heute der Gruppe der Sommergetreideunkräuter zugeordnet werden, auch in Wintergetreidebeständen entwickeln (WILLERDING 1986, 334 f.).

\subsubsection{Bodennahe oder bodenferne Ernteweise?}

Das Unkrautspektrum der Vorratsgruben und Darröfen kann in hochwüchsige und niedrigwüchsige Arten gegliedert werden. Da bei der Ernte Blütenteile, Früchte und Samen von Getreideunkräutern ins Erntegut gelangen, kann das Unkrautspektrum über die Ernteweise Auskunft geben. Reste niedrigwüchsiger Arten gelangen bei bodennaher Ernte mit der Sense ins Erntegut. In geringem Umfang sind sie auch dann im Getreidevorrat vertreten, wenn sich das Getreide vor der Ernte gelegt hat (s. u.). Hingegen werden hochwüchsige und kletternde Arten bei der bodenfernen Ernte erfaßt. Während bei der bodenfernen Ährenernte der „klassischen“ Getreide wie Weizen und Gerste die Getreidehalme in Bündeln gegriffen und die Ähren mit der Sichel geschnitten wurden, lassen sich die Hirsekörner ernten, indem die Rispen büschelweise erfaßt und über einem Korb ausgeschlagen werden oder mit einer kammartigen Schaufel, ähnlich dem Heidelbeerkamm, durchfahren werden (GoY 1938, 20 f.).

Tiefschneidende Bronzesicheln wurden wahrscheinlich schon in der Bronzezeit eingesetzt, da des öfteren, wenngleich nur in geringer Zahl, auch niedrigwüchsige Unkrautarten in den Pflanzenrestspektren erfaßt sind (KNÖRZER 1991, 194).

Nun zeigt die Aufstellung in Tab. 23, daß im Rullstorfer jungbronzezeitlichen Material die hochwüchsigen Kräuter mit $98 \%$ bei weitem überwiegen. Reste niedrigwüchsiger Arten wie beispielsweise Blütenkelche von Scleranthus annuus sind hingegen in sehr geringem Umfang in die Befunde gelangt. In Rullstorf wurde daher in der jüngeren Bronzezeit die bodenferne Ernteweise ausgeführt.

Bei Betrachtung der Nachuntersuchung für das 6.-2. Jh. v. Chr. (Tab. 24) ergibt sich eine bemerkenswerte Verschiebung im Unkrautspektrum: Der Anteil der niedrigwüchsigen Unkräuter erreicht annähernd $12 \%$. Dieser relativ hohe Wert geht auf die große Zahl der Nachweise von Spergula arvensis zurück, die jedoch eventuell absichtlich in die Getreidevorräte gelangt sind. Der meist als Ackerunkraut klassifizierte Ackerspörgel wurde auch als Sammelpflanze genutzt. Heute wird er als Zwischenfrucht für Grünfutter angebaut (BEHRE u. KUČAN 1994, 47).

Wird die Summe aus allen Unkrautresten dieses Zeithorizontes gebildet, liegt der Anteil der niedrigwüchsigen Arten unter $2 \%$. Dieser Wert kommt den Angaben von BEHRE (1990, 160) nahe. Das von ihm untersuchte Material war aus sehr großen Erdproben bereits auf der Grabung von Hilfskräften ausgeschlämmt worden.

Als methodischer Aspekt zeigt sich, daß wegen des sehr großen Probenvolumens das Unkrautspektrum in den Untersuchungen von BEHRE (1990) vollständig erfaßt wurde. Die Nachuntersuchungen bestätigen das bereits festgestellte Unkrautspektrum. Jedoch konnte der Anteil der nachgewiesenen kleinen Früchte und Samen am Unkrautspektrum, die zumeist von niedrigwüchsigen Arten stammen, durch sorgfältige Probenaufbereitung erhöht werden. Neben dem Probenvolumen hat demnach auch die Probenaufbereitung maßgeblichen Einfluß auf die Zusammensetzung des Artenspektrums.

Die Ernteweise in der Vorrömischen Eisenzeit änderte sich gegenüber der jüngeren Bronzezeit nicht. Es wurde weiterhin bodenfern geerntet, denn 98 bzw. $88 \%$ der Unkrautreste stammen von hochwüchsigen Arten. Die Pflanzenreste der niedrigwüchsigen Arten zeigen, daß sich das Getreide in der Vorrömischen Eisenzeit teilweise vor 
Tab. 23. Verkohlte Unkrautreste der jüngeren Bronzezeit aus Rullstorf nach Wuchsformen.

\begin{tabular}{ll|rr|rrr}
\hline \multirow{2}{*}{} & \multirow{2}{*}{ Wuchs } & \multicolumn{2}{|c|}{ Häufigkeit } & \multicolumn{2}{c}{ Stetigkeit } & \\
& & {$[\mathrm{n}]$} & {$[\%]$} & {$[\mathrm{n}]$} & {$[\%]$} & \\
\hline Chenopodium album s. 1. & hoch & 127 & 13,82 & 5 & 15,79 & Weißer Gänsefuß \\
Chenopodium cf. ficifolium & hoch & 1 & 0,11 & 1 & 2,63 & Feigenblättriger Gänsefuß \\
Polygonum convolvulus & hoch & 142 & 15,45 & 5 & 18,42 & Windenknöterich \\
Polygonum lapathifolium & hoch & 431 & 46,90 & 8 & 26,32 & Ampferknöterich \\
Polygonum persicaria & hoch & 191 & 20,78 & 11 & 31,58 & Flohknöterich \\
Viscaria cf. vulgaris & hoch & 2 & 0,22 & 1 & 2,63 & Gewöhnliche Pechnelke \\
Vicia cf. tetraspermum & hoch & 3 & 0,33 & 2 & 5,26 & Viersamige Wicke \\
Echinochloa crus-galli & hoch & 5 & 0,54 & 2 & 5,26 & Hühnerhirse \\
Bromus secalinus & hoch & 1 & 0,11 & 1 & 2,63 & Roggentrespe \\
\hline Summe & & 903 & 98,26 & & & Vogelknöterich \\
\hline Polygonum aviculare & niedrig & 2 & 0,22 & 1 & 5,26 & Kleiner Sauerampfer \\
Rumex acetosella & niedrig & 1 & 0,11 & 1 & 2,63 & Einjähriges Knäuelkraut \\
Scleranthus annuus & niedrig & 3 & 0,33 & 2 & 5,26 & Ackerspörgel \\
Spergula arvensis & niedrig & 4 & 0,44 & 2 & 5,26 & Kleine Brennessel \\
Urtica urens & niedrig & 1 & 0,11 & 2 & 2,63 & Ackerveilchen \\
Viola tricolor s. l. & niedrig & 5 & 0,54 & 1 & 2,63 & \\
\hline Summe & & 16 & 1,74 & 38 & 38,00 & \\
\hline
\end{tabular}

Tab. 24. Verkohlte Unkrautreste des 6.-2. Jh. v. Chr. in Rullstorf nach Wuchsformen.In den Spalten unter dem $\Sigma$-Zeichen sind die neu erhobenen Daten und die Daten von BeHRE (1990) zusammengefaßt.

\begin{tabular}{|c|c|c|c|c|c|c|c|c|}
\hline & Wuchs & $\begin{array}{c}\text { eigene } \\
\text { Daten } \\
{[\mathrm{n}]}\end{array}$ & $\begin{array}{c}\text { BEHRE } \\
(1990) \\
{[\mathrm{n}]}\end{array}$ & $\begin{array}{c}\Sigma \\
{[\mathrm{n}]}\end{array}$ & $\begin{array}{c}\text { eigene } \\
\text { Daten } \\
\%\end{array}$ & $\begin{array}{c}\Sigma \\
{[\%]}\end{array}$ & $\begin{array}{c}\text { Stetigkeit } \\
\quad \Sigma[\mathrm{n}]\end{array}$ & \\
\hline Chenopodium album s. 1. & hoch & 50 & 140 & 190 & 11,66 & 3,06 & 2 & Weißer Gänsefuß \\
\hline Chenopodium cf. ficifolium & hoch & 7 & - & 7 & 1,63 & 0,11 & 1 & Feigenblättriger Gänsefuß \\
\hline Chenopodium cf. polyspermum & hoch & - & 2 & 2 & - & 0,03 & 1 & Vielsamiger Gänsefuß \\
\hline Polygonum convolvulus & hoch & 6 & 65 & 71 & 1,40 & 1,14 & 3 & Windenknöterich \\
\hline Polygonum lapathifolium & hoch & 201 & 3407 & 3608 & 46,85 & 58,18 & 4 & Ampferknöterich \\
\hline Polygonum persicaria & hoch & 42 & 1020 & 1062 & 9,79 & 17,13 & 5 & Flohknöterich \\
\hline Urtica dioica & hoch & 1 & - & 1 & 0,23 & 0,02 & 1 & Große Brennessel \\
\hline Galeopsis tetrahit/speciosa & hoch & - & 8 & 8 & - & 0,13 & 1 & Gewöhnl./Bunter Hohlzahn \\
\hline Galeopsis segetum & hoch & - & 1 & 1 & - & 0,02 & 1 & Gelber Hohlzahn \\
\hline Galium cf. spurium & hoch & - & 20 & 20 & - & 0,32 & 2 & Saat-Labkraut \\
\hline Vicia hirsuta & hoch & - & 3 & 3 & - & 0,05 & 2 & Rauhhaarwicke \\
\hline cf. Sinapis arvensis & hoch & - & 268 & 268 & - & 4,32 & 2 & ähnlich Acker-Senf \\
\hline Avena fatua & hoch & - & 2 & 2 & - & 0,03 & 2 & Flughafer \\
\hline Bromus secalinus & hoch & 4 & - & 4 & 0,93 & 0,06 & 1 & Roggentrespe \\
\hline Echinochloa crus-galli & hoch & 52 & 753 & 805 & 12,12 & 12,98 & 2 & Hühnerhirse \\
\hline Setaria viridis & hoch & 15 & 36 & 51 & 3,50 & 0,82 & 2 & Grüne Borstenhirse \\
\hline Summe & & 378 & 5725 & 6103 & 88,11 & 98,42 & 10 & \\
\hline Polygonum $a$ & niedrig & 3 & 2 & 5 & 0,70 & 0,08 & 3 & Vogelknöterich \\
\hline Rumex acetosella & niedrig & 17 & 23 & 40 & 3,96 & 0,65 & 2 & Kleiner Sauerampfer \\
\hline Scleranthus annuus, Kelch & niedrig & 1 & - & 1 & 0,23 & 0,02 & 1 & Einjähriges Knäuelkraut \\
\hline Spergula arvensis & niedrig & 30 & 15 & 45 & 6,99 & 0,73 & 2 & Ackerspörgel \\
\hline Urtica urens & niedrig & - & 2 & 2 & - & 0,03 & 1 & Kleine Brennessel \\
\hline Viola tricolor & niedrig & - & 4 & 4 & - & 0,06 & 2 & Acker-Veilchen \\
\hline Solanum nigrum & niedrig & - & 1 & 1 & - & 0,02 & 1 & Schwarzer Nachtschatten \\
\hline Summe & & 51 & 47 & 98 & 11,89 & 1,58 & 10 & \\
\hline
\end{tabular}


Tab. 25. Auswahl der in Rullstorf nachgewiesenen Unkrautarten und ihre Bodenfaktoren (ELLENBERG et al. 1992,11 f.).

\begin{tabular}{lccrr}
\hline & Feuchtezahl (F) & Reaktionszahl (R) & Stickstoffzahl (N) \\
\hline Chenopodium album s. 1. & 4 & $\mathrm{x}$ & 7 & Weißer Gänsefuß \\
Polygonum convolvulus & 5 & $\mathrm{x}$ & 6 & Windenknöterich \\
Polygonum lapathifolium & 8 & $\mathrm{x}$ & 8 & Ampferknöterich \\
Polygonum persicaria & 5 & 7 & 7 & Flohknöterich \\
Sinapis arvensis & $\mathrm{x}$ & 8 & 6 & Ackersenf \\
Echinochloa crus-galli & 5 & $\mathrm{x}$ & 6 & Hühnerhirse \\
Spergula arvensis & 5 & 3 & 6 & Ackerspörgel \\
Rumex acetosella agg. acetosella & 3 & 2 & 2 & Kleiner Sauerampfer \\
Scleranthus annuus, Kelch & 5 & 2 & 5 & Einjähriges Knäuelkraut \\
\hline
\end{tabular}

Erläuterungen

\begin{tabular}{llll}
\hline & Feuchtezahl (F) & Reaktionszahl (R) & Stickstoffzahl (N) \\
\hline 1 & Starktrockniszeiger & Starksäurezeiger & stickstoffärmste Standorte \\
2 & $\downarrow$ & $\downarrow$ & $\downarrow$ \\
3 & Trockniszeiger & Säurezeiger & stickstoffarme Standorte \\
4 & Trocknis- bis Frischezeiger & $\downarrow$ & $\downarrow$ \\
5 & Frischezeiger & Mäßigsäurezeiger & mäßig stickstoffreiche Standorte \\
6 & Frische- bis Feuchtezeiger & $\downarrow$ & $\downarrow$ \\
7 & Feuchtezeiger & Schwachsäure- bis Schwachbasenzeiger & stickstoffreiche Standorte \\
8 & Feuchte- bis Nässezeiger & $\downarrow$ & ausgesprochene Stickstoffzeiger \\
9 & Nässezeiger & Basen- u. Kalkzeiger & übermäßig stickstoffreiche Standorte \\
$\mathrm{x}$ & indifferent & indifferent & indifferent \\
\hline
\end{tabular}

der Ernte gelegt hat und so mit dem Boden in Berührung kam. Aus diesem Grund gelangten Reste niedrigwüchsiger Unkräuter in das Erntegut (BEHRE 1976, 10). Zudem wurde der Ackerspörgel, dessen Samen großen Anteil an den Nachweisen der niedrigwüchsigen Unkräuter haben, möglicherweise auch als Sammelpflanze nach dem Mähen der Felder abgeerntet (BEHRE u. KUČAN 1994, 47).

\subsubsection{Bodengüte der Ackerflächen}

Von den ökologischen Zeigerwerten (ELLENBERG et al. 1992, 11 f.) können nach dem aktualistischen Prinzip Hinweise auf die Standorte der Pflanzen abgelesen werden (Tab. 25). Insbesondere die drei Bodenfaktoren Feuchtigkeit, Bodenreaktion und Stickstoffversorgung können Auskunft über die Beschaffenheit der Herkunftsflächen der Pflanzen geben.

In den jungbronzezeitlichen Vorratsgruben sind die vier Unkrautarten Ampfer-, Floh- und Windenknöterich sowie Weißer Gänsefuß am häufigsten und auch am stetigsten vertreten. In der Vorrömischen Eisenzeit erreichen zudem Echinochloa crus-galli und Sinapis arvensis höhere Werte. Alle diese Arten wachsen auf frischen bis feuchten Böden. Sie bevorzugen neutrale Böden oder sind gegenüber der Bodenreaktion indifferent. Zudem kommen diese Arten meist auf Böden mit guter Stickstoffversorgung vor. Folglich ist anzunehmen, daß die in Rullstorf genutzten
Ackerflächen gedüngt wurden. Vermutlich geschah dies, indem das Vieh auf den abgeernteten Feldern oder auf den Brachen geweidet wurde.

Die wenigen Nachweise von Scleranthus annuus, von Rumex acetosella und von Spergula arvensis belegen, daß vereinzelt auch Säurezeiger zum Unkrautspektrum der jüngeren Bronzezeit und der Vorrömischen Eisenzeit in Rullstorf gehörten. Demnach kamen in der Umgebung von Rullstorf auch saure Böden vor.

\subsubsection{Funde von Mutterkorn (Claviceps purpurea)}

Vier Sklerotien vom Mutterkorn sind als besondere Funde aus einem Gersten- und Emmervorrat der jüngeren Bronzezeit hervorzuheben (Abb. 28). Das Alter der mit ihnen vergesellschafteten Getreidekörner beläuft sich auf $2880 \pm 30$ BP, kal. 1030 (1126-1001) v. Chr. Unter den Makroresten aus den Darröfen der Vorrömischen Eisenzeitl in Rullstorf befanden sich 19 Sklerotien des Mutterkorns (BEHRE 1990, 160).

Der Nachweis des Mutterkorns in prähistorischem Material gelang bisher sehr selten. Aus dem schottischen Myrehead stammen zwei spätbronzezeitliche Befunde, die neben Weizen, Gerste und einzelnen Roggenkörnern jeweils ein Mutterkornsklerotium enthalten. Weitere Funde datieren 
in jüngere Zeiten (AARONSON 1989, 248 u. dort zitierte Autoren).

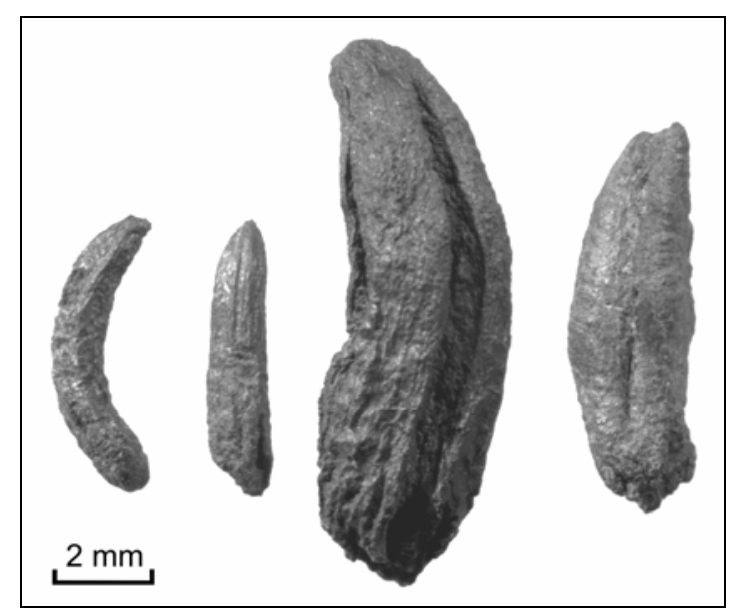

Abb. 28. Verkohlte Sklerotien von Claviceps purpurea (Mutterkorn), jungbronzezeitlich, Befund 6273.

Der Erreger des Mutterkorns ist der Schlauchpilz Claviceps purpurea. Die Pilzsporen werden vom Wind auf die Fruchtknoten der Getreideblüten getragen und induzieren dort das Wachstum der Sklerotien an Stelle des Getreidekorns. Dieser Pilz kann alle Getreidearten befallen (BECKER-Dillingen 1927, 181, 304, 418, 500, 581). Heute ist er auf dem windblütigen Roggen am häufigsten verbreitet. In Rullstorf kam er höchstwahrscheinlich auf Emmer oder auf Gerste oder vielleicht auch auf beiden Arten vor. Mutterkorn enthält giftige Alkaloide. Seinen Namen bekam es, weil es in der Medizin als wehenförderndes Mittel und als Abortivum eingesetzt wurde. Der Verzehr großer Mengen Mutterkorn ruft Gliederschmerzen, Erbrechen und Durchfall hervor, schädigt das Nervensystem und führt schließlich zum Tode. In der Neuzeit gab es mehrfach Mutterkornepidemien, die Vergiftungsfolgen wurden auch als „Antoniusfeuer“ bezeichnet (BROCKHAUS 1932, 105; VAN DER SANDEN 1996, 119)

Mit Hilfe des Tausend-Korn-Gewichts von rezentem Emmer aus biologisch-dynamischen Anbau, welches KÖRBER-GroHNE $(1994,27)$ mit 36,7 g angibt, kann das Frischkorngewicht der Körner aus dem Rullstorfer Getreidevorrat (Befund 6273) ermittelt werden. Die 13.800 Gersten- und Emmerkörner hätten demnach ein Gewicht von ca. $500 \mathrm{~g}$. Auf diese $500 \mathrm{~g}$ Getreide entfallen vier Mutterkornsklerotien. Heute sind in Deutschland in anzuerkennendem Saatgut bis zu drei Mutterkornsklerotien auf 500 g Getreide zugelassen (BROUWER 1972, 240). Ohne Mutterkornbekämpfung im Getreideacker und ohne Saatgutreinigung wäre der Mutterkornanteil im Getreide heute viel höher, als er es in der Bronzezeit war.

Der Befall von Gerste und Emmer in der jüngeren Bronzezeit hielt sich also in Grenzen. In dem gereinigten jungbronzezeitlichen Getreidevorrat (Befund 6300) sind keine Mutterkornsklerotien enthalten. Das Mutterkorn aus dem ungereinigten Vorrat wäre vermutlich vor der Weiterverarbeitung noch ausgelesen worden.

\section{4 $\mathrm{Zu}$ Landwirtschaft und Ernährung in Rullstorf seit der jüngeren Bronzezeit}

Die Rullstorfer Pflanzenreste geben Auskunft über die vegetabilen Ernährungsgrundlagen der Siedler von der Bronzezeit bis ins Frühe Mittelalter. Im Laufe der Zeit änderte sich das Kulturpflanzenspektrum, wie es die Fundtabellen (Kap. 4.3) und das Diagramm (Abb. 29) erkennen lassen. Da jedoch in den verschiedenen Zeithorizonten die Probenzahlen (3-38) und auch die Fundzahlen (23-20.895) stark variieren, dürfen die Prozentwerte einzelner Taxa aus den verschiedenen Zeithorizonten nicht unmittelbar miteinander verglichen werden. Vielmehr gilt es zu beobachten, daß einzelne Arten verschwinden und neue Arten zum Kulturpflanzenspektrum hinzutreten. Wegen der hohen Proben- und Fundzahlen liegen in Rullstorf die aus archäobotanischer Sicht aussagekräftigsten Zeithorizonte in der jüngeren Bronzezeit und in der Vorrömischen Eisenzeit.

Wie es für die Geest im allgemeinen gilt, wurden auch in Rullstorf unter den Kulturpflanzen in allen Zeitabschnitten Getreide am häufigsten nachgewiesen. Getreide ist in verkohltem Material jedoch generell überrepräsentiert. Das ist darauf zurückzuführen, daß Getreidekörner zur Lagerung über dem Feuer getrocknet und geröstet wurden und auch bei der Essenszubereitung leicht mit dem Feuer in Berührung kamen. Insbesondere die Spelzgetreide haben große Verkohlungschancen, da sie, um entspelzt werden zu können, vermutlich gedarrt oder geröstet wurden. Seltener sind in verkohltem Material ölhaltige Früchte wie solche des Leins anzutreffen (WILLERDING 1991, 43 f.). Sofern sie überhaupt erhitzt wurden, sind sie anschließend oftmals bis zur Unkenntlichkeit deformiert und folglich kaum zu bestimmen. Trotz der unterschiedlichen Repräsentanz der Arten gewährt das verkohlte Pflanzenmaterial Einblick in die Lebensverhältnisse der Rullstorfer Bevölkerung.

\subsubsection{Nahrungspflanzen der Rullstorfer Siedler}

Für die Versorgung der Rullstorfer Siedler mit Kohlenhydraten stand zu allen Zeiten die Gerste, insbesondere die Spelzgerste, zur Verfügung, die vermutlich zu Grütze verarbeitet wurde.

Neben der mit einer weiten ökologischen Amplitude ausgestatteten Gerste spielte in der jüngeren Bronzezeit der stärkehaltige, kleberreiche Emmer noch eine bedeutende Rolle, aus dessen Korn überwiegend Brei und in geringem Umfang auch Brot hergestellt wurden. Sein Anteil geht jedoch im Verlauf der Eisenzeit zurück (Abb. 29). In der Zeit nach Christi Geburt scheinen die Spelzweizenarten Emmer und auch Einkorn höhere Werte zu erreichen. Dies darf jedoch nicht über ihren Bedeutungsverlust 


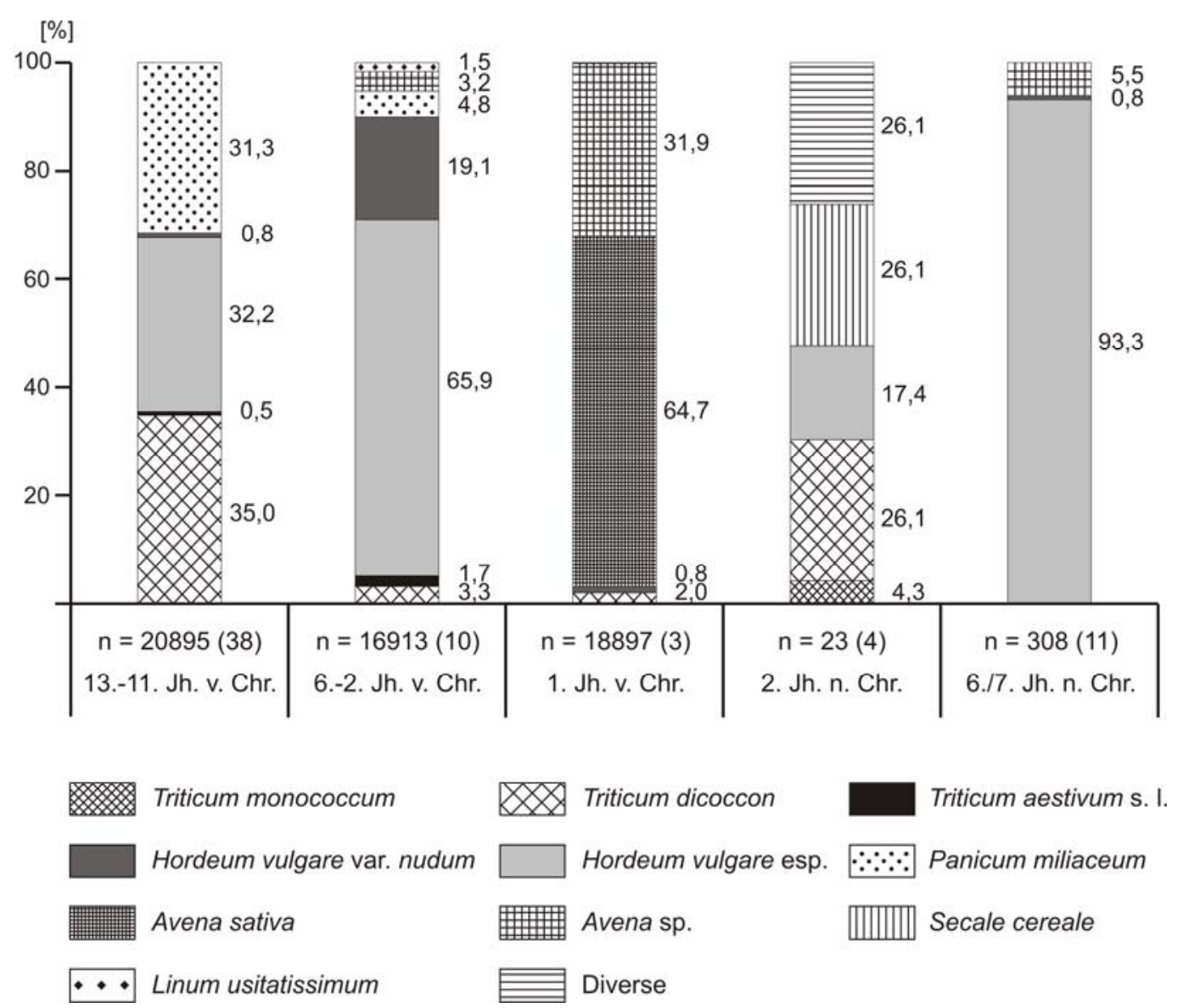

Abb. 29. Verkohlte Getreidereste der verschiedenen Zeithorizonte in Rullstorf in Prozentwerten nach den absoluten Häufigkeiten (Werte $<0,4 \%$ sind den Fundtabellen in Kap. $4.3 \mathrm{zu}$ entnehmen). In Klammern ist die jeweilige Probenzahl angegeben. Die jungbronzezeitliche Datierung basiert auf der ${ }^{14} \mathrm{C}$-Methode, alle weiteren Datierungen wurden anhand der Keramik vorgenommen.

hinwegtäuschen, denn der geringe Fundumfang gibt die Anteile der verschiedenen Kulturpflanzenarten verzerrt wieder.

Selten ist das klassische Brotgetreide Saatweizen im Rullstorfer Fundspektrum vertreten. Die armen Sandböden der Altmoränenlandschaft bei Rullstorf sind für den Anbau des anspruchsvollen Saatweizens wenig geeignet. Dennoch wurde diese Nacktweizenart in Rullstorf angebaut.

In erheblichem Ausmaß wird der jungbronzezeitliche Getreidebestand hingegen durch die Rispenhirse erweitert, die sich leicht erwärmende Sandböden und sandige Lehmböden bevorzugt. Hirse wurde in Norddeutschland bislang selten in archäobotanischem Material nachgewiesen. Sowohl für die Rispenhirse als auch für die Gerste ist ihre Verarbeitung zu Grütze und Brei anzunehmen. Spätestens jedoch seit dem Fund eines Brotes aus Hirse und Gerste im Ipweger Moor (BEHRE 1991b) ist bekannt, daß beide Getreide auch zur Herstellung von Backwerk genutzt wurden.

Hafer und Roggen wurden erst während der Eisenzeit als Kulturpflanzen etabliert. Saathafer ist eine sekundäre
Kulturpflanze und wurde als solche erst durch den Ackerbau treibenden Menschen selektiert. Die Abstammung des Saathafers ist bislang jedoch noch nicht endgültig geklärt (KÖRBER-GROHNE 1994, 56 f.). Der Saathafer wurde von den Rullstorfer Siedlern des 1. Jh. v. Chr. angebaut. Für Norddeutschland ist der Rullstorfer Saathafervorrat der älteste sichere Nachweis seines Anbaus in Monokultur. Hafer ist besonders fett- und proteinreich. Um gedeihen zu können, bevorzugt er ein gemäßigtes Klima mit hohem Niederschlag und hoher Luftfeuchtigkeit.

Auch der Roggen ist eine sekundäre Kulturpflanze. Als Unkrautroggen mit Kulturpflanzenmerkmalen konnte er sich im Laufe der Zeit besonders auf armen Sandböden gegenüber anspruchsvollen Getreidearten durchsetzen. Die Einführung der bodennahen Ernteweise in der Vorrömischen Eisenzeit bewirkte, daß der Roggen bei der Ernte nicht mehr ausgelesen wurde. So gelangte er ins Saatgut und breitete sich als konkurrenzstarke Art in den Getreidefeldern immer weiter aus. Für die Römische Kaiserzeit konnte schließlich sein gezielter Anbau als Sommergetreide mehrfach nachgewiesen werden (BEHRE 1992, 146 f.; 2001, 76; MÜLLER-WILLE et al. 1988, 63 f.). In Rullstorf wurde Unkrautroggen für die jüngere Bronzezeit 
nachgewiesen. Als Brotgetreide erweiterte der Roggen das Nahrungsangebot der Siedler seit dem 2. Jh. n. Chr.

Ölhaltige Früchte und Samen sind, wie oben angeführt, selten unter verkohlten Pflanzenresten anzutreffen. Der Rullstorfer Lein stammt aus der Vorrömischen Eisenzeit und fügt sich daher ins Bild der norddeutschen Leinfunde, denn dort ist der Lein (Linum usitatissimum), der seit dem Neolithikum zum mitteleuropäischen Kulturpflanzeninventar zählt, ebenfalls erst seit der älteren Eisenzeit nachgewiesen (KÖRBER-GROHNE 1994, 373). Unverkohlte Reste des Leins traten beispielsweise in großen Mengen in Feuchtbodensiedlungen wie den ältereisenzeitlichen Siedlungen Hatzum-Boomborg und Oldendorp an der Ems auf (BEHRE 1970, 39 f.; BRANDT u. BEHRE 1976, 454).

Lieferanten von vegetabilem Eiweiß wie Linse (Lens culinaris) und Erbse (Pisum sativum), die in Mitteleuropa bereits zur Zeit der ältesten Ackerbauernkultur (der neolithischen Bandkeramik) einen wichtigen Beitrag zur Ernährung leisteten, sind in Rullstorf gleichfalls erst in der Vorrömischen Eisenzeit im Fundspektrum vertreten. Als weitere Hülsenfrucht ist die Ackerbohne (Vicia faba), die nicht mit dem Ensemble neolithischer Kulturpflanzen nach Mitteleuropa gekommen ist, sondern deren älteste Funde in die Bronzezeit datieren (BEHRE 1998, 101; SCHULTZEMotel 1994, 36), in Rullstorf mit einem einzigen Exemplar in der Vorrömischen Eisenzeit nachgewiesen. Dieses fügt sich ins Bild der mitteldeutschen bronze- und eisenzeitlichen Funde ein (Schultze-Motel 1973, 127 f.). Vicia faba, die Pferde- oder Ackerbohne, war in den norddeutschen Marschensiedlungen seit der Römischen Kaiserzeit meist eine der wichtigsten Kulturpflanzen. In den kaiserzeitlichen und frühmittelalterlichen Wurtensiedlungen Feddersen Wierde, Ldkr. Cuxhaven (KöRBER-GROHNE 1967, 174 f.), Elisenhof und Tofting, Schleswig-Holstein (BEHRE 1976, 15 f. u. 72) sowie in Niens, Butjadingen (BEHRE 1991, 151), waren neben Samen besonders viele Stengelbruchstücke und Hülsen erhalten. Auf der norddeutschen Geest sind Pferdebohnennachweise hingegen selten. Im völkerwanderungszeitlichen Loxstedt-Littstücke im Ldkr. Cuxhaven erreichte die Pferdebohne immerhin 3,6\% am Kulturpflanzenspektrum (BEHRE 1998b, 295).

Als Sammelpflanzen werden Wildpflanzen bezeichnet, von denen Teile gesammelt und genutzt werden. Häufig ist der Status einer Pflanze als Sammelpflanze ein historisch bedingter, vorübergehender Zustand (WILLERDING 1978, 13). Für Rullstorf sind besonders die einheimische Eiche und Hasel als Sammelpflanzen hervorzuheben. Eicheln enthalten wie Haselnüsse sehr viel Fett und ergänzen dadurch die kohlenhydrathaltige Nahrung der Siedler. Eicheln können nach dem Rösten verzehrt oder wegen ihres hohen Stärkegehaltes auch gemahlen und dem Getreidemehl beigemengt werden.

Vitaminhaltiges Obst wurde in allen Zeiten gesammelt. Für Rullstorf sind Apfel, Schlehe und Walderdbeere zumindest in der jüngeren Bronzezeit und der Vorrömischen Eisenzeit belegt.
Die Siedler in Rullstorf verstanden es, das naturräumliche Potential der die Siedlung umgebenden Altmoränenlandschaft zu nutzen. Sowohl die Gerste als auch die Rispenhirse sind Feldfrüchte, die auf den dortigen Sandböden gut gedeihen. Sammelfrüchte wie die Eichel, die Haselnuß und die Walderdbeere konnten den im Umfeld der Siedlung verbreiteten Eichenmischwäldern entnommen werden (Kap. 3.4.2 und 3.4.3).

\subsubsection{Zum jüngerbronzezeitlichen Kulturpflanzenspektrum}

Die wesentliche agrartechnische Neuerung in Mitteleuropa während der Bronzezeit war der Einsatz von Zugtieren zum Pflügen der Äcker. Der rindergezogene Ard löste den vom Menschen gezogenen Handhaken ab. Er erleichterte den Ackerbau erheblich und führte zur Ausdehnung der Ackerfläche. Durch diesen agrartechnischen Fortschritt stieg die Bedeutung pflanzlicher gegenüber tierischer Kost (BEHRE 1998a, 96 f.). Obwohl die Kenntnis des Kulturpflanzenbestandes im nördlichen Mitteleuropa in der Bronzezeit noch lückenhaft ist, zeigen archäobotanische Untersuchungen, daß in der Bronzezeit neue Arten kultiviert wurden. Aus dem Neolithikum wurden als Grundbestand die Spelzweizenarten Emmer und Einkorn übernommen. Als neue Arten treten Rispenhirse, Dinkel und Acker- oder Pferdebohne hinzu (BEHRE 1998a, 101 f.).

Viele der bronzezeitlichen Kulturpflanzennachweise stammen nur von einzelnen Körnern oder deren Abdrücken (HoPF 1982). Umfangreiche Funde aus der mittleren Bronzezeit gibt es in den Niederlanden und in Westfalen (vgl. BAKEls 1991; BuURMANN 1979; NeEF 1985). Aus den ostdeutschen Bundesländern sind nur wenige bronzezeitliche Fundstellen bekannt, von denen wiederum nur einige in jüngerer Zeit archäobotanisch bearbeitet wurden. Häufig wurden dort Hülsenfrüchte nachgewiesen. So setzt sich ein jungbronzezeitlicher Fund aus dem thüringischen Nebra an der Unstrut überwiegend aus Samen von Pferde- bzw. Ackerbohne, Erbse und Linse zusammen. Zudem treten Gerste und Emmer auf (SCHULTZE-MOTEL 1973, 127 f.). Bei Drehna in der Niederlausitz liegt ein mittelbronzezeitliches Gräberfeld, aus dem Bruchstücke von verkohlten Hirsefladen oder verkohltem Hirsebrei, außerdem Ackerbohnen, Linsen sowie Saatweizen und Gerste sichergestellt wurden (RÖSLER 1983, 62).

Wichtige bronzezeitliche und in den Übergang von der Bronze- zur Eisenzeit datierende Fundstellen archäobotanischen Materials aus Nordwestdeutschland sind in Tab. 26 zusammengestellt.

Unter den bronzezeitlichen Fundstellen Nordwestdeutschlands kommt der jungbronzezeitlichen Siedlung bei Rullstorf eine herausragende Stellung zu: Unter 20.895 verkohlten Kulturpflanzenresten aus 38 Vorratsgruben wurden 8 verschiedene Taxa nachgewiesen. Keine andere der in Tab. 26 aufgeführten 


\begin{tabular}{|c|c|c|c|c|c|c|c|c|c|c|c|c|c|c|}
\hline Lokalität & $\begin{array}{c}\text { unkalibrierte } \\
\text { Radiokarbondaten } \\
\text { bzw. Zeitstufe }\end{array}$ & $\begin{array}{c}\text { kalibrierte } \\
\text { Radiokarbondaten } \\
\text { (kalibriert mit Calib 4.3) }\end{array}$ & $\begin{array}{l}0 \\
\text { ปั } \\
\frac{3}{3} \\
\vdots \\
5 \\
\frac{0}{1} \\
\frac{1}{0}\end{array}$ & 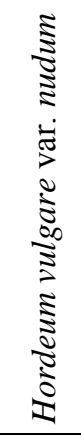 & 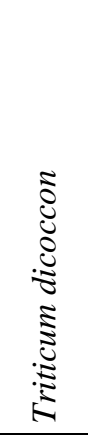 & 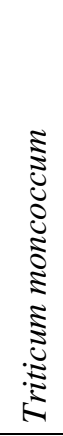 & 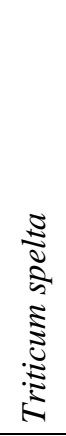 & 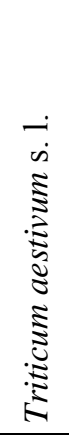 & $\begin{array}{l}\frac{\tilde{J}}{\tilde{u}} \\
\frac{\tilde{u}}{u} \\
\frac{\tilde{U}}{\tilde{U}} \\
\tilde{U}\end{array}$ & $\begin{array}{l}\dot{2} \\
\text { के } \\
0 \\
\dot{0} \\
\dot{\nabla}\end{array}$ & 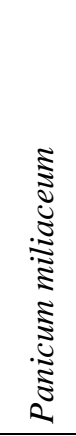 & $\begin{array}{c}\text { Zahl } \\
\text { der } \\
\text { Taxa }\end{array}$ & $\begin{array}{c}\text { Zahl } \\
\text { der } \\
\text { Proben }\end{array}$ & Kornzahl \\
\hline 1 Hünzingen, Ldkr. Rotenburg (Wümme) & ältere BZ & - & + & - & ++ & - & - & - & - & $\mathrm{r}$ & - & 3 & unbek. & 378 \\
\hline 2 Inden, Ldkr. Jülich (KNÖRZER 1968) & - & 1250 v. Chr.* & +++ & - & +++ & + & + & - & - & - & +++ & 5 & 1 & unbek. \\
\hline 3 Gittrup, Münster (NEEF 1985) & - & 1220 v. Chr.* & + & - & ++ & - & - & ++ & - & - & +++ & 4 & 1 & 1300 \\
\hline 4 Rullstorf, Ldkr. Lüneburg & $\begin{array}{l}2963 \pm 29 \mathrm{BP} \\
2880 \pm 30 \mathrm{BP}\end{array}$ & $\begin{array}{l}1176(1259-1127) \text { v. Chr. } \\
1030(1126-1001) \text { v. Chr. }\end{array}$ & +++ & + & +++ & + & - & + & $\mathrm{r}$ & + & +++ & 8 & 38 & 20895 \\
\hline 5 Brill, Ldkr. Wittmund (BEHRE 1979) & $2845 \pm 50 \mathrm{BP}$ & $1001(1049-922)$ v. Chr. & +++ & - & ++ & - & - & - & - & - & - & 2 & 5 & 19668 \\
\hline 6 Harkenbleck, Ldkr. Hannover (BEHRE 1982) & $2735 \pm 65 \mathrm{BP}$ & 877 ( $969-818)$ v. Chr. & + & $\mathrm{r}$ & +++ & $\mathrm{r}$ & - & - & - & - & $\mathrm{r}$ & 5 & 3 & 4047 \\
\hline 7 Wiesens, Ldkr. Aurich (BEHRE 1982) & $2550 \pm 355 \mathrm{BP}$ & $786(1110-205) \mathrm{v} . \mathrm{Chr}$. & $\mathrm{r}$ & +++ & - & - & - & - & - & - & - & 2 & 1 & 4671 \\
\hline $\begin{array}{l}8 \text { Flögeln-Eekhöltjen, Ldkr. Cuxhaven } \\
\text { (BEHRE u. KUČAN 1994) }\end{array}$ & $2450 \pm 65 \mathrm{BP}$ & $532(763-405)$ v. Chr. & ++ & + & + & $\mathrm{r}$ & - & + & - & ++ & - & 6 & 1 & 918 \\
\hline 9 Lemke, Ldkr. Nienburg (BEHRE 1998b) & $2445 \pm 65 \mathrm{BP}$ & $534(762-404)$ v. Chr. & +++ & + & + & - & - & + & - & + & - & 5 & 1 & 3356 \\
\hline 10 Altenwalde, Ldkr. Cuxhaven (BEHRE 1998b) & Wende BZ/EZ & - & + & +++ & - & - & - & + & $\mathrm{r}$ & + & $\mathrm{r}$ & 6 & 5 & 16456 \\
\hline 11 Appeln, Ldkr. Cuxhaven (BEHRE 1998b) & Wende BZ/EZ & - & $\mathrm{r}$ & + & + & - & - & + & - & - & $\mathrm{r}$ & 5 & 8 & 33 \\
\hline 12 Hesel, Ldkr. Leer (BEHRE 1998b) & Wende BZ/EZ & - & +++ & - & $\mathrm{r}$ & - & - & - & - & + & - & 3 & 1 & 4184 \\
\hline \multirow[t]{2}{*}{13 Marmstorf bei Hamburg (BEHRE 1998b) } & Wende BZ/EZ & - & + & - & $\mathrm{r}$ & - & - & - & - & $\mathrm{r}$ & - & 3 & 1 & 13 \\
\hline & & & 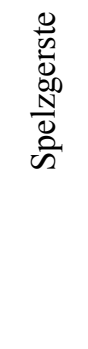 & 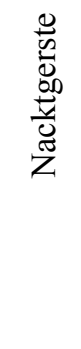 & $\underset{\Xi}{\grave{\Xi}}$ & $\begin{array}{l}\Xi \\
\stackrel{0}{\Xi} \\
\text { 迅 }\end{array}$ & 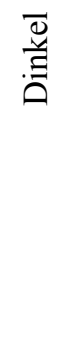 & 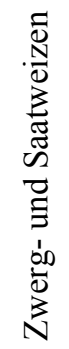 & $\begin{array}{l}0 \\
0 \\
00 \\
0 \\
0 \\
01\end{array}$ & 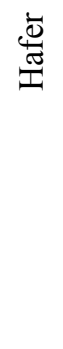 & 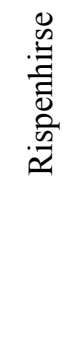 & & & \\
\hline
\end{tabular}

$\mathrm{r}=1-2$ Exemplare; + bis $+++=$ steigende Häufigkeit.

Mit * versehene Angaben wurden direkt aus der Literatur übernommen, Angaben BP lagen hier nicht vor. 
Grabungen weist einen ähnlich hohen Fundreichtum auf. Dennoch decken sich die in Rullstorf nachgewiesenen Taxa mit denen aus den benachbarten Gebieten.

Das Kulturpflanzenspektrum aus bronzezeitlich datierten Ausgrabungen in Nordwestdeutschland wird zumeist von Gerste und Emmer dominiert (KNÖRZER 1971, 193 f.). Dieses gilt vor allem für die älteren Fundstellen (Hünzingen bis Brill, Tab. 26), darunter auch Rullstorf. Nacktgerstenanbau, der in Rullstorf nur in geringem Umfang stattfand, ist durch die großen Vorratsfunde aus Wiesens und Altenwalde für den Übergang der jüngeren Bronze- zur Eisenzeit belegt. Auffällig ist, daß die Nachweise des Emmers generell am Übergang zur Eisenzeit ausdünnen. Während der Bronzezeit wurde der im südlichen Mitteleuropa zum sicheren Kulturpflanzenbestand zählende Nacktweizen nur selten in der Altmoränenlandschaft Nordwestdeutschlands angebaut (BEHRE 1998a, $101 \mathrm{f}$.). Roggen stand in der Bronzezeit noch als Unkraut in den Getreideäckern. Einzelne Körner vom Hafer treten in den meisten archäobotanisch untersuchten bronzezeitlichen Fundstellen auf. In Flögeln, Ldkr. Cuxhaven, wurde eine Haferart vermutlich bereits in der späten Bronzezeit kultiviert (BEHRE u. KUČAN 1994, 31 f.). Die Rullstorfer prähistorischen Pflanzenreste zeichnen sich dadurch aus, daß sie den Saathaferanbau in Norddeutschland schon in der Vorrömischen Eisenzeit absichern.

Die ältesten großen Rispenhirse-Vorratsfunde Norddeutschlands stammen ebenfalls aus dem verkohlten Rullstorfer Material. Sie bestätigen, daß diese so wichtige Kulturpflanze der in Ostdeutschland verbreiteten Lausitzer Kultur und der in Süddeutschland verbreiteten Urnenfelderkultur (KÜSTER 1997, 5) während der jüngeren Bronzezeit auch in Nordwestdeutschland angebaut wurde. Wie es der Beleg eines einzelnen Kornes aus der Siedlung „Im Örtjen“ bei Flögeln, Ldkr. Cuxhaven, zeigt, war die Rispenhirse in dieser Region jedoch schon seit dem Neolithikum bekannt (BEHRE u. KUČAN 1994, 39). In Altenwalde und in Appeln, Ldkr. Cuxhaven, wurden einzelne Rispenhirsekörner aus der Wende von der Bronzezur Eisenzeit nachgewiesen (BEHRE 1998, 284 f.). Ein weiterer großer norddeutscher Rispenhirsefund aus Stelle bei Hamburg stammt hingegen erst aus dem 1. Jh. v. Chr. (KROLL 1980, 376 f.).

Schon für den Beginn des 4. Jahrtausends v. Chr. wies KNÖRZER (1972, 397) ein Rispenhirsekorn in Langweiler, Kr. Jülich, im Rheinland nach. In Westfalen und im mittleren Niedersachsen ist der jungbronzezeitliche Rispenhirseanbau durch Funde aus Gittrup bei Münster und Harkenbleck im Ldkr. Hannover belegt (NEEF 1985; BEHRE 1982, 289 f.; 1996, 7).

In Süddeutschland und angrenzenden Ländern war die Rispenhirse seit der jüngeren Bronzezeit eine der wichtigen Kulturpflanzen (RöSCH 1998, 117). In Zeltingen-Rachtig, Kr. Bernkastel-Wittich, wurde sie für eine bronze- bis hallstattzeitliche Siedlung neben Dinkel, Emmer, Einkorn, Lein und Gerste nachgewiesen (CLEMENS et al. 1994, 479).
In Südbayern ist die Rispenhirse durch zwei urnenfelderzeitliche Vorratsfunde aus Straubing-Öberau und aus Viecht belegt. Dort tritt sie zudem regelmäßig in Streufunden und in anderen Fundkomplexen auf (KÜSTER 1995, 102). Ihre besondere Bedeutung in der süddeutschen Urnenfelderzeit hebt RöSCH $(1995,430)$ dadurch hervor, daß er diesen Abschnitt als Hirse-Dinkel-Gerste-Zeit beschreibt. Tatsächlich sind die Funde in Südwestdeutschland besonders zahlreich: Ein urnenfelderzeitlicher Rispenhirsevorrat stammt aus Burkheim am Kaiserstuhl (KÜSTER 1988b, 265). Des weiteren müssen die umfangreichen Funde aus Knittlingen im Enzkreis, die anhand von Holzkohle auf $2885 \pm 34$ BP, kal. 1046 (1185-1002) v. Chr., datiert sind (RösCH 1995, $427 \mathrm{f}$.), angeführt werden. Auf dem urnenfelderzeitlichen Fundplatz Wiesloch-Weinäcker am nördlichen Oberrhein besaß Panicum eine hohe Stetigkeit und eine hohe Häufigkeit (RöSCH 1993, 98). Auch in UnteruhldingenStollenwiesen sowie in Hagnau-Burg spielte die Rispenhirse in dieser Zeit eine bedeutende Rolle (RösCH 1993, 98 f.). Zudem war sie in Tamm-Hohenstange in Nordwürttemberg um 600 v. Chr. mit geringen 7,7\% der Kulturpflanzen immerhin die zweithäufigst nachgewiesene Art, sie wurde dort nur vom Dinkel mit 73 \% übertroffen (PIENING 1982, 254).

Des öfteren belaufen sich die subfossilen Hirsereste auch in Süddeutschland nur auf wenige Körner. So wurde beispielsweise in der frühmittelbronzezeitlichen Siedlung Uhingen-Römerstraße $91 \mathrm{im} \mathrm{Kr}$. Göppingen ein einziges Korn gefunden (KARG 1988, 236). Jedoch wird die Bedeutung der Hirse für die jungbronzezeitliche Urnenfelderkultur dadurch keinesfalls geschmälert. Häufig sind Panicum-Karyopsen im Fundspektrum von Trockenbodensiedlungen unterrepräsentiert, obwohl ihre Verkohlungschancen während der Nahrungszubereitung denen der anderen Getreide entsprechen. Warum dies der Fall ist, konnte bislang noch nicht zufriedenstellend beantwortet werden (RÖSCH et al. 1992, 217).

In der Schweiz breitete sich der Hirseanbau seit der späten Bronzezeit aus (Grabung ZürichMozartstraße/Zürichsee, BROMBACHER u. JACOMET 1997, 234; Zug-Sumpf, JACOMET u. KARG 1996, 236 u. 245). Im bronzezeitlichen Hauterive-Champréveyres am Neuenburger See kam neben der Rispen- auch die Kolbenhirse vor, die ein Element der mediterranen Florenregion ist (JACQUAT 1988, 55 f.; 1989, 74). Möglicherweise zeigt ihre Anwesenheit einen kulturellen und wirtschaftlichen Einfluß des Mittelmeergebietes auf die westliche Urnenfelderkultur auf (vgl. KÜSTER 1995, 102). Besonders umfangreich sind die Rispenhirsefunde aus dem urnenfelderzeitlichen Stillfried an der March in Niederösterreich (KOHLERSCHNEIDER 2001, 131).

Ein Blick auf die bronzezeitlichen Nachweise der Rispenhirse in weiteren Nachbarstaaten Deutschlands zeigt, daß sie in den Niederlanden (WILLERDING 1970, 347 f.) und Frankreich eine stärkere Verbreitung erfuhr. In Frankreich bildete die Rispenhirse neben Gerste und Emmer einen 
wichtigen Bestandteil des bronzezeitlichen Kulturpflanzenspektrums (BAKELS 1991, 286 f.). Älteste Funde datieren dort ins frühe Neolithikum. In der Bronzezeit breitete sich die Rispenhirse nach Westen aus, jedoch wurde sie in Südfrankreich erst seit der Eisenzeit angetroffen (MARINVAL 1992, 260 f.). In Dänemark ist sie nur spärlich nachgewiesen (JENSEN 1991, 338). In Polen wiederum war die Rispenhirse in der Bronzezeit weit verbreitet; ihre Körner wurden in jeder zweiten bronzezeitlichen Fundstelle angetroffen (WASYLIKOWA et al. 1991, 227).

Die jungbronzezeitlichen Vorratsfunde der Rispenhirse aus dem norddeutschen Rullstorf lassen den Norden und den Süden Deutschlands in der jüngeren Bronzezeit näher zusammenrücken, weil das Kulturpflanzenspektrum nun größere Überschneidungen aufweist als bislang angenommen. Die angebauten Halmfrüchte der jungbronzezeitlichen Lüneburger Gruppe decken sich, unter Ausnahme des Dinkels und der gelegentlich nachgewiesenen Kolbenhirse, mit denen der jungbronzezeitlichen Urnenfelderkultur. Hingegen bleibt der jungbronzezeitliche Dinkelanbau dem aktuellen Forschungsstand zufolge spezifisch für die Urnenfelderzeit in Süddeutschland und angrenzende Regionen. 


\section{Zusammenfassung}

Im Bereich der prähistorischen Siedlungen bei Rullstorf nordöstlich von Lüneburg wurden nach umfangreicher Geländeprospektion Bohrkerne dreier Lokalitäten zur Rekonstruktion der Vegetations- und Umweltverhältnisse palynologisch bearbeitet. Zudem wurden aus den prähistorischen Siedlungen und einem sächsischen Gräberfeld auf dem Kronsberg bei Rullstorf verkohlte Pflanzenreste sowie Pflanzenabdrücke untersucht, um Rückschlüsse auf die Landwirtschaft in prähistorischer Zeit zu gewinnen. Die Funde wurden aus Vorratsgruben, Darröfen und Pfostenlöchern geborgen. Der überwiegende Teil der hier untersuchten subfossilen Pflanzenfunde datiert in die jüngere Bronzezeit (21.898 Reste). Weiteres Material (22.760 Reste inklusive der von BEHRE [1990] bearbeiteten Funde) stammt aus einer Siedlung des 6.-2. Jh. v. Chr. BEHRE (1990) und KROLL (1980) untersuchten zudem 18.897 Reste einer Siedlung aus dem 1. Jh. v. Chr. Geringere Fundmengen wurden in der vorliegenden Arbeit für die Römische Kaiserzeit (23 Reste) und das Frühe Mittelalter (308 Reste sowie 14 Pflanzenabdrücke) nachgewiesen.

Die Entnahmeorte von zwei Pollenprofilen befinden sich im Bereich der Niederterrasse der Elbe im Nordosten Lüneburgs. Das Elbaer Moor liegt ca. $8 \mathrm{~km}$ und der Rullstorfer Osterteich ca. $1 \mathrm{~km}$ vom Ausgrabungsgelände Kronsberg bei Rullstorf entfernt. Die zugehörigen Pollendiagramme können daher nur über den peripheren Wirtschaftsraum der Rullstorfer Siedler Auskunft geben. Das Elbaer Moor, dessen organische Ablagerungen und Torfe eine Mächtigkeit von maximal $120 \mathrm{~cm}$ besitzen, entstand in einer im Präboreal vernäßten Senke und entwickelte sich im weiteren Verlauf des Holozäns zu einem Hochmoor. Für die älteren Abschnitte des Profils aus dem Rullstorfer Osterteich (PZ IV bis PZ VI/VII nach Firbas), dessen Gesamtmächtigkeit maximal $97 \mathrm{~cm}$ beträgt, wurde eine Verlandungsserie, die zur Entwicklung eines Erlenbruchwaldtorfes führte, rekonstruiert. Es fehlt hier jedoch Material aus dem jüngeren Atlantikum, dem Subboreal und dem älteren Subatlantikum (PZ VII bis PZ IX nach Firbas). Im jüngeren Subatlantikum (Mittelalter und Frühe Neuzeit, PZ X nach Firbas) wurden dort Seggentorfe gebildet. Das dritte Pollenprofil wurde im Almstorfer Moor im Bereich der Endmoränenwälle des Bevenser Beckens im Ldkr. Uelzen geborgen. Es ermöglicht den Vergleich des Ablaufs der Vegetationsgeschichte auf reichen Böden mit dem auf armen Altmoränenböden, wie sie im Nordosten Lüneburgs verbreitet sind. Die Mudden und die Torfe des Pollenprofils aus dem Almstorfer Moor $(166 \mathrm{~cm})$ sind beinahe vollständig subatlantischen Alters (PZ IX und PZ X nach Firbas).

Im Präboreal breiteten sich auf den armen Sandböden des Raums Lüneburg lichte Birken-Kiefernwälder aus, in denen sich schließlich im Boreal die Kiefer durchsetzte. Im Verlauf des Boreals wanderten die Eichenmischwaldarten in die Region ein. Die hier vorgelegten Untersuchungen bestätigen, daß die Hasel die Wälder auf den armen
Altmoränenböden im Boreal nicht dominierte. Dieses steht im Gegensatz zu Regionen mit reichen Jungmoränenböden. $\mathrm{Zu}$ Beginn des Atlantikums dehnten sich in der Niederung weite Erlenbruchwälder aus. Auf der Hohen Geest etablierten sich als vorherrschende Vegetation nun die mosaikartig strukturierten linden- und ulmenreichen Eichenmischwälder. In den Mischwäldern der unmittelbaren Umgebung Lüneburgs breitete sich die Hasel zu Beginn des Atlantikums stark aus. Dieses Ereignis wurde mittels der Radiokarbon-Methode auf $7140 \pm 55$ BP, kal. 6007 (60565924) v. Chr., datiert.

Im Pollendiagramm aus dem Elbaer Moor setzt ein allmähliches Absinken der Ulmen-Werte zu Beginn des Subboreals ein. Aus dem weiteren Verlauf dieses Rückgangs liegt eine Radiokarbon-Datierung auf $4430 \pm 55$ BP, kal. 3064 (3308-2924) v. Chr., vor, die zugleich für die ersten in diesem Pollendiagramm auftretenden Pollenkörner der Rotbuche gilt.

Im Mittelpunkt der vorliegenden Untersuchungen stand der menschliche Einfluß auf die Landschaft. Die Träger der in Norddeutschland noch lange Zeit verbreiteten mesolithischen Jäger-Sammler-Kultur lebten weitgehend in Einklang mit ihrer Umwelt, die sich als dichte Waldlandschaft darbot. Erst um etwa 3000 v. Chr. verursachten die standortgebundenen Bauern der jüngeren Trichterbecherkultur bei Rullstorf eine auf ihr Siedlungsumfeld begrenzte Auflichtung der bis dahin dichten Eichenmischwälder, die sich pollenanalytisch erfassen läßt. Möglicherweise steht der Eintrag erster Kulturpflanzen-PK im Elbaer Moor sogar mit der trichterbecherzeitlichen Siedlung bei Rullstorf in Zusammenhang.

In der Bronzezeit war der Eintrag siedlungszeigender Pollen-Typen in das Elbaer Moor ebenfalls gering. Dennoch konnte anhand der archäobotanischen Untersuchungen auf dem Kronsberg bei Rullstorf nachgewiesen werden, daß im Raum Lüneburg Ackerbau betrieben wurde. Die wichtigsten Anbaufrüchte der jungbronzezeitlichen Siedler waren dort Hordeum vulgare, Triticum dicoccon und Panicum miliaceum. Vorratsfunde der Rispenhirse weisen der Rullstorfer Grabung eine Schlüsselstellung bei der Rekonstruktion der Ausbreitungsgeschichte dieses kleinkörnigen Getreides zu, handelt es sich doch um den bislang ältesten bekannten Rispenhirse-Vorratsfund in Norddeutschland; sein jungbronzezeitliches Alter ist zudem durch eine Radiokarbon-Datierung auf $2963 \pm 29$ BP, kal. 1176 (1259-1127) v. Chr., abgesichert. Die Rispenhirse war demnach auch im Nordosten Niedersachsens eine der wichtigen bronzezeitlichen Kulturpflanzen. Dieser Nachweis rückt den Kulturkreis der Lüneburger Gruppe in die Nähe der süddeutschen Urnenfelderkultur, in der die Hirse eine so bedeutende Rolle spielte, daß dort der urnenfelderzeitliche Abschnitt auch als Hirse-DinkelGerste-Zeit bezeichnet wird. Die in den Vorratsfunden enthaltenen Unkräuter belegen, daß Sommergetreide 
kultiviert und Ährenernte betrieben wurde. Zudem zeigen die begleitenden Unkräuter, daß die Ackerflächen in Bereichen mit günstiger Bodengüte lagen, jedoch wurden auch saure Böden genutzt. Aus der jungbronzezeitlichen Siedlung bei Rullstorf wurden in geringem Umfang Pflanzen nachgewiesen, die in den Eichenmischwäldern der näheren Siedlungsumgebung gesammelt wurden.

Im Pollendiagramm aus dem Elbaer Moor ist anhand erhöhter NBP-Werte am Übergang zur Vorrömischen Eisenzeit (Beginn des Subatlantikums) eine Ausweitung oder Verlagerung von Siedlungs- und Wirtschaftsflächen zu verzeichnen, die inmitten des Eichenmischwaldes lagen. In dieser Zeit kam es hier zur ersten nennenswerten Ausbreitung der Besenheide auf den armen Sandböden der Altmoränenlandschaft. Wiederum sind es die Ergebnisse der archäobotanischen Untersuchungen bei Rullstorf, die den Ackerbau genauer beschreiben. Das Kulturpflanzenspektrum wurde durch Hafer und Lein erweitert. Jedoch waren Spelzgerste, Emmer und Saatweizen häufiger vertreten als Hafer, Rispenhirse und Lein.

Ein ungereinigter jungbronzezeitlicher GetreideVorratsfund und einer der Darröfen der Vorrömischen Eisenzeit enthielten Sklerotien vom Mutterkorn, die bislang selten für prähistorische Zeiten archäobotanisch nachgewiesen wurden.

Die pollenanalytischen Ergebnisse aus dem Almstorfer Moor erweitern die Kenntnis vom Ablauf der Siedlungsund Vegetationsgeschichte in Nordostniedersachsen seit dem Subatlantikum. Die vorherrschende Vegetation war hier wie im Norden Lüneburgs der Eichenmischwald. Jedoch mag die Linde in der Umgebung dieses Moores aufgrund der günstigeren Bodenverhältnisse etwas stärker verbreitet gewesen sein als auf den armen Sandböden im Nordosten Lüneburgs. Anhand des Polleneintrags der Siedlungszeiger konnte zudem eine Siedlungskontinuität für die Vorrömische Eisenzeit in diesem Gebiet festgestellt werden.

Die Ausgrabungen auf dem Kronsberg bei Rullstorf haben für die Kulturpflanzengeschichte in zweifacher Hinsicht besondere Bedeutung, da hier nicht nur der älteste Rispenhirsevorrat, sondern auch der älteste Saathafervorrat Norddeutschlands gefunden wurde. Letzterer belegt den Anbau dieser sekundären Kulturpflanze in Monokultur schon für die ausgehende Vorrömische Eisenzeit.

In der Römischen Kaiserzeit wurde schließlich als weitere sekundäre Kulturpflanze der Roggen angebaut, und zwar zunächst als Sommergetreide. Anhand des Pollendiagramms aus dem Almstorfer Moor wurde für dessen Einzugsgebiet entgegen dem archäologischen Befund auch für die Römische Kaiserzeit eine Siedlungskontinuität nachgewiesen. Dort breiteten sich in dieser Zeit besonders
Bestände der Rot- und der Hainbuche in den Eichenmischwäldern aus.

Ein deutlicher völkerwanderungszeitlicher Siedlungsrückgang zeichnet sich allein im Pollendiagramm aus dem Almstorfer Moor ab. Diese Zeitstellung wird durch zwei Radiokarbon-Datierungen bestätigt. Zwar gibt es schwache Hinweise auf eine Restbevölkerung, jedoch dehnten sich die Wälder stark aus. Besonders die Schatthölzer Rot- und Hainbuche waren in den vom Menschen aufgelichteten Wäldern begünstigt, so daß sie sich weiter ausbreiten konnten.

Der mittelalterliche Landesausbau, der im Raum Lüneburg vor allem im 13. Jh. stattfand, bewirkte erneut deutliche Landschaftsveränderungen, die sich pollenanalytisch nachweisen lassen. Der Landesausbau ist in den Pollendiagrammen aus dem Elbaer Moor und aus dem Almstorfer Moor am plötzlichen Anstieg der Siedlungszeiger-Kurven $\mathrm{zu}$ erkennen. Der intensive Roggenanbau dieser Zeit und die damit verbundene Plaggenwirtschaft führten eine starke Ausweitung der Heideflächen herbei, wodurch die Waldflächen immer stärker zurückgedrängt wurden. Die günstige Bodengüte in der Umgebung des Almstorfer Moores ist nicht zuletzt daran zu erkennnen, daß sich Calluna hier im Gegensatz zur Umgebung des Elbaer Moores erst im Späten Mittelalter auf weiten Flächen ausbreitete. Der Holzbedarf der Lüneburger Saline war zunächst durch die Holzvorräte in der Umgebung Lüneburgs gedeckt. Jedoch wurden im 14. Jh., wie das Pollendiagramm aus dem Almstorfer Moor zeigt, Buchen im Bevenser Becken geschlagen, deren Holz vermutlich für die Lüneburger Saline bestimmt war.

Auf die mit dem spätmittelalterlichen Landesausbau verbundene intensive Siedlungsphase folgte im Einzugsbereich des Elbaer Moores eine Wüstungsperiode, die sich im Pollendiagramm durch einen Rückgang der Siedlungszeiger abzeichnet. Eine solche ist im Bereich des Almstorfer Moores nicht nachweisbar. Hier ist der Rückgang der siedlungszeigenden Pollen-Typen kaum zu erkennen. Beides bestätigt den historischen Forschungsstand.

Ein Hiatus im Pollenprofil aus dem Rullstorfer Osterteich wurde mit Hilfe von historischen Karten zeitlich eingegrenzt. Vermutlich entstand diese Schichtlücke des Pollenprofils, als im 15. Jh. im Zuge des Ausbaus der Lüneburger Landwehr Erdarbeiten durchgeführt wurden.

Die jüngsten Ablagerungen und Torfe aller drei hier bearbeiteten Pollenprofile datieren ins Späte Mittelalter und in die Frühe Neuzeit. Hingegen wurde die systematische Aufforstung mit Kiefern im 18. und 19. Jh. in keinem der Diagramme erfaßt. 


\section{Literatur}

AABY, B., 1983: Forest development, soil genesis and human activity illustrated by pollen and hypha analysis of two neighbouring podzols in Draved Forest, Denmark. Danmarks Geologiske Undersøgelse 2:114. København.

AARONSON, S., 1989: Fungal parasites of grasses and cereals. Their rôle as food or medicine, now and in the past. Antiquity 63, 247-257.

ANDERSEN, S. T., 1973: The differential pollen productivity of trees and its significance for the interpretation of a pollen diagramm from a forested region. In: H. J. B. Birks u. R. G. West (Hrsg.), Quaternary plant ecology, 109-115. Oxford.

Andersen, S. T., u. RASMussen, K. L., 1993: Radiocarbon wiggledating of elm declines in northwest Denmark and their significance. Vegetation History and Archaeobotany 2, 125135.

AssendORP, J. J., 1999: Die Häuser der Trichterbecherkultur in Nordostniedersachsen. Berichte zur Denkmalpflege in Niedersachsen 19, 180-185.

AverDieCK, F. R., 1957: Ein Moorprofil sagt über die Vegetationsgeschichte seiner Umgebung aus. Harburger Jahrbuch 7, 109-122.

AverdieCK, F. R., 1958: Pollenanalytische Untersuchungen zur Vegetationsgeschichte im Osten Hamburgs. Mitteilungen der Geographischen Gesellschaft in Hamburg 53, 161-176.

AverdieCK, F. R., 1976: Palynologische Untersuchungen zur Altersbestimmung und Vegetationsgeschichte des Alstertals. In: H. Caspers (Hrsg.), Die Hamburger Alster. Mitteilungen des Geologisch-Paläontologischen Instituts der Universität Hamburg. Sonderband Alster, 81-89. Hamburg.

Averdieck, F. R., u. Münnich, K. O., 1957: Palynologische Betrachtungen zur Siedlungsgeschichte im Norden Hamburgs unter Zuhilfenahme neuerer Datierungsmethoden. Hammaburg 11, 9-22.

BAKELS, C. C., 1991: Western continental Europe. In: W. van Zeist, K. Wasylikowa u. K.-E. Behre (Hrsg.), Progress in Old World paleaoethnobotany, 279-298. Rotterdam.

BAuER, I., KARG, S., u. SteinHAuSER, R., 1995: Kulinarische Reise in die Vergangenheit. Schriften des Kantonalen Museums für Urgeschichte Zug 44. Steinhausen.

BECKER, K., 1995: Paläoökologische Untersuchungen in Kleinmooren zur Vegetations- und Siedlungsgeschichte der zentralen Lüneburger Heide. Mikrofiche. Diss., Univ. Hannover.

BeCKER-Dillingen, J., 1927: Handbuch des Getreidebaues einschließlich Mais, Hirse und Buchweizen. Berlin.

BeHRE, K.-E., 1966: Untersuchungen zur spätglazialen und frühpostglazialen Vegetationsgeschichte Ostfrieslands. Eiszeitalter und Gegenwart 17, 69-84.

BeHRE, K.-E., 1972: Kultur- und Wildpflanzenreste aus der Marschgrabung Jemgumkloster/Ems (um Christi Geburt). Neue Ausgrabungen und Forschungen in Niedersachsen 7, 164-184.

Behre, K.-E., 1976a: Beginn und Form der Plaggenwirtschaft in Nordwestdeutschland nach pollenanalytischen Untersuchungen in Ostfriesland. Neue Ausgrabungen und Forschungen in Niedersachsen 10, 197-224.

Behre, K.-E., 1976b: Die Pflanzenreste aus der frühgeschichtlichen Wurt Elisenhof. Studien zur Küstenarchäologie Schleswig-Holsteins A:2. Bern.
BEHRE, K.-E., 1977: Acker, Grünland und natürliche Vegetation während der römischen Kaiserzeit im Gebiet der Marschensiedlung Bentumersiel/Unterems. Probleme der Küstenforschung im südlichen Nordseegebiet 12, 67-84.

BEHRE, K.-E., 1979: Ein jungbronzezeitlicher Getreidefund aus Ostfriesland. In: U. Körber-Grohne (Hrsg.), Festschrift Maria Hopf zum 65. Geburtstag am 14. September 1979. ArchaeoPhysika 8, 11-20. Köln.

BeHRE, K.-E., 1980: Zur mittelalterlichen Plaggenwirtschaft in Nordwestdeutschland und angrenzenden Gebieten nach botanischen Untersuchungen. In: H. Beck, D. Denecke u. H. Jankuhn (Hrsg.), Untersuchungen zur eisenzeitlichen und frühmittelalterlichen Flur in Mitteleuropa und ihrer Nutzung. Abhandlungen der Akademie der Wissenschaften in Göttingen, Philologisch-Historische Klasse 3:116, 30-44. Göttingen.

BEHRE, K.-E., 1981: The interpretation of anthropogenic indicators in pollen diagrams. Pollen et Spores 23, 225-245.

BEHRE, K.-E., 1982: Zwei jungbronzezeitliche Getreidefunde aus Niedersachsen. Nachrichten aus Niedersachsens Urgeschichte 51, 281-292.

BEHRE, K.-E., 1983: Ernährung und Umwelt der wikingerzeitlichen Siedlung Haithabu. Die Ergebnisse der Untersuchungen der Pflanzenreste. Die Ausgrabungen in Haithabu 8. Neumünster.

BEHRE, K.-E., 1990: Kulturpflanzen und Unkräuter der vorrömischen Eisenzeit aus der Siedlung Rullstorf, Ldkr. Lüneburg. Nachrichten aus Niedersachsens Urgeschichte 59, 141-165.

BEHRE, K.-E., 1991a: Umwelt und Ernährung der frühmittelalterlichen Wurt Niens/Butjadingen nach den Ergebnissen der botanischen Untersuchungen. Probleme der Küstenforschung im südlichen Nordseegebiet 18, 141-168.

BEHRE, K.-E., 1991b: Zum Brotfund aus dem Ipweger Moor, Ldkr. Wesermarsch. Berichte zur Denkmalpflege in Niedersachsen 11,9 .

Behre, K.-E., 1992: The history of rye cultivation in Europe. Vegetation History and Archaeobotany 1, 141-156.

BeHRE, K.-E., 1993: Die tausendjährige Geschichte des TeesdalioArnoseridetums. Phytocoenologia 23, 449-456.

BeHRE, K.-E., 1996: Landschaft und Landwirtschaft in der Bronzezeit Niedersachsens. Die Kunde N. F. 47, 1-12.

BeHRE, K.-E., 1998a: Landwirtschaftliche Entwicklungslinien und die Veränderungen der Kulturlandschaft in der Bronzezeit Europas. In: B. Hänsel (Hrsg.), Mensch und Umwelt in der Bronzezeit Europas, 91-109. Kiel.

BEHRE, K.-E., 1998b: Urgeschichtliche Kulturpflanzenfunde aus den nordwestdeutschen Geestgebieten. Probleme der Küstenforschung im südlichen Nordseegebiet 25, 281-302.

BeHre, K.-E., 1999: Die letzte Mahlzeit des „Jungen von Kayhausen“. Eine Untersuchung der Speisereste aus dem Darmtrakt. Schriftenreihe des Staatlichen Museums für Naturkunde und Vorgeschichte Oldenburg, Beiheft 10:1, 7678.

BeHRE, K.-E., 2000: Der Mensch öffnet die Wälder - zur Entstehung der Heiden und anderer Offenlandschaften. Rundgespräche der Kommission für Ökologie der Bayrischen Akademie der Wissenschaften 18, 103-116.

BEHRE, K.-E., 2001: Neues zur Geschichte des Getreideanbaus in Niedersachsen. Archäologie in Niedersachsen 4, 74-77. 
BEHRE, K.-E., u. JACOMET, S., 1991: The ecological interpretation of archaeobotanical data. In: W. van Zeist, K. Wasylikowa u. K.-E. Behre (Hrsg.), Progress in Old World palaeoethnobotany, 81-108. Rotterdam, Brookfield.

BEHRE, K.-E., u. KUČAN, D., 1986: Die Reflektion archäologisch bekannter Siedlungen in Pollendiagrammen aus verschiedener Entfernung - Beispiele aus der Siedlungskammer Flögeln, Nordwestdeutschland. In: K.-E. Behre (Hrsg.), Anthropogenic indicators in pollen diagrams, 95-114. Rotterdam, Boston.

Behre, K.-E., u. KUČAN, D., 1994: Die Geschichte der Kulturlandschaft und des Ackerbaus in der Siedlungskammer Flögeln, Niedersachsen, seit der Jungsteinzeit. Probleme der Küstenforschung im südlichen Nordseegebiet 21. Oldenburg.

Benkert, D., FukareK, F., u. Korsch, H. (Hrsg.), 1998: Verbreitungsatlas der Farn- und Blütenpflanzen Ostdeutschlands. Jena.

BenZler, J., 1965: Aufbau und Altersgliederung des Holozäns der Lüneburger Elbmarsch. Eiszeitalter und Gegenwart 16, 113115.

Benzler, J., u. Meyer, K.-D., 1989: Die Entstehung der Lüneburger Elbmarsch. In: O. Puffahrt (Hrsg.), 100 Jahre Artlenburger Deichverband 1889-1989, 16-18. Lüneburg.

BergGren, G., 1969: Atlas of seeds and small fruits of NorthwestEuropean plant species with morphological descriptions 2 . Cyperaceae. Stockholm.

BergGren, G., 1981: Atlas of seeds and small fruits of NorthwestEuropean plant species with morphological descriptions 3 . Salicaceae-Cruciferae. Stockholm.

Beug, H.-J., 1961: Leitfaden der Pollenbestimmung für Mitteleuropa und angrenzende Gebiete. Stuttgart.

BEUG, H.-J., 1992: Vegetationsgeschichtliche Untersuchungen über die Besiedlung im Unteren Eichsfeld, Landkreis Göttingen, vom frühen Neolithikum bis zum Mittelalter. Neue Ausgrabungen und Forschungen in Niedersachsen 20, 261-339.

Beug, H.-J., HENRION, I., u. SCHMÜSER, A., 1999: Landschaftsgeschichte im Hochharz. Die Entwicklung der Wälder und Moore seit dem Ende der letzten Eiszeit. Clausthal-Zellerfeld.

BorngÄSSER, E., 1941: Das „Große Moor“ bei Deimern, ein Hochmoor in der Lüneburger Heide. Botanisches Centralblatt, Beiheft B:51, 33-71.

BRANDT, I., 1951: Planterester i et Moselig fra Borremose. Aarbøger for Nordisk Oldkyndighed og Historie 1950, 342351 .

Brandt, K., u. Behre, K.-E., 1976: Eine Siedlung der älteren vorrömischen Eisenzeit bei Oldendorp/Unterems mit Aussagen $\mathrm{zu}$ Umwelt, Ackerbau und Sedimentationsgeschehen. Nachrichten aus Niedersachsens Urgeschichte 45, 447-458.

BrockHAus, 1932: Mutterkorn. In: Der Große Brockhaus 13. 15. Auflage, 105. Leipzig.

Brombacher, C., u. JACOMET, S., 1997: Ackerbau, Sammelwirtschaft und Umwelt. Ergebnisse archäobotanischer Untersuchungen. In: J. Schibler, H. Hüster-Plogmann, S. Jacomet, C. Brombacher, E. Groß-Klee u. A. Rast-Eicher, Ökonomie und Ökologie neolithischer und bronzezeitlicher Ufersiedlungen am Zürichsee. Monographien der Kantonsarchäologie Zürich 20, 220-299. Zürich, Egg.

Brothwell, D., 1986: The bog man and the archaeology of people. London.
Brouwer, W., 1972: Handbuch des speziellen Pflanzenbaus 1. Weizen, Roggen, Gerste, Hafer, Mais. Berlin.

BuURMANN, J., 1979: Cereals in circles, crop activities in Bronze Age Bovenkarspel (the Netherlands). In: U. Körber-Grohne (Hrsg.), Festschrift Maria Hopf zum 65. Geburtstag am 14. September 1979. Archaeo-Physika 8, 21-37. Köln.

DeLfS, J., 2000: Heidewirtschaft. Plaggenhieb und Streunutzung in der Lüneburger Heide. Museumsdorf Hösseringen, Materialien zum Museumsbesuch 33. Hösseringen.

DÖRflER, W., 1989: Pollenanalytische Untersuchungen zur Vegetations- und Siedlungsgeschichte im Süden des Landkreises Cuxhaven, Niedersachsen. Probleme der Küstenforschung im südlichen Nordseegebiet 17, 1-75.

DÖRfLER, W., 1990: Geschichte des Hanfanbaus in Mitteleuropa aufgrund palynologischer Untersuchungen und von Großrestnachweisen. Prähistorische Zeitschrift 65, 218-244.

Dörfler, W., u. WiEThOlD, J., 2000: Holzkohlen aus den Herdgruben von Rennfeueröfen und Siedlungsbefunden des spätkaiserzeitlichen Eisengewinnungs- und Siedlungsplatzes am Kammberg bei Joldelund, Kr. Nordfriesland. In: A. Haffner, H. Jöns u. J. Reichstein (Hrsg.), Frühe Eisengewinnung in Joldelund, Kr. Nordfriesland. Band 2. Naturwissenschaftliche Untersuchungen zur Metallurgie- und Vegetationsgeschichte. Universitätsforschungen zur Prähistorischen Archäologie 59, 217-262. Bonn.

EIDE, F., 1981: Key for Northwest European Rosaceae pollen. Grana 20, 101-118.

EllenberG, H., 1996: Vegetation Mitteleuropas mit den Alpen in ökologischer, dynamischer und historischer Sicht. 5. Auflage. Stuttgart.

Ellenberg, H., Weber, H. E., DÜll, R., Wirth, V., Werner, W., u. Paulissen, D., 1992: Zeigerwerte von Pflanzen in Mitteleuropa. Scripta Geobotanica 18. Göttingen.

Engel, F., 1978: Die Kurhannoversche Landesaufnahme des 18. Jahrhunderts. Erläuterungen zur Neuausgabe als amtliches historisches Kartenwerk im Maßstab 1:25000 mit Blattübersicht und Zeichenerklärung. 2. Auflage. Hannover.

ERdtMan, G., u. Sorsa, P., 1971: Pollen and spore morphology/plant taxonomie. Pteridophyta. Stockholm.

FÆGRI, K., 1993: Bestimmungsschlüssel für die nordwesteuropäische Pollenflora. Jena, Stuttgart, New York.

FÆgri, K., Iversen, J., Kaland, P. E., u. KRZYwinsKi, K., 1989: Textbook of pollen analysis. 4. Auflage. Chichester, New York.

FIRBAS, F., 1949: Waldgeschichte Mitteleuropas 1. Allgemeine Waldgeschichte. Jena.

FIRBAS, F., 1952: Waldgeschichte Mitteleuropas 2. Waldgeschichte der einzelnen Landschaften. Jena.

GARBERS, H.-V., 1990: Grundzüge antiker Eisenverhüttung auf dem Kronsberg in Rullstorf, Landkreis Lüneburg. In: F. M. Andraschko u. W.-R. Teegen (Hrsg.), Gedenkschrift für Jürgen Driehaus, 49-56. Mainz.

GARVE, E., 1994: Atlas der gefährdeten Farn- und Blütenpflanzen in Niedersachsen und Bremen. Naturschutz und Landschaftspflege in Niedersachsen 30:2. Hannover.

GeBERS, W., 1985a: Jungbronzezeitliche und eisenzeitliche Getreidevorratshaltung in Rullstorf, Landkreis Lüneburg. Ein Zeugnis urgeschichtlicher Vorratswirtschaft. Berichte zur Denkmalpflege in Niedersachsen 5, Beiheft 1, 146-150. 
GeBERS, W., 1985b: Neue Ergebnisse zu den jungbronzezeitlichen Grab- und Beigabensitten auf einem Urnenfriedhof bei Rullstorf, Ldkr. Lüneburg. Berichte zur Denkmalpflege in Niedersachsen 5, Beiheft 1, 168-173.

GeBERS, W., 1985c: Grabungen im Bereich einer Siedlung der jüngeren römischen Kaiserzeit und der Völkerwanderungszeit in Rullstorf, Ldkr. Lüneburg. Berichte zur Denkmalpflege in Niedersachsen 5, Beiheft 1, 191-196.

GeBERS, W., 1985d: Ein sächsischer Kultplatz mit Gräberfeld in Rullstorf, Ldkr. Lüneburg. Berichte zur Denkmalpflege in Niedersachsen 5, Beiheft 1, 276-281.

GeBERS, W., 1986a: Grabanlagen und Grabsitten der jüngeren vorrömischen Eisenzeit bei Rullstorf. Berichte zur Denkmalpflege in Niedersachsen 6, 79-81.

GeBers, W., 1986b: Zum sächsischen Brand- und Körpergräberfeld in Rullstorf. Berichte zur Denkmalpflege in Niedersachsen 6, 85-87.

GeBERS, W., 1995: Fünfzehn Jahre Grabung Rullstorf, eine Bilanz. Berichte zur Denkmalpflege in Niedersachsen 15, 56-60.

GEBERS, W., u. LÜTH, F., 1984: Siedlung und Gräberfeld auf dem Kronsberg bei Rullstorf im Kreis Lüneburg, ein Vorbericht. Hammaburg N. F. 6, 99-114.

GeBERS, W., u. LÜTH, F., 1996: Rullstorf 1. Die archäologischen Untersuchungen im Bereich der Fundstelle 5. Grabungsjahre 1979-1982. Katalog. Hannover.

GeEL, B. VAN, 1978: A palaeoecological study of Holocene peat bog sections in Germany and The Netherlands. Review of Palaeobotany and Palynology 25, 1-120.

GeEL, B. VAN, 1979: Preliminary report on the history of Zygnemataceae and the use of their spores as ecological markers. In: D. C. Bharadwaj, K. M. Lele u. R. K. Kar (Hrsg.), Proceedings of the Fourth International Palynological Conference, Lucknow, 1976-1977. Band 1, 467-469. Lucknow.

Geel, B. van, Bohncke, S. J. P., u. Dee, H., 1981: A palaeoecological study of an upper Late Glacial and Holocene sequence from „De Borchert“, The Netherlands. Review of Palaeobotany and Palynology 31, 367-448.

Geel, B. van, Hallewas, D. P., u. Pals, J. P., 1983: A late Holocene deposit under the Westfriese Zeedijk near Enhuizen (Prov. Noord-Holland, the Netherlands). Palaeoecological and archaeological aspects. Review of Palaeobotany and Palynology 38, 269-546.

GeHRKE, D., 1999: Zur Frühgeschichte der Dahlenburger Gegend. Bemerkungen zur Archäologie des östlichen Landkreises Lüneburg. Schriftenreihe zur Heimatgeschichte der Samtgemeinde Dahlenburg 8. Dahlenburg.

GeHrKe, D., 2000: Archäologie und Heimatgeschichte im Landkreis Lüneburg. Husum.

Goy, G., 1938: Das Rätsel der Hirse. Tatsachen und Theorien um eine vergessene Getreideart. Nürnberger Beiträge zu den Wirtschafts- und Sozialwissenschaften 67, 5-86.

GRIPP, K., 1924: Über die äußerste Grenze der letzten Vereisung in Nordwest-Deutschland. Mitteilungen der Geographischen Gesellschaft in Hamburg 36, 161-245.

Grosse-BrauckmanN, G., 1972: Über pflanzliche Makrofossilien mitteleuropäischer Torfe 1. Gewebereste krautiger Pflanzen und ihre Merkmale. Telma 2, 19-55.

Grosse-BrauckmanN, G., 1974: Über pflanzliche Makrofossilien mitteleuropäischer Torfe 2. Weitere Reste, Früchte und Samen,
Moose u. a. und ihre Bestimmungsmöglichkeiten. Telma 4, 51117.

Grosse-Brauckmann, G., u. Streitz, B., 1992: Pflanzliche Makrofossilien mitteleuropäischer Torfe 3. Früchte, Samen und einige Gewebe. Telma 22, 53-102.

HAgEdorn, J., 1965: Umgestaltung des glazigenen Reliefs der norddeutschen Altmoränengebiete am Beispiel des Uelzener Beckens. Eiszeitalter und Gegenwart 16, 116-120.

HARCK, O., 1972: Nordostniedersachsen vom Beginn der jüngeren Bronzezeit bis zum frühen Mittelalter. Materialhefte zur Urund Frühgeschichte 7. Hildesheim.

HÄßLER, H.-J., 1991a: Vorrömische Eisenzeit. In: H.-J. Häßler (Hrsg.), Ur- und Frühgeschichte in Niedersachsen, 193-237. Stuttgart.

HäßLER, H.-J., 1991b: Völkerwanderungs- und Merowingerzeit. In: H.-J. Häßler (Hrsg.), Ur- und Frühgeschichte in Niedersachsen, 285-320. Stuttgart.

HAeupler, H., u. SchÖNFelder, P. (Hrsg.), 1988: Atlas der Farnund Blütenpflanzen der Bundesrepublik Deutschland. Stuttgart.

HeEge, E., u. MAIER, R., 1991: Jungsteinzeit. In: H.-J. Häßler (Hrsg.), Ur- und Frühgeschichte in Niedersachsen, 109-154. Stuttgart.

HelbeK, H., 1951: Tollundmandens sidste maaltid. Et botanisk bidrag til belysning of oldtidens kost. Aarbøger for Nordisk Oldkydighed og Historie, 1950, 311-341.

HeLbeK, H., 1958: Grauballemandens sidste måltid. Kuml 1958, 83-116.

HeIDER, S., 1995: Die Siedlungs- und Vegetationsgeschichte im Ostteil des Elbe-Weser-Dreiecks nach pollenanalytischen Untersuchungen. Probleme der Küstenforschung im südlichen Nordseegebiet 23, 51-115.

HeINKEN, T., 1995: Naturnahe Laub- und Nadelwälder grundwasserferner Standorte im niedersächsischen Tiefland. Gliederung, Standortsbedingungen, Dynamik. Dissertationes Botanicæ 239. Berlin.

HILlmAN, G., 1984: Reconstructing crop husbandry practices from charred remains of crops. In: R. Mercer (Hrsg.), Farming practice in British prehistory. Edinburgh.

Höfle, H.-C., 1991: Über die interne Struktur und die stratigraphische Stellung mehrerer Endmoränenwälle im Bereich der Nordheide bis östlich Lüneburg. Geologisches Jahrbuch A:126, 151-169.

HoffMeister, J., u. SCHNelle, F., 1945: Klima-Atlas von Niedersachsen. Oldenburg.

Holden, T. G., 1986: Preliminary report on the detailed analyses of macroscopic remains from the gut of Lindow Man. In: I. M. Stead, J. B. Bourke u. D. Brothwell (Hrsg.), Lindow Man. The body in the bog, 116-125. London.

HoPF, M., 1955: Formveränderungen von Getreidekörnern beim Verkohlen. Berichte der Deutschen Botanischen Gesellschaft 68:4, 191-193.

Hopf, M., 1973: Getreide, Äpfel und Eicheln. In: H. Hingst, Eine bronzezeitliche Siedlung bei Schmalstede, Kr. RendsburgEckernförde. Offa 30, 200-204.

Hopf, M., 1975: Beobachtungen und Überlegungen bei der Bestimmmung von verkohlten Hordeum-Früchten. Folia Quaternaria 46, 83-92.

Hopf, M., 1982: Vor- und frühgeschichtliche Kulturpflanzen aus dem nördlichen Deutschland. Katalog vor- und frühgeschichtlicher Altertümer 22. Mainz. 
HoRNIG, C., 1993: Das spätsächsische Gräberfeld von Rullstorf, Ldkr. Lüneburg. Internationale Archäologie 14. Buch am Erlbach.

HÜPPE, J., 1993: Entwicklung der Tieflands-Heidelandschaften Mitteleuropas in geobotanisch-vegetationsgeschichtlicher Sicht. Berichte der Reinhold-Tüxen-Gesellschaft 5, 49-75.

IVERSEN, J., 1941: Landnam i Danmarks Stenalder. Danmarks Geologiske Undersøgelse 2:66, 1-68.

IVERSEN, J., 1944: Viscum, Hedera and Ilex as climate indicators. Geologiska Föreningens i Stockholm Förhandlinger 66, 463483.

IVERSEN, J., 1973: The development of Denmark's nature since the last glacial. Danmarks Geologiske Undersøgelse 5:7-C. Københaven.

JACOMET, S., 1987: Prähistorische Getreidefunde. Eine Anleitung zur Bestimmung prähistorischer Gersten- und Weizen-Funde. Basel.

JACOMET, S., BrombaCher, C., u. Dick, M., 1989: Archäobotanik am Zürichsee. Ackerbau, Sammelwirtschaft und Umwelt von neolithischen und bronzezeitlichen Seeufersiedlungen im Raum Zürich. Ergebnisse von Untersuchungen pflanzlicher Makroreste der Jahre 1979-1988. Berichte der Züricher Denkmalpflege, Monographien 7. Zürich.

JACOMET, S., u. KARG, S., 1996: Ackerbau und Umwelt der Seeufersiedlungen von Zug-Sumpf im Rahmen der mitteleuropäischen Spätbronzezeit. Ergebnisse archäobotanischer Untersuchungen. In: Regierungsrat des Kantons Zug (Hrsg.), Die spätbronzezeitlichen Ufersiedlungen von Zug-Sumpf 1. Die Dorfgeschichte, 198-386. Zug.

JACOMET, S., u. KREUZ, A., 1999: Archäobotanik. Aufgaben, Methoden und Ergebnisse vegetations- und agrargeschichtlicher Forschung. Stuttgart.

JACQUAT, C., 1988: Hauterive-Champréveyres 1. Les plantes de l'âge du Bronze. Catalogue des fruits et graines. Archéologie neuchâteloise 7. Saint-Blaise.

JACQUAT, C., 1989: Hauterive-Champréveyres 2. Les plantes de l'âge du Bronze. Contribution à l'histoire de l'environment et de l'alimentation. Archéologie Neuchâteloise 8. Saint-Blaise.

JÄGER, K.-D., 1966: Die pflanzlichen Großreste aus der Burgwallgrabung Tornow, Kreis Calau. In: J. Herrmann, Tornow und Vorberg. Schriften der Sektion für Vor- und Frühgeschichte 21, 164-189. Berlin.

JANKOVSKÁ, V., u. KoMÁREK, J., 2000: Indicative value of Pediastrum and other coccal green algae in palaeoecology. Folia Geobotanica 35, 59-82.

Jensen, H. A., 1991: The nordic countries. In: W. van Zeist, K. Wasylikowa u. K.-E. Behre (Hrsg.), Progress in Old World palaeoethnobotany, 335-350. Rotterdam, Brookfield.

Jones, G., Wardle, K., Halstead, P., u. Wardle, D., 1986: Kornspeicherung in Assiros. Spektrum der Wissenschaften, 1986:Mai, 88-95.

Kalis, A. J., 1988: Zur Umwelt des frühneolithischen Menschen. Ein Beitrag der Pollenanalyse. In: Landesdenkmalamt BadenWürttemberg (Hrsg.), Der prähistorische Mensch und seine Umwelt. Festschrift für Udelgard Körber-Grohne zum 65. Geburtstag. Forschungen und Berichte zur Vor- und Frühgeschichte Baden-Württembergs 31, 125-137. Stuttgart.

KARG, S., 1988: Pflanzenreste aus zwei Bodenproben der frühmittelbronzezeitlichen Siedlung Uhingen-Römerstraße 91 (Kreis Göppingen). In: Landesdenkmalamt Baden-
Württemberg (Hrsg.), Der prähistorische Mensch und seine Umwelt. Festschrift für Udelgard Körber-Grohne zum 65. Geburtstag. Forschungen und Berichte zur Vor- und Frühgeschichte in Baden-Württemberg 31, 231-237. Stuttgart.

KatZ, N. J., KatZ, S. V., u. KiPIANI, M. G., 1965: Atlas and keys of fruits and seeds occuring in the quaternary deposits of the USSR. Moskau.

KeLm, H.-J., u. STURM, K., 1988: Waldgeschichte und Waldnaturschutz im Regierungsbezirk Lüneburg. Grundlagen und Ziele. Jahrbuch des Naturwissenschaftlichen Vereins für das Fürstenthum Lüneburg 38, 47-82.

KIRLEIS, W., 1998: Vegetationsgeschichtliche Untersuchungen über die spätholozäne Siedlungsgeschichte im Gebiet des Rambower Moores, Landkreis Prignitz, westliches Brandenburg. Unveröffentlichte Diplomarbeit, Univ. Göttingen.

KLINK, H.-J., 1995: Vegetation. In: H. Liedtke u. J. Marcinek (Hrsg.), Physische Geographie Deutschlands. 2. Auflage, 158195. Gotha.

KNÖRZER, K.-H., 1968: 6000jährige Geschichte der Getreidenahrung im Rheinland. Decheniana 119, 113-124.

KNÖRZER, K.-H., 1970: Novaesium 4. Römerzeitliche Pflanzenfunde aus Neuss. Limesforschungen 10. Berlin.

KNÖRZER, K.-H., 1971: Eisenzeitliche Pflanzenfunde im Rheinland. Bonner Jahrbücher 171, 40-58.

KNÖRZER, K.-H., 1972: Subfossile Pflanzenreste der bandkeramischen Siedlung Langweiler 3 und 6, Kreis Jülich, und ein urnenfelderzeitlicher Getreidefund innerhalb dieser Siedlung. Bonner Jahrbücher 172, 395-403.

KNÖRZER, K.-H., 1991: Deutschland nördlich der Donau. In: W. van Zeist, K. Wasylikowa u. K.-E. Behre (Hrsg.), Progress in Old World palaeoethnobotany, 189-206. Rotterdam, Brookfield.

KÖHNCKE, F., 1965: Untersuchungen in der frühkaiserzeitlichen Siedlung auf dem Wiernitzberg bei Almstorf, Kreis Uelzen. Neue Ausgrabungen und Forschungen in Niedersachsen 2, 191-199.

KÖRBER-GroHNE, U., 1964: Bestimmungsschlüssel für subfossile Juncus-Samen und Gramineen-Früchte. Probleme der Küstenforschung im südlichen Nordseegebiet 7. Hildesheim.

KÖRBER-GroHNE, U., 1967: Geobotanische Untersuchungen auf der Feddersen Wierde. Feddersen Wierde 1. Wiesbaden.

KÖRBER-GROHNE, U., 1994: Nutzpflanzen in Deutschland. Kulturgeschichte und Biologie. 3. Auflage. Stuttgart.

KOHLER-SCHNEIDER, M., 2001: Verkohlte Kultur- und Wildpflanzenreste aus Stillfried an der March als Spiegel spätbronzezeitlicher Landwirtschaft im Weinviertel, Niederösterreich. Mitteilungen der Prähistorischen Kommission der Österreichischen Akademie der Wissenschaften Wien, Philosophisch-Historische Klasse 37. Wien.

Kremser, W., 1990: Niedersächsische Forstgeschichte. Rotenburg/Wümme.

Kroll, H., 1975: Ur- und frühgeschichtlicher Ackerbau in Archsum auf Sylt. Eine botanische Großrestanalyse. Diss., Univ. Kiel.

Kroll, H., 1980: Einige vorgeschichtliche Vorratsfunde von Kulturpflanzen aus Norddeutschland. Offa 37, 372-383. 
KUBITZKI, K., 1961: Zur Synchronisierung der nordwesteuropäischen Pollendiagramme (mit Beiträgen zur Waldgeschichte Nordwestdeutschlands). Flora 150, 43-72.

KuBITZKI, K., u. MÜNNICH, K. O., 1960: Neue ${ }^{14}$ C-Datierungen zur nacheiszeitlichen Waldgeschichte Nordwestdeutschlands. Berichte der Deutschen Botanischen Gesellschaft 73:4, 137146.

KUČAN, D., 1986: Ältereisenzeitliche Kulturpflanzenreste aus der Siedlung Hamburg-Langenbek. Probleme der Küstenforschung im südlichen Nordseegebiet 16, 87-97.

KuČAN, D., 1995: Ein Beitrag zur Geschichte der Kulturpflanzen in Bosnien mit neuen Funden aus der früheisenzeitlichen Wallburg Klisura Kadića Brdo Sokolac. Probleme der Küstenforschung im südlichen Nordseegebiet 23, 153-173.

KUČAN, D., 1998: Auswertung der Pflanzenabdrücke in neolithischer Keramik aus der Grabung Walmstorf, Gemeinde Emmendorf, Landkreis Uelzen. Unveröffentlichtes Manuskript.

KÜSTER, H., 1988a: Vom Werden einer Kulturlandschaft. Vegetationsgeschichtliche Studien am Auerberg (Südbayern). Quellen und Forschungen zur prähistorischen und provinzialrömischen Archäologie 3. Weinheim.

KÜSTER, H., 1988b: Urnenfelderzeitliche Pflanzenreste aus Burkheim, Gemeinde Vogtsburg, Kreis BreisgauHochschwarzwald (Baden-Württemberg). In: Landesdenkmalamt Baden-Württemberg (Hrsg.), Der prähistorische Mensch und seine Umwelt. Festschrift für Udelgard Körber-Grohne zum 65. Geburtstag. Forschungen und Berichte zur Vor- und Frühgeschichte in BadenWürttemberg 31, 261-268. Stuttgart.

KÜSTER, H., 1995: Postglaziale Vegetationsgeschichte Südbayerns. Geobotanische Studien zur prähistorischen Landschaftskunde. Berlin.

KÜSTER, H., 1997: Kulturpflanzen der Bronzezeit. In: K.-F. Rittershofer (Hrsg.), Demographie der Bronzezeit. Paläodemographie - Möglichkeiten und Grenzen. Internationale Archäologie 36, 1-5. Rahden.

LAMSchus, C., 1993: Die Holzversorgung der Lüneburger Saline in Mittelalter und früher Neuzeit. In: S. Urbanski, C. Lamschus u. J. Ellermeyer (Hrsg.), Recht und Alltag im Hanseraum, 321333. Lüneburg.

LANG, G., 1994: Quartäre Vegetationsgeschichte Europas. Jena, Stuttgart, New York.

LANGE, E., 1979: Verkohlte Pflanzenreste aus den slawischen Siedlungsplätzen Brandenburg und Zirzow (Kreis Neubrandenburg). In: U. Körber-Grohne (Hrsg.), Festschrift Maria Hopf zum 65. Geburtstag am 14. September 1979. Archaeo-Physika 8, 191-207. Köln.

LAUX, F., 1998: Zur Besiedlung des Bardengaues in den Jahrhunderten um Christi Geburt und die Langobarden. Eine Betrachtung zum Problem der Siedlungskontinuität. Die Kunde N. F. 49, 143-164.

LAUXTERMANN, B., 2001a: Eine außergewöhnliche Pferdebestattung auf dem spätsächsischen Gräberfeld in Rullstorf. Berichte zur Denkmalpflege in Niedersachsen 21, 42-43.

LauXtermann, B., 2001b: Ein Mitglied des sächsischen Adels. Der Krieger im Holzkammergrab 5095. Berichte zur Denkmalpflege in Niedersachsen 21, 45-46.
LEERHOFF, H., 1985: Niedersachsen in alten Karten des 16. bis 18 Jahrhunderts aus den niedersächsischen Staatsarchiven. Neumünster.

LesEmanN, B., 1969: Pollenanalytische Untersuchungen zur Vegetationsgeschichte des Hannoverschen Wendlandes. Flora B $158,480-519$.

LEUSCHNER, C., 1994: Walddynamik auf Sandböden in der Lüneburger Heide (Nordwest-Deutschland). Phytocoenologia 22, 289-324.

LOSERT, H., 1953: Pollenanalytische Untersuchungen am „Blanken Flat" bei Vesbeck. Mitteilungen der Floristisch-Soziologischen Arbeitsgemeinschaft N. F. 4, 137-146.

LOSERT, H., 1969: Zur Verbreitung von Myrica gale im Regierungsbezirk Lüneburg. Mitteilungen der FloristischSoziologischen Arbeitsgemeinschaft N. F. 14, 32-35.

MAKOWSKI, H., 1983: Lüneburg und die Heide. Jahrbuch des Naturwissenschaftlichen Vereins für das Fürstenthum Lüneburg 36, 11-24.

MANSFELD, R., 1986: Verzeichnis landwirtschaftlicher und gärtnerischer Kulturpflanzen (ohne Zierpflanzen). 2. Auflage. Berlin.

MANTEL, K., 1990: Wald und Forst in der Geschichte. Hannover.

MARINOVA, E., 2001: Vergleichende paläobotanische Untersuchung zur Vegetationsgeschichte und zur Entwicklung der prähistorischen Landnutzung in Bulgarien. Diss., Univ. Bonn.

MarinVAL, P., 1992: Archaeobotanical data on millets Panicum miliaceum and Setaria italica in France. Review of Palaeobotany and Palynology 73, 259-270.

MARTin, O., 1967: Bericht über die Untersuchung der Speisereste in der Moorleiche von Dätgen. Offa 24, 77-78.

MAtthaEI, G., 1956: Kurze Geschichte des 1000jährigen Lüneburg. In: Stadt Lüneburg (Hrsg.), 1956 - Tausend Jahre Lüneburg, 3-21. Lüneburg.

MeIBEYER, W., 1970: Die naturräumlichen Einheiten auf Blatt 74 Salzwedel. Geographische Landesaufnahme 1:200000, Band 74. Bonn-Bad Godesberg.

MeIBEYER, W., 1980: Die naturräumlichen Einheiten auf Blatt 58 Lüneburg. Geographische Landesaufnahme 1:200000, Band 58. Bonn-Bad Godesberg.

Mellinger, J., 2001: Atlas des Fürstentums Lüneburg um 1600. Veröffentlichungen des Instituts für historische Landesforschung der Universität Göttingen 41. Bielefeld.

Metzler, A., u. Wilbertz, O. M., 1991: Bronzezeit. In: H.-J. Häßler (Hrsg.), Ur- und Frühgeschichte in Niedersachsen, 155192. Stuttgart.

MEYER, K.-D., 1994: Exkursionsführer zur Quartärgeologie des nordöstlichen Niedersachsen. Geschiebekunde Aktuell, Sonderheft 4. Hamburg.

MEYER, K.-D., 1998: Geschiebekundlich-stratigraphische Untersuchungen in der südlichen Lüneburger Heide. Mitteilungen aus dem Geologischen Institut der Universität Hannover 38, 179-189.

Michael, E., 1997: Das Zisterzienserkloster Scharnebeck. In: Landkreis Lüneburg (Hrsg.), Einblicke. Heimatbuch für den Landkreis Lüneburg 3, 149-164. Lüneburg.

Middelhave, L., 1950: Die Landwehren der Stadt Lüneburg. Lüneburger Blätter 1, 15-29. 
MiLDENBERGER, G., u. KÖHNCKE, F., 1962: Untersuchungen in der römerzeitlichen Siedlung Almstorf, Kreis Uelzen. Nachrichten aus Niedersachsens Urgeschichte 31, 158-163.

Moore, P. D., Webb, J. A., u. Collinson, M. E., 1991: Pollen analysis. 2. Auflage. Oxford u.a.

Müller-Wille, M., Dörfler, W., Meier, D., u. Kroll, H., 1988: The transformation of rural society, economy and landscape during the first millenium AD. Archaeological and palaeobotanical contributions from northern Germany and southern Scandinavia. Geografiska Annaler B 70:1, 53-68.

NeEF, R., 1985: Botanische Funde aus den vorgeschichtlichen und frühmittelalterlichen Emssand-Siedlungen Gittrup und Ostbevern. Ausgrabungen und Funde in Westfalen-Lippe 3, 89-100.

NIEDERSÄCHSISCHES LANDESVERWALTUNGSAMT / LANDESVERMESSUNG (Hrsg.), 1972: Topographische Übersichtskarte 1:200000, Blatt CC 3126 Ost, Hamburg. Hannover.

NIEDERSÄCHSISCHES LANDESVERWALTUNGSAMT LANDESVERMESSUNG (Hrsg.), 1994: Topographische Karte 1:25000, Blatt 2628 Artlenburg. 9. Auflage. Hannover.

NIEDERSÄCHSISCHES LANDESVERWALTUNGSAMT LANDESVERMESSUNG (Hrsg.), 1994: Topographische Karte 1:25000, Blatt 2728 Lüneburg. 8. Auflage. Hannover.

NIEDERSÄCHSISCHES LANDESVERWALTUNGSAMT

LANDESVERMESSUNG (Hrsg.), 1995: Topographische Karte 1:25000, Blatt 2729 Scharnebeck. 8. Auflage. Hannover.

NIEDERSÄCHSISCHES LANDESVERWALTUNGSAMT LANDESVERMESSUNG (Hrsg.), 1995: Topographische Karte 1:25000, Blatt 2830 Dahlenburg. 8. Auflage. Hannover.

NIEDERSÄCHSISCHES LANDESVERWALTUNGSAMT

LANDESVERMESSUNG (Hrsg.), 1995: Topographische Karte 1:25000, Blatt 2930 Himbergen. 8. Auflage. Hannover.

NIEDERSÄCHSISCHES LANDESVERWALTUNGSAMT

LANDESVERMESSUNG, u. HistORISCHE KOMMISSION FÜR NIEDERSACHSEN (Hrsg.), 1959: Kurhannoversche Landesaufnahme des 18. Jahrhunderts 1:25000, Blatt 68 Scharnebeck, aufgenommen 1776. Hannover.

Nilsson, Ö., u. HJelmquist, H., 1967: Studies on the nutlet structure of South Scandinavian species of Carex. Botaniska Notiser 120, 460-485.

OBERDORFER, E., 1990: Pflanzensoziologische Exkursionsflora. 6. Auflage. Stuttgart.

Osten, G., 1961: Die Wüstungen des Landkreises Lüneburg. Lüneburger Blätter 11/12, 31-65.

Osten, G., 1965: Die Wüstungen des Landkreises Uelzen. Lüneburger Blätter 15/16, 139-196.

Overbeck, F., 1952: Das Große Moor bei Gifhorn im Wechsel hygrokliner und xerokliner Phasen der nordwestdeutschen Hochmoorentwicklung. Niedersächsisches Landesamt für Landesplanung und Statistik / Veröffentlichungen A 1:41. Bremen.

OvERBECK, F., 1975: Botanisch-geologische Moorkunde unter besonderer Berücksichtigung der Moore Nordwestdeutschlands als Quellen zur Vegetations-, Klima- und Siedlungsgeschichte. Neumünster.

Overbeck, F., u. SchneIder, S., 1938: Mooruntersuchungen bei Lüneburg und Bremen und die Reliktnatur von Betula nana L. in Nordwestdeutschland. Zeitschrift für Botanik 33, Sonderdruck, Jena
Pals, J. P., Geel, B. van, u. Delfos, A., 1980: Palaeoecological studies in the Klokkeweel bog near Hoogkarspel, Prov. of Noord-Holland. Review of Palaeobotany and Palynology 30, 371-418.

PARRA BARRIENTOS, O. O., 1979: Revision der Gattung Pediastrum Meyen, Chlorophyta. Bibliotheca Phytologica 48. Vaduz.

PASCHER, A. (Hrsg.), 1931: Bryophyta Sphagnales, Bryales, Hepaticae. Die Süßwasser-Flora Mitteleuropas 14. 2. Auflage. Jena.

Peglar, S. M., u. BiRKs, H. J. B., 1993: The mid-Holocene Ulmus fall at Diss Mere, South-East England - disease and human impact? Vegetation History and Archaeobotany 2, 61-68.

PIENING, U., 1982: Botanische Untersuchungen an verkohlten Pflanzenresten aus Nordwürttemberg. Fundberichte aus BadenWürttemberg 7, 239-271.

PoHL, D., 1998: Stand der Ausweisung von Naturschutzgebieten in Niedersachsen am 31.12.1997. Informationsdienst Naturschutz Niedersachsen 98:5. Hildesheim.

PотT, R., 1985: Vegetationsgeschichtliche und pflanzensoziologische Untersuchungen zur Niederwaldwirtschaft in Westfalen. Abhandlungen aus dem Westfälischen Museum für Naturkunde 47:4, 3-75.

Ротт, R., 1988: Entstehung von Vegetationstypen und Pflanzengesellschaften unter dem Einfluß des Menschen. Düsseldorfer Geobotanische Kolloquien 5, 27-54.

PunT, W. (Hrsg.), 1976: The Northwest European pollen flora 1. Amsterdam, Oxford, New York.

PunT, W., u. Blackmore, S. (Hrsg.), 1991: The Northwest European pollen flora 6. Amsterdam, Oxford, New York, Tokyo.

Punt, W., Blackmore, S., u. Clarke, G. C. S. (Hrsg.), 1988: The Northwest European pollen flora 5. Amsterdam, Oxford, New York, Tokyo.

Punt, W., u. Clarke, G. C. S. (Hrsg.), 1980: The Northwest European pollen flora 2. Amsterdam, Oxford, New York.

Punt, W., u. Clarke, G. C. S. (Hrsg.), 1981: The Northwest European pollen flora 3. Amsterdam, Oxford, New York.

Punt, W., u. Clarke, G. C. S. (Hrsg.), 1984: The Northwest European pollen flora 4. Amsterdam, Oxford, New York, Tokyo.

PyritZ, E., 1972: Binnendünen und Flugsandebenen im niedersächsischen Tiefland. Göttinger Geographische Abhandlungen 61. Göttingen.

RABIEN, I., 1953: Zur Bestimmung subfossiler Knospenschuppen. Paläontologische Zeitschrift 27, 57-66.

REINSTORF, E., 1929: Elbmarschkultur zwischen Bleckede und Winsen an der Luhe in ihrer erd- und menschengeschichtlichen Entwicklung. Harburg.

REINSTORF, E., 1952: Kulturgeschichte des Lüneburger Landes. Winsen.

RHEINISCHES LANDESMUSEUM TRIER, 1994: Jahresbericht des Landesamtes für Denkmalpflege, Abteilung Archäologische Denkmalpflege, Amt Trier, für den Regierungsbezirk Trier und den Kreis Birkenfeld, 1992. Trierer Zeitschrift 57, 461-494.

Rösch, M., 1993: Zum Ackerbau der Urnenfelderkultur am nördlichen Oberrhein. Botanische Untersuchungen am Fundplatz Wiesloch-Weinäcker, Rhein-Neckar-Kreis. Archäologische Ausgrabungen in Baden-Württemberg 1992, 95-99. 
Rösch, M., 1995: Exkurs: Die Pflanzenreste. In: R. Baumeister, Außergewöhnliche Funde der Urnenfelderzeit aus Knittlingen, Enzkreis. Bemerkungen zu Kult und Kultgerät der Spätbronzezeit. Fundberichte aus Baden-Württemberg 20, 423448.

Rösch, M., 1996: Archäobotanische Untersuchungen in der spätbronzezeitlichen Ufersiedlung Hagnau-Burg (Bodenseekreis). In: Landesdenkmalamt Baden-Württemberg (Hrsg.), Siedlungen im Alpenvorland 4. Forschungen und Berichte zur Vor- und Frühgeschichte in Baden-Württemberg 47, 239-313. Stuttgart.

Rösch, M., 1998: The history of crops and crop weeds in southwestern Germany from the Neolithic period to modern times, as shown by archaeobotanical evidence. Vegetation History and Archaeobotany 7, 109-125.

RÖSCH, M., JACOMET, S., u. KARG, S., 1992: The history of cereals in the region of the former Duchy of Swabia (Herzogtum Schwaben) from the Roman to the Post-Medieval period. Vegetation History and Archaeobotany 1, 193-231.

ROESLER, H., 1983: Eine mittelbronzezeitliche Opferstelle auf dem Gräberfeld der Lausitzer Kultur von Drehna, Kr. Luckau. Ausgrabungen und Funde 28, 57-64.

Roessler, L., 1987: Erdgeschichte von Lauenburg. 2. Auflage. Ratzeburg.

RothMAleR, W., 1991: Exkursionsflora von Deutschland 3. Atlas der Gefäßpflanzen. 8. Auflage. Berlin.

SANDEN, W. VAN DER, 1996: Mumien aus dem Moor. Die vor- und frühgeschichtlichen Moorleichen aus Nordwesteuropa. Amsterdam.

Schiemann, E., 1948: Weizen, Roggen, Gerste. Systematik, Geschichte und Verwendung. Jena.

SchNeEKLOTH, H., 1963: Das „Hohe Moor“ bei Scheeßel (Kreis Rotenburg/Hannover). Geologisches Jahrbuch, Beiheft 55, 1104. Hannover.

SCHNEEKLOTH, H., u. TÜXEN, J., 1979: Die Moore in Niedersachsen 6. Bereich des Blattes Hamburg-Ost der Geologischen Karte der Bundesrepublik Deutschland 1:200000. Göttingen.

Schoch, W. H., Pawlik, B., u. Schweingruber, F. H., 1988: Botanische Makroreste. Ein Atlas zur Bestimmung häufig gefundener und ökologisch wichtiger Pflanzensamen. Bern.

Schrader, E., 1958: Niedersachsen. Die Biographie einer Landschaft. Hildesheim.

SCHULtZe-Motel, J., 1973: Jungbronzezeitliche Kulturpflanzenreste aus Nebra (Unstrut). Jahresschrift für Mitteldeutsche Vorgeschichte 57, 127-135.

Schultze-Motel, J., u. Gall, W., 1994: Archäologische Kulturpflanzenreste aus Thüringen. Weimarer Monographien zur Ur- und Frühgeschichte 32. Stuttgart.

SCHWAAR, J., 1983: Spät- und postglaziale Vegetationsstrukturen im oberen Wümmetal bei Tostedt, Landkreis Harburg. Jahrbuch des Naturwissenschaftlichen Vereins für das Fürstenthum Lüneburg 36, 139-166.

SCHWAAR, J., 1985: Subfossile Kleinseggenrieder, versunkene Hochmoore, natürliche Kiefernvorkommen und bis ins Mittelalter überdauernde Ulmenmischwälder bei Lauenbrück, Kreis Rotenburg/Wümme. Jahrbuch des Naturwissenschaftlichen Vereins für das Fürstenthum Lüneburg 37, 161-175.
SCHWAAR, J., 1988: Nacheiszeitliche Waldentwicklung in der Lüneburger Heide. Jahrbuch des Naturwissenschaftlichen Vereins für das Fürstenthum Lüneburg 38, 25-46.

SchwARZ, W., 1991: Römische Kaiserzeit. In: H.-J. Häßler (Hrsg.), Ur- und Frühgeschichte in Niedersachsen, 238-284. Stuttgart.

SElle, W., 1936: Die nacheiszeitliche Wald- und Moorentwicklung im südöstlichen Randgebiet der Lüneburger Heide. Jahrbuch der Preußischen Geologischen Landesanstalt zu Berlin für das Jahr 1935, Band 56, 371-421.

SELLE, W., 1939: Ergänzung zur nacheiszeitlichen Wald- und Moorentwicklung im südöstlichen Randgebiet der Lüneburger Heide. Pollenanalysen eines kleinen Moores bei Grussendorf. Jahrbuch der Preußischen Geologischen Landesanstalt zu Berlin für das Jahr 1938, Band 59, 272-288.

SElle, W., 1962: Beiträge zur Vegetationsgeschichte des Weichselspätglazials und des Postglazials im südlichen Randgebiet der Lüneburger Heide. Bericht der Naturhistorischen Gesellschaft Hannover 106, 41-47.

Sprockhoff, E., 1975: Atlas der Megalithgräber Deutschlands 3. Niedersachsen - Westfalen. Textband. Bonn.

STARK, J., 1996: Spätsächsische Grabbefunde aus Rullstorf. Erste Ergebnisse der Ausgrabung 1995. Berichte zur Denkmalpflege in Niedersachsen 15, 47-52.

StOCKMARR, J., 1971: Tablets with spores used in absolute pollenanalysis. Pollen et Spores 13, 615-621.

Stuiver, M., u. Reimer, P. J., 1993: Extended ${ }^{14} \mathrm{C}$ data base. A revised calib $3.0{ }^{14} \mathrm{C}$ age calibration program. Radiocarbon 35 , 215-230.

Stuiver, M., Reimer, P. J., Bard, E., Beck, J. W., Burr, G. S., Hughen, K. A., Kromer, B., McCormac, G., Plicht, J. VAN DER, u. SPURK, M., 1998: INTCAL 98 radiocarbon age calibration, 24.000-0 cal. BP. Radiocarbon 40, 1041-1083.

WALTHER, H., u. LIETH, H., 1967: Klimadiagramm-Weltatlas. Jena.

Wasylikowa, K., CÂrciumaru, M., Hajnalová, E., Hartyányi, B. P., Pashrevich, G. A., u. Yanushevich, Z. V., 1991: EastCentral Europe. In: W. van Zeist, K. Wasylikowa u. K.-E. Behre (Hrsg.), Progress in Old World palaeoethnobotany, 207239. Rotterdam, Brookfield.

Wegewitz, W., 1957: Ein Rennfeuerofen aus einer Siedlung der älteren Römerzeit in Scharmbeck (Kreis Harburg). Nachrichten aus Niedersachsens Urgeschichte 26, 3-25.

WERNECK, H. L., 1955: Die römischen Getreidefunde in Wels. Jahrbuch Musealverein Wels 1955, 103-112.

WiETHOLD, J., 1998: Studien zur jüngeren postglazialen Vegetations- und Siedlungsgeschichte im östlichen SchleswigHolstein. Universitätsforschungen zur Prähistorischen Archäologie 45. Bonn.

WILLERDING, U., 1970: Vor- und frühgeschichtliche Kulturpflanzenfunde in Mitteleuropa. Neue Ausgrabungen und Forschungen in Niedersachsen 5, 287-375.

Willerding, U., 1978: Die Paläo-Ethnobotanik und ihre Stellung im System der Wissenschaften. Berichte der Deutschen Botanischen Gesellschaft 91, 3-30.

Willerding, U., 1979: Zum Ackerbau in der jüngeren vorrömischen Eisenzeit. In: U. Körber-Grohne (Hrsg.), Festschrift Maria Hopf zum 65. Geburtstag am 14. September 1979. Archaeo-Physika 8, 309-330. Köln.

WiLlERDING, U., 1986: Zur Geschichte der Unkräuter Mitteleuropas. Neumünster. 
Willerding, U., 1991: Präsenz, Erhaltung und Repräsentanz von Pflanzenresten in archäologischem Fundgut. In: W. van Zeist, K. Wasylikowa u. K.-E. Behre (Hrsg.), Progress in Old World palaeoethnobotany, 25-51. Rotterdam, Brookfield.

Willerding, U., u. Hillebrecht, M.-L., 1994: PaläoEthnobotanik. Fragestellung, Methoden und Ergebnisse. In:
B. Herrmann (Hrsg.), Archäometrie. Naturwissenschaftliche Analyse von Sachüberresten, 137-152. Berlin.

WuLF, F.-W., 1991: Karolingische und ottonische Zeit. In: H.-J. Häßler (Hrsg.), Ur- und Frühgeschichte in Niedersachsen, 321-368. Stuttgart.

ZEIST, W. VAN, 1967: Archaeology and palynology in the Netherlands. Review of Palaeobotany and Palynology 4, 45-65. 


\section{Anhang}

Tab. 27. Die prospektierten Moore mit den wichtigsten Daten.

\begin{tabular}{|c|c|c|c|c|c|c|c|c|}
\hline $\mathrm{Nr}$. & Bezeichnung & $\begin{array}{l}\text { Rechts- und } \\
\text { Hochwerte } \\
\text { (Gauß-Krüger) }\end{array}$ & erfaßt in / auf & $\begin{array}{l}\text { Labor- } \\
\text { kürzel }\end{array}$ & heutiger Zustand & zur Stratigraphie & $\begin{array}{l}\text { Eignung } \\
\text { für Pollen- } \\
\text { analyse }\end{array}$ & $\begin{array}{l}\text { pollenanalytisch } \\
\text { ermitteltes Alter der } \\
\text { Torfe und Mudden }\end{array}$ \\
\hline 1 & - & $\begin{array}{ll}\text { r } & 3594920 \\
\text { h } & 5909500\end{array}$ & $\begin{array}{l}\text { TK 25, Bl. Artlenburg } \\
\text { (2628) }\end{array}$ & - & $\begin{array}{l}\text { vernäßte Senke, etwa } 15 \text { m Durchmesser, } \\
\text { Röhricht }\end{array}$ & $\begin{array}{l}\text { sekundärer } \\
\text { Sandeintrag }\end{array}$ & ungünstig & - \\
\hline 2 & Elbaer Moor & $\begin{array}{l}\text { r } 3595200 \\
\text { h } 5908555\end{array}$ & $\begin{array}{l}\text { TK 25, Bl. Artlenburg } \\
(2628)\end{array}$ & E $1-5$ & $\begin{array}{l}\text { Hochmoor mit Sphagnum, Andromeda, } \\
\text { Oxycoccus, Erica, Drosera, Carex } \\
\text { inflata, Jungwuchs von Betula; } \\
\text { Torfentnahmegruben mit Wasser gefüllt, } \\
\text { hier Phragmites, Hydrocotyle } \\
\text { randlich Eriophorum angustifolium, } \\
\text { Molinia coerulea, Betula, Alnus; } \\
\text { durch aufgegebenen bäuerlichen } \\
\text { Torfstich zergliedert; } \\
\text { ringsum Kiefernforst }\end{array}$ & $\begin{array}{l}\text { Hochmoortorf } \\
\text { (HMT) über Sand } \\
\text { mit Bändern von } \\
\text { Niedermoortorf } \\
\text { (NMT) und Mudde }\end{array}$ & gut & $\begin{array}{l}\text { ausgehendes } \\
\text { Spätglazial bis } \\
\text { Subatlantikum }\end{array}$ \\
\hline 3 & NSG Bültenmoor & $\begin{array}{l}\text { r } 3596200 \\
\text { h } 5909580\end{array}$ & $\begin{array}{l}\text { TK 25, Bl. Artlenburg } \\
(2628)\end{array}$ & BM 1-4 & $\begin{array}{l}\text { Moorzentrum komplett abgetorft, hier } \\
\text { geringmächtige Bodenauflage mit } \\
\text { Eriophorum angustifolium, Drosera } \\
\text { intermedia; } \\
\text { randlich Kiefern-Erlen-Birkenwald, von } \\
\text { bäuerlichem Torfstich zergliedert }\end{array}$ & $\begin{array}{l}\text { im Kiefern-Erlen- } \\
\text { Birkenwald: } \\
130 \mathrm{~cm} \text { HMT über } \\
10 \mathrm{~cm} \text { Mudde über } \\
\text { Sand; häufig } \\
\text { Sandbänder }\end{array}$ & gut & $\begin{array}{l}\text { Subboreal bis } \\
\text { Subatlantikum }\end{array}$ \\
\hline 4 & - & $\begin{array}{l}\text { r } 3597340 \\
\text { h } 5908500\end{array}$ & $\begin{array}{l}\text { TK 25, Bl. Artlenburg } \\
\text { (2628), (Ausg. 1919- } \\
\text { 1942) }\end{array}$ & - & $\begin{array}{l}\text { vernäßte Senke mit Phragmites in } \\
\text { Birken-Erlenbruchwald }\end{array}$ & $\begin{array}{l}\text { humoser Sand, } \\
\text { Bauschutt }\end{array}$ & ungünstig & - \\
\hline 5 & $\begin{array}{l}\text { Niedermoor bei } \\
\text { Scharnebeck }\end{array}$ & $\begin{array}{ll}\mathrm{r} & 3598700 \\
\mathrm{~h} & 5909100\end{array}$ & $\begin{array}{l}\text { SCHNEEKLOTH u. } \\
\text { TÜXEN (1979), } \\
\text { Nr. 703, TK 25, } \\
\text { Bl. Artlenburg (2628) }\end{array}$ & SBK 1 & $\begin{array}{l}\text { landwirtschaftlich genutzte Fläche und } \\
\text { Erlen-Birken-Bruchwald }\end{array}$ & $\begin{array}{l}69 \mathrm{~cm} \text { NMT über } \\
67 \mathrm{~cm} \text { Mudde über } \\
\text { Sand }\end{array}$ & mäßig & - \\
\hline 6 & NSG Streitmoor & $\begin{array}{l}\text { r } 3594760 \\
\text { h } 5906600\end{array}$ & $\begin{array}{l}\text { TK 25, Bl. Lüneburg } \\
\text { (2728) }\end{array}$ & - & $\begin{array}{l}\text { stark gestörtes Niedermoor, viele Birken- } \\
\text { und Erlenstubben, dichter Bestand von } \\
\text { Myrica gale, wird renaturiert }\end{array}$ & $\begin{array}{l}\max .70 \mathrm{~cm} \mathrm{NMT} \\
\text { über Sand }\end{array}$ & ungünstig & - \\
\hline
\end{tabular}




\begin{tabular}{|c|c|c|c|c|c|c|c|c|}
\hline $\mathrm{Nr}$. & Bezeichnung & $\begin{array}{l}\text { Rechts- und } \\
\text { Hochwerte } \\
\text { (Gauß-Krüger) }\end{array}$ & erfaßt in / auf & $\begin{array}{l}\text { Labor- } \\
\text { kürzel }\end{array}$ & heutiger Zustand & zur Stratigraphie & $\begin{array}{l}\text { Eignung } \\
\text { für Pollen- } \\
\text { analyse }\end{array}$ & $\begin{array}{l}\text { pollenanalytisch } \\
\text { ermitteltes Alter der } \\
\text { Torfe und Mudden }\end{array}$ \\
\hline 7 & „Tiergarten“ & $\begin{array}{l}\text { r } 4400800 \\
\text { h } 5907300\end{array}$ & $\begin{array}{l}\text { DGK 5, } \\
\text { Bl. Scharnebeck }\end{array}$ & - & $\begin{array}{l}\text { Buchenmischwald mit Fagus, Ilex } \\
\text { aquifolium, Vaccinium myrtillus, } \\
\text { Dryopteris, }\end{array}$ & $30-35 \mathrm{~cm}$ Torf & - & - \\
\hline 8 & „Feld Harms““ & $\begin{array}{l}\text { r } 4400900 \\
\text { h } 5907200\end{array}$ & $\begin{array}{l}\text { DGK 5, } \\
\text { Bl. Scharnebeck }\end{array}$ & $\begin{array}{l}\text { H } 1 \\
\text { H } 2\end{array}$ & $\begin{array}{l}\text { Vermoorung mit Juncus, Luzula } \\
\text { luzuloides, Glyceria, Lythrum, } \\
\text { Filipendula, Equisetum }\end{array}$ & $\begin{array}{l}195 \mathrm{~cm} \text { NMT über } \\
\text { Sand }\end{array}$ & gut & Mittelalter \\
\hline 9 & $\begin{array}{l}\text { Sauerbach, } \\
\text { Nutzfelder Moor }\end{array}$ & $\begin{array}{l}\text { r } 4401500 \\
\text { h } 5906500\end{array}$ & $\begin{array}{l}\text { DGK } 5 \text {, } \\
\text { B1. Grevenhorn }\end{array}$ & SB 1 & bachbegleitender Bruchwald & $\begin{array}{l}74 \mathrm{~cm} \text { sandiger } \\
\text { NMT über Sand, }\end{array}$ & gut & - \\
\hline 10 & $\begin{array}{l}\text { Rullstorfer Moor/ } \\
\text { Herrschaftlicher } \\
\text { Osterteich }\end{array}$ & $\begin{array}{l}\text { r } 4401800 \\
\text { h } 5908400\end{array}$ & $\begin{array}{l}\text { DGK 5, } \\
\text { B1. Neu Rullstorf }\end{array}$ & - & $\begin{array}{l}\text { landwirtschaftlich genutzte Fläche, } \\
\text { z. T. Maisanbau }\end{array}$ & $\begin{array}{l}\text { sekundärer Boden- } \\
\text { auftrag }\end{array}$ & ungünstig & - \\
\hline 11 & $\begin{array}{l}\text { Dorfteich } \\
\text { Rullstorf }\end{array}$ & $\begin{array}{l}\text { r } 4402450 \\
\text { h } 5907200\end{array}$ & DGK 5, Bl. Rullstorf & - & Pferdeweide & $\begin{array}{l}\text { Sand, sekundärer } \\
\text { Bodenauftrag }\end{array}$ & ungünstig & - \\
\hline 12 & $\begin{array}{l}\text { Rullstorfer } \\
\text { Osterteich }\end{array}$ & $\begin{array}{l}\text { r } 4402450 \\
\text { h } 5907600\end{array}$ & $\begin{array}{l}\text { DGK 5, Bl. Rullstorf. } \\
\text { Kurhannoversche } \\
\text { Landesaufnahme, } \\
\text { Bl. Scharnebeck (68). } \\
\text { Abriß der Landwehren } \\
\text { von Lüneburg, Daniel } \\
\text { Frese 1576 (LEERHOFF } \\
\text { 1985, 123) }\end{array}$ & $\begin{array}{l}\text { OB } 1 \\
\text { OB } 2\end{array}$ & $\begin{array}{l}\text { feuchte Weide mit Dünenkuppen, Quelle } \\
\text { bei Düne }\end{array}$ & $\begin{array}{l}70 \mathrm{~cm} \text { NMT, } 30 \mathrm{~cm} \\
\text { Mudde über Sand }\end{array}$ & mäßig & $\begin{array}{l}\text { ausgehendes } \\
\text { Spätglazial bis } \\
\text { Subatlantikum }\end{array}$ \\
\hline 13 & - & $\begin{array}{l}\text { r } 4402700 \\
\text { h } 5908700\end{array}$ & $\begin{array}{l}\text { DGK 5, } \\
\text { B1. Grevenhorn }\end{array}$ & - & Erlenbruch & Legmoor & ungünstig & - \\
\hline 14 & - & $\begin{array}{l}\text { r } \quad 4402900 \\
\text { h } 5908650\end{array}$ & $\begin{array}{l}\text { DGK 5, } \\
\text { B1. Grevenhorn }\end{array}$ & NKO 1 & $\begin{array}{l}\text { Bruchwald, z. T. stehendes Wasser, } \\
\text { mehrere, durch Dünenwälle getrennte } \\
\text { flache Mulden }\end{array}$ & $\begin{array}{l}277 \mathrm{~cm} \text { NMT, } \\
\text { Mudde, Sandbänder }\end{array}$ & gut & Subatlantikum \\
\hline 15 & - & 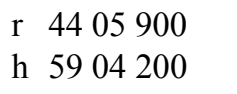 & $\begin{array}{l}\text { TK 25, Bl. } \\
\text { Scharnebeck (2729) }\end{array}$ & - & Bruchwald & Sand & ungünstig & - \\
\hline 16 & - & $\begin{array}{lll}\text { r } & 4407650 \\
\text { h } & 5904200\end{array}$ & $\begin{array}{l}\text { TK 25, Bl. } \\
\text { Scharnebeck (2729) }\end{array}$ & - & Ackerbrache / Maisanbau & - & ungünstig & - \\
\hline
\end{tabular}




\begin{tabular}{|c|c|c|c|c|c|c|c|c|}
\hline $\mathrm{Nr}$. & Bezeichnung & $\begin{array}{l}\text { Rechts- und } \\
\text { Hochwerte } \\
\text { (Gauß-Krüger) }\end{array}$ & erfaßt in / auf & $\begin{array}{l}\text { Labor- } \\
\text { kürzel }\end{array}$ & heutiger Zustand & zur Stratigraphie & $\begin{array}{l}\text { Eignung } \\
\text { für Pollen- } \\
\text { analyse }\end{array}$ & $\begin{array}{l}\text { pollenanalytisch } \\
\text { ermitteltes Alter der } \\
\text { Torfe und Mudden }\end{array}$ \\
\hline 17 & - & $\begin{array}{l}\text { r } \quad 4408550 \\
\text { h } 5906640\end{array}$ & $\begin{array}{l}\text { TK 25, B1. } \\
\text { Scharnebeck (2729) }\end{array}$ & RON 1 & $\begin{array}{l}\text { kleines Hochmoor mit Oxycoccus } \\
\text { palustris, Eriophorum vaginatum, } \\
\text { Molinea coerulea, Calluna vulgaris, } \\
\text { Jungwuchs von Betula; } \\
\text { ringsum Kiefernforst }\end{array}$ & $\begin{array}{l}159 \mathrm{~cm} \text { weitgehend } \\
\text { unzersetzter } \\
\text { Sphagnum-Torf } \\
\text { (Sph. acutifolia) } \\
\text { über Sand }\end{array}$ & gut & Subatlantikum \\
\hline 18 & - & $\begin{array}{l}\text { r } \quad 4410550 \\
\text { h } 5906500\end{array}$ & $\begin{array}{l}\text { digitale } \\
\text { bodenkundliche Karte } \\
\text { (NLfB), } \\
\text { TK 25, B1. } \\
\text { Scharnebeck (2729) }\end{array}$ & - & landwirtschaftliche Nutzfläche, & $\begin{array}{l}\max .35 \mathrm{~cm} \\
\text { humoser Sand über } \\
\text { Sand, anmoorig }\end{array}$ & - & - \\
\hline 19 & - & $\begin{array}{llll}\text { r } & 44 & 17 & 160 \\
\text { h } & 5906 & 060\end{array}$ & $\begin{array}{l}\text { GK 25, Bl. Bleckede } \\
(2730)\end{array}$ & $\begin{array}{l}\text { AWE I, } \\
\text { AWE II }\end{array}$ & Röhricht & $\begin{array}{l}208 \mathrm{~cm} \text { NMT mit } \\
\text { Holz unter } 143 \mathrm{~cm} \\
\text { Auelehmauflage }\end{array}$ & mäßig & - \\
\hline 20 & $\begin{array}{l}\text { LSG Melbecker } \\
\text { Moor }\end{array}$ & $\begin{array}{l}\text { r } 3590420 \\
\text { h } 5890300\end{array}$ & $\begin{array}{l}\text { OVERBECK u. } \\
\text { SCHNEIDER (1938), } \\
\text { TK 25, Bl. } \\
\text { Bienenbüttel (2828) }\end{array}$ & $\begin{array}{l}\text { MEL } \\
\text { I-IV }\end{array}$ & $\begin{array}{l}\text { Birkenbestände mit Vaccinium im } \\
\text { Unterwuchs }\end{array}$ & $\begin{array}{l}375 \text { cm HMT, } \\
\text { schluffiger Ton, } \\
\text { glimmerhaltig, Sand }\end{array}$ & gut & $\begin{array}{l}\text { ausgehendes } \\
\text { Spätglazial bis } \\
\text { Subatlantikum }\end{array}$ \\
\hline 21 & Scharmoor & $\begin{array}{l}\text { r } \quad 4412000 \\
\text { h } 5889000\end{array}$ & $\begin{array}{l}\text { TK 25, Bl. } \\
\text { Dahlenburg (2830) }\end{array}$ & THO I & $\begin{array}{l}\text { Kiefern-Birken-Wald, von } \\
\text { aufgegebenem bäuerlichen Torfstich } \\
\text { zergliedert }\end{array}$ & $\begin{array}{l}110 \mathrm{~cm} \text { HMT über } \\
165 \mathrm{~cm} \text { NMT über } \\
\text { mind. } 100 \mathrm{~cm} \\
\text { Mudde; } \\
\text { Gesamtmächtigkeit } \\
\text { nicht erbohrt! }\end{array}$ & gut & Atlantikum \\
\hline 22 & $\begin{array}{l}\text { NSG Almstorfer } \\
\text { Moor }\end{array}$ & $\begin{array}{lll}\mathrm{r} & 44 & 12500 \\
\mathrm{~h} & 58 & 86000\end{array}$ & $\begin{array}{l}\text { TK 25, B1. } \\
\text { Dahlenburg (2830) } \\
\text { und Himbergen }(2930)\end{array}$ & $\begin{array}{l}\text { ALM I, } \\
\text { ALM II }\end{array}$ & Erlenbruchwald & $\begin{array}{l}160 \mathrm{~cm} \text { Mudde über } \\
\text { Sand }\end{array}$ & gut & $\begin{array}{l}\text { Subboreal und } \\
\text { Subatlantikum }\end{array}$ \\
\hline 23 & - & 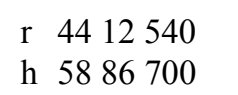 & $\begin{array}{l}\text { TK 25, Bl. } \\
\text { Dahlenburg (2830) }\end{array}$ & STR I & $\begin{array}{l}\text { Bruchwald, von aufgegebenem } \\
\text { bäuerlichen Torfstich zergliedert }\end{array}$ & $\begin{array}{l}229 \mathrm{~cm} \text { HMT über } \\
\text { Sand }\end{array}$ & ungünstig & Subboreal und älter \\
\hline 24 & - & $\begin{array}{llll}\mathrm{r} & 44 & 12 & 800 \\
\mathrm{~h} & 58 & 86 & 250\end{array}$ & $\begin{array}{l}\text { TK 25, Bl. } \\
\text { Dahlenburg (2830) }\end{array}$ & - & Weiden-Bestand & - & ungünstig & - \\
\hline 25 & Schweinemoor & $\begin{array}{l}\text { r } \quad 4414700 \\
\text { h } 5890200\end{array}$ & $\begin{array}{l}\text { TK 25, Bl. } \\
\text { Dahlenburg (2830) }\end{array}$ & - & - & - & - & - \\
\hline
\end{tabular}




\begin{tabular}{|c|c|c|c|c|c|c|c|c|}
\hline $\mathrm{Nr}$. & Bezeichnung & $\begin{array}{l}\text { Rechts- und } \\
\text { Hochwerte } \\
\text { (Gauß-Krüger) }\end{array}$ & erfaßt in / auf & $\begin{array}{l}\text { Labor- } \\
\text { kürzel }\end{array}$ & heutiger Zustand & zur Stratigraphie & $\begin{array}{l}\text { Eignung } \\
\text { für Pollen- } \\
\text { analyse }\end{array}$ & $\begin{array}{l}\text { pollenanalytisch } \\
\text { ermitteltes Alter der } \\
\text { Torfe und Mudden }\end{array}$ \\
\hline 26 & $\begin{array}{l}\text { Großes Moor, } \\
\text { Dahlenburg }\end{array}$ & $\begin{array}{lll}\text { r } & 44 & 16040 \\
\text { h } & 5894290\end{array}$ & $\begin{array}{l}\text { TK 25, Bl. } \\
\text { Dahlenburg (2830) }\end{array}$ & DBG I & Eschenwald & $\begin{array}{l}251 \mathrm{~cm} \text { NMT über } \\
\text { Sand }\end{array}$ & gut & - \\
\hline 27 & - & $\begin{array}{lll}\text { r } & 44 & 14797 \\
\text { h } & 5898323\end{array}$ & $\begin{array}{l}\text { SCHNEEKLOTH u. } \\
\text { TÜXEN (1979), } \\
\text { Nr. 712; TK 25, Bl. } \\
\text { Dahlenburg (2830) }\end{array}$ & - & $\begin{array}{l}\text { landwirtschaftliche Nutzfläche und } \\
\text { Bruchwald }\end{array}$ & $\begin{array}{l}280 \mathrm{~cm} \text { Torf mit } \\
\text { Feinsandlagen }\end{array}$ & - & - \\
\hline 28 & - & $\begin{array}{llll}\mathrm{r} & 44 & 15800 \\
\mathrm{~h} & 5890000\end{array}$ & $\begin{array}{l}\text { TK 25, Bl. } \\
\text { Dahlenburg (2830) }\end{array}$ & - & - & - & - & - \\
\hline
\end{tabular}


Tab. 28. Auflistung der aus zeichnerischen Gründen nicht im Pollendiagramm des Profils Elbaer Moor dargestellten Taxa.

\begin{tabular}{|c|c|c|}
\hline & Tiefe $[\mathrm{cm}]$ & Anzahl \\
\hline Cladium & 75 & 1 \\
\hline Urtica & 39 & 1 \\
\hline Mentha & 83 & 1 \\
\hline Salvia & 93 & 1 \\
\hline Myriophyllum & 9 & 1 \\
\hline Dryopteris & 21 & 1 \\
\hline Pediastrum boryanum & 109 & 1 \\
\hline Diatomee & 81 & 1 \\
\hline Juglans & 3 & 1 \\
\hline \multirow[t]{2}{*}{ Frangula alnus } & 5 & 1 \\
\hline & 65 & 1 \\
\hline \multirow[t]{6}{*}{ Populus } & 27 & 1 \\
\hline & 35 & 3 \\
\hline & 37 & 2 \\
\hline & 75 & 1 \\
\hline & 87 & 1 \\
\hline & 101 & 2 \\
\hline \multirow[t]{2}{*}{ Caryophyllaceae p. p. } & 1 & 2 \\
\hline & 7 & 1 \\
\hline \multirow[t]{2}{*}{ Ranunculus acris-Typ } & 7 & 2 \\
\hline & 21 & 1 \\
\hline \multirow[t]{3}{*}{ Scabiosa } & 25 & 1 \\
\hline & 47 & 1 \\
\hline & 61 & 1 \\
\hline \multirow[t]{2}{*}{ Blechnum spicant } & 11 & 2 \\
\hline & 79 & 1 \\
\hline
\end{tabular}

Tab. 29. Auflistung der aus zeichnerischen Gründen nicht im Pollendiagramm des Profils Rullstorfer Osterteich dargestellten Taxa.

\begin{tabular}{|c|c|c|}
\hline & Tiefe $[\mathrm{cm}]$ & Anzahl \\
\hline Abies & 47 & 1 \\
\hline Ilex & 77 & 3 \\
\hline \multirow[t]{2}{*}{ Aesculus } & 17 & 1 \\
\hline & 27 & 1 \\
\hline Populus & 85 & 1 \\
\hline Myrica & 77 & 3 \\
\hline Sambucus-nigra-Тyp & 17 & 2 \\
\hline Evonymus europaea & 31 & 1 \\
\hline \multirow[t]{2}{*}{ Cladium mariscus } & 27 & 1 \\
\hline & 67 & 1 \\
\hline \multirow[t]{2}{*}{ Cannabis-Typ } & 17 & 1 \\
\hline & 31 & 1 \\
\hline Convolvulus arvensis & 9 & 1 \\
\hline Plantago major/media-Typ & 27 & 1 \\
\hline Campanula-Тур & 9 & 1 \\
\hline \multirow[t]{2}{*}{ Anemone-Тур } & 31 & 1 \\
\hline & 37 & 1 \\
\hline \multirow[t]{2}{*}{ Labiatae } & 9 & 1 \\
\hline & 31 & 1 \\
\hline Impatiens & 31 & 1 \\
\hline \multirow[t]{2}{*}{ Eu-Rumex } & 1 & 1 \\
\hline & 31 & 1 \\
\hline Euphorbia & 27 & 2 \\
\hline Knautia & 1 & 1 \\
\hline Prunella vulgaris & 17 & 2 \\
\hline Humulus-Тур & 97 & 1 \\
\hline Valeriana officinalis & 9 & 1 \\
\hline Mentha-Typ & 31 & 1 \\
\hline Lythrum & 9 & 1 \\
\hline cf. Nuphar & 31 & 1 \\
\hline \multirow[t]{2}{*}{ Polypodium vulgare } & 41 & 1 \\
\hline & 97 & 2 \\
\hline Botrychium & 9 & 1 \\
\hline \multirow[t]{2}{*}{ Phaeoceros laevis } & 31 & 1 \\
\hline & 67 & 4 \\
\hline Lycopodium inundatum & 77 & 1 \\
\hline Mougeotia sp. & 9 & 1 \\
\hline Closterium idiosporum & 31 & 1 \\
\hline \multirow[t]{2}{*}{ Тур 16A } & 17 & 1 \\
\hline & 57 & 1 \\
\hline Тyp 353D & 57 & 1 \\
\hline
\end{tabular}




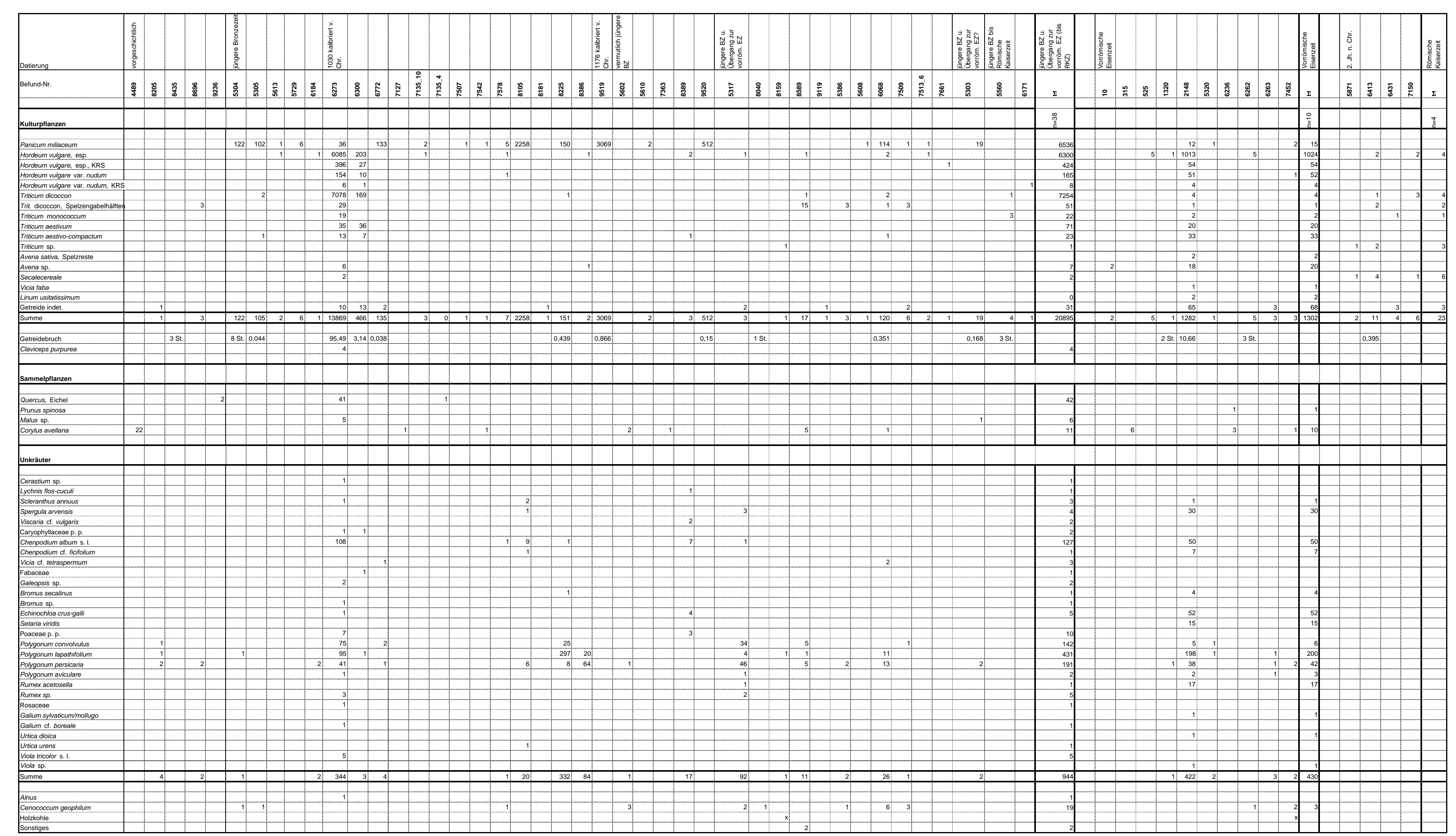

